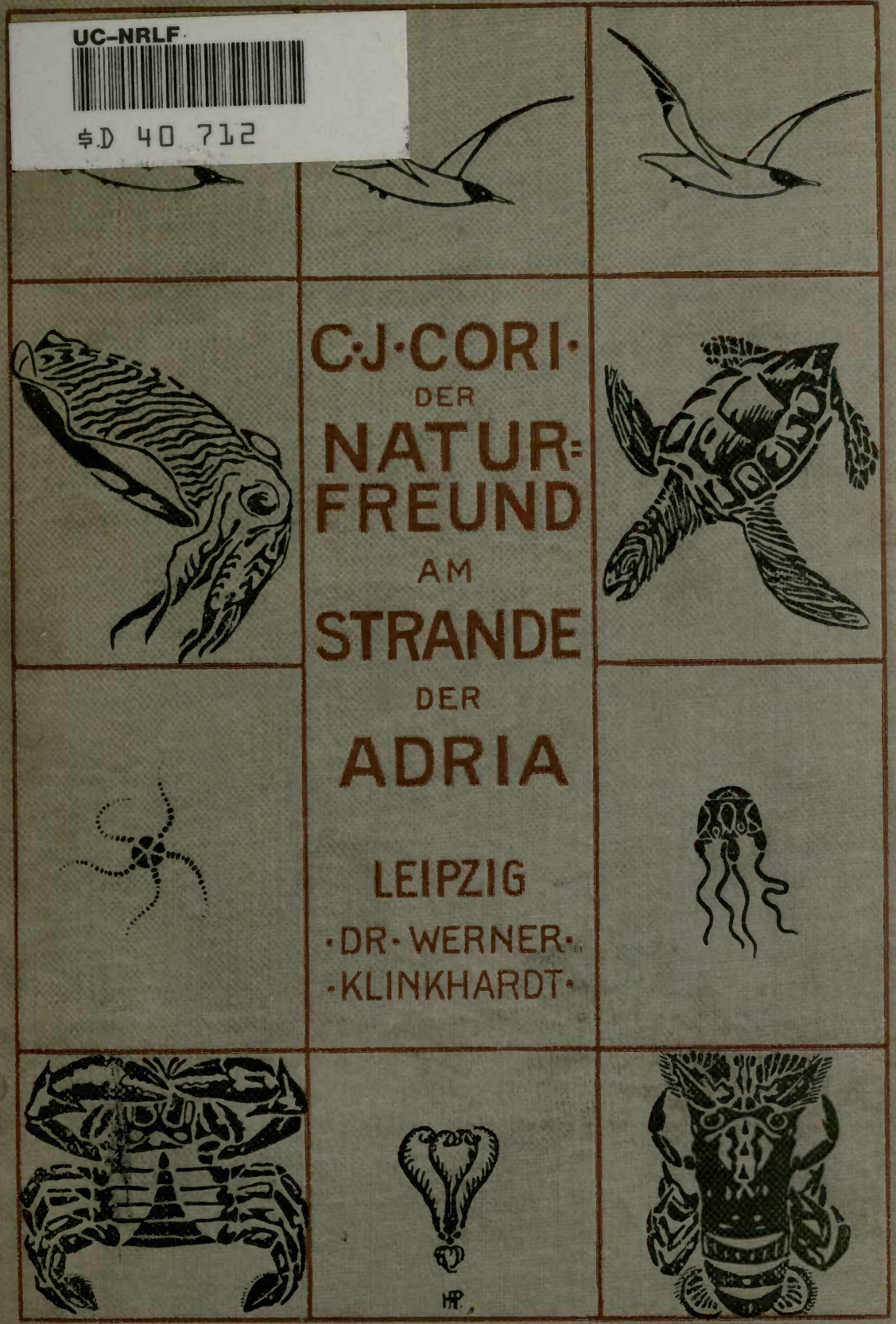



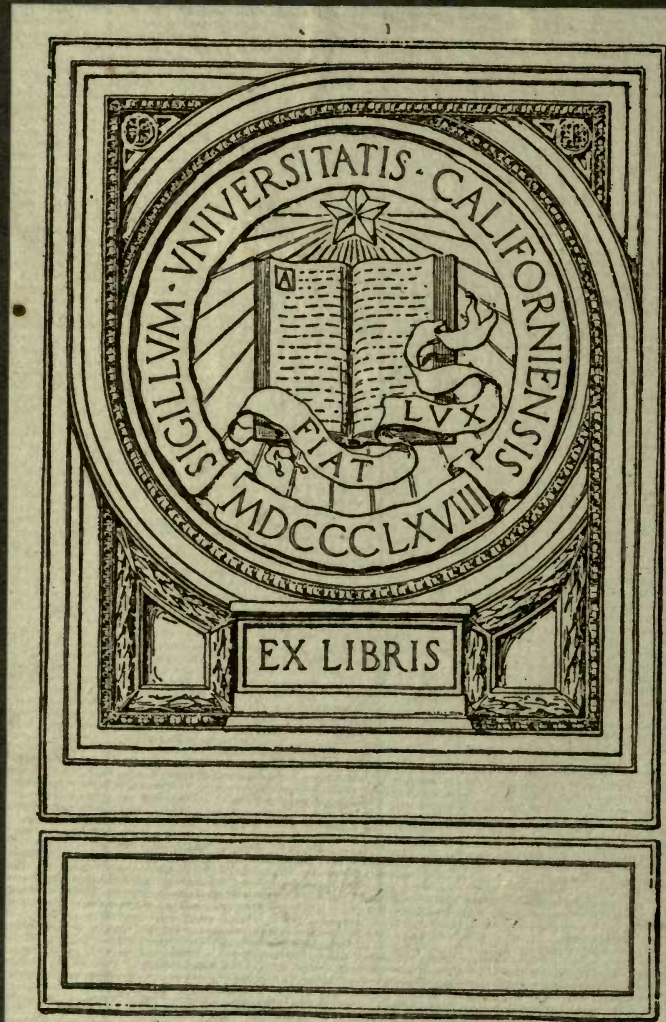



Tafel I.

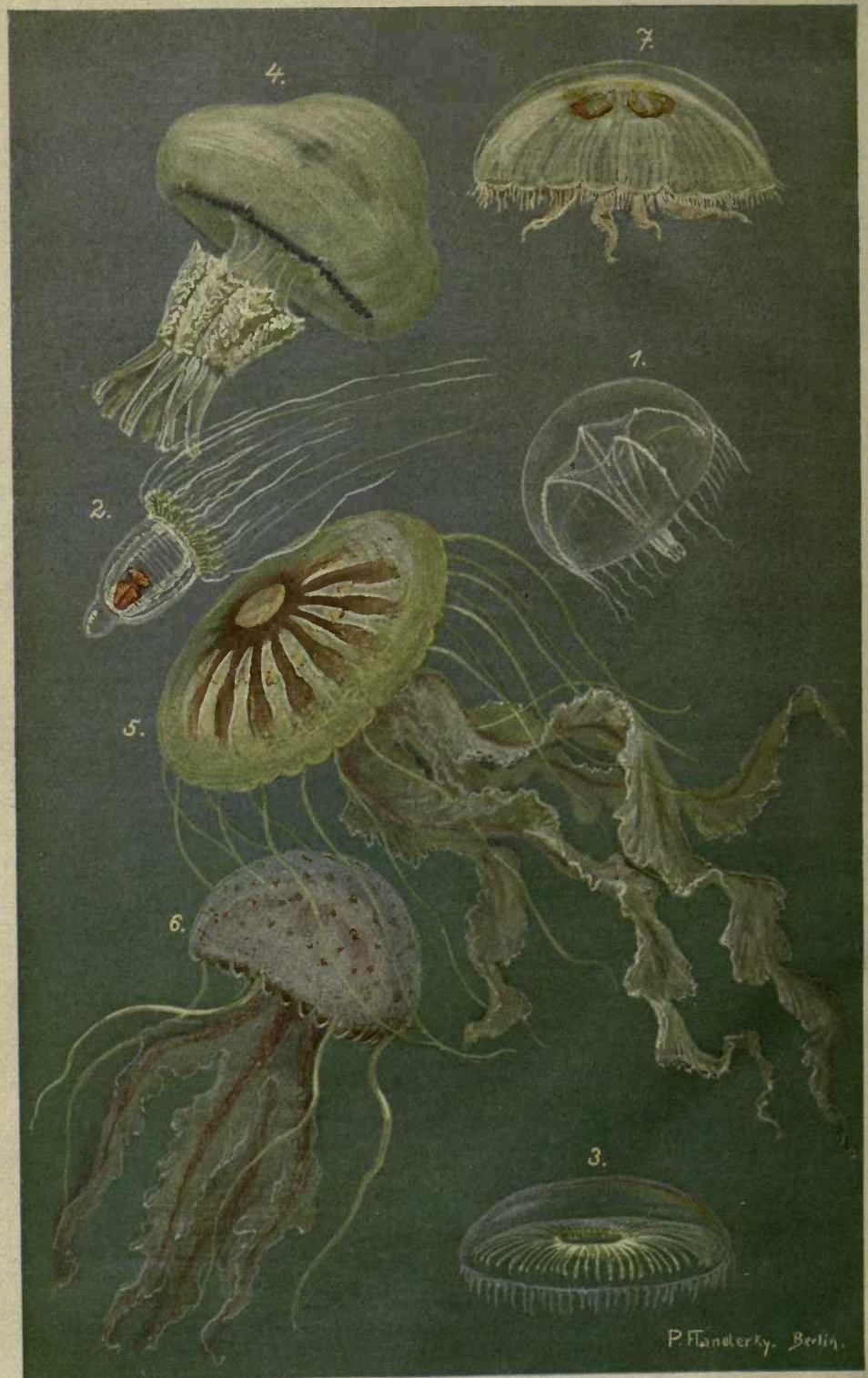




\section{TAFELERKLĂRUNG}

\section{Tafel I}

Figur

1. Tima flavilabris eine ganz durchfichtige Medufe mit einem Schirmdurchmeffer bis $5 \mathrm{~cm}$.

2. Tiara pilleata mit einem rotgefärbten Magenfchlauch (S. 117). Schirmdurchmeffer bis $2 \mathrm{~cm}$.

3. Aequorea forscalea (S. 116). Magen und die entlang der Radiärkanäle entwickelten Gefchlechtsdrüfen grau gefärbt. Schirmdurchmeffer $20-40 \mathrm{~cm}$.

4. Rhizostoma Cuvieri (S. 114, 115, 135), eine der größten Medufen mit einem Schirmdurchmeffer von $20-30$, ja bis $80 \mathrm{~cm}$. Im Schutge des Schirmes fchwimmen nicht felten Jungfilche. Achtung vor Quallenfchnupfen (S. 115).

5. Chrysaora mediterranea (S. 116). Schirmdurchmeffer 10 bis $30 \mathrm{~cm}$.

6. Pelagia noctiluca (S. 116). Schirmdurchmeffer $5-8 \mathrm{~cm}$. Neffelt heftig.

7. Ohrenqualle (Aurelia aurita) (S. 116). Schirmdurchmeffer bis $40 \mathrm{~cm}$. Bezüglich Medufen fiehe ferner Fig. 20, 21 u. $43 a$ u. b. 



\title{
DER NATURFREUND
}

\section{AM STRANDE DER ADRIA UND \\ DES MITTELMEERGEBIETES}

\author{
VON
}

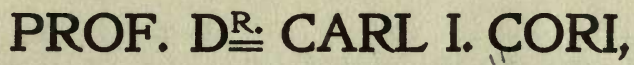

DIREKTOR DER K. K. ZOOLOGISCHEN STATION IN TRIEST

1 FARBIGE, 21 TAFELN IN SCHWARZDRUCK MIT 191 FIGUREN

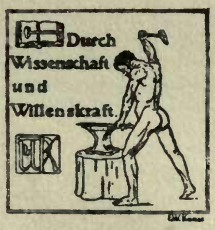

LEIPZIG 1910

VERLAG VON DR. WERNER KLINKHARDT. 

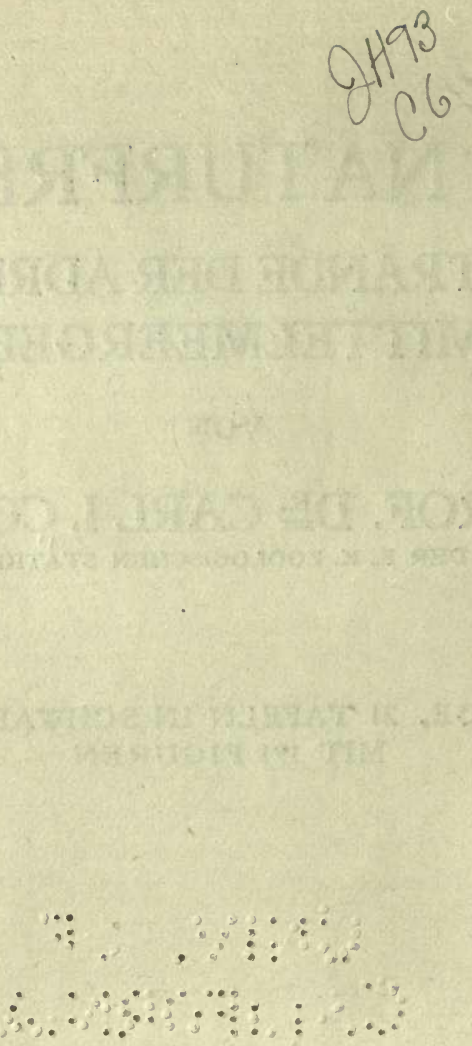

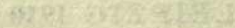

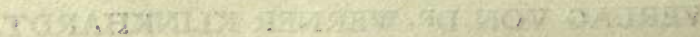

Drud ron Ernft Hedrich Nahf, G.m. b. H., Leipzig. 


\section{IN HALT.}

Vorwort und Einleitung

I. Uber die Entftehung des Mittelmeeres und der Adria 1

II. Am Flachitrande der "Lidi", der adriatifchen Nehrungen und die Spuren im Sande . . . . . 5

III. Die Lagune und ihr Leben . . . . . . . . 24

IV. Die Zofterawiefen der Flachfee . . . . . . . 39

V. Die Felfenküfte . . . . . . . . . . . 61

VI. Auf Schleppnetzfahrten . . . . . . . 83

VII. Plankton und planktonifche Tiere . . . . . 105

VIII. Tiere der Hochfee . . . . . . . . . . . 122

Einige empfehlenswerte Bücher über das Meer und fein

Leben . . . . . . . . . . . . . 142

Regifter .............. 143 



\section{VORWORT UND EINLEITUG.}

B ei Studien- und Sammelfahrten im Gebiete der Adria und des Mittelmeeres kamen wir oft mit Menfahen in Berührung, die dem Meere mit feiner Fülle an Neuem, Schönem und Großartigem und feinem Reichtum an Tier- und Pflanzenformen das größte Intereffe entgegenbrachten, und die mangels einer geeigneten Anleitung dankbar waren für einige Worte der Unterweifung und Belehrung. Schon vor Jahren reifte daher die Idee, einen kleinen Führer für den Naturfreund am Meeresftrande abzufaffen. Doch hat fich die Durchführung diefes Planes nicht fo rafh bewerkftelligen laffen. Vor allem follten eigene Erfahrungen in reicherem Umfange gefammelt werden, und hierzu bot fich Gelegenheit bei den zahlreichen Sammelfahrten im Golfe von Trieft und insbefondere durch die Beteiligung an den Arbeiten zur Durchforfhung des Adriatifhen Meeres, die feit einer Reihe von Jahren durch den "Verein zur Förderung der naturwiffenfchaftlichen Erforfchung der Adria in Wien" in dankenswerter Weife in Angriff genommen worden find. Studienaufenthalte in Meffina, Neapel und Villefranche bei Nizza boten die Möglichkeit, vor allem die reiche, pelagifche Fauna diefer für den Zoologen unvergleichlich intereffanten Punkte kennen zu lernen.

Was wir verfucht haben in den folgenden Blättern in fchlichter Form zu fchildern, ift zum größten Teil die Wiedergabe von perfönlich Erlebtem und eigenen Eindrüdken. Es foll aber damit nicht fo fehr die Abficht verfolgt werden, eine eingehendere Darftellung der Syftematik und Organifation der marinen Lebewelt zu geben, - diefen Zwedk erfulllen bereits vorhandene ausgezeichnete Bücher, - fondern es follte mit unferem Büchlein dem Naturfreunde oder dem, der ein folcher werden möchte, ein Begleiter in die Hand gegeben werden, der ihn zur Beobachtung anrege und ihm eine Orientierung über die wichtigften Erfcheinungen des marinen Lebens ermögliche. Es fei verziehen, wenn wir uns mit unferen Ausführungen vielfach fpeziell an den Binnenländer wenden, aber diefem ift 
ja alles das, was das Meer betrifft, neu. Bei der reichen Fülle des Stoffes fiel es uns oft recht fchwer, das Gebiet eng $z u$ begrenzen und uns Befchränkungen aufzuerlegen. Die marine Flora konnte dabei nur eine geringe und beftimmte Berüdkfichtigung finden, denn die Behandlung diefes Stoffes wäre ja doch die Aufgabe eines Botanikers.

Es gibt wohl kaum eine fchönere Ausfüllung der Zeit während eines Aufenthaltes an See, als fich ein wenig mit der Natur zu befchäftigen. Gelegenheit hierzu if in reichfter Fülle vorhanden, man braucht hierfür nur das nötige Intereffe zu haben, und diefes ift erfreulicherweife im großen Publikum in reichem Maße vorhanden.

Wenn wir hier gleich einige Winke geben dürfen, wie man es anfangen foll, um der Natur näher zu kommen, fo können wir kurz fagen, daß hierzu eigentlich nur Vorliebe und ein offener Blidk nötig ift. Man beobachte vor allem und lerne fehen! Die Zuneigung zur Befchäftigung mit der Natur kann ferner wefentlich durch Sammeltätigkeit gefördert werden. Was bietet hierzu fchon der Strand allein für bequeme und reiche Gelegenheit. Eine Menge Conchilien, trodkene Schwämme und anderes brauchen da nur aufgelefen zu werden. Um ganze Tiere mit heimnehmen zu können, ift es am bequemften, diefe in eine in jeder Apotheke erhältliche Formol(-Formaldehyd)löfung zu übertragen (das Mifchungsverhältnis ift ein Teil des käuflichen 40 prozentigen Formaldehydes mit 19 Teilen Süßoder Meerwaffer). Manche der Formen ziehen fich dabei leider ein und zufammen, - denn zur Vermeidung deffen wäre eine vorherige Narkotifierung derfelben nötig - aber recht viele bleiben in der Form gut erhalten. Sie bieten dann zu Haufe noch Gelegenheit zur weiteren Betätigung mit dem Gegenftande.

Vor allem trachte man direkt im Freien die Lebewelt zu belaufdhen. Die herrlichfte Gelegenheit bietet hierzu der Gebrauch des fogenannten Gudkfenfters (fiehe Seite 63), das man beim Baden oder von einem Kahne aus benützen kann. Jede Badeanftalt am Meere follte einige folcher Fenfter zur Verfügung halten. Es wird fich hoffentlich mit der Zeit auch erreichen laffen, daß man in befuchteren Strandorten der 
Adria und des Mittelmeeres einige Behelfe für diefe Zwedse erhalten kann, wie einfache Planktonnetze, Tafchenlupen, Glashafen und dergleichen. Vor allem fuche man auch den Anfchluß an Fifcher bei ihren Fifchereifahrten. Selbft der Sportsmann würde hierbei Gelegenheit haben, neue, intereffante und anregende Betätigung $\mathrm{zu}$ finden. Wir denken hierbei vor allem an das Fifchen mit der Langleine (fiehe Seite 92).

Sehr zu empfehlen ift ferner, einzelne Tiere und Pflanzen in Glasgefäße, in fogenannte Zudkergläfer, zu fetzen und zu zeichnen. Das Zeichnen if felbft für den Naturforfcher eine Unterfuchungsmethode, denn das, was ich mit Bleiftift und Farben auf dem Papier fefthalten will, muß ich mir genauer anfchauen. Dabei kommt man auf eine Menge Dinge und Einzelheiten, die fonft leicht entgangen wären, und was ich mir genauer betrachtete, hinterläßt einen tieferen Eindrudk im Gehirn. Das Zeichnen und Malen wird heute vielfach aus Liebhaberei betrieben, - eigentlich follte es als ein wertvolles Bildungsmittel jeder Menfch fo gut als es feine Fähigkeiten erlauben, erlernen - und für folche Amateure wird gerade das Formenund Farbenftudium der Meerestiere und -pflanzen fehr viel Anregendes und Neues bieten. Für diejenigen, welche in diefer Fertigkeit weniger geübt find, follen fpeziell die Abbildungen der Tafeln XVI als Vorbild dienen, die mit Abficht in einer möglicht einfachen Methode lediglich mit Bleiftift und eventuell farbigen Crayons hergeftellt, das Charakteriftifche zu betonen trachten. In dem vorliegenden Buche find faft alle in demfelben behandelten Formen durch Abbildungen vertreten.

Die Eindrüdke, die wir am Meere empfangen haben, follen natürlich nicht wieder im Getriebe des Alltagslebens verfinken und verwifht werden, fondern fie wären durch Lektüre zu pflegen, fie follen fozufagen auf diefe Weife in uns weiterleben. Diefem Zwedke möge ein Verzeichnis einiger einfhlägiger Werke dienen (fiehe S. 142). Wer die Mittel aufwenden will, kann fich endlich ein kleines Stüdxchen Meer auch im Binnenlande durch Anlage eines Seewafferaquariums fchaffen.

Es gereicht mir endlich zur angenehmen Pflicht, aller derjenigen dankbarft zu gedenken, die mir ihre Hilfe bei der 
Durchführung diefes Werkchens angedeihen ließen. So habe ich Frl. Hanna von Hütterott in Trieft für die Anfertigung der Taf. XVI herzlichen Dank zu fagen, und ebenfo Herrn Priv.-Doz. Dr. Hans Przibram in Wien für die äußerft gefchmadkvolle Kompofition des Umfchlages. Ferner hat bei dem illuftrativen Teil in hervorragendem Maße Herr Friedrich Theuer in Wien mitgeholfen. Gerne hätten wir unferen urfprünglichen Plan, alle Figuren in Farben zu bringen, ausgeführt und auch noch in den Text eingeftreute Abbildungen gebracht, aber dies fcheiterte leider an den hohen Reproduktionskoften. So mußten wir uns mit einer einzigen Farbtafel über Medufen, die der bekannte akademifche Maler Paul Flanderky in Berlin anfertigte, begnügen. Viele Zeichnungen hat endlich die bewährte Hand des Herrn Adolf Kasper, Lektor für wiffenfchaftliches Zeichnen der Univerfität in Wien, ausgeführt. Schließlich habe ich noch Herrn Priv.Doz. Dr. Frits Lippich in Prag, fowie meinem Affiftenten Herrn Dr. Carl Lehnhofer für die Mithilfe bei der Durchführung der Korrekturen des Drudkes und für die Anfertigung des Indexes zu danken.

Trieft, Ende Juni 1909. 


\section{I.}

\section{UBER DIE ENTSTEHUNG DES MITTELMEERES UND DER ADRIA.}

W em das Meer zum erftenmal am Frühmorgen eines in füdlichem Sonnenfchein gebadeten Tages wie mit einem Schlage vorgezaubert wird, der müßte kein Gefühlsmenfch fein, wenn er nicht in diefem Momente feinem tiefen Eindrudk durch einen Ausruf der Bewunderung Luft machen würde. Diefer erfte mächtige Eindrudk erregt einen ganzen Komplex der nachhaltigften Empfindungen in uns. Und wer wieder nach dem Norden heimkehrend einen letzten Blick in diefen großen blauen Spiegel tut, der verläßt das Geftade mit dem Gefühl der Sehnfucht. Die Analyfe aller diefer Empfindungen ift fchwierig, - die Gefühle der äfthetifchen Sphäre haben meift die Oberhand - und nur eine dunkle Ahnung von der Allmacht des Meeres und feiner Bedeutung für die gefamte Lebewelt ruht in der Tiefe unferes Bewußtfeins. Die folgenden Blätter follen dem Zwedk gewidmet fein, dem Naturfreunde bei feinen Fahrten im Gebiete des Mittelmeeres und der Adria oder bei feinen Wanderungen entlang des fandigen Strandes und der klippenreichen Küfte diefe neue Welt in ihrer eigentlichen Bedeutung zu erfchließen.

Wenn wir durch die Natur wandeln, follen wir es uns zum. Prinzipe machen, die uns begegnenden Erfcheinungen nicht als eine gegebene Sache hinzunehmen, fondern immer nach der Urfächlichkeit und der Abhängigkeit derfelben von einander zu fragen. Nur auf diefem Wege werden wir imftande fein, ein wenig auf den Grund der Dinge zu kommen und das Verfändnis für unfere Welt zu vervollkommnen. Dann wird auch die Vorliebe und Befchäftigung mit der Natur jenen hohen bildenden Wert, den man noch viel zu wenig würdigt, befitzen. Wir dürfen alfo nicht den paffiven Zufchauer auf diefer Bühne abCori, Der Naturfreund. 
geben, fondern wir follen, wenn von diefer zu uns gefprochen wird, dem lernbegierigen Schüler gleich nicht müde werden im Fragen.

Was jeder an fich felbft erleben und erkennen muß, daß alles individuelle Leben auf dem Entftehen und Vergehen fußt, gilt auch für die gefamte Lebewelt und für den Erdball überhaupt. Unfere Frageftellung foll fich daher nicht ausfaließlich auf die unmittelbaren Erfheinungen beziehen, fondern es ift oft außerordentlich lehrreich, den Blidk in die Vergangenheit $z u$ richten, um manches Unverftandene zu erfaffen. Die Wiffenfchaft, die uns hier Lehrer und Führer fein kann, ift die Geologie, die Gefhichte der Erde und fagen wir beffer die Gefhichte der Erde und ihres Lebens. Es ist bedauerlich, daß man in weiten Kreifen trots des unverkennbaren Intereffes für Naturwiffenfchaften gerade dieser Disziplin noch fehr fremd gegenüberfteht. Welchen Genuß würde eine gewiffe Schulung auf diefem Gebiete dem Wanderer, den es aus Freude an der Natur in die Berge zieht, bereiten, wenn er einigermaßen über die Prinzipien des Aufbaues und der Gefhichte unferer mächtigen Alpenkette unterrichtet wäre. So kehrt er denn meift aus einer ihm fremd gebliebenen Welt heim. Wir halten es daher für vorteilhaft, die folgenden Ausführungen über das Leben des Mittelmeeres und der Adria mit einer kurzen Schilderung der Entftehungsgefchichte diefes Meeres einzuleiten.

Unferer jetzigen Erdperiode geht eine gestaltungsreiche Epoche voran, die die Geologen Tertiär benennen und während diefer hat fich die Bildung des Mittelländifchen Meeres durch den Einbruch der Erdrinde vollzogen. Welch gewaltige Brüche und Verfhiebungen der Erdkrufte müffen damals vor fich gegangen fein, wenn wir bedenken, daß auf diefe Weife Tiefen bis zu 4000 Metern gebildet wurden. Das Adriatifche Meer verdankt den gleichen Prozeffen feine Bildung, aber es ift bemerkenswert, daß die damalige Bruchlinie nicht mit der jetzigen Strandlinie der Adria übereinftimmt. Zuerft ftellte diefe nur eine kleine Seitenbucht des Mittelmeerbeckens vor und reichte nicht fo weit nach Norden, wie dies heute durch die Städte Venedig und Trieft markiert wird. Dies läßt fich fehr fchön 
an den Tiefenverhältniffen des Adriatifchen Meeres erkennen. Betrachtet man eine Seekarte, auf welcher die Tiefenlotungen eingetragen find, fo findet man dann quer über die Adria eine Tiefengrenzlinie vom Vorgebirge Gargano der italienifchen Halbinfel über die Infeln Tremiti, Pelagofa und Lagofta zum dalmatinifchen Feftlande verlaufen. Südlich von diefer fällt das Meer rafch zu den bedeutenden Tiefen von über 1000 Metern ab. Im Gegenfaty dazu finden sich nördlich von diefer Grenzlinie nur geringe Tiefen, die abgesehen von dem nach der Infel Pomo benannten Becken mit einer Maximaltiefe von 250 Metern, noch unter 100 Metern heruntergehen. $\mathrm{Ja}$ in der Richtung gegen Norden wird das Meer immer feichter und feichter. Jene früher genannten Infeln ftellen nun die Verlaufsrichtung und Refte des alten Tertiärftrandes dar.

Im Gegenfaty zu dem oben erwähnten füdlich von der Infel Pelagofa gelegenen Tiefenbedken der Adria ift der erwähnte nördliche feichte Teil derfelben eine jüngere und ganz junge Bildung. Jenes adriatifche Seichtmeer war nämlich urfprünglich eine durch abgelagerten Schotter und Sand der Alpenflüfe aufgefchüttete Landfläche, die erft fpäter vom Meere infolge von Senkungsvorgängen überflutet wurde.

Bei einer Fahrt im öflichen Teil des Mittelmeeres und entlang der Küfte Dalmatiens find wir überrafcht über die Unzahl von Infeln, Infelchen, Felsriffe und Untiefen, welche fich hier entlang und oft mehr oder weniger parallel der Küfte hinziehen. Der Eindruck diefes Infelgewirres wird dadurch noch eigenartiger, daß fich nicht felten auf diefen Eilanden und Infeln anfehnliche Gebirgsrüdken erheben. Nicht nur die Geftalt und Lage diefer Felseilande, auch die Streichungsrichtung der Gebirgszüge deuten auf die innige Zufammengehörigkeit mit dem dahinter liegenden Feftlande hin. So wie vor unferen Augen eine vereifte Fläche beim Eisgange zu wogen, sich $z \mathfrak{u}$ biegen und $z \mathfrak{u}$ brechen beginnt, wie fich dann am Rande diefer Bruchzone Eistafel um Eistafel loslöft, wie aber noch immer der Zufammenhang mit dem Ganzen erkennbar ift, fo haben wir uns vorzuftellen, daß im Mittelmeergebiete mächtige Kräfte derartig weitgehende Zerreißungen 
der Erdfcholle bewirkt haben und ein förmliches Trümmerfeld, die vielen Archipele der Inseln Shuf. Jene Kräfte, welche fich in den vergangenen Zeiten des Tertiär und fpäter mit großer Energie betätigten, find aber durchaus nicht ganz zur Ruhe gekommen und verfhiedene Anzeichen fprechen dafür, daß fie fich auch jett noch weiter regen, wenn auch in geringerem Umfange. Wir denken dabei an die in hiftorifchen Zeiten erkennbaren Küftenverfchiebungen und in frifcher Erinnerung aus jüngfter Zeit ftehen noch die furchtbaren Eindrüdke der Erdbebenkataftrophe von Meffina. Wir find gewohnt, in jeder Betätigung aktives, fortfchreitendes Leben verkörpert zu fehen. Dies wäre aber ein gefehlter Standpunkt, wollte man in diefem Sinne die reiche tektonifche Tätigkeit beurteilen, die während des Tertiär Gebirge auftürmte und tiefe Ozeane fchuf und welche bis in unfere Tage nackklingt. Vielmehr find dies Alterserfcheinungen unferer Erde, die infolge des Erkaltungsprozeffes fhrumptt und deren Antlity fich in Falten legt.

Eingangs haben wir auf die hohe Bedeutung des Meeres als eine Welt reichen Lebens hingewiefen, und da drängt fich uns nach der Befprechung der Entftehung des Mittelmeeres und der Adria nun auch die Frage nach der Gefhichte der marinen Tiere und Pflanzen auf. Hier muß uns wieder die Geologie-Palaeontologie Auffchluß geben. Und fie zeigt uns in der Tat, daß die gegenwärtige Mittelmeerfauna im wefentlichen die alte marine Tertiärfauna darftellt. 


\section{Tafel II}

Figur

8. Tethya lyncurium (S. 72), kugelförmige, fchwefelgelbe Knollen von $4-5 \mathrm{~cm}$ Durchmeffer.

9. Korkschwamm (Suberites massa) (S. 94), orangegelb bis zinnoberrot, wächft in anfehnlich großen Stüdken von ziemlich fefter Konfiftenz.

10. Meerorange (Suberites domuncula) (S. 94) lebt fymbiotifch mit dem Einfiedlerkrebs (Paguristes maculatus).

11. Ein Stein, vom Bohrschwamm (Vioa typica) (S. 66 u. 75) vollftändig unterminiert. Durch die kleinen Löcher auf der Oberfeite fteht der Schwamm mit der Außenwelt in Verbindung.

12. Raspaillia viminalis, ein braungefärbter Schwamm, der neben Kiefelnadeln auch ein Gerüft aus Hornfafern befitzt. Im vorliegenden Falle fitst die Schwammkolonie auf der Schale der Mufchel (Venus verrucosa).

13. Kautschukschwamm (Chondrosia reniformis) bildet in der untergetauchten Zone der Felsküfte und auf lofen Steinen gelbe bis graue knollenartige UUberzüge von gummiartiger Konfiftenz und mit fchlüpfriger Oberfläche.

14. Aplysina aërophoba (S. 71), ein Schwamm mit Hornfafergerüft von fchwefelgelber Farbe.

15. Spongelia pallescens (S. 47), Schwamm mit Hornfafergerüft von weicher Befchaffenheit; Farbe grau, braun, lila.

16. Badeschwamm (Euspongia officinalis) (S. 71) bildet runde aber auch unregelmäßig geformte Klumpen von dunkelbrauner Farbe. 
Tafel II

10

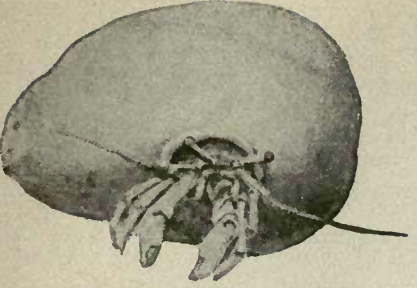

15

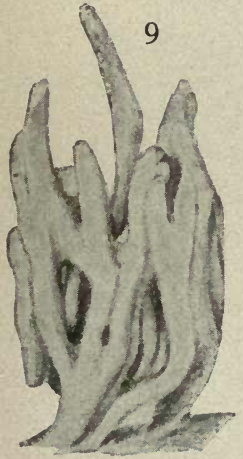

sit,

- $3-2 \times-2$

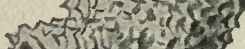

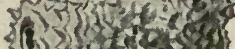

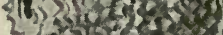

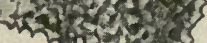

netso?

Fin 120 in senminge

8

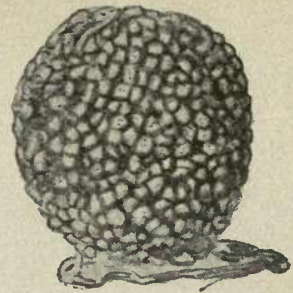

14

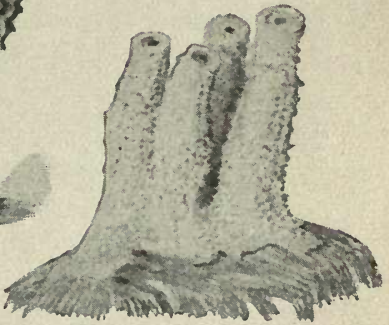

11
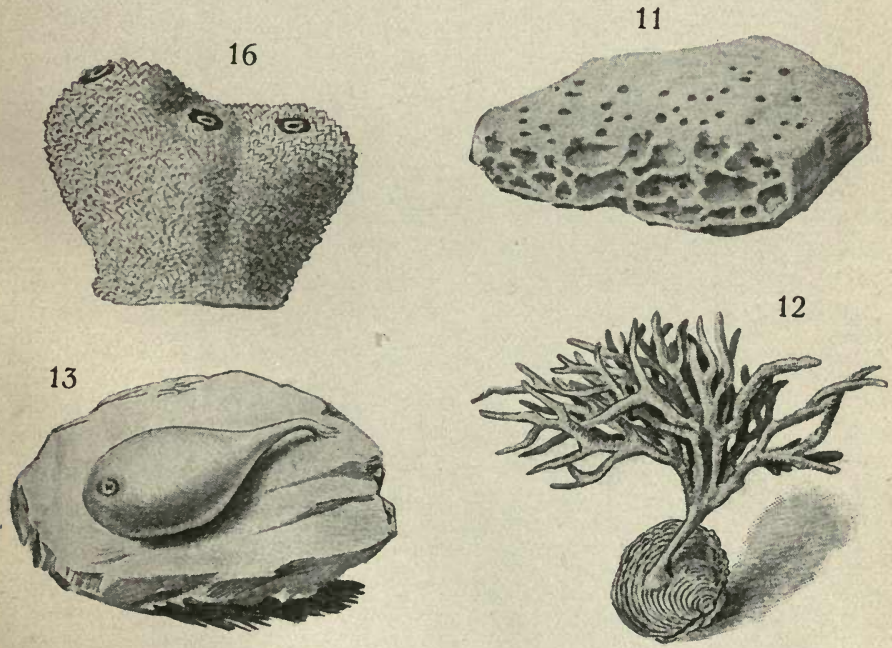
II.

\section{AM FLACHSTRANDE DER „LIDI“, DER ADRIA- TISCHEN NEHRUNGEN UND DIE SPUREN IM SANDE.}

$\mathrm{M}$ it den Meerestieren und -pflanzen kann man kaum auf andere Weife fo bequem und in fo innige Berührung kommen wie beim Baden am Flachftrande der Nehrung. Die hohe Waffer- und Luftemperatur des adriatifchen Gebietes erlaubt $j a$ in ausgiebigfter Weife die Benutzung des Bades und man hat reichlich Gelegenheit zum Beobachten, verbringt man doch einen großen Teil des Tages am Strande amphibifch bald im Waffer, bald auf den fonnendurchglühten Sandflächen. Eigentlich muß man fagen, daß fich hier das Leben des Meeres jedem aufdrängt und insbefondere dem Binnenländer muß es anziehend erfcheinen, diefes etwas näher kennen zu lernen.

Es wird fich zunächft als nütlich erweifen, die Entftehung der Nordküfte der Adria vom Po bis zum Ifonzo, der adriatifchen Lagunenküfte, und deren geographifche Bedeutung zu befprechen. Im I. Kapitel wurde bereits gefagt, daß der nördliche Seichtteil des Gebietes urfprünglich eine Anfchüttungsebene, von Alpenflüffen bewirkt, fei. Diefelben Flüffe, die nun fhon durch Jahrtaufende ihre Tätigkeit entfalten, wie der Po, der Tagliamento, der Ifonzo und wie fie alle heißen, fetyen ihre Arbeit auch in unferen Tagen fort. Sie führen unentwegt aus den Bergen Gerölle, Sand, feinft zermahlenen Felfen und Humus mit fich. Die Steine und der gröbere Sand werden hauptfächlich im Unterlaufe in der norditalienifchen Ebene abgelagert, da hier mit der Abnahme des Gefälles die treibende Kraft des ftrömenden Waffers nicht mehr ausreicht, um diefes fchwere Material mit fich noch weiter zu führen. Während fich diefe Flüffe in ihrem Oberlaufe tief in den felfigen Talgrund 
einfahneiden konnten (wie z. B. im Etfch- und Ifonzotal), zeigen fie in der Ebene fehr breite Flußbetten, die nur zur Zeit der Schneefchmelze und reicher Niederfchläge voll gefüllt find, für gewöhnlich aber nur fpärliche Wafferadern zwifchen oft enormen breiten Schotterfeldern (Tagliamento) aufweifen. Sobald ein folcher Flußlauf mit dem Meere in Berührung kommt, wird ihm der leţte Reft feiner Kraft geraubt und er ift nicht einmal mehr imftande, den feinen Sand weit ins Meer hinaus zu tragen. Nur das Mehl der zermahlenen Felfen und die mitgeriffenen Humusteile werden erft im Meere ausgefällt und bilden dann hier den feinen grauen Schlamm und Schlick. Der Sand dagegen lagert fich in der Flußmündung $a b$, fodaß leţtere fchließlich durch eine Sandbarre verftopft wird. Der Fluß muß fich infolgedeffen einen neuen Weg zum Meere fuchen und fo entftehen nach und nach immer wieder neue Mündungsarme, die aus dem Hauptflußbett landeinwärts entfpringend fich wie die Afte einer Pinie ausbreiten; es find dies die bekannten Deltabildungen, wie fie jedem größeren Fluß an feiner Meeresmündung eigen find. Daneben fpielt fich aber noch ein anderer Prozeß mit dem feinen Sande ab. Diefer wird nämlich von den Meeresftrömungen und vom Seegang aus feiner urfprünglichen Lage in der Flußmündung feitlich vertragen und zu dammartigen Bildungen, den Nehrungen oder "Lidi", wie man fie im adriatifchen Gebiete nennt, aufgehäuft. Durch folche Sanddämme werden dann feichte Uferpartien des Meeres abgedämmt, und es entftehen landwärts davon Deichflächen, die von Kanälen, ehemaligen Mündungsarmen, eingefaßt find. Durch Windwirkung kann ferner der feine Sand des Strandes zu den bekannten Dünenhügeln aufgehäuft werden. Endlich entfaltet auch noch die Erfheinung der Flut und Ebbe dadurch einen geftaltenden Einfluß in diefem Gebiete, daß bei Flut und Ebbe periodenweife die Deichflächen überfchwemmt und wieder trocken gelegt werden. Während der Flutzeit lagert dann das Waffer feine in reicher Menge mitgeführten Sinkftoffe auf den Schlammbänken der Lagunendeiche $a b$, während die Kanäle durch die Gezeitenftröme von der Verfchlammung frei gehalten werden. 
Wenn man alfo das Gebiet diefer Flüffe von ihrer Mündung bis ins Feftland hinein verfolgt, fo fieht man, daß fie Land aufbauen und daß fie durch ihre Tätigkeit die weite fruchtbare norditalienifche Ebene gefchaffen haben. Diefer Landbildungsprozeß vollzieht fich etappenweife. Zuerft entfteht die Nehrung an dem Mündungskegel des Fluffes. Als das nächife Stadium erkennen wir die feichten Deichflächen. Wenn diefe durch die Sinkftoffe genügend ausgefüllt find, fiedelt fich auf ihnen eine reiche Flora von das Salz vertragenden, fogenannten Halophytpflanzen an. Leţtere befördern vor allem das Fortfchreiten des Verlandungsprozeffes. Solche Gebiete verwandeln fich alsbald in Sumpf- und Wiefenlandfchaft und endlich in fruchtbares Kulturland. Dies möge zur Orientierung über das Gebiet dienen, von welchem wir in diefem und dem nächiten Kapitel fprechen werden.

Wir wollen zunächit mit einigen Strichen die Lebensbedingungen des Lagunenftrandes als einen Lebensbezirk - die Hauptrolle fpielen hierbei die Wafferbewegung, der Gas- und Salzgehalt des Waffers, die Temperatur und das Licht - kennen lernen und dann einige markante Beifpiele der uns hier begegnenden Tierformen befprechen. Wie wir eingangs erwähnthaben, verdanken die Nehrungen ihre Entftehung der gemeinfamen Arbeit der Flüfe und des Meeres und jene Strandbildungen beftehen aus feinem grauen Sande. Wenn man eine Handvoll von diefem näher betrachtet, erkennt man fchon mit bloßem Auge, natürlich noch beffer mit einer Tafchenlupe, daß er nicht bloß aus verfchieden gefärbten Sandkörnchen, fondern auch aus vielen Fragmenten von Mufchel- und Schnedkengehäufen und Krebspanzern befteht, daß ihm ferner viele Gehäufe von Foraminiferen, einzelligen Lebewefen mit Kalkgehäufen fehr mannigfaltiger Geftalt, beigemircht find, und daß endlich eine Menge Detritus zerfallener organifcher Subftanz einen gewiffen Anteil bildet. So fehen wir denn, daß fich auch die Organismenwelt an dem Aufbau des Sandftrandes beteiligt. Insbefondere kann man an den Brandungslinien große Mengen von Mufchelfcherben durch die auslefende Wirkung des Waffers zufammengetragen finden. 
Wir haben alfo hier ein recht labiles Material vor uns, in dem wenig Ruhe herrfcht, und in dem, insbefondere wenn die Wogenmaffen mit ihrer zentnerfdhweren Gewalt vom Sturme bewegt gegen den Sandftrand anftürmen, fortwährend Umwälzungen und Verfchiebungen ftattfinden. Ein Blidk auf eine Seekarte oder ein nach diefer hergeftelltes Diagramm zeigt ferner, daß der Böfchungswinkel des Gebietes gegen das Meer ein $\mathrm{fehr}$ geringer ift und daß die Böfchungslinie ftufenförmig gebrochen erfheint. Infolgedeffen weift die Küfte auf ziemlich weite Stredken nur geringe Waffertiefen auf. Die Küftengeftalt ift eine Folge der Einwirkung des bewegten Waffers auf den Sandftrand, der fich wie eine plaftifche Maffe verhält. Aber nicht nur durch die unmittelbar auf die Wafferfläche wirkenden Winde kommt die Waffermaffe in Bewegung, fondern fie wird auch noch durch die parallel mit der Küfte verftreichenden Strömungen weitergetragen. Und gerade in dem ftetig bewegten fauerftoffreichen Waffer müffen wir das ewig belebende und verjüngende Moment erkennen, das in unerfchöpflicher Weife immer wieder neues Leben im Meere fhafft.

Es find aber auch noch andere phyfikalifche Momente, die für die Organismenwelt des Meeres eine Rolle fpielen. Vor allem ift von Bedeutung der Salzgehalt des Waffers. An den Nehrungsküften muß diefer felbftverftändlich ziemlich ftarken Schwankungen im Ablauf eines Jahres unterworfen fein, da hier Flüffe und Süßwafferläufe, denen fie ja ihre Entftehung verdanken, ausmünden und das Meerwaffer mehr weniger ausfüßen. Trotsdem finden wir aber hier, wenn es fich nicht gerade um Mündungsgebiete der Süßwafferzuläufe handelt, insbefondere im Sommer noch, recht falzreiches Waffer von durchfannittlich $3,0-3,5 \%$ Salzgehalt. Gerade diefer Salzreichtum hat für die Fauna und Flora diefer Zone eine große Bedeutung. Flüffigkeiten, die ein höheres fpezififches Gewicht befityen, alfo fchwerer als reines Süßwaffer find, erwärmen fich zwar langfamer als diefes, halten aber dafür die Temperatur länger in fich feft. Aus diefem Grunde ftellt das Meerwaffer der Adria vermöge feines hohen Salzgehaltes nicht bloß einen fehr guten Wärmeakkumulator dar, fondern diefer wird auch durch die fehr wirk- 



\section{Tafel III}

Figur

17. Aglaophenia pluma (S. 98,116 , Fig. 43 a, b) gehört zu den fkelettbildenden Hydroidpolypen. Es find Tierkolonien von federartiger Geftalt, deren Gefchlechtstiere in Form von reduzierten, fich nicht loslöfenden Medufen in eigenen Gefchlechtszellen (Chitinkapfeln) entftehen. Länge bis $20 \mathrm{~cm}$. Findet fich auf Algen und Steinen an der Felsküfte (untergetauchte Form) und im Mufchelfandgebiet.

18. Antennularia antennina (S. 98,116 , Fig. $43 a$, b), ebenfalls eine Hydroidpolypenkolonie mit Skelettbildung. Länge bis $20 \mathrm{~cm}$. Vorkommen wie Fig. 17.

19. Tubularia indivisa, am Ende der einfachen oder verzweigten Stämme fitzen die Polypenköpfchen mit einem doppelten Tentakelkranz, zwifchen welchen fich die reduzierten Medufen als Gefhlechtstiere in Form von Trauben entwidkeln. Länge bis $20 \mathrm{~cm}$. Vorkommen wie Fig. 17.

20. Fischreuse (Podocoryne carnea), kleiner nadkter Hydroidpolyp mit 8-12 Tentakel, findet fich auf dem Gehäufe der Fifchreufenfchnedke (Nassa reticulata) angesiedelt (Symbiose). Länge $5 \mathrm{~mm}$. Das Gefchlechtstier ift die fich loslöfende kleine Medufe Dysmorphosa carnea, Figur 43a.

21. Cladonema radiatum (S. 45) if eine kleine Medufe von 2-3 mm Schirmdurchmeffer und von brauner Farbe. Sie ftellt das Gefchlechtstier des kleinen Polypen Stauridium productum vor.

22. Seeblase (Physalia) (S. 117) gehört mit zu den größten Röhrenquallen.

23. Physophora hydrostatica (S. 118) ebenfalls eine Röhrenqualle; lebhaft fharlachrot gefärbt. Länge ca. $20 \mathrm{~cm}$. Fig. 39. 
Tafel III

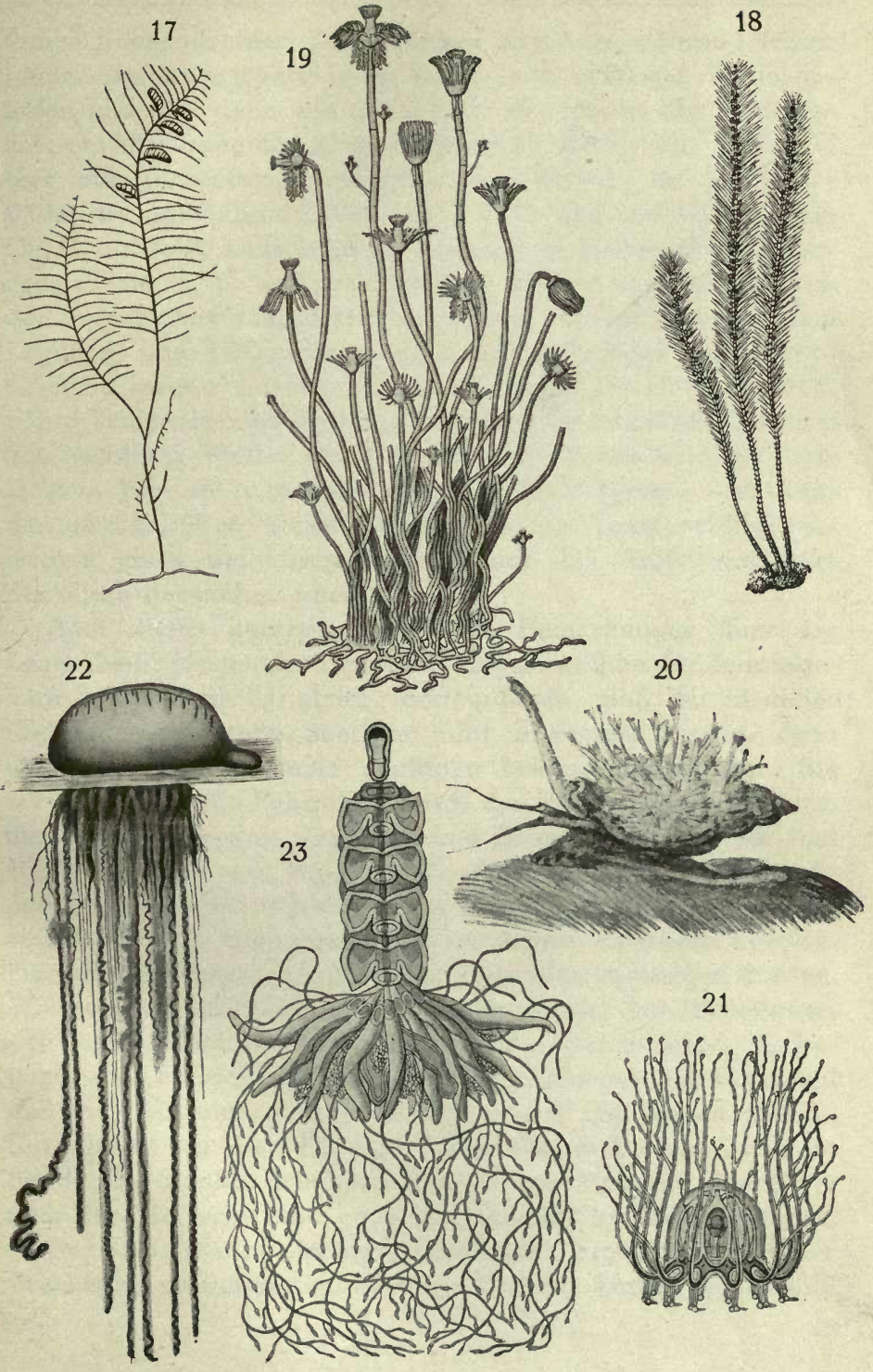



famen Sonnenftrahlen des füdlichen Himmels während feiner langen Befonnungsperiode im Sommer in kräftiger Weife geladen und gibt dann die angehäufte Wärme in der Winterszeit zur Milderung des Klimas allmählich wieder ab. Während hier das Jahrestemperaturmittel des Waffers an der Oberfläche die anfehnliche Höhe von $15^{\circ} \mathrm{C}$. und am Grunde von $12^{\circ}$ C. aufweift, kann man im Sommer in Küftennähe Temperaturen bis $25^{\circ} \mathrm{C}$. und mehr meffen. In dem uns intereffierenden Gebiete bewirken ferner die vielen Sinkftoffe, welche dem Lagunen- und Küftenwaffer des Nehrungsftrandes einen grünlichen Farbenton und eine milchige Trübung verleihen, eine erhöhte Temperaturfpeicherung. Denn es läßt fich fefttellen, daß fich getrübtes Waffer fchneller durch die Sonne erwärmt, als klares. Hier fei noch die Bemerkung hinzugefügt, daß unter den phyfikalifchen Momenten die Höhe des Temperaturjahresmittels einen wefentlichen Einfluß auf das Größenwachstum der Tiere auszuüben fheint.

Nach diefen kurzen allgemeinen Bemerkungen über die Lebensbedingungen der Tier- und Pflanzenwelt an derNehrungsküfte wollen wir es gleich vorweg fagen, daß wir in diefer feichten Zone große Seetiere nicht erwarten dürfen, denn diefe fänden hier keine günftigen Lebensbedingungen. Sie würden ja ftändig Fährniffen durch den Wogengang und durch die Wafferbewegung von Flut und Ebbe ausgefetyt fein und für fie beftände nur zu leicht die Gefahr zu ftranden. Trołdem ift in diefem Gebiete ein reiches Leben entwidkelt, aber es handelt fich vorwiegend um im Sande wohnende Formen, von welchen wir einige Beifpiele im folgenden befprechen werden. Wandeln wir zur Ebbezeit am trocken gelegten Sandftrande und auf den wafferentblößten ausgedehnten Sandbänken, fo begegnen wir allerlei "Spuren im Sande“, Bildungen, die uns fremd find und die unfere Aufmerkfamkeit auf fich lenken müffen. Unterfuchen wir diefe Dinge, fo zeigt fich, daß fie von den im Sande eingegraben lebenden Tieren herrühren und daß fie je nach der Tierform eine ganz charakteriftifche Geftalt haben.

Der Sandwurm (Arenicola piscatorum) (Fig. 47). Nahe jener Grenze, bis zu welcher bei mittlerer Flut das Waffer regelmäßig 


\section{II. Am Flachftrande der "Lidi“, der adriatifchen Nehrungen}

reicht, findet man häufig im Sande kleine trichterartige Vertiefungen, auf deren Böfchungen in radiärer Anordnung gefchlängelte Sandwürftchen in äußerft charakterifcher Weife angeordnet find. Es find dies die Kotmaffen, welche der „Sandwurm" ausftößt. Diefes Tier ift ein grünfhwarz gefärbter Wurm von ca. $30 \mathrm{~cm}$ Länge, welcher fenkrecht im Sande und mit dem Mundende nach unten eingegraben if. Seine Haut erzeugt ein grün gefärbtes fchleimiges Sekret zur Auskleidung und Imprägnierung feiner Sandröhre.

Wir müffen hier zum Verftändniffe einige kurze Bemerkungen über die Befchaffenheit des Sandes diefes Gebietes einfhieben. Zur Zeit der Ebbe ftellt diefer eine ziemlich fefte Dedke über einer darunter liegenden mit Waffer durchtränkten zähflüffigen Sandfchicht dar, die wir Schwimmfand nach dem Mufter des Bergmannes nennen wollen.

Die Arenicola reicht mit ihrem Kopfe bis in den Schwimmfand, denn fie frißt diefen feiner vielen organifhen Beftandteile halber. Die Refte des Verdauungsprozeffes find dann die Sandmaffen, welche vom Wurme wieder ausgeftoßen werden. Er verfährt dabei fo, daß er mit dem Hinterende aus der Röhre bis nahe an den Rand des trichterförmigen Feldes herauskriecht und dann die Kotmaffen während des rafchen Zurüdkziehens herausfpritzt.

Mit einigen Worten möge hier die Organifation der Würmer (Anneliden) und die Bedeutung diefer Tiergruppe für die Forfchung befprochen werden. Der hervorftechendfte Charakter diefer Klaffe befteht in der Gliederung ihres Körpers, die man auch Segmentierung oder Metamerie nennt. Außerlich kommt diese durch die Wiederholung Ptummelförmiger Bewegungsorgane und innerlich durch eine mit diefen in Zahl übereinftimmende Wiederholung von Organkomplexen zum Ausdruck. Die Parapodien, wie man diefe Stummelfüße nennt, fetzen fich aus zwei Aften zufammen, die zur Stütye Borftenbündel enthalten und je einen Fühler befitzen. Außerdem trägt der gegen den Rüdken zu gelegene Aft noch einen federförmigen Kiemenanhang. Diefe Eigentümlichkeit der Gliederung des Körpers teilen die Würmer mit einer Anzahl anderer Tiertypen, aber 
fie ftellen im Vergleich zu diefen den einfacheren Zuftand, und zugleich den Ausgangspunkt für die höhere Organifation diefer anderen Gruppen dar. Daraus ergibt fich die Bedeutung der Anneliden für die Abftammungslehre. Insbefondere find recht auffällig diefe Beziehungen zwirchen den Würmern und den Krebfen. So hat man die hoch differenzierte Extremität der leţteren von den einfachen Annelidenparapodien abgeleitet. Ahnliches gilt auch vom Kopfe der Krebfe und Gliedertiere. Ja man hat fogar eine Theorie verfucht, nach welcher die Wirbeltiere aus annelidenähnlichen Vorfahren hervorgegangen wären. Man befehe fich daher genau den Sandwurm auf diefe oben erwähnten Eigentümlichkeiten hin.

Beim Graben im Sande mit einem Spaten findet man übrigens noch andere Würmer, die in ihrer Organifation mit jener der Arenicola übereinftimmen, nur daß keiner deren Größe erreicht.

Der Sipunculus nudus. Es ift dies ein recht intereffantes Tier und ebenfalls eine Wurmform, aber ohne Gliederung. Sein walzenförmiger fingerdicker Körper, feine fleifchfarbige runzelige Haut und die lebhaften Kontraktionsbewegungen find fo charakteriftifch und abweichend von anderen fandbewohnenden Tieren, daß man diefe Form fofort erkennen muß. Am Vorderende wird von Zeit zu Zeit ein Kranz von kurzen Fäden, fogenannten Tentakeln, hervorgeftredkt, deren Hauptfunktion wahrfcheinlich in der Atmung befteht. Auch der Sipunculus ift ein fandfreffendes Tier.

$\mathrm{Zu}$ den typifchen Bewohnern des Sandes gehören ferner die Mufheln; es find dies Weichtiere mit einer zweiklappigen Schale, während die ihnen nahe verwandten Schnedken nur eine Schale in Form eines mehr oder weniger fpiralig gewundenen Gehäufes befitzen. Wir wollen hier zunächft einige Bemerkungen vorwegfhicken, ehe wir daran gehen, die uns am Nehrungsftrande begegnenden Mufdheln zu behandeln. - Alle Tiere waren urfprünglich frei lebende Formen oder ftammen von folchen $a b$, aber faft in jeder Tiergruppe fehen wir ein oder mehrere Vertreter die feftitzende Lebensweife annehmen. Vergleicht man dann leţtere mit freilebenden Verwandten, fo 
ift man oft aufs höchfte überrafcht, wie groß der Unterfchied in der Organifation in beiden Fällen ift und es läßt fich zeigen, daß diefe Veränderungen und Umgeftaltungen eben durch die Annahme der feftityenden Lebensweife bedingt wurden. Diefes Kapitel böte außerordentlich viel Intereffantes $\mathrm{zu}$ einer eigenen und ausführlichen Behandlung. Trotz der Mannigfaltigkeit der Erfcheinungen fehen wir aber durch die ganze Gruppe der feffilen Tiere viele gemeinfame Züge auftreten. Âhnliche Erfcheinungen bewirkt übrigens auch das Leben im Sande und Schlamme. Die Mufcheln find nun dadurch lehrreich, daß fie als fand- und fchlammbewohnende Wefen vielfache Ubergänge zur feftfitzenden Lebensweife zeigen.

Die Mefferfcheide (Solen vagina) (Fig. 107). Diefe Mufchel lebt in einer felbft gegrabenen Röhre und dadurch erklärt fich zunächft das Wachstum des Tieres hauptfächlich in der Längsachfe, eine Erfcheinung, der wir gerade bei Röhrenbewohnern häufig begegnen. Die Offnungen des Tieres für den Eintritt des Meerwaffers, das als Atemwaffer dient, und gleichzeitig die in demfelben fuspendierten Nahrungsteilchen zuführt, und ferner die Auswurfsöffnung für die Entfernung des Atemwaffers und der Schladken der Stoffwechfelvorgänge, liegen am Ende von zwei kurzen miteinander verwachfenen Röhren. Die Mufchel ift dabei in der Sandröhre mit ihrem Hinterende, welches diefe Ein- und Austrittspforten trägt, gegen die Mündung derfelben orientiert. Alle Mufcheln befitzen an beiden Seiten ihres Körpers eine Hautfalte, den fogenannten Mantel, welcher an feiner Oberfläche die Schalen erzeugt, und zwifchen fich die Kiemen und den Fuß einhüllt. Bei der Mefferfcheide fällt uns auf, daß die freien Mantelränder, die fonft bei den Mufcheln entlang der Schale hervorragen, hier miteinander bis auf eine ganz kleine Öfnung verwachfen find, fo daß der Raum zwifchen den Mantellappen, die fogenannte Kiemenhöhle, nach außen abgefchloffen erfcheint. Diefe Verwachfung der Mantelränder ift ebenfalls mit der Lebensweife in einer Sandröhre in Zufammenhang $\mathrm{zu}$ bringen und verhindert das Eindringen von Sandkörnchen und Fremdkörpern in die Mantelhöhle. Ferner fei noch darauf hingewiefen, daß bei allen Mufcheln der Kopf- 
abfchnitt infolge des Mangels an Sinnesorganen, wie Taftern und Augen, nicht abgefetzt erfcheint. Solche Organe haben viele feftfitzende Tiere verloren, was aber nicht ausfchließt, daß diefe trotzdem auf Licht reagieren.

Die Archen-Kammufchel (Pectunculus) (Fig. 110). In der Menge der verfchiedenartigen leeren Mufchelfchalen, die am Strande angefchwemmt zu finden find, fällt befonders die Schale der Archen-Kammufchel durch eine befondere Didke und Maffigkeit der Schalenklappen auf. Lettere find deshalb auch zum Schneiden von Kameen, einer in Italien hod entwidkelten Technik, fehr geeignet. Bei den Mufcheln werden die beiden Schalenhälftendurch ein elaftifches Band, das fogenannte Schloßband, miteinander verbunden und an den Stellen der Anheftung desfelben zeigen die Schalen meift Leiften oder Zähne, fo daß fie fich beim Öffnen und Schließen wie in Angeln - hier nennt man diefe Einrichtung Schloß - zwangläufig bewegen.- Bei der vorliegenden Form hat das Schloß eine auffallende Länge und außerdem find auch noch an den freien Schalenrändern ineinander eingreifende Zähne ausgebildet. Die Mufchel erinnert in ihrer Kugelform an die Geftalt von Steinen, welche durch das Waffer bewegt und zu rundlichen Körpern geformt worden find, wie man folche im Strandgefchiebe häufig findet. Wenn wir diefe erwähnten Eigenfchaften in bezug auf die ungewöhnliche Didkfchaligkeit und in bezug auf die folide Verbindung der Schalenhälften, fowie die Form des Tieres in Zufammenhang miteinander betrachten, und wenn wir die Archen-Kammufchel vorwiegend im Sande und im Gerölle des Flachtrandes antreffen, fo erfcheint es uns höchft wahrfcheinlich, daß die genannten Einrichtungen den Zwedk eines Schutges gegen die Brandungsbewegungen des Waffers in den feichten Uferregionen, insbefondere bei Sturm, verfolgen; aber auch das Kriechen und Wandern in dem feften Grunde des Strandes fetzt eine widerftandsfähigere Schale voraus als bei folchen Formen, die im weichen Schlamm- oder Sandgrunde leben.

Die warzige Venusmufchel (Venus verrucosa) (Fig. 12). In ähnlichem Sinne wie dies für die Archen-Kammufchel ausgeführt wurde, ift wohl die Geftalt und die Eigentümlichkeit 
der Schale diefer ebenfalls in der Strandzone häufigen Mufchel aufzufaffen. Speziell die hohen Leiften auf ihrer Schalenaußenfeite bewirken jedenfalls eine feftere Verankerung im Boden.

Der Herzfeeigel (Echinocardium mediterraneum). Beim Graben im Sande ftoßen wir nicht felten auf kugelige Körper, die wegen ihrer eigentümlichen Form und ihrer ftacheligen Befchaffenheit unfer Intereffe erregen. Wir haben den Herzfeeigel vor uns, welcher im Sande vergraben am Grunde einer Röhre lebt. Es ift nun von Intereffe, diefen Seeigel mit jenen an felfigen Küftengebieten lebenden in bezug auf die Körperform zu vergleichen. Leţtere zeigen nämlich einen regelmäßig radiären Körperbau, indem ihre Organe und Organgruppen nicht wie bei den Würmern hintereinander, fondern um eine Adhfe herum ftrahlenförmig angeordnet find. Wir können diefen Bauplan, wie er der Gruppe der Stachelhäuter zukommt, mit einem Rade vergleichen, wobei die Radnabe die Hauptachfe, die Speichen die radiär angeordneten Nebenachfen repräfentieren. Aus diefer Organanordnung refultieren entweder fheibenförmige, walzenförmige oder kugelige Organismen (Seeftern, Seewalze, Seeigel), je nachdem die Entwidklung des Körpers mehr in den Neben- oder Hauptachfen erfolgt, bezw. beide Achfen eine relative Verkürzung erfahren haben, wie dies bei den Seeigeln der Fall ift. Den radiären Körperbau zeigt auch eine andere aber viel einfacher gebaute Gruppe von Tieren, nämlich die Polypen und Medufen. Es fei jedoch hervorgehoben, daß es fich hier nicht um Eigenfchaften handelt, die auf dem Wege der Verwandtfchaft begründet find, fondern es liegen hier nur Parallelerfcheinungen vor. Aber gerade dadurch gewinnt diefes Beifpiel an Intereffe, denn es läßt fich vermuten, daß diefelben äußeren Momente und eine ähnliche Lebensweife bei diefen zwei ganz verfchiedenen Tiergruppen den radiären Körperbau bewirkt haben. Die Sache ift noch dadurch intereffanter, daß die Seeigel, wie alle Stachelhäuter, wahrfcheinlich von fymmetrifchen Vorfahren abftammen. Befehen wir uns nun den Herzfeeigel genauer, fo bemerken wir, 
daß deffen radiärer Körperbau eine Störung aufweift, indem der After aus feiner unfprünglichen Lage in der Hauptachfe herausgerüdkt erfcheint und fich dem Munde genähert hat. Dies hat zur Folge, daß der radiäre Charakter des Körpers in einen mehr oder weniger fymmetrifchen Zuftand übergeführt ift. Derartig vom Typus abweichende Seeigel bezeichnet man als irreguläre. Sie find bereits in früheren Erdepochen aufgetreten und noch heute vielfach verbreitet. Alle diefe leben eingegraben im Meeresgrunde und nähern fich daher in ihrer Lebensweife den Röhrenbewohnern. Die Verfchiebung des Afterfeldes gegen den Mund, bezw. die Annäherung beider und die Stredkung des Körpers aus der Kugelform in eine mehr elypfoide muß eben als eine Folgeerfcheinung diefer Lebensgewohnheit aufgefaßt werden.

Synapta digitata. Dem Sipunculus nicht unähnlich ift die Synapta, welche zu den Seewalzen gehörig, eine Verwandte der Seeigel, Seefterne, Schlangenfterne und Haarfterne ift, und daher ebenfalls im Körperbau den radiären Typus zeigt. Der walzenförmige Körper der Seewalzen oder Holothurien ift durch die vorwiegende Entwidklung in der Hauptachfe bei Verkürzung der radiären Nebenachfen entftanden. Der Norm nach befiten diefe Formen an der ganzen Oberfläche des Körpers Füßchen in fünf Reihen angeordnet. Jene Füßhenreihen fehlen aber der Synapta, und diefer Mangel läßt fich durch die grabende Lebensweife erklären. Die Haut diefes Tieres fühlt fich rauh und klebrig an infolge von kleinen in die Körperwand eingelagerten, ankerförmigen Kalkkörperchen; fchon bei Lupenvergrößerung kann man diefe Gebilde in der ziemlich durchfichtigen Haut ausnehmen. Solche Kalkkörperchen kommen allen Holothurien in manigfacher Geftalt zu und ftellen primitive Skelettbildungen dar. Bei der Synapta fcheinen die erwähnten Kalkankerchen eine Rolle bei dem Feftetzen im Schlamm- oder Sandgrund zu fpielen. Merkwürdigerweife bohren fich diefe Tiere mit dem Hinterende voran in den Meeresgrund ein, während bei der Mehrzahl der das Sediment bewohnenden Formen das vordere Körperende der grabende Teil ift. Noch eine andere Eigen- 
tümlichkeit zeigt die Synapta; fie zerbricht ungemein leicht, fobald fie aus dem Schlamme oder Sande herausgenommen und gereizt wird. Die Erfcheinung des felbfttätigen Zerreißens oder Abwerfens von Körperteilen ift im Tierreich durchaus nicht felten, fondern findet fich in verfchiedenen Gruppen. Die Bedeutung derfelben ift jedoch keine einheitliche. In manchen Fällen ift das Zerftüdkeln, wie z. B. bei den Würmern eine Form der ungefchlechtlichen Vermehrung, und ift dann meift mit Regenerationsvorgängen verbunden. Krebfe können felbfttätig Extremitäten abwerfen, fie können "autotomieren“, und hierin ift eine Schutgeinrichtung gegenüber ihren Feinden zu erblidken. Bei unferer Seewalze liegt jedenfalls eine ganz befonders große Reizbarkeit der Haut vor, welche eine derartig krampfhafte Kontraktion der Hautmuskulatur auslöft, daß die dünne Körperwand fchließlich durchreißt.

Der Eichelwurm (Balanoglossus). (Fig. 52.) Von den Spuren im Sande zur Ebbezeit find endlich fehr auffallende Bildungen kleine Häufchen von mehr oder wenig fpiralig gedrehten Sandwürftchen. Wenn man genauer zufchaut, fieht man nicht felten im Zentrum diefer Bildungen das Würftchen aus dem Boden hervorquellen, und an diefer Stelle trägt es dann knapp über dem Boden als Umhüllung wie einen gelblich gefärbten Schleimring. Bei Erfchütterung oder Berührung zieht fich letzterer fofort zurück. Es handelt fich auch in diefem Falle um die an die Oberfläche ausgeftoßenen Kotmaffen eines fandfreffenden Tieres, des Eichelwurmes, eines für die Forfchung hochintereffanten Tieres von wurmartiger Geftalt. Auch der Eichelwurm liegt bei der Nahrungsaufnahme mit dem Kopfe nach abwärts und nimmt den leichtflüffigen Sand der Schwimmfandfchicht in fich auf. Wie aus der Abbildung diefes Tieres zu erfehen ift, laffen fich an demfelben mehrere Körperabfhnitte unterfcheiden. Das Kopfende hat die Form eines kegelförmigen, fehr beweglichen Rüffels und diefer ift von einer kragenartigen Hautfalte umgeben, innerhalb welcher fich die weite Mundöffnung findet. Durch kombiniertes Zufammenarbeiten der beiden Teile wird der Sand portionenweife in den Mund befördert. Auf die Eichel- und Kragenregion folgt dann 



\section{Tafel IV}

Figur

24. Pferdeaktinie (Actinia equina) (S. 78). Rot mit einem blauen Rand um die Bafis und blauen Warzen unter der Anfatsftelle der Tentakel. Länge bis $5 \mathrm{~cm}$.

25. Actinia cari (S. 79), grün mit dunkleren Querftreifen.

26. Wachsrose (Anemonia sulcata) (S. 79,98$)$ grau bis apfelgrün; die Tentakelenden oft karminrot. Länge bis $15 \mathrm{~cm}$, Durchmeffer des Körpers bis $10 \mathrm{~cm}$.

27. Anemonia contarini, eine kleine Aktinienform, welche gewöhnlich in großer Menge auf den Blättern vom Seegras (Zostera) fitgt und im Habitus an die Wachsrofe erinnert.

28. Edelsteinrose (Bunodes gemmaceus). Fleifchfarben bis rosarot, Körper mit regelmäßigen Reihen von Wärzchen befetst. Länge $2-6 \mathrm{~cm}$.

29. Ragactis pulchra (S. 89). Die Mundfcheibe und Tentakel zeigen in grau eine intereffante Färbung und Zeichnung, der Körper ift unregelmäßig rot gefledkt auf hellerem Untergrund. Vorkommen im Mufchelfandgebiet.

30. Aiptasia mutabilis (S. 80) befitt einen wenig konfiftenten Körper und ziemlich lange Tentakel, welche auf einer verbreiterten Mundfcheibe entfpringen. Die Färbung ift variabel.

31. Sonnenrose (Heliactis bellis) (S. 79, 98). Die Mundfcheibe ift gegenüber dem kurzen zylindrifchen Körper ftark ausgebreitet. Farbe variiert in braunen Tönen. (Länge bis $8 \mathrm{~cm}$ ). Alle die bisher genannten Aktinien befeftigen fich an der Unterlage mit einer Haftfheibe.

32. Ilyanthus partenopeus (S. 47) vergräbt fich in den Meeresgrund bis an die Mundfcheibe. Diefe Anemone ift gelblich gefärbt und ftark durchfheinend. Länge bis $8 \mathrm{~cm}$.

33. Cylinderrose (Cerianthus membranaceus) (S. 47) in der Farbe ungemein variierend; $f$, auch Fig. 38. 


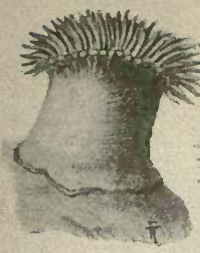

28
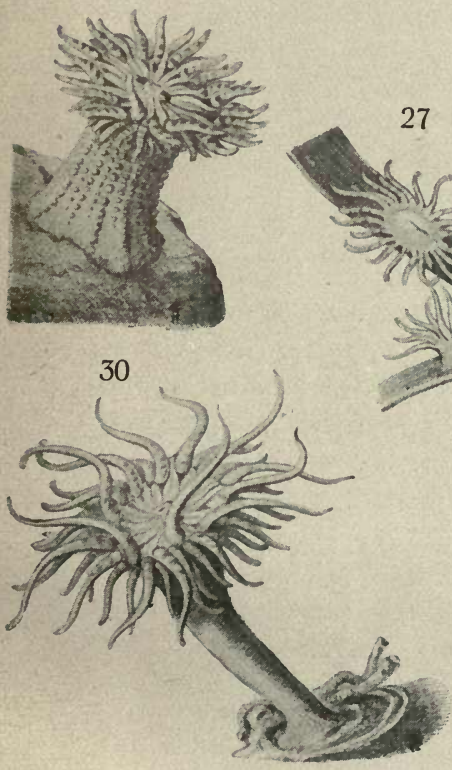
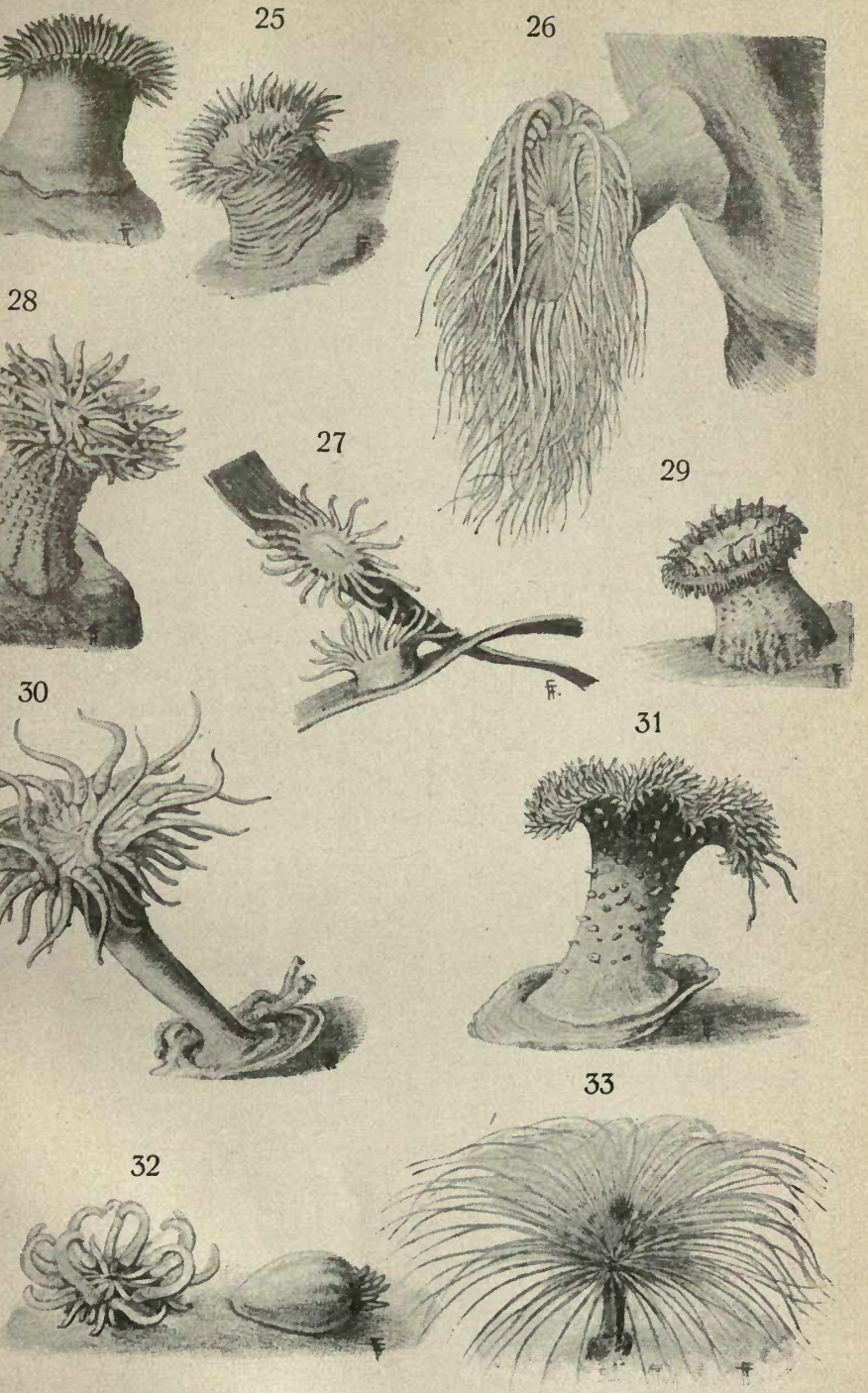

ein auffallend gelb gefärbter Abfchnitt mit flügelartig verbreiterten Rändern und mit einer kielartigen Erhebung in der Mittellinie des Rüdxens. In diefer Region find Kiemen entwickelt, die ähnlich wie bei den Fifchen Durchbrechungen der Leibeswand darftellen, fo daß das mit dem Munde aufgenommene Waffer durch die Kiemenlöcher feitlich wieder abfließen kann. Indem hierbei die Kiemen umfpült werden wird die im Körper gebildete giftige Kohlenfäure nach außen abgegeben, während andererfeits der im Waffer gelöfte Sauerftoff aufgenommen wird. An die Kiemenregion fchließt fich dann ein Körperabfchnitt an, der durch zottenartige Anhänge ausgezeichnet ift; es ift dies die fogenannte Leberregion. Der leţte Teil des Körpers erfcheint fchlauchförmig und fehr dünnwandig und enthält im wefentlichen den im angefreffenen $\mathrm{Zu}$ ftande des Wurmes prall mit Kot erfüllten Darm.

Der Eichelwurm zeigt abgefehen von den Kiemen auch in feiner fonftigen Organifation Anklänge an den Bauplan der fogenannten Chordatiere, zu welchen die Manteltiere, das Lanzettfifchchen und die Wirbeltiere gehören. Vielfach harren diefe Eigentümlichkeiten noch einer Aufklärung durch die Forfchung und dies alles, fowie die nicht ganz geklärte Stellung des Tieres im Syfteme macht den Eichelwurm zu einer fehr intereffanten Form.

Auch der Eichelwurm zeigt die Eigentümlichkeit zu zerbrechen. Im vorliegenden Falle ift es vorwiegend die äußerft dünnwandige Darmregion, die, folange fie prall mit Sand gefüllt ift, fo empfindlich erfcheint. Hat fich der Darm feines Inhaltes entleert, dann ift diefe Gefahr befeitigt und darauf beruht der Kunftgriff, um dieses Tier unverleţt aus dem Sande herauszugraben. Die verloren gegangene Darmregion wird übrigens leicht regeneriert.

Wir fehen alfo, daß eine ganze Anzahl von Tieren, die gleichzeitig individuenreich auftreten, im Sande eingegraben leben und Sandfreffer find. Der Boden des Flachftrandes erfcheint uns zwar als ein für die Ernährung ganz fteriles Material, und wenngleich die in demfelben enthaltene Nahrungsmenge eine relativ geringe ift, fo bleibt fie in der Natur doch C ori, Der Naturfreund. 
nicht unausgenütt liegen. Bei diefer Form der Ernährung, die natürlich nur durch eine Spezialifierung für diefen $\mathrm{Z}$ wedk möglich wird, ift der in den Darm aufgenommene Sand bloßer Ballaft, und es refultieren daher große Mengen von Kot, der aus reinem Sande oder Schlamm befteht und von den Tieren, wie wir gefehen haben, an die Oberfläche gefchafft wird Ähnliches tun ja audh die das Feftland bewohnenden Regenwürmer.

Hier fei die Bemerkung eingefhaltet, daß man im Flyfh, einer intereffanten Formation der Kreide und des Tertiärs, welche im Triefter Gebiete als Mergel und Sandftein auftritt, Foffilien findet, die mit verfhiedenen Namen bezeichnet und verfchieden gedeutet werden. Diefe Bildungen kann man leicht in den Flyfchplatten, mit welchen die Hauptftraße von Grado und die Straßen von Trieft gepflaftert find, finden. Noch inftruktiver ift es, zu diefem $Z$ wedk die Steinbrüche folcher Platten felbft aufzufuchen. Diefe Dinge, um welche es fich im vorliegenden Falle handelt, find ihrem Wefen nach nicht Abdrüdke von Körpern, fondern Ausfüllungen von Röhren. Nach unferer Meinung find es aber nichts anderes als die Kotfäulen von Tieren des Tertiär, welche den Flyfhfand bewohnten und fich durch diefen fozufagen durchfraßen. Dabei erfüllten fie die gefreffenen Röhren fofort wieder mit den aus Sand oder fandigem Schlamm beftehenden Kotmaffen. Durch Verfuche im Aquarium hat fich nun fefttellen laffen, daß der jeţt lebende Eichelwurm unter beftimmten Verhältniffen diefelben oben erwähnten Bildungen erzeugen kann. Seit dem Tertiär hat fich die marine Fauna nicht viel verändert, und der Eichelwurm hat damals wohl ficher fchon beftanden. So glauben wir nicht fehl zu gehen, gewiffe Foffilien der Flyfchzone, die fogenannten Hieroglyphen, diefer Tiergruppe zuzufchreiben und als Kotfäulen anzufprechen. Für den Beobachter am Strande ift es gewiß fehr intereffant und lehrreich, dort Gelegenheit zu haben, die Art und Weife folcher Foffilbildungen vor vielen Jahrtaufenden heute vor Augen geführt zu fehen.

Wieder eine Anzahl anderer Tiere kriechen auf den Sandflächen des Flachftrandes und den Sandbänken herum und vergraben fich aber zeitweilig, jedoch häufig nur des Verftedkes 
halber, in dem weichen Sande, insbefondere auch dann, wenn fie von der Ebbe überrafht werden. Um diefe Formen zu beobachten, empfiehlt es fich, felbft ins Waffer zu gehen und die feichten Partien nahe dem Strande abzufuchen. Als häufigfte Vertreter diefer Gruppe wären Krebfe und Schnedken zu nennen.

Die Strandkrabbe (Carcinus maenas) (Fig. 77, s. S. 33). Diefem Krebfe begegnet man hier fehr häufig und er bietet einen für den Binnenländer ganz ungewohnten Anblick, wenn er in feinen flinken feitwärts gerichteten Bewegungen entlang der durch die Wellen erzeugten Rillen des Sandftrandes behende dahinftelzt, um nach irgend einer Beute zu fuchen. Fühlt fich der Carcinus bedroht, fo gräbt er fich mit den Hinterfüßen rafch ein, und aus dem Sandgrunde ragen dann nur die geftielten Augen hervor. So verftedkt überdauert er auch die Ebbezeit am trodken gelegten Strande felbft in der füdlichen Sonne. Wenn man das Tier erfaßt, fo verfällt es plötlich in eine Art Krampfzuftand und fieht dann wie tot aus. Durch diefen $\mathrm{Zu}-$ ftand von Scheintod fchütt es fich gegen Feinde, die nur auf die fich bewegenden Beutetiere aufmerkfam werden können. Eine weitere Schutzeinrichtung befteht in der Fähigkeit, daß diefe Krabben, wie die meiften Krebfe ihre Extremitäten felbfttätig abzuwerfen vermögen. Padkt man die Strandkrabbe bei einem der beiden Scherenfüße etwas unfanft, fo if faft ficher zu erwarten, daß fie uns diefen in der Hand zurüdkläßt, während fie felbft das Weite fucht. Auf diefe Weife kann das Tier unter Umftänden einer Gefahr entrinnen und fein Leben retten. Der Verluft einer oder mehrerer Füße ift ja kein großer, da fie wieder regenerirt werden. Der Strandkrabbe werden wir noch einmal im Lagunengebiete begegnen, wo fie in wirklich großen Mengen vorkommt.

Hier möge noch eine Bemerkung über den Bau der Krabben angefchloffen werden. Sie gehören im Syftem zu den Krebfen und diefe find eigentlich langgeftredkte Tiere. Bei den Krabben ift aber eine Verkürzung der Längsachfe des Körpers dadurch eingetreten, daß der Schwanz nach der Baucheite gefchlagen erfcheint und gleichzeitig einer mehr oder weniger ftarken Reduktion unterlegen ift. In Zufammenhang mit diefer Ver- 
kürzung zeigt der Körper diefer Tiere die Tendenz, in die Breite zu wachfen. Auf diefe Weife repräfentieren die Krabben einen eigenen Geftaltungstypus unter den Krustazeen, und es ift intereffant, wie innerhalb desfelben, je nach der Lebensweife, Entwidklungen in ganz verfhiedenen Richtungen erfolgten. Zur Erläuterung deffen könnte man viele lehrreiche und merkwürdige Beifpiele anführen.

$\mathrm{Da}$ drängt fich wohl die Frage auf nach der Veranlaffung für die Entftehung und Ausbildung diefer vom Typus abweichenden Körpergeftalt der Krabben. Wir wollen es gleich vorweg fagen, daß wahrfheinlich die Brutpflege, eine bei Krebfen fehr weit verbreitete Erfcheinung, die Urfache hierfür abgegeben hat. Zur Darlegung diefer Anficht ließe fich eine kontinuierliche Reihe von Krebsformen zufammenftellen. Am Anfang diefer wollen wir als bekannte Form den Hummer (Fig. 72) nennen. Er befitzt einen langgeftredrten und gegliederten Hinterleib, der beim Männchen immer, beim Weibchen dagegen nur fo lange ausgeftredkt halten wird, als an deffen Unterfeite keine Eier getragen werden. If dies jedoch der Fall, dann erfheint das Abdomen nach der Bauchfeite hin gefchlagen, fo daß fich auf diefe Weife ein Brutraum für die Eier formiert. Die Eier des Hummers verweilen bis zum Ausfchlüpfen der Jungen bis elf Monate im Schutge des weiblichen Schwanzes und die Stellung des letzteren wird durch Kontraktion beftimmter Muskeln bewirkt, für die durch die ganze Zeit der Brütung ein fpezieller Reiz zu diefer Kontraktionstellung beftehen muß. Diefer bei dem genannten Tiere nur temporär beftehende Zuftand hat fich bei anderen Krebfen nach und nach zu einem dauernden ausgebildet, wie z. B. bei dem Bärenkrebs (Scyllarus) (Fig. 67) und Galathaea (Fig. 73) und hat fich auch auf die Männchen übertragen. Die weitere Folge war dann eine geringere Ausbildung und ein Rudimentärwerden des Hinterleibsabfchnittes. Am weiteften ift diefer Körperteil bei den Krabbenmännchen degeneriert, wo er fchmal und klein ift, während er bei den Weibchen zum Schutse der Eier noch deckelartig verbreitert erfcheint.

Der Einfiedlerkrebs (Diogenes varians) (Fig. 74). Jeder Befucher des Flachftrandes wird feine Aufmerkfamkeit auf eine 

Figur

\section{Tafel V}

34. Seefeder (Pteroides spinosa) (S. 98). Wie der Name befagt, erinnert diefes Tier an die Geftalt einer Feder, eigentlich handelt es fich um eine Aktinienkolonie, deren Einzeltiere (Aktinienpolypen) auf den einzelnen blattartigen Seitenzweigen fitzen. Länge $10-30 \mathrm{~cm}$, Farbe grau bis braun.

35. Korkkoralle (Alcyonium palmatum), lokal mano di S. Pietro, Hand des hl. Petrus genannt. Es handelt fich auch hier um eine Aktinienkolonie von hellroter Farbe und $10-30 \mathrm{~cm}$ Länge. Die einzelnen Polypen entfalten fich in Form achtAtrahliger Rofetten. Da die Skeletteile nur als kleine Kalkkörperchen vorhanden find, hat diefes Tier eine weiche Befchaffenheit. In der Abbildung ift der abgerundete im Meeresgrunde fteckende Teil weggelaffen.

36. Warzenkoralle (Gorgonia-Eunicella) (S. 89), eine Tierkolonie mit baumförmiger Verzweigung und eingelagertem Hornfkelett, Farbe grau, Länge $20-40 \mathrm{~cm}$. Die Einzelpolypen entfalten fich erft dann, wenn die Kolonie in ein Aquarium übertragen wird und zur Ruhe gekommen ift.

37. Ein Einzelpolyp der Warzenkoralle entfaltet.

38. Schmarotzeraktinien (Adamsia Rondeletii) (S. 100) lebt in fymbiotifchem Verhältnis entweder mit der Stachelfchnedke (Murex) oder mit dem Einfiedlerkrebs Paguriftes maculatus.

39. Segelqualle (Velella spirans) (S. 118). Blau. (Vergl. Fig. 22 u. 23).

40. Cydippe plumosa (S. 119). Längsdurchmeffer $5-20 \mathrm{~mm}$.

41. Venusband (Cestus veneris) (S. 119). Länge bis $1 \frac{1 / 2}{2}$.

42. Melonenqualle (Beroe Forskalii) bis $15 \mathrm{~cm}$ lang, rofa bis rot.

43a. Podocoryne carnea (S. 111 Generationswechfel, 116 Hydromedufe, vergl. Fig. 20). Polyp rechts mit Medufenknofpen, die fich dann als kleine Meduschen loslöfen und zu den freifchwimmenden Medufen (Gefchlechtstieren) werden.

43b. Scyphopolyp (S. 111 Generationswechfel, 116 Scyphomedufe) in Querteilung begriffen; die fich loslöfenden Scheibchen find die freifchwimmenden Scyphomedufen. 
Tafel V
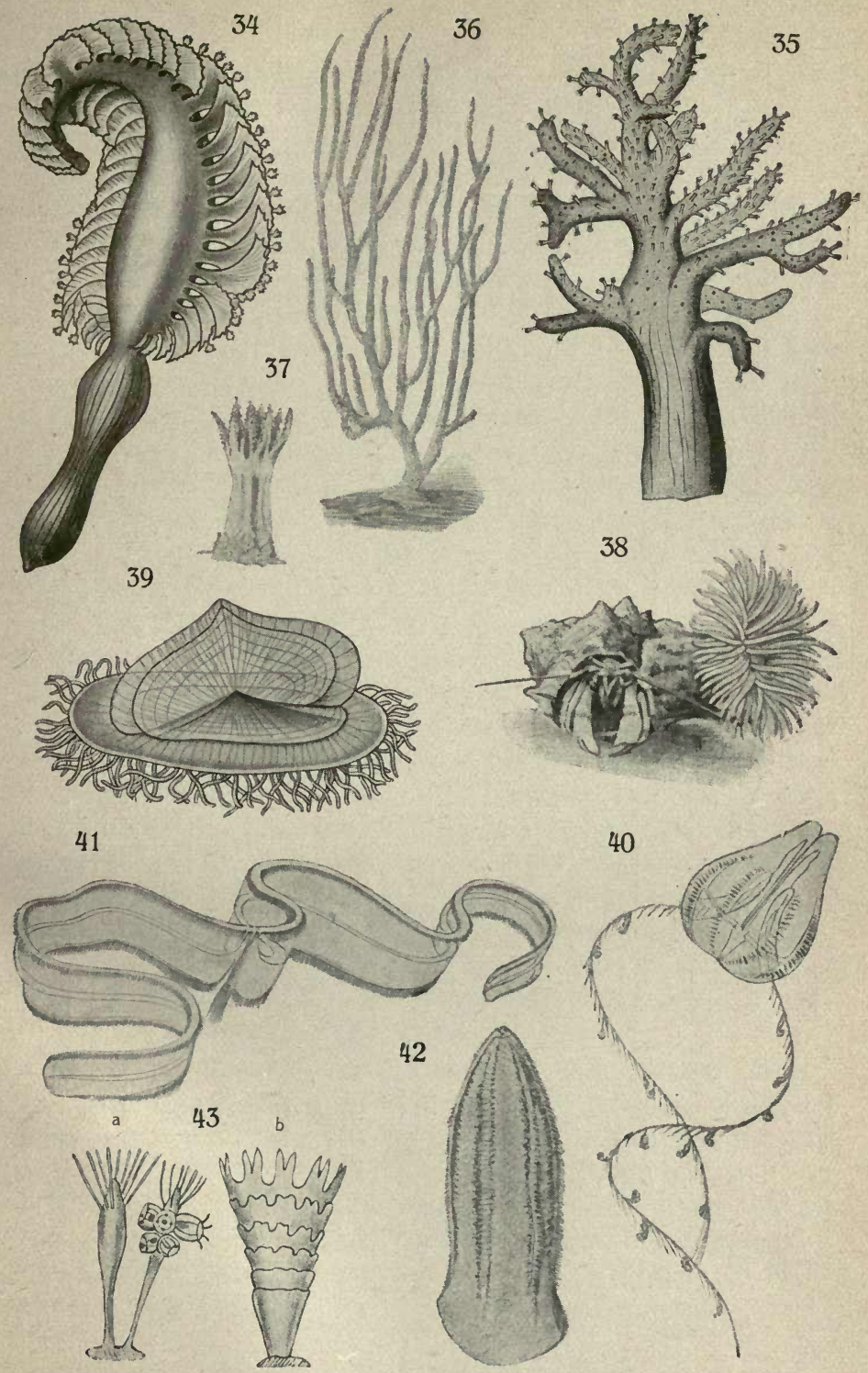


$$
3 \cdot x^{2}=
$$


Menge kleiner Schnedkengehäufe von Cerithium vulgare gelenkt finden, die aber zum größten Teile nicht mehr von der Schnedke felbft bewohnt find, fondern von dem kleinen Einfiedlerkrebfe, Diogenes varians genannt; diefer krabbelt mit feiner Behaufung auf der Suche nach Nahrung eifrigft herum. Unter dem Einfluß der feften Wohnung im Schnedkengehäufe hat zunächlt der Hinterleib diefer Krebfe die ftarre Befchaffenheit, wie fie fonft freilebenden Krebsformen zukommt, verloren und ift weichfchalig geworden. Ganz auffällig ift ferner die fpiralige Drehung des Körpers und man vermutet richtig, wenn man dies als eine Anpaffung an die gedrehte Behaufung auffaßt. Die Affymetrie, die daraus refultiert, macht fich auch an den beiden verfhieden großen Scheren bemerkbar, eine Eigentümlichkeit, die aber auch vielen freilebenden Krebfen zukommt.

Die Spaltfüßler (Mysideen) (Fig. 69). Wir wollen hier noch einer Krebsgattung, der Myfideen, Erwähnung tun, weil fie fich im feichten Waffer entlang des Flachitrandes, wo fie in Mengen vorkommt, leicht beobachten läßt. Diefe zarten durchfichtigen Krebschen machen beim Schwimmen im Waffer eher den Eindrudk von kleinen Fifchchen. Sie gehören zu einer artenreichen Gruppe, die dadurch intereffant ift, daß deren Vertreter in ihrem Schwanzfächer zwei Gleichgewichtsorgane tragen, welche fchon bei Lupenvergrößerung als zwei kleine Bläschen erkenntlich find. Im Haushalte des Meeres fpielen diefe Tiere infofern eine Rolle, als fie zu gewiffen Zeiten der Sardelle und anderen Fifchen eine reichliche Nahrungsquelle abgeben. Im Hafen von Grado fieht man Myfideen zur Sommerszeit in dichten Maffen an der Oberfläche herumfchwimmen. Man trachte fie mit einem kleinen Handnetze zu erbeuten.

Cerithium vulgatum (Fig. 90). In der in Rede ftehenden Region finden wir ferner häufig die fchon erwähnte Schnecke Cerithium herumkriechen. Sie befitzt ein turmartig erhobenes Gehäufe, auf welchen fich häufig Algen angefiedelt haben.

Cyclonassa neritea. Eine andere Schnecke ift die Cyclonaffa, die immer im Sande wühlend angetroffen und erft bei der Ebbezeit bemerkt wird, wenn ihre Kriechfpur in Form eines fortfchreitenden Sandwalles fie verrät. Zum Unter- 
fhied von Cerithium befitt diefe Form ein flaches Gehäufe, deffen breites Mündungsfeld vom Schleifen am Sande ganz abgefcheuert und poliert erfheint.

Bei Spaziergängen am flachen Sandftrande wird unfere Aufmerkfamkeit noch auf vielerlei andere Gegenftände gelenkt, die hier verftreut liegen und deren fich das Meer entledigt hat, - Holz, Refte von Kleidungsftüdken, Konfervenbïchfen, Korke, Glasfcherben, Algenmaffen, Mufchelfchalen u. a. Manches diefer Fundftüdke hat gewiß feine intereffante Gefchichte, Freud und Leid können an ihm haften. Unfere Adria kann ja recht temperamentvoll und aufgeregt fein, aber im Vergleiche $z u$ den europäifchen Nordmeeren ift fie noch ein gutmütiges Element. Unglüdksfälle zur See gehören zu den Seltenheiten, und daher find fo traurige Begegnungen wie entfeelte Körper von Schiffbrüchigen nicht zu befürchten. Dagegen findet man oft eine Menge Refte tierifcher Körper. Sie ftammen meift von Tieren, welche nicht in der feichten Strandzone, fondern in dem fich diefer unmittelbar anfchließenden Gebiete oder auch fchwimmend im offenen Meere vorkommen. Wir wollen nur einige der häufigften derartigen Strandgüter erwähnen.

Sehr vielfach find die Gerüfte und Skelette von Schwämmen zu finden. Zum Teil ift dann oft noch die urfprüngliche fchöne Farbe in blaffen Tönen erhalten. Mufchelfchalen gibt es da in Menge und unter diefen fallen befonders auf die weißen flachen Schalen von Auftern (Fig. 114) und die fchwarzen Schalenklappen der Miesmufhel (Fig. 115), ferner begegnet man den Kalkröhren von Röhrenwürmern (Fig. 49, 50) und endlich großen Klumpen von kleinen aneinander geklebten Hornkapfeln. Diefe Ballen find die Eikokkons der Leiftenfdhnedke, der Murex brandaris (Fig. 97), die den klaffifchen Völkern den koftbaren Purpurfarbftoff lieferte. Auch die Rüdkenfhulpen von Sepien kann man auflefen, die ja dem Binnenländer bekannt fein dürften.

Befehen wir uns jetzt einmal die Sandfläche, die gegen das Feftland $z u$ von zufammengefdhwemmten Algen und Seegras begrenzt wird. Eine Unmenge kleiner fpringender 'Wefen, kleine Flohkrebfe, fliehen vor jedem Schritte oder 
verfhwinden in kleinen im Sande gegrabenen fpaltförmigen Gruben. Diefes hüpfende Völkchen ift dadurch intereffant, daß es uns wie manche andere marine Tiere das allmähliche Aufgeben des Meeres als Wohnfätte und den Ubergang zum Feftlandstier vor Augen führt. Alles Leben auf Erden if ja dem Meere entfproffen und fo auch die heutige kontinentale Fauna und Flora. Die Wege, die von hier aus genommen wurden, waren allerdings verfchiedenartige. Jedenfalls war aber einft die Flachfee die Propagationsftätte für die Mannigfaltigkeit des Lebens und wenn wir am Abend nach Sonnenuntergang im vergoldeten Dämmerlicht am Strande wandeln, fei es unter einem friedlich abgetönten Abendhimmel oder im Klange der tofenden See, dann ift die richtige Stimmung, an längft vergangene Tage der Gefchichte des Lebens, von der wir ja nur eine ahnende Vorftellung befitzen, zu denken, - denn wir befinden uns an der Geburtsftätte alles Seins. Glüdklich jeder, der Auge und Empfinden für folche Momente befitzt. 


\section{III. \\ DIE LAGUNE UND IHR LEBEN.}

$\mathrm{D}$ ie Lagune, welche befonders im Gebiete der nördlichen Adria eine reiche Entwidklung zeigt, bietet eine fo eigenartige Szenerie dar, daß man hier in eine fremde Welt zu kommen glaubt. Merkwürdig ift vor allem der rafche Wechfel in dem Bilde, der fich vollzieht, wenn man vom Meeresftrande kommend kaum hundert Schritt landeinwärts geht und feinen Blidk über die Lagunenlandfchaft fchweifen läßt. Eine weite Wafferfläche, nur wenig von Vegetationsftreifen unterbrochen, breitet fich vor uns aus, und im Hintergrunde ift das Bild von der hohen Mauer der Alpen begrenzt. Das Auge findet felten Ruhepunkte und die Lagune erfcheint im erften Moment eintönig und tot. Man muß fich aber erft in die Befonderheiten und Feinheiten diefer Landfchaft hineinleben, um ihre Eigenart und ihre Bedeutung in geographifher, hiftorifcher und biologifcher Richtung ganz erfaffen zu lernen. Uns fchwebt hier fpeziell als Beifpiel die nordadriatifche Lagune vor.

Wir wollen uns nun deffen erinnern, was wir im erften Kapitel gefagt haben, daß nämlich das Lagunengebiet nur eine Phafe in der Bildung einer Anfchüttungsebene, alfo ein Stadium der Landbildung, im vorliegenden Falle der norditalienifhen Tiefebene, darfellt und es ift gewiß lehrreich, das, was hier von den Alpenflüffen durch Jahrtaufende gefchaffen wird, vom Beginne an entftehen zu fehen. Dann halten wir uns vor Augen, daß hier durch zwei Jahrtaufende romanifche Kulturzentren wie Aquileja, Ravenna, Venedig u. a. geblüht haben, die den mächtigften Einfluß auf die geiftige und kulturelle Entwidklung der Nadhbargebiete nahmen. Wir erinnern uns ferner an die bedeutungsvollen Kämpfe und Kriege, die fich hier abgefpielt und die die Gefchichte Europas in beftimmte Bahnen gedrängt haben. 



\section{Tafel VI}

Figur

44. Spadella (S. 43). Länge $5 \mathrm{~mm}$.

45. Seeraupe (Aphrodite aculeata), ein bis $30 \mathrm{~cm}$ langer Wurm, der fich durch die fchönen irifierenden Farben feines Haarund Borftenkleides auszeichnet; er bewohnt vorwiegend den Mufchelfand.

46. Nereis gehört einer artenreichen Gruppe von Würmern an, die man häufig in der Strandregion zur Zeit der Ebbe unter Steinen findet. Länge bis $10 \mathrm{~cm}$. Sie werden als Köder für die Angel verwendet.

47. Sandwurm (Arenicola piscatorum) (S. 9). Länge bis $25 \mathrm{~cm}$, Farbe dunkeloliv. Diefer Wurm dient ebenfalls vielfach als Köder.

48. Bonellia viridis, ein merkwürdiger graugefärbter Wurm (bis $15 \mathrm{~cm}$ lang), der in Steinfpalten und Löchern lebt und feinen Rüffel lang ausftredken kann. Mit Hilfe desfelben gewinnt er die Nahrung. Das abgebildete Tier ift ein Weibchen, die Männchen find zwerghaft klein (1-2 mm) und leben im Darm der weiblichen Tiere.

49. Serpel (Serpula) (S. 22, 66).

50. Protula (S. 22, 66). Merkwürdig an diefen beiden Tieren if die Eigentümlichkeit, daß fie fich, wenn ein Schatten auf fie fällt, in die Röhre zurüdkziehen.

51. Seenelke (Spirographis Spallanzanii) (S. 48) wird bis $50 \mathrm{~cm}$ lang und kleinfingerdidk. Farbe der Kieme gelb bis braun und violett.

52. Eichelwurm (Balanoglossus clavigerus) (S. 16). Länge bis $50 \mathrm{~cm}$, Farbe im vorderen Abfhnitt gelb, in der Leberregion olivgrün, in der Darmregion hellgelb. 


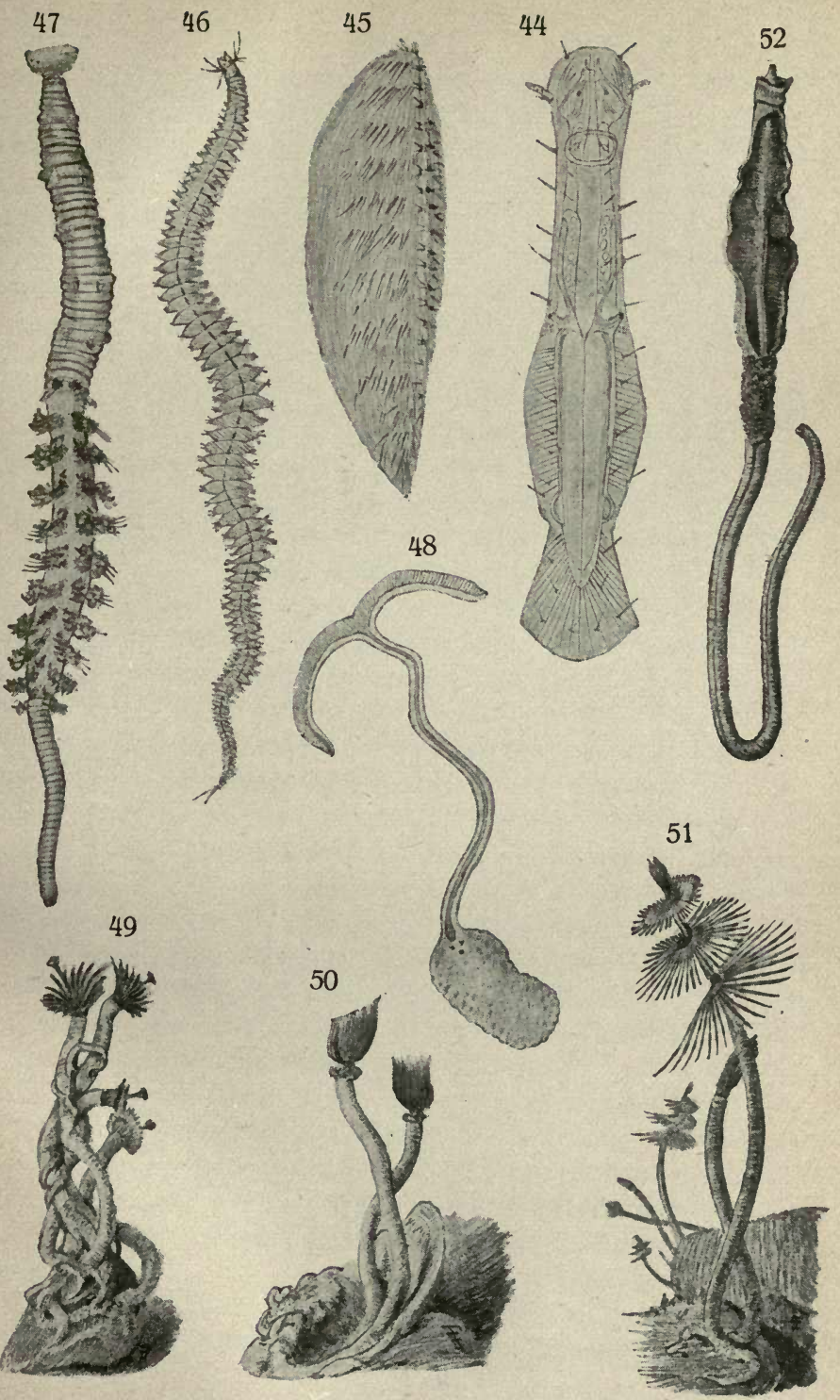


307

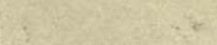


Das Charakteriftifche der Lagune befteht darin, daß hier feichte und verfchieden große Wafferflächen von Kanälen in vielfach gewundenem Verlaufe eingefaßt werden. Leţtere find zum Teil alte Mündungsarme des betreffenden Fluffes diefes Gebietes, zum andern Teil find fie lediglich durch die nagende und errodierende Wirkung des Flut- und Ebbeftromes entftanden. Die gewundene Form der Kanäle ift eine charakteriftifche Erfcheinung bei Wafferläufen im ebenen Gebiete, und ift dadurch bedingt, daß das Waffer aus Mangel eines ftärkeren Gefälles jedem kleinen Hindernis aus dem Wege geht, ftatt es wegzuräumen. Befonders augenfällig tritt der Gegenfats zwifchen den Deichflächen und den Kanälen aber zur Zeit der Ebbe hervor. Dann repräfentieren fich uns erftere als Schlammbänke, in denen nur in mulden- und kanalartigen Vertiefungen noch etwas Waffer ftehen bleibt.

Das Eindringen des Meerwaffers in Form der Flutwelle und das Abfließen der durch die Flut im ganzen Gebiete geftauten Waffermaffe bewirkt oft ftarke Strömungserfcheinungen. Da die Lagune vom Feftlande her Süßwaffer zugeführt erhält, kommen hier zwei Wafferqualitäten von phyfikalifh ftark verfchiedenen Eigenfchaften ftändig miteinander in Berührung. An folchen Punkten, wo die Strömungen fehlen, fchichtet fich über das fhwerere Meerwaffer das leichtere Süßwaffer. In Flußmündungen dringt das Seewaffer am Boden lagernd oft erheblich weit ein und mit ihm gleichzeitig verfchiedene Meerestiere und -pflanzen. Wenn die Ausfüßung des falzigen Waffers in fehr hohem Maße erfolgt ift, fpricht man von bradkifchem Waffer. An Punkten mit lebhafter Strömung und durch den Wind werden dagegen beide Wafferqualitäten durcheinander gemifcht. Auf alle Fälle refultieren aus der unmittelbaren Berührung von Süßwaffer und Meerwaffer lebhafte Diffufionen, die im allgemeinen von der Tier- und Pflanzenwelt des Meeres fchlecht vertragen werden. Defto mehr find wir überrafcht, im Lagunengebiet trotgdem ein reiches marines Leben entwidkelt zu fehen.

Einen wichtigen Faktor in der Summe derjenigen äußeren Einflüffe, die wir zufammen als Lebensbedingungen bezeichnen, 
fpielt weiter die Temperatur des Waffers und der Luft. Die klimatifchen Verhältniffe des adriatifchen Lagunengebietes find im allgemeinen dadurch charakterifiert, daß der Sommer fehr warm ift, daß der Ubergang zum Herbfte mit heftigen Regengüffen einfeţt und daß fich die Temperatur bis gegen das Ende des Jahres ungefähr auf einer ähnlichen Höhe hält, wie während der Monate März und April in Mitteleuropa. Die jährliche Wärme- und Vegetationsperiode ift alfo eine recht lange. Die kalten Fallwinde, die aus dem gebirgigen Hinterlande herabftürzen, wie die gefürchtete Bora, feţen bereits im Herbfte einige Male ein, es prävalieren aber in diefer Zeit noch die füdlichen warmen Lufttrömungen, wie der Scirocco. Vorherrfchend find die kalten Winde dagegen im Jänner und Februar. Dann kann hier die Temperatur auch bis unter den Nullpunkt finken und Kanäle und Lagunendeiche vereifen in folchen Zeiten. Vom März an mildert bereits der wieder vorherrfhende Scirocco die winterlich niedrige Temperatur. Die Wärmezuftände des Lagunenwaffers find alfo im Ablaufe eines Jahres durch fehr große Temperaturdifferenzen, die die ungewöhnliche Spanne von $30^{\circ} \mathrm{C}$. auf das Jahr berechnet, erreichen können, ausgezeichnet. In nicht unbedeutendem Umfange können fich endlich auch die täglichen Temperaturfhwankungen abfpielen. Im Meere dagegen vollzieht fich der jährliche und tägliche Gang der Temperatur in Form von flachen Kurven, die ftarke Kontrafte nicht kennen. In bezug auf die Wirkung der Sonne und der abkühlenden Winde im Bereiche der Lagune wäre ferner zu berüdkfichtigen, daß die Wafferfchicht hier im allgemeinen eine geringe Mädhtigkeit befitt und daß nur die Hauptkanäle Tiefen bis fünf und mehr Meter zeigen. Infolgedeffen kann fich das Seichtwaffer durch die fommerliche Sonne bis über jenen Temperaturpunkt erwärmen, der für das Beftehen des Lebens kritifh wird. Ein großes Sterben ift daher manchesmal im Sommer unter den Fifhen und anderen Tieren der Lagunendeiche und feichten Kanäle zu beobachten. Andererfeits findet im Winter eine ftarke Abkühlung der Waffermaffen ftatt. Für viele Formen ift in der warmen Jahreszeit wie im Winter der weiche Schlammgrund noch 
ein Refugium, das ihnen Schuts gegen diefe Schädlichkeiten gewährt.

Einen wichtigen Faktor der Lebensbedingungen bildet ferner das Licht im Haushalte der Natur. Vor allem ift diefes notwendig für die Lebensprozeffe der Pflanzen. Aber auch das Tier verhält fich nicht indifferent gegen diefes, fchon aus dem Grunde, weil das Licht gleichzeitig auch Wärmeftrahlen mit fich führt. Im Lagunengebiete zeigt das Waffer eine ftarke Trübung und einen milchig grünlichen Farbenton, hervorgerufen durch viele Sinkftoffe, die zum Teil organifher Natur, wie Pflanzenrefte und Schleim, zum Teil anorganifche Körper wie Schlamm und Sand find. Durch diefe Trübung wird einerfeits das Licht ftark zurüdkgehalten, andererfeits wirken aber diefe im Waffer fuspendierten Körper als Wärmeakkumulatoren, fo daß fich im Sommer das Lagunenwaffer verhältnismäßig ftärker erwärmt, als dies bei klarem Waffer der Fall wäre.

Die Faktoren, die die Lebensbedingungen für die Fauna und Flora der Lagune ausmachen, zeigen alfo, wie wir gefehen haben, große und oft unvermittelt einfetzende Gegenfätze. In diefem Punkte ähnelt das Gebiet den Verhältniffen am Feftlande und denen des Süßwaffers. Im Meere dagegen ift die Fauna und Flora an gleichmäßig ablaufende Verhältniffe gewöhnt. Dies bedingt, daß fich hier eine fehr mannigfaltige Formenwelt findet, während das adriatifhe Haffgebiet eine gewiffe Monotonie in der Formenentfaltung erkennen läßt. Eine Erklärung für diefen auffallenden Unterfchied im fauniftifhen und floriftifhen Bilde beider Gebiete, die ja ganz benachbart liegen, ift in dem Umitande zu fuchen, daß fich nur relativ wenige Vertreter der marinen Lebewefen diefen befonderen und wechfelvollen Lebensbedingungen gewachfen erwiefen haben, obgleich die Zufahrtftraße vom Meere hierher eine breite und ftets offene ift, fo daß die Einwanderung von diefer Seite eine leichte fein follte. Darin beftätigt fich aber wieder die Tatfache, daß die Tiere nicht eine gleichmäßige Lebensenergie befitzen, indem die einen oft eine erftaunliche Modulationsfähigkeit zeigen, während fich andere wie Spezialmafchinen verhalten, die mit großer Prä- 
zifion arbeiten, aber in ihrer Arbeit doch eine große Einfeitigkeit zeigen.

Wenn wir nun darangehen, einige Beifpiele aus der Lebewelt der Lagune zu befprechen, wollen wir zunächit mit einigen freifchwimmenden Formen beginnen. Ahnlich wie am Flachftrande, find auch hier die Verhältniffe wenig günftig für die Entfaltung folcher Organismen.

Die fpaltfüßigen Krebfe, Myfideen (f. Seite 21). Wenn man in den Lagunenkanälen mit Hilfe eines fogenannten Planktonnetzes, - hierzu eignet fich auch ein aus fchütterem Baumwollftoff, fogenanntem Kaliko, hergeftelltes einfaches Netz -, fifcht, fo erbeutet man faft regelmäßig nebft anderen kleinen Tierchen auch Myfideen, die wir bereits am Flachftrande angetroffen haben. Ihre Organifation zeigt viele urfprüngliche Charaktere des Krebstypus. Diefe Tiergruppe hat eine weite Verbreitung auf der Erde und fie wird unter den verfchiedenften Lebensbedingungen dank ihrer großen Anpaffungsfähigkeit angetroffen.

Der Granatkrebs, auch Crevet genannt (Palaemon) (Fig. 70). Häufige Krebsformen in den Lagunen find auch die Krevetten, welche ähnlich wie die Myfideen ein ausgedehntes Verbreitungsgebiet befitzen und fowohl im Meere, wie im Bradkwaffer fich finden, ja einige leben fogar im Süßwaffer. Diefe intereffante Tatfache läßt fich fo deuten, daß die Palämoniden entweder im Begriffe find in das Süßwaffer einzuwandern oder daß fie, wenn fie in diefem auftreten, überlebende Refte einer einft marinen Fauna aus einer Zeit darftellen, während welcher das Binnenland von Meeresgebieten bededkt war. Letztere Anficht ift die geltende. Nach Verluft des Zufammenhanges folcher Gebiete mit dem Meere haben fich einzelne Komponenten der urfprünglichen Meeresfauna erhalten, indem fie fich an das Leben im Süßwaffer gewöhnten. Derartige Formen nennt man Reliktenformen und fie befitzen großes Intereffe für den Biologen wie für den Geologen und Geographen. Es darf aber das Auftreten folcher Reliktentiere nicht als der unumftrittene Beweis dafür betrachtet werden, daß das von ihnen gegenwärtig bewohnte Gebiet unbedingt 
einftmals Meer gewefen fein müffe, denn folche Formen können ja auch felbfttätig weiter wandern oder verfchleppt werden. Befonders lehrreich ift die Krevettenform Palaemonetes varians, welche von Küftenpunkten und aus Binnengewäffern von Europa und Amerika bekannt ift und die durch ihre vielfachen von der Ortlichkeit und äußeren Umftänden abhängige Variationen der Körperform eine große Plaftizität dukumentiert. Aber auch die gewöhnlichen Krevetten (Palaemon verfchiedener Spezies) finden fich nicht bloß im Meere, fondern auch im Bradkwaffer der Lagune und in Flußmündungen. Die rote Farbe der gekochten Tiere ift eine Todeserfcheinung, denn im Leben find fie fehr durchfichtig, eine Eigenfchaft vieler Meerestiere, die ihnen einen gewiffen Schuts vor ihren Nachftellern gewährt. Die Granaten haben hier für den Menfchen als Nahrungsmittel nicht jene Bedeutung wie dies an den Küften der Nordund Oftfee der Fall ift, wo fie in großen Mengen gefangen und auf den Markt gebracht werden. Die Lagunenfifher der Adria verwenden fie außerdem als Köder zum Fange des gefchätzten Wolfsbarfhes.

Der Wolfbarfh, Branzino (Labrax lupus) (Fig. 150) und die Gold braffe, Orada (Chrysophrys aurata) (Fig. 152), beides fehr gefchätte Tafelfifche, die fhon von den Römern gezüchtet worden find, finden fich im Lagunengebiet hauptfächlich in den gegen das Meer ausmündenden Kanälen. Sie leben und gedeihen in gleicher Weife im Meere als auch im Bradkwaffer und ftellen mit anderen folchen Formen Fifche vor, die vielleicht im Begriffe ftehen ins Süßwaffer und Feftland einzuwandern.

Die Meeräfchen, Cievolo und Volpino lokal genannt (Mugil) (Fig. 154). Diefe Fifche finden fich überall im adriatifchen und Mittelmeergebiete an der algenbewachfenen Flachküfte, insbefondere aber an Flußmündungen, in Häfen und in der Lagune. Es find dies faft durchwegs Gebiete mit fehr veränderlichem Salzgehalte und die Meeräfche erweift fich daher gar nicht empfindlich gegen große Unterfhiede in der Salinität des Waffers. In Seen, wie in dem Vranafee in Dalmatien mit einem außerordentlich geringen Salzgehalt, gedeihen die dort künflich eingefetzten Mugils vorzüglich. Alfo 
auch diefer Fifh fcheint fich auf dem Wege aus dem Meere ins Feftlandgebiet $z u$ befinden.

Die Hauptnahrung der Meeräfchen find pflanzliche Stoffe, die fie mit ihren fleifchigen Lippen direkt abäfen, wie man folches nicht felten bei Wanderungen am Strande direkt beobachten kann. Im Lagunengebiete werden diefe Tiere mit Hilfe von Flut und Ebbe in der Weife gefangen, daß die zur Flutzeit vom Waffer bededkten Schlammbänke durch Schilfmatten vollitändig eingezäunt werden. Wenn mit Eintritt der Ebbe das Waffer von den Lagunendeichen abfließt, ziehen auch die Meeräfchen wieder den Kanälen zu und fangen fich dabei in Neţtrichtern, die der erwähnten Umzäunung eingefügt find. Am Flachftrande der Meeresküfte dagegen ftellt man ihnen mit einem fpiralig angeordneten Netze, dem fogenannten Saltarello, nach, in das fie wie in ein Labyrinth geraten und fich in den Netymafchen fangen. Zum Teil fuchen fie anch die Netwand zu überfpringen, aber der Fifcher, der diefe Gewohnheit kennt, läßt die Wafferfläche mit einem Neţbufen überragen, fo daß die Tiere beim Verfuche das Neţ zu überfpringen, in den Netzbaufch fallen. In Dalmatien werden die laichreifen Eierftödke der genannten Fifche eingefalzen und liefern dann die fogenannte Botarga, die als Ledkerbiffen gilt und nicht billig ift.

Das Vermögen, aus dem Waffer herauszufchnellen, kommt nicht wenigen Meerfifchen zu. Bei kleineren Formen hat fich diefe Fähigkeit aus Fluchtverfuchen vor den ihnen nachftellenden größeren Gegnern herausgebildet. In der Kategorie der Raubfirche ift diefe Eigenfchaft wieder im Zufammenhang mit dem Nahrungserwerb beim Jagen kleinerer Fifche entftanden.

Der Aa1, Bifatto (Anguilla vulgaris) (Fig. 162). Ein recht häufiges Tier im Lagunengebiet ift der Aal, der bei Tag im Schlamm verborgen liegt und erft mit Eintritt der Dunkelheit der Nahrung nachgeht. Intereffant ift deffen Lebensgefchichte. Im Herbfte ziehen die erwachfenen Aale aus den Süßwafferläufen des Binnenlandes dem Meere zu, um dann in Tiefen von 1000 und mehr Metern die Eier abzulegen. Schon bald nach Beginn diefer Wanderungen verändert der Aal fein Kolorit und feine Augen werden größer. Es ift dies die Vorbereitung 
zur Umwandlung aus einem Fluß- in einen Tieffeefifc. Die Eier kennt man bisher noch nicht, wohl aber weiß man jetst auf Grund von Experimenten, daß jene vollftändig glasklaren, durchfichtigen, bandförmig fchmalen Fifche mit dem winzig kleinen Kopfe Lepthocephalen genannt, die in der Tieffee lebenden Larven des Aales find (Fig. 163). Letztere verwandeln fich dann in runde zunächft noch durchfichtige fpäter pigmentierte Jungaale, der fog. Montée (Montata), deren regelmäßiges Erfcheinen und Einwandern in die Süßwafferläufe zur Frühjahrszeit eine höchft intereffante Erfcheinung ift. Die Montéeaale vermögen mit der Behändigkeit eines Wurmes an fteilen Felsund Wehrwänden hinaufzukriechen und überhaupt viele Hinderniffe zu bezwingen. So befiedeln fie die Flüfle bis in ihre letzten Verzweigungen. Hier mäften fie fich dann an, um nach 4-5 Jahren als gefchlechtsreif werdende Tiere wieder dem Meere zum Laichgefchäft zuzuftreben. So lange man die Lebensgefchichte diefes Fifches nicht fo vollitändig kannte, war er förmlich ein Fabeltier.

Der Aal gehört alfo zu jener Gruppe von Fifchen, die teilweife im Meere und Süßwaffer leben. Wenn wir die fonft fcharfe Kluft in der Lebensweife zwifchen Süßwaffer- und Salzwafferfauna berüdkfichtigen, fo muß man folche Fälle, die fich noch durch andere Beifpiele vermehren laffen, als höchit merkwürdig bezeichnen. Insbefondere gilt dies vom Flußaal, den der erwachende Gefchlechtstrieb zur beftimmten Jahreszeit ins Meer zu gehen zwingt, der fich hier zum Tieffeetier umwandelt, der ganz befonders organifierte Jugenditadien befitst und deffen Jungfifche nach Abfolvierung diefer Metamorphofe regelmäßig im Frühjahr durch zwangsweife Wanderung in dichten Scharen wieder das Süßwaffer auffuchen. Man deutet dies fo, daß der Aal urfprünglich ein ausfchließlich das Meer bewohnender Fifch, wie dies heute noch bei verwandten Formen, wie der Muräne, dem Meeraal (Conger) der Fall ift, gewefen war und daß er erft fpäter in das Feftland einwanderte, ohne aber die Beziehungen zum Meere vollftändig aufgegeben zu haben. Kein anderes Beifpiel diefer Art zeigt fo komplizierte und gegenfatzreiche Verhältniffe wie die Lebensgefchichte 
des genannten Fifches. Diefer hat jedenfalls fchon einen Schritt weiter getan, als jene Bradkwafferfifche, die vor der Hand mit dem Feftlande zunächft nur an den Pforten desfelben, den Flußmündungen, Fühlung nehmen.

Die meiften Methoden des Fifhfanges bafieren darauf, den Wander- und Zufammenfcharungstrieb der Fifhe bei Eintritt der Laichzeit auszunützen. Auch dem Aale kommt man in den Lagunen auf diefe Weife bei, indem man in die Lagunenkanäle Schilfzäune einbaut, die in der Richtung gegen das Meer miteinander konvergieren und nur eine ganz fchmale Offnung frei laffen, durch welche der wandernde Aal in eine dahinter liegende als Falle dienende Kammer gelangen muß. Von hier aus gibt es kein Entweichen mehr. Seit alter Zeit hat man diefe Fangmethode befonders in den Lagunen von Commacchio bei Ravenna ausgebildet; die dortigen ausgedehnten derartigen Fangeinrichtungen liefern ein jährliches Erträgnis von mehr als einer Million Lire. Das adriatifhe Gebiet verfieht einen anfehnlichen Teil von Mitteleuropa mit marinierten Aalen

Wenn in der Lagune für die Entwidklung einer freifchwimmenden Fauna die Verhältniffe wenig günftig lagen, fo findet fich hier andererfeits eine den Schlamm bewohnende Tierwelt reich entwickelt. Die Schlammbänke entftehen in den zwifchen den Kanälen gelegenen feichten Wafferflächen, in denen zur Zeit der Flut die aus anorganifhen und organifhen Subftanzen beftehenden Sinkftoffe ausgefüllt werden. Der fich bildende graue Schlamm ift fehr feinflodkig und weich, fo daß man beim Gehen über die wafferentblößten Schlammflächen bis an die Knie einfinkt. Die tieferen Schlammfchichten erfcheinen durch die Tätigkeit von Schwefelbakterien fchwarz gefärbt, ein Zeichen, daß hier organifche Subftanz reichlich vorhanden ift. Wo der Tifch gededkt ift, da finden fich auch alsbald Effer ein. Daher befteht die Schlammfauna zum großen Teil aus fchlammfreffenden Formen. Es follen nun einige markante Erfcheinungen aus diefer Gruppe befprochen werden.

Die Würmer (Anneliden). Wenn man Schlamm mit einem Spaten aus der zur Ebbezeit vom Waffer entblößten Deichfläche entnimmt, fo finden fich in demfelben viele Anneliden, 


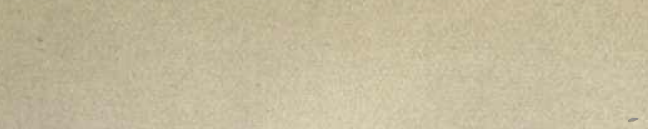

$\mathrm{C}^{2}+\mathrm{x}^{2}$

$202+\frac{10}{2}+30$ 


\section{Tafel VII}

Figur

53. Meereicheln (Seebocken) (Balanus tintinnabulum) (S. 80). Farbe rot bis dunkelbraun, Querdurchmeffer $3-5 \mathrm{~cm}$.

54. Freifhwimmende Larve, Nauplius genannt, von der Meereichel.

55. Cypristadium im Larvenleben von Balanus; in diefem Stadium erfolgt alsbald die Feftetyung.

56. Entenmuschel (Lepas anatifera) (S. 81 ) bis $30 \mathrm{~cm}$ lang.

57. Phronima sedentaria (S. 121) in dem Mantel einer Feuerwalze fitzend. Länge $2-3 \mathrm{~cm}$.

58. Flohkrebs (Gammarus). Die Familie der Flohkrebfe ift ungemein artenreich. Größe 2-20 mm. Färbung meift weiß, es gibt aber auch sehr bunt, meift rot gefärbte Spezies.

59. Kehlfüßer (Proto pedata). Länge $10 \mathrm{~mm}$. Zu den Flohkrebfen gehörig; findet fich häufig auf Algen und Hydroidpolypftödkchen.

60. Virbius (S. 43). Länge $3-4 \mathrm{~cm}$.

61. Marine Wassermilbe (Ponthydrachnide) (S. 43). 
Tafel VII

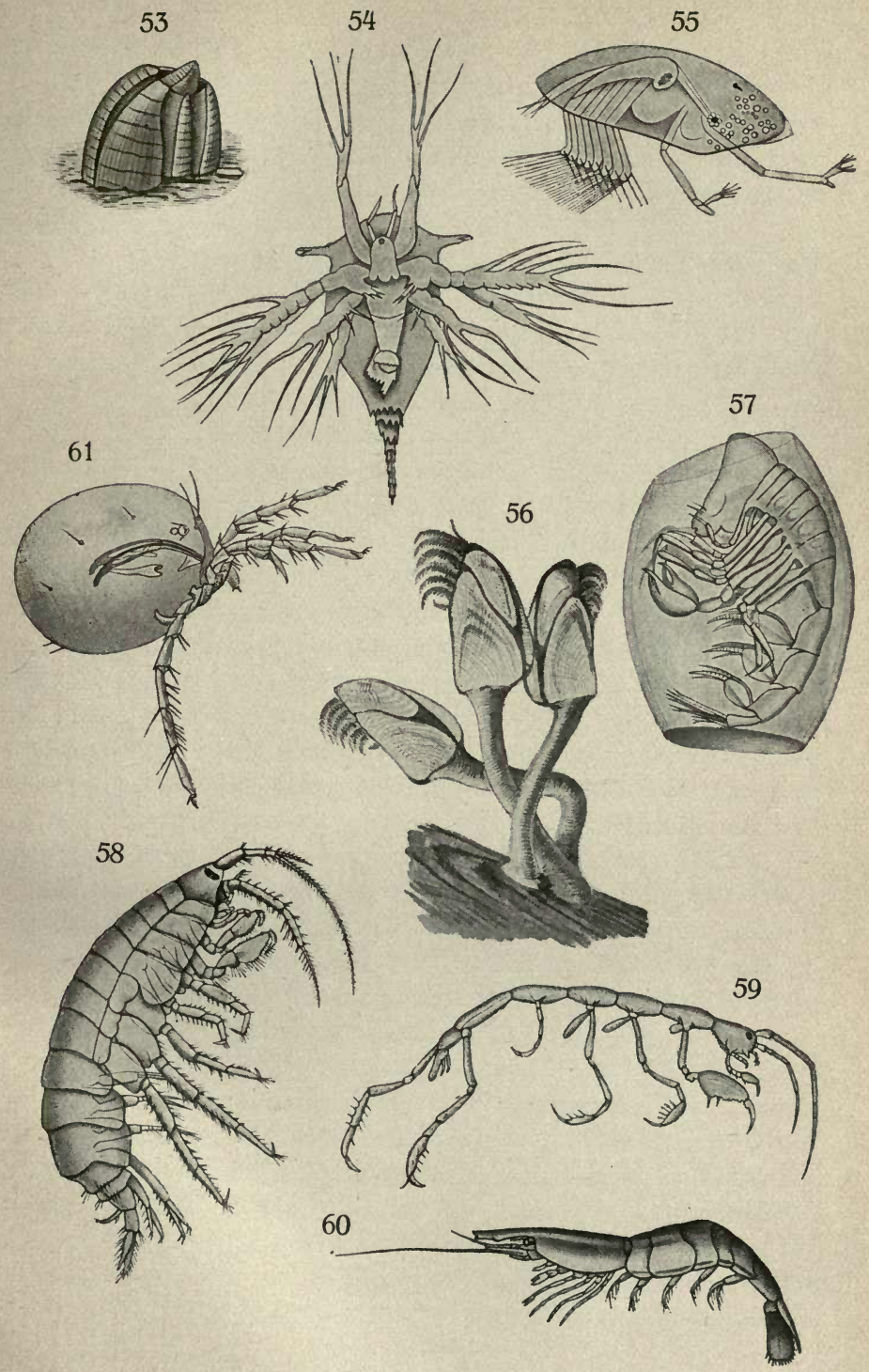


die in felbft gegrabenen Röhren leben und den Schlamm freffen. Sie tragen wohl am meiften mit dazu bei, das Sediment in ähnlicher Weife chemifch zu bearbeiten, wie dies am Feftlande die Regenwürmer mit dem Humus beforgen, d. h. fie entfernen zu ihrer eigenen Ernährung die organifchen Subftanzen aus dem Schlamm.

Gebia litoralis (Fig. 64). Zur Zeit der Ebbe lenken eine große Menge von Löchern, die überall die Schlammflächen und die Ränder der Kanäle bededken, die Aufmerkfamkeit auf fich. Es fieht faft fo aus, als ob jemand aus Langweile mit einem Stodke in den weichen Grund Löcher geftoßen hätte. Von Zeit zu Zeit läßt fich beobachten, wie fich das Waffer in diefen Offnungen $z \mathfrak{u}$ trüben und $z \mathfrak{u}$ bewegen beginnt. Wenn man neben diefen Bildungen mit dem Fuße rafch einen Tritt in den Schlammgrund ausführt, fo wird dann hiedurch ein kleiner fingerlanger, weißlich erfheinender Krebs herausgefchleudert, der aber fofort ängftlich eine andere Röhre auffucht oder fich im Schlamme einzugraben beginnt. Diefe Art des Fanges der Gebia - die Fifcher nennen fie Corbola, auch Scardobola, wird von den Fifchern zum Einfammeln des genannten Tieres, das haupträchlich als Köder Verwendung findet, in Anwendung gebracht. Für uns hat diefer Krebs hauptfächlich deswegen Intereffe, weil er in dem in Rede ftehenden Gebiete mit eine charakteriftifche Form, eine fogenannte Leitform, darftellt und in enormen Mengen auftritt. An diefer Form fällt uns ferner auf die Dünnfchaligkeit und Weichheit des Panzers und die breite Form der Gliedmaßen und endlich die ftarke Behaarung derfelben. Diefe Eigentümlichkeiten ftehen im Zufammenhange mit dem Leben in einer Röhre.

Die Strand krab be (Carcinus maenas) (Fig.77, s. S. 19) haben wir bereits als eine Erfcheinung des Nehrungsftrandes kennen gelernt. Während fie aber dort nicht als befonders häufig vorkommend bezeichnet werden kann, treffen wir fie im Lagunengebiete in wirklich großen Mengen. Für die Lagunenfifcher hat die Strandkrabbe die Bedeutung einer anfehnlichen Erwerbsquelle, indem diefe Tiere zur Zeit des Sardellenfanges von Frauen, die hochgefchürzt durch den Schlamm waten, geCori, Der Naturfreund. 
fammelt und in ganzen Schiffsladungen nach den iftrianifhen Küftenorten verfrachtet werden. Die Fifcher verwenden fie hier beim Fange der Sardellen in geftampftem Zuftande als Köder, der entlang der Sardellennetge ausgeftreut wird.

Die Herzmufchel (Cardium edule) (Fig. 105). Diefe Murchel kann infolge ihres häufigen Auftretens in der Lagune ebenfalls als eine Leitform bezeichnet werden. Außerdem handelt es fich hier ähnlich wie bei Palämonetes um eine geographifch weit verbreitete und auch in das Binnenland eindringende Tierform, deren gleiche Spezies bereits im Tertiör lebte. Ja diefe Familie tritt fogar fchon in den älteften foffilführenden Schichten, wie dem Silur, auf. Wir haben fomit hier eine Form vorliegen, die ein anfehnlich langes Stüdk der Entwidklungsgefchichte der Lebewelt unferes Planeten mit erlebt hat.

Die Herzmufhel beobachte man in feichtem Waffer oder in ein mit Sand und Schlamm befhidktes Gefäß übertragen, wie fie fich mit ihrem winkelförmig abgebogenen Fuße durchs Waffer weiterfchnellen kann. Auch das Eingraben in den Grund erfolgt mit diefem Körperteil. Es ragen dann nur die beiden mit Warzen und Fäden befeţten Atemröhren aus der Sand- oder Schlammfläche heraus.

In der Lagune find wir bisher einer Anzahl von Tierformen begegnet, die wohl auch anderen Faunengebieten zukommen, die aber fozufagen vorherrfhende, nie fehlende und charakteriftifche Tiere des adriatifchen Haffgebietes find, und es intereffiert befonders die Tatfache, daß fie hier in folchen Mengen auftreten. Dies läßt fich unter Berüdkfichtigung folgender Momente verftehen. Es handelt fich zunächlt um Tiere mit einer großen Toleranz gegenüber Verfchiedenheiten des fie umgebenden Milieus. Dadurch find fie im Vorteil gegenüber anderen Lebewefen, deren Organifation durchfchnittlich auf beftimmte Lebensbedingungen abgeftimmt ift. Das Lagunengebiet bietet nun tatfächlich von den Lebensverhältniffen des Meeres ftark abweichende Zuftände. Hier treten aber diefe "Leitformen" als alleinherrfchende auf, deren Propagation durch reichliche Nahrung gefördert wird und durch den Ausfall feindlicher Konkurrenten keine Schädigung erleidet. 
Die Vogelwelt der Lagune. Zur Zeit der Ebbe tummelt fich in der Lagune auf den vom Waffer entblößten Schlammflächen eine des Lebens zufriedene und muntere Gefellfchaft herum. Scharen von allerhand Sumpfvögeln finden hier einen reich befetzten Tifh; denn können fie es fo leicht wo anders bequemer haben? Sie brauchen ja nur den Schnabel in den Schlamm zu ftecken, um eines ledkeren zappelnden Biffens in Form eines Wurmes oder eines Krebfes habhaft zu werden. Der Ornithologe wie der Nimrod, beide können hier diefe buntgemifchte Vogelwelt mit dem Trieder wie aus nächfter Nähe in ihrem Treiben beobachten und Seltenheiten unter diefen entdecken. Speziell in den Wintermonaten ift dann die Adria der Sammelplaty der Entenfauna Mitteleuropas und insbefondere, wenn die Bora eiskalt über das Meer hinwegfegt, fuchen dann die Enten Schuty in der Lagune. Hier jagt man fie verfteckt in einem in den Boden verfenkten Faffe fitzend, indem man das Wild mit Hilfe von hölzernen Lodkenten herbeitäufcht. Gute Schützen finden auf diefe Weife eine reiche Stredke. Eine andere Art der Entenjagd befteht darin, daß fich der Lagunenfifcher in einem ganz leichten und kleinen Flachkahn, gerade groß genug für eine Perfon, den Entenfchwörmen nähert und aus liegender Stellung mittels einer altmodifchen großkalibrigen Perkuffionsflinte einen Hagel von Blei in den auffehenden Entenfchwarm fendet. Diefe Waffe ift faft eine kleine Kanone, und ihr ftarker Rüdxftoß muß durch ein untergelegtes Kiffen gemildert werden. Warum zieht der eifrige Nimrod des Kontinentes nicht im Winter in diefes Gebiet?

Die Pflanzenwelt der Lagune. Wir haben bisher immer nur von der Tierwelt diefes Gebietes gefprochen und der Pflanzenwelt noch nicht gedacht. Diefe tritt uns hier in zwei Formen entgegen, als die niedrig organifierten Algen und als die höher ftehenden Gefäßpllanzen. Für die Algen bietet diefes Terrain keinen fehr günftigen Boden. Sie find daher auch durch nicht viele Gattungen und Arten vertreten, und diefe zeigen vielfach andere Wachstumsformen und zum Teil Degenerationserfcheinungen gegenüber Exemplaren aus dem freien Meere. Eine befondere Erfheinung find hier aber die fogenannten See- 
knödel. Sie entftehen dann, wenn an anderen Orten gewachfene Algen durch Meeresftrömungen auf die Schlamm- und Sandbänke gebracht, hier in ftändiger Bewegung erhalten und gerollt werden. Daraus refultieren dann kugelige Formen der betreffenden Algenart, wie der grünen V alonia, deren Körper aus Blafen und Schläuchen befteht oder der roten Rythiplöa und anderer. Solche Seeknödel finden fich auch am Grunde enger Meereskanäle zwifchen Infeln und dies erklärt fich dadurch, daß auch hier durch ftärkere Meeresftrömung losgelöfte Algenindividuen unter fortwährender Bewegung weiter wachfen.

Von den höher organifierten Pflanzen, den fogenannten Gefäßpflanzen hat das Seegras (Zoftera) eine reiche Entwidklung im Lagunengebiete. Es bildet hier, wenn die Waffertiefe eine entfprechende ift, ausgedehnte Rafen. Wir werden diefer Pflanze noch einmal begegnen bei der Befprechung der Zofterawiefen, die an der Flachküfte und in Buchten eine ausgedehnte Entfaltung zeigen.

Der fogenannten Salz- oder Halophytflora haben wir bereits Erwähnung getan, als wir von den Prozeffen der Verlandung der Lagune fprachen. Die Pflanzen vertragen im allgemeinen fehr fchlecht das Salz bezw. das Meerwaffer, ja diefes entfaltet für fie direkt eine Giftwirkung. Die Feftlandsvegetation dringt daher nur bis zu einer fcharf gezogenen Grenze gegen das Meer vor. Eine Gruppe von Pflanzen, die geographifh eine weite Verbreitung befitgt, findet fich aber gerade am Meeresftrande und auch im Binnenlande an Stellen mit falzhaltigem Boden und an Binnenfalzfeen. Diefe Salzpflanzen zeichnen fich meift durch ftark verholzte Teile und durch die fleifhige Befchaffenheit ihrer Stengel und Blätter aus. Beide Eigenfchaften werden als eine Einrichtung zum Schutge gegen zu ftarken Wafferverluft durch Tranfpiration aufgefaßt. Dadurch machen diefe Formen einen verkrüppelten und degenerierten Eindrudk. Einzelne diefer Halophytgewächfe treten auf den Lagunenflächen, die durch Schlammablagerung bereits über das normale Wafferniveau erhöht find, als vorherrfchende Beftände auf, wie z. B. die Statice limoneum mit mit ihren blauen Blütenrifpen. 

Figur

\section{Tafel VIII}

62. Heuschreckenkrebs (Squilla mantis) (S. 103). Länge bis $20 \mathrm{~cm}$. Am Endglied des Schwanzes zwei runde dunkelbraune Fledken.

63. Sandgarnele (Crangon vulgaris) (S. 53$) 5-7 \mathrm{~cm}$ lang.

64. Gebia litoralis (S. 33), Länge $5 \mathrm{~cm}$. An den Extremitäten behaart. Färbung grünlichgrau.

65. Alpheus (S. 72) bis $3 \mathrm{~cm}$ lang. Durchfcheinend im Innern, die Eingeweide grün durchfchimmernd.

66. Callianassa subterranea gräbt im fandigen Flachftrande bis metertiefe Wohnröhren. Auch diefe Form befitgt gleich Alpheus zwei ungleiche Scheren.

67. Bärenkrabbe (Scyllarus arctus) (S. 20) bis $10 \mathrm{~cm}$ lang, Färbung dunkelbraun.

68. Ligia (S. 81) $1,5-2,5 \mathrm{~cm}$ lang, grau. 
Tafel VIII
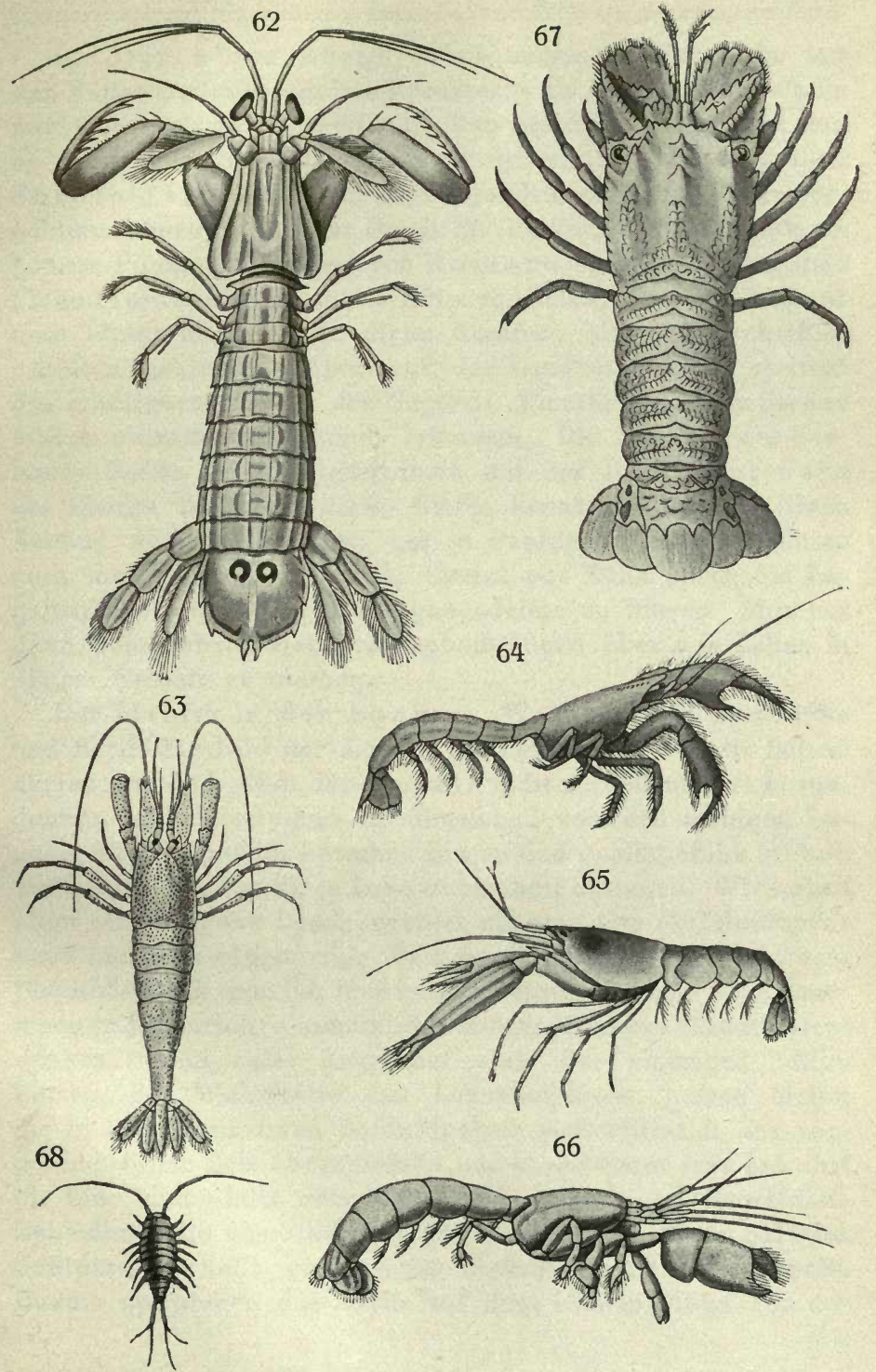

Die Dünen der Adria. Diefe zeigen im Vergleiche mit den Küften der europäifchen Nordmeere am adriatifchen Geftade nur eine geringe Entwidklung. Von befonderem Intereffe find fie hier aber durch die Beftände der echten Pinie, die nach The obald Fifcher ein für die Dünenformation des Mittelmeergebietes charakteriftifcher Baum ift. Einftmal erftredkte fich ein ganzer Pinienwaldftreifen von Ravenna bis zum fagenreichen Fluffe Timao, alfo bis in die Nähe von Trieft. Und jeţt find nur noch einige kleine Refte diefer Konifere als Naturdenkmäler erhalten geblieben. Aber auf der Landkarte laffen vielfach die erhaltenen Namen der Gegend: „Pinetta" noch die Stellen folcher ehemaliger Beftände erkennen. Die Befucher des Seebades Grado haben Gelegenheit, auf der Düne Centenara ein kleines Wäldchen diefer Kiefer kennen zu lernen. Einen Ausflug dahin follte man um fo weniger unteriaffen, als es auch fonft fehr lehrreich ift, einmal per Kahn durch die Lagunenkanäle und über die Lagunendeiche zu fahren. Man hat dann Gelegenheit, vielerlei Beobachtungen über das Leben in diefem Gebiete zu machen.

Der Menfch in der Lagune. Wenn wir das fauniftifhe und floriftifhe Bild der Lagune zu fkizzieren verfucht haben, dürfen wir doch audh des Menfchen nicht vergeffen. Das ausgedehnte Gebiet derfelben ift abgefehen von den wenigen Lagunenftädten fpärlich bewohnt und es find ausfchließlich Fifcher, welche dem Waffer ihren Lebensunterhalt abringen. Wir haben fhon eingangs das Lagunengebiet als eine dem Mitteleuropäer neue und ganz ei genartige Welt bezeichnet. Ja, mit ein wenig Phantafie kann man fich hier in längft entfchwundene Tage, fozufagen in Kinderjahre menfchlicher Kulturgefchichte zurüdkverfetyt denken, wenn unfer Auge auf einer der niedrigen Schilfhütten, der Wohnftätte des Lagunenfifchers, haften bleibt, die in ihrer primitiven Befchaffenheit wahrfcheinlich aus vorgefchichtlicher Zeit übernommen und in der Form treu bewahrt ift. Eine kleine Infel oder ein Damm trägt in der Regel diefe Behaufung, die eigentlich nur ein direkt auf die Erde gefetztes Schilfdach darftellt; einige Tamamixfträucher und verkrüppelte Bäume umrahmen das Idyll, auf dem ebenen Plaţe vor der 
Hütte treiben fich Kinder, Hühner und Hunde herum, ausgehängte bunte Wärhe fügt dem Bilde etwas lebhaftere Farbe ein und im nahen Kanal liegen in einem hafenartigen Ausfchnitt desfelben die kleinen einfachen Fifcherbarken. Mitunter find folche Fifcherhütten zu kleinen Anfiedlungen vereinigt.

Der Menfch bewahrt in diefer Bauweife feiner Behaufungen zweifelsohne uralte Lebensgebräuche, die er wahrfcheinlich vom Urbewohner diefes Gebietes ererbte. Jedenfalls war die Fifcherei das erfte Intereffe, das den Menfchen in diefen wenig wohnlichen Gebieten fich anfiedeln ließ und erft aus der auf diefem Wege gewonnenen Vertrautheit mit dem Waffer und dem Meere hat fich Handel, Taufdrverkehr und Shiffahrt entwidkelt. Es würde aber gewiß eine falfhe Deutung der Tatfachen fein, wenn wir die gefchilderte Bauart und Befiedlungsweife nur in dem Sinne, als ein ftarres Fefthalten alter übernommener Gebräuche auffaffen möchten. Vielmehr ift es

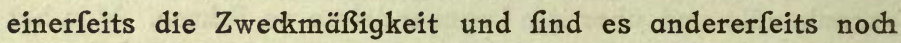
Gründe äußerer Notwendigkeit, unter welchen Gefichtspunkten wir diefe Erfcheinung zu beurteilen haben. In der Lagune ftehen ja dem Menfchen keine anderen Baumaterialien zur Verfügung als kümmerliche Afte und Schilf. Erftere liefern das Gerippe diefer Wohnungen und das Schilfrohr zum Eindecken ift ein reichlich vorhandenes und ausgezeichnetes Material, welches im Sommer gegen Hitze und im Winter gegen Kälte Schuts bietet.

An einem Sommertage in der weiten einfamen Lagunenlandfhaft mit ihrem zitternden Lichte, den azurnen Tönen und der brütigen Luft müfen wir dies Bild betrachten und wir wollen dies nicht vom Standpunkt des momentanen Eindrudkes tun, fondern wir wollen es uns zeitlich in unermeßlich weite Räume der Erdgefhichte auseinander gezogen denken. Die Landfchaft, die einft der Tertiärmenfch befchaute, fie nimmt Geftalt an. Auch damals mag der Landfchaftscharakter der einer Lagunenfzenerie gewefen fein. Ja, wir erkennen alte Bekannte der Gegenwart, Sumpfvögel, Mufcheln und Krebfe. Faft enttäufht find wir, denn im Grunde genommen fieht es faft gar nicht viel anders aus. Neugierig möchten wir deshalb unfere Gedanken auch in ferne Zeiten nach uns vordringen laffen. - 
IV.

\section{DIE ZOSTERAWIESEN DER FLACHSEE.}

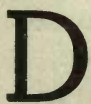

er fauniftifche und floriftifhe Charakter der Flachfee fteht unverkennbar in inniger Abhängigkeit von der geologifchen Befchaffenheit des Strandes. Das Gefamtbild wechfelt alfo hier je nachdem eine felfige Küfte oder Sandftrand vorliegt. In der Adria, fpeziell in ihrem nördlichen Seichtteile wird durch das hier in gefchloffenen Beftänden auftretende Seegras (Zoftera), auf ausgedehnten Territorien eine fehr charakteriftifhe Organismengemeinfhaft gefchaffen. Mit einer reichen Entwidklung von Pflanzen- und Algenwuchs verbindet fich in diefen Gebieten ein mannigfaltiges Tierleben.

Das Seegras findet fich immer in Küftennähe oder in gefchütten Buchten bei geringer Waffertiefe. Leţtere fcheint jeweils beftimmt $z u$ fein durch den Grad der Durchfichtigkeit bezw. Lichtdurchläffigkeit des Waffers. Das zweite Moment für das Gedeihen diefer Pflanze ift die Qualität des Grundes, in welchem fie wächft. Das Optimum ift für fie eine Mifhung von Schlamm und Sand, wie eine folche überall dort $\mathrm{zu}$ finden ift, wo Flyfchlandfchaft die Küfte bildet. In der Lagune gedeiht fie auch auf fait reinem Sdłlammboden. Dagegen ift entlang der Weftküfte Iftriens, die aus Kreidekalk befteht, die geringe und fpärliche Entfaltung der Zoftera unverkennbar. Die Urfache hierfür liegt wohl darin, daß fich in diefem Gebiete der Sandboden infolge der auswafchenden Wirkung der Strömungen und Brandungsbewegung nicht mit Schlamm anreichern kann.

Die Zoftera gehört zu den wenigen Gefäßpflanzen, welche auch im falzigen Meerwaffer zu gedeihen vermögen. Aber fie zeigt in diefer Eigenfchaft außerdem eine große Anpaffungsfähigkeit und findet fich daher nicht bloß an Orten verfchiedenen Salzgehaltes, fondern ihre Plaftizität kommt auch durch 
die weite geographifche Verbreitung zum Ausdrudk. Hierzu wäre zu bemerken, daß nicht fo fehr die verfchiedene Konzentration an Salz für das Gedeihen folcher anpaffungsfähiger Pflanzen- und Tierformen das ausfchlaggebende Moment ift, fondern daß der Wechfel im Salzgehalte nicht zu unvermittelt erfolgen darf. Experimentell hat fich für Meerestiere wie Meerespflanzen nadweifen laffen, daß diefe bei unvermittelter Ubertragung aus normalem Seewaffer in Süßwaffer ftarben; wurde eine allmähliche Verdünnung jenes vorgenommen, fo vertrugen fie fchließlich auch den Mangel an Salz. In ähnlicher Weife gelang umgekehrt die Uberführung gewiffer Süßwaffertiere aus Süßwaffer in Seewaffer.

Im Pflanzenleben fpielt das Licht, wie fchon früher erwähnt, eine lebenswichtige Rolle. Die in Rede ftehende Pflanze erweift fich als fehr lichtbedürftig und diefe Eigenfchaft teilen mit ihr die Grünalgen des Meeres. Daher finden fich leţtere faft ausfchließlich im feichten Waffer und auch dem Seegras find hierdurch Grenzen für die Wanderung in die Tiefe gezogen.

Ein fehr charakteriftifhes Moment für die küftennahen $\mathrm{Ge}-$ biete und für die Flachfee ift die faft ftändige Wafferbewegung, die durch Wind, durch das Spiel von Ebbe und Flut, fowie durch den regelmäßigen Küftenftrom bewirkt wird. Die langen bandformigen Zofterablätter fieht man dann immer in der Richtung der jeweiligen Wafferbewegung eingeftellt und es hat den Anfchein, daß diefe Blattform geradezu eine Folge des ftändigen Zuges auf die Gewebe darfellt. Im Boden erfcheint die Pflanze durch die Befchaffenheit ihrer Wurzeln gut verankert.

Intereffant ift der einer Gerftenähre ähnliche Blütenftand diefer Pflanze, deren Blütezeit in die Monate April - Mai fällt. Während am Feftlande die Blüten in der Luft ihre Entfaltung nehmen und ihre Beftäubung bezw. die Ubertraguug des Polens auf die Narbe meif durch Infekten beforgt wird, hat diesbezüglich die ftändig im Waffer untergetauchte Zofterablüte befondere Anpaffungen an diefe Verhältniffe.

Bei den marinen Pflanzen und Algen lernen wir eine Eigenfhaft kennen, welche am Feftlande fehr wenig und im Süß- 

Figur

\section{Tafel IX}

69. Mysis oculata (S. 21, 28) ganz durchfichtig, ca. $1,5 \mathrm{~cm}$ lang. 70. Granatkrebs, Crevet (Palaemon) (S. 28). Länge 5-10 cm.

71. Languste (Palinurus) (S. 69) bis $40 \mathrm{~cm}$ lang, in der Färbung braun; zum Unterfchied vom Hummer fehlen diefer Form Scherenfüße.

72. Hummer (Homarus vulgaris) (S.20,68) bis $48 \mathrm{~cm}$ lang, Färbung dunkelbraun bis fchwarz, frifh gehäutete Exemplare zeigen auch lebhaft blaue Farbentöne. Diese Abbildung ftellt ein eiertragendes Weibchen mit dem gegen die Bauchfeite gefchlagenen Schwanze dar.

73. Galathea strigosa (S. 20). Länge bis $15 \mathrm{~cm}$, Färbung rot mit blauen Querbinden. Bewohner der felfigen Flachküfte.

74. Einsiedlerkrebs (Diogenes varians) (S. 20, 100) lebt meift in leeren Gehäufen von Cerithium und Naffa (Fia. 90 u. 20).

75. Gonoplax rhomboides lebt vergraben im fandig-fchlammigen Grunde. 

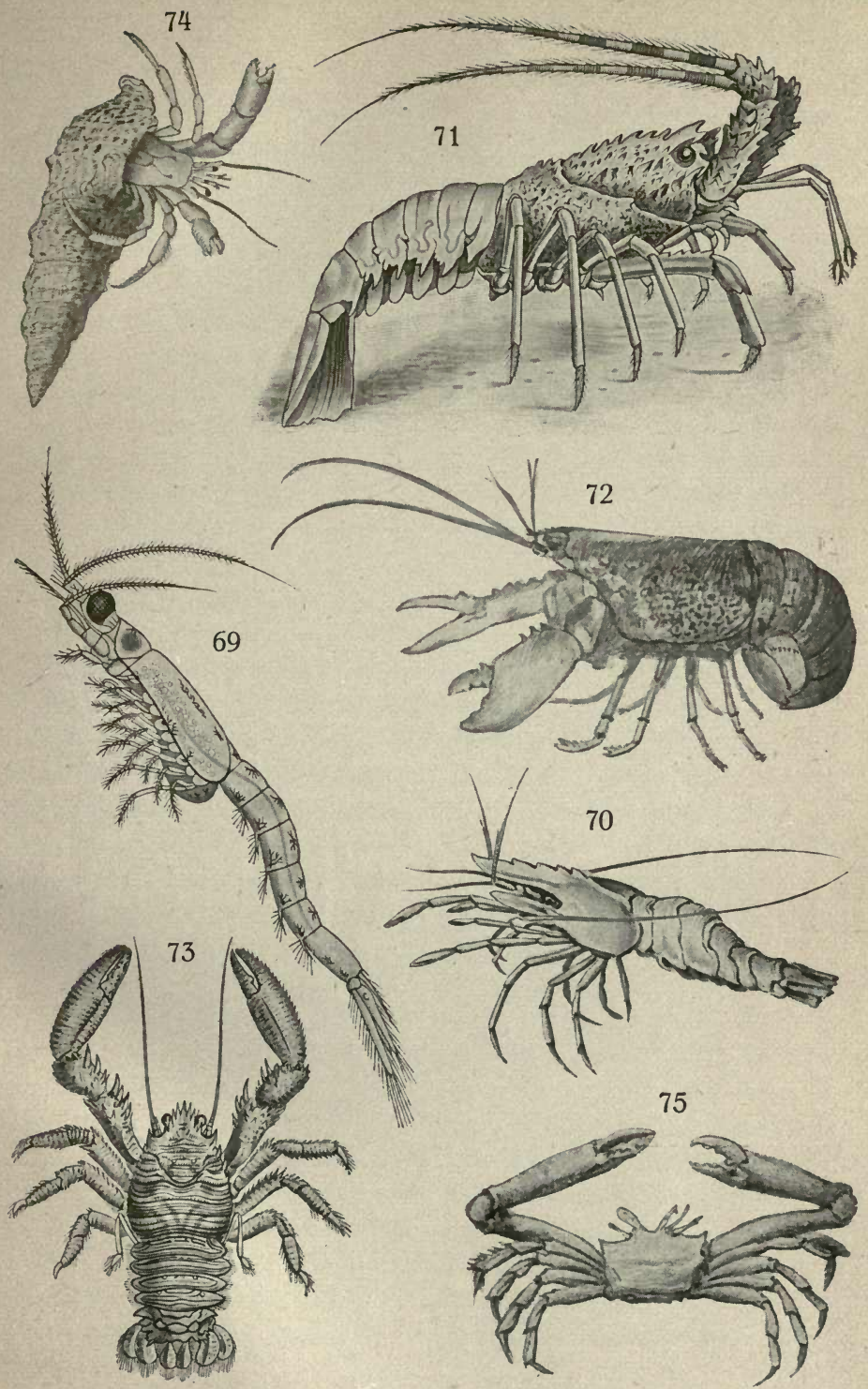

waffer auch nur in geringem Umfange ausgebildet ift, - die Tropen machen vielleicht hierin eine Ausnahme -, nämlich die außerordentlich weitgehende Raumausnütung dadurch, daß fich auf einem Individuum andere Formen anfiedeln, und dies geht fo weit, daß auf den epiphytifchen Formen wieder andere fitzen können. Es handelt fich dabei nicht etwa nur um pflanzliche Wefen, fondern auch um Tiere. Wir werden bei anderer Gelegenheit diefe Eigentümlichkeit in der Lebewelt des Meeres nochmals kennen lernen, aber da wir ihr bei der Zoftera das erftemal begegnen, foll auf diefe Erfheinung fofort aufmerkfam gemacht werden. Trotgdem das Zofterablatt für die Befiedlung nicht befonders geeignet erfcheint, fo finden wir doch allerlei Rotalgen, ferner verfahiedene feftritzende Tiere faft als typifche Formen epiphytifch auf demfelben auftreten. Zwifchen den Zofterapflanzen entfaltet fich gewöhnlich der Meerfalat, Ulva lactuca, eine Grünalge, in üppiger Weife.

Es ift eine auffallende Erfcheinung, daß im Meere fo wenige Gefäßpflanzen ihre Exiftenz finden und daß das marine Pflanzenleben in überwiegender Weife durch die niedrig organifierten Algen repräfentiert ift. Dies erklärt fich damit, daß jene ihre eigentliche Heimat am Feftlande haben und Begleiterfcheinungen bei der Bildung der Kontinente darftellen. Diejenigen wenigen im Meere vorkommenden Pflanzengenera, wie die Zoftera, Cimotocea, Pofitonia ufw. find erft wieder fpäter dahin vom Feftlande gewandert, wie dies unter den Landtieren die Waaltiere $u$. a. getan haben.

Die Gebiete der Zofterarafen gewinnen auch dadurch Intereffe, daß hier fortwährend Mifchungen von verfchiedenen fauniftifchen Bezirken ftattfinden. So lebt das ganze Jahr hindurch im ficheren Schutge des Didkichts der Zofterapflanzen eine für diefe Bezirke charakterifche, fchwebende und fchwimmende Kleinwelt pflanzlicher und tierifcher Natur. Am Grunde felbft befteht die Fauna zum Teil aus feftfitzenden, zum anderen Teil aus den Sandgrund bewohnenden Formen, und diefe Tiere bilden zufammen das ftabile Kontingent für diefe Zone. Außerdem läßt fich eine Lifte von beweglichen Grundtieren zufammenftellen, die je nach der Jahreszeit fich hierher ziehen 
und wieder in Gebiete größerer Waffertiefe wegwandern. Die Meeresftrömungen führen ferner hierher ftändig neues Material von der fchwebenden Kleinwelt, dem fogenannten Plankton von anderen Orten und der offenen See. Endlich wäre die formenreiche Fifchfauna, die hier einen reich gededkten Tifch findet, zu nennen, um das Bild zu vervollftändigen.

Alfo abgefehen davon, daß die phyfikalifchen Zuftände an den in Rede ftehenden Orten an und für fich vorteilhafte Lebensbedingungen fchaffen, fo fpielt zweifelsohne der Seegraswald als folcher eine die Fauna begünftigende Rolle. Er bietet einerfeits einen natürlichen Schut, Zufluchtsort und günftige Laichplätse für verfchiedene Seetiere, andererfeits bedeutet er eine anfehnliche Oberflächenvergrößerung für epiphytifche, d. h. feftgewachfene Formen und ebenfo für die nicht ftändig fchwimmende und temporör fitzende und kriechende Kleinfauna. Wir begegnen daher hier einem ungemein mannigfaltigen und reichen Leben. Wenn wir in Teilen des offenen Meeres felbft bei den geringen Tiefen von zirka 25 bis 30 Metern, wie im Golfe von Trieft, die Menge an Lebewefen vergleichen mit jener im Zofteragebiet der Flackü̈te, indem wir jedesmal eine Wafferfäule von der Oberfläche bis zum Grunde und auch die Lebewesen in und auf demfelben in Betracht ziehen, fo würden wir überrafcht fein, um wieviel reicher im Verhältnis das Meer in Küftennähe bevölkert ift. $\mathrm{Da}$ die hier vorkommenden einzelnen Tierarten nur zum geringen Teil Pflanzenfreffer find und haupträchlich auf tierifche Nahrung angewiefen erfcheinen, fo läßt fich verftehen, daß der Nahrungserwerb einen fcharfen Kampf in diefer Tiergemeinfchaft zur Folge hat. Für leţtere fpielt befonders die Mikrofauna eine große und wichtige Rolle. Intereffant ift weiter die Tatfache, daß die Zoftera von keinem Seetier angegriffen und gefreffen wird.

Um einen Uberblidx über die Lebensgemeinfchaft in den Zofterawiefen der Flachfee zu gewinnen, ift es nötig, mit verfhiedenen Methoden $z \mathfrak{u}$ fifchen, wie mit Planktonnezen, mit kleinen Schleppnetzen. Das überrafchendfte Bild gewährt aber wohl der Netjinhalt jenes von den territorialen Fifchern häufig 
gebrauchten großen Grundfchleppnetzes, des fogenannten Grippos, und man follte die Gelegenheit nicht verabfäumen, einer folchen Fifcherei beizuwohnen, denn der Inhalt diefes Netzes liefert eine recht anfchauliche Mufterkarte eines großen Teiles der Zofterafauna.

Wir wollen nun den Inhalt eines Fanges mit Hilfe eines Planktonnetyes, das durch den Zofterawald gezogen wurde, genauer betrachten. Das Glas, in welches der Netzinhalt übergeführt wurde, zeigt zunächft einen getrübten Inhalt, herrührend von einer Menge fchlammiger und fhleimiger Beimengungen. Sobald fich diefe aber zu Boden gefenkt haben, fieht man dann eine Fülle von Tieren wie Schatten durch das Waffer fchießen, denn faft alle find mehr oder weniger durchfichtig. Vorherrfchend find es $\mathrm{Krebstiere,} \mathrm{die} \mathrm{wir} \mathrm{zum} \mathrm{Teil}$ fchon kennen gelernt haben, wie z. B. die Myfis (Fig. 69), aber es find noch andere kleine Krufter unter ihnen. Während fich jedoch am Nehrungsitrande und auch in der Lagune nur eine oder wenige Arten der Myfideen, wohl jedoch in großer Individuenanzahl fanden, ift im Zofteragebiet der Artenreichtum diefer Tiere ein viel größerer. Ein intereffantes Tier ift weiter der Virbius (Fig. 60), ein dem Palämon nahe ftehender aber viel kleinerer Krebs, infotern als er je nach dem umgebenden Farbenton fein Kolorit von grün in rot und umgekehrt wechfeln kann. Beim Durchmuftern des Fanges mit Hilfe einer Tafchenlupe bemerkt man ferner marine Waffermilben (Ponthydrachniden) (Fig. 61), kleine runde fpinnenartige Tiere mit lebhaft fich bewegenden Beinen. Diefe Tiere verdienen insbefondere deswegen hervorgehoben zu werden, weil fie zu einer dem Meere fremden Tiergruppe gehören, nämlich zu den Spinnen, welche als luftatmende Tiere Feftlandsformen und fozufagen Produkte des Feftlandes find. Sie wären daher jenem kleinen Kreis von Tieren zuzuzählen, welche vom Feftlande wieder in die Heimat ihrer Vorfahren, dem Meere, zurüdkgekehrt find.

Eine andere typifche Tierform diefes Gebietes ift die Spadella (Fig. 44). Sie gehört zu den eigentümlichen und im Meere weit verbreiteten glashellen Hakenkieferwürmern, 
deren verwandtfchaftliche Stellung $z \mathfrak{u}$ den anderen Gruppen der wirbellofen Tiere eine noch nicht aufgeklärte ift. Die Chaetognathen, wie ihr wiffenfhaftlicher Name ift, find im Meere freifchwimmende und fdhwebende Formen von fifchähnlicher Geftalt. Sie befityen Floffenfäume, und ihr Mund erfcheint von einem Kranze von Greifhaken umftellt. In der Gruppe diefer Würmer ift die Spadella fpeziell durch die Eigenfchaft ausgezeichnet, fich mit dem Sekrete von Klebzellen an der Unterlage feftheften zu können; nur zur Erbeutung der Nahrung, die hauptfächlich aus kleinen Krebfen befteht, verläßt fie ihre Verankerung, indem fie fich mit einer fchnellenden Bewegung auf jene losftürzt.

Unfer Nety hat ferner eine große Menge anderer kleiner Würmer erbeutet, es find fogenannte Strudelwürmer, die Turbellarien, deren Namen gerechtfertigt wird, wenn man diefe Tiere unter dem Mikrofkop betrachtet. Dann fieht man, daß der ganze Körper mit einem Pelz feinfter fhwingender Härchen, fogenannten Wimperhaaren, bedeckt ift, die durch ihre rhythmirchen Bewegungen einen Wafferftrom erzeugen und das Tier wie mit taufend und taufend kleinen Rudern durchs Waffer fchwimmend oder gleitend fortbewegen. Die Turbellarien bilden eine ungemein gattungs - und artenreiche Klaffe mit einer univerfellen Verbreitung über die ganze Erde und einer weitgehenden Anpaffung an alle möglichen Lebensbedingungen. Daraus erklärt fich die Mannigfaltigkeit und Verfchiedenheit in Größe, Form und Kolorit. Die marinen Turbellarien werden bis handtellergroß und find platt oder langgeftredkt wurmartig. Ihre Oberfeite erfcheint meift mit einer charakteriftifhen und oft bunt gefärbten Zeichnung verfehen, während die Unterfeite ge wöhnlich einfarbig ift und einen indifferenten Ton zeigt. Die Formen, um welche es fich im vorliegenden Falle handelt, find kleine Tiere von mehr weniger rundem Querfhnitt und bei ihnen herrfchen grüne und graugrüne und braune Töne vor. Sie kriechen für gewöhnlich, können aber auch mit Hilfe ihrer Bewimperung fchwimmen.

$\mathrm{Zu}$ diefen hier aufgezählten Tierformen gefellen fich dann je nach der Jahreszeit verfhiedene andere Formen; wir müffen 
uns aber begnügen, nur die kleine Medufe Cladonema radiatum (Fig. 21) zu nennen, welche fich mit Hilfe ihrer verzweigten Tentakel an der Unterlage feftheften kann.

Wenn wir die Lebensweife der zwifhen den Zofterapflanzen frei lebenden Mikrofauna, von welcher nur einige wenige Vertreter oben angeführt wurden, betrachten, fo fällt uns als ein gemeinfamer $\mathrm{Zug}$ diefer Tiere auf, daß bei ihnen das Schwimmen eingefchränkt ift, indem fie fitzend auf ihre Beute lauern und nur $\mathrm{zu}$ dem $\mathrm{Zwedke}$ fhwimmen, um fie zu erhafchen oder kriechend leţtere fuchen. Das Schwimmen hat für fie ferner wohl auch noch eine Bedeutung bei der Flucht und bei der Wanderung in andere Gebiete. Beifpiele aus diefer Gruppe von Tieren find deshalb von Intereffe, weil fie uns den Weg zur Annahme der feftitzenden Lebensweife zeigen können. Wenn wir nun fpäter fehen werden, wie groß die Zahl der feftfitzenden Tiere ift, die gleich den Pflanzen ftändig an den Ort gebunden find, und wenn wir erfahren, daß faft jede Klaffe der wirbellofen Tiere einzelne, mehrere oder viele Vertreter, die unabhängig voneinander die feffile Lebensweife angenommen haben, befittt, und wenn wir endlich in Betracht ziehen, welchen umgeftaltenden Einfluß der Ubergang zu diefer Lebensführung mit fich bringt, fo drängt fich die Frage nach der Urfache und den Motiven diefer höchft intereffanten Erfcheinung auf. Diefe find jedenfalls mannigfaltige, aber das Grundmotiv war wohl immer das Beftreben nach einem erleichterten Nahrungserwerb in Ausnüţung hierzu günftiger äußerer Umftände.

An diefer Stelle mögen noch einige Formen Erwähnung finden, die ftändig auf den Zofterahalmen und Algenzweigen herumkriechen, wie der Inachus und Stenorhynchus (Fig. 80, 81). Beide Krebfe gehören zur Gruppe der Krabben und zeichnen fich durch ihren kleinen Körper und durch die im Verhältnis zu diefem langen Gliedmaßen aus, fo daß fie große Ahnlichkeit mit Spinnen gewinnen. Diefelbe Geftaltung wiederholt fich auch bei den Krebsformen aus der Tieffee und findet fich alfo in zwei ganz voneinander verfhiedenen Wohnbezirken. Und die Urfache hierfür? Die allgemeinen äußeren Lebensbedingungen find $z \mathfrak{u}$ different in beiden Bezirken, um folche Ge- 
ftaltungen als Parallelerfcheinungen hinftellen zu können. Dagegen wird die Sachlage damit aufgeklärt, daß es fich in beiden Fällen um ähnliche Lebensweifen handelt. Am Grunde der Ozeantiefen ift die Aufgabe zu löfen, einen Körper mittels Extremitäten über die ganz weichen Schlammflächen hinwegtragen zu können. Daher der kleine Körper zur möglichften Verringerung des Gewichtes und die langen Beine, welche diefe Laft über eine größere Fläche verteilen. In der Flachfee dagegen handelt es fich um Klettertiere, die mit den langen Beinen von Algenzweig zu Algenzweig zu ftelzen imftande find und dies wird ebenfalls durch eine Volums- und Gewichtsverringerung am Körper unterftütt. An diefen Tieren lernen wir weiter eine Erfheinung kennen, der wir nochmals in ausgefprochenerem Maße begegnen und dann ausführlicher behandeln werden. Sie maskieren fich, $d$. h. fie befeftigen auf ihrem Körper und ihren Extremitäten allerlei Algen und andere Dinge aus ihrer Umgebung und machen fich dadurch diefer ähnlicher, und fohwerer in diefer erkennbar.

Was befonders dem Gebiete der Zofterarafen feinen Charakter aufdrüdkt, ift die Bodenfauna, die zum überwiegenden Teile aus fo großen Formen befteht, daß diefe ohne befondere Hilfsmittel und mit bloßem Auge in bezug auf ihre Organifation und Körperfunktionen der Beobachtung zugänglich find. Die Vertreter diefer fauniftifchen Gruppe find teils feftitzende, teils kriechende Tiere. Letztere wandern je nach Bedürfnis aus dem tiefen Waffer gegen die flache Küfte und zurück. Der Wandertrieb ift hauptfächlich durch das Laichgefchäft bedingt, und diefer Umftand verdient deshalb Intereffe, weil er andeutet, daß diefe Formen urfprünglich Küftenformen waren. Die Flachfee und die Meeresküfte ift ja im Verlaufe der Gefhichte der marinen Fauna der Hauptproduktionsort für viele Tiertypen gewefen und wird es wohl auch noch bleiben. Die Wanderung folcher Küftenformen ift aber auch noch vom Wetter abhängig, indem fich diefe bei Wind und Seegang von der Küfte in tiefere und ruhigere Wafferfchichten zurüdkziehen.

Wir wollen zunächft einige Repräfentanten der im Meeresgrunde feftritzenden Tiere kennen lernen. Indem wir die 
Formen auffteigend im Syfteme des Tierreiches befprechen, hätten wir zunächft die Schwämme (Spongien) zu nennen. Sie find hier vertreten durch die Gattungen Spongellia (Fig. 15) und Oscarella. Bei erfterem Genus ift der Weichkörper durch ein Horngerüft ähnlich wie beim Badefchwamm geftütst. Diefes erweift fich aber nicht für die gleichen Zwedke brauchbar wie das des Badefchwammes. Die Oscarella ift eine fkelettlofe Form, die rundliche Ballen von fchöner veilchenblauer Farbe bildet. An die Spongien fchließen fich hinfichtlich der einfachen Organifation die Neffeltiere an, von welchen zwei Formen eingegraben im Grunde des vorliegenden Gebietes leben. Es ift der Cerianthus, die Fadenrofe (Fig. 33) und der Ilyanthus (Fig. 32). Die Seeanemonen oder Aktinien, wie man diefe Formen auch nennt, find für gewöhnlich an der Unterlage mittels einer Art Saugfcheibe feftgewachfene Tiere mit einem zylindrifhen meift kurzen Körper. Der Cerianthus weicht nun infofern von diefem Typus $a b$, als er eine wurmartig und langgeftredkte Aktinienform von ca. $40-50 \mathrm{~cm}$ Länge ift.

Trotgdem diefe Tiere ein noch primitiv organifiertes Nervenfyftem befitzen, fo zeigen fie doch bereits ein zwedkmößiges $\mathrm{Zu}-$ 1ammenwirken ihrer beiden Tentakelkränze bei der Nahrungsaufnahme aus dem umgebenden Waffer. Das Zufammenarbeiten diefer Tentakel kann man fehr hübfch an einem Cerianthus beobachten, der in einem Glas mit Meerwaffer untergebracht ift und mit Plankton gefüttert wurde. Man fieht dann fofort die Randtentakel fich lebhaft bewegen und fobald ein Krebschen einen folchen Tentakel berührt hat, bleibt es gelähmt an demfelben kleben. Nun kontrahiert fich der betreffende Tentakel und zieht fich durch die Mundtentakel hindurch, wodurch das Beutetier von diefen übernommen und fchließlich dem Mund zugeführt wird.

Bei langfamer Fahrt mit einem Kahne über die Seegraswiefen kann man bei genügend durchfichtigem Waffer einzeln oder in Gruppen zufammenftehend fchöne blumenartige Gebilde auf Stengeln fitzend lehen, die aber alsbald durch die Erfchütterung der Ruderfchläge bliţartig verfchwinden. Wir 
haben in diefen Tieren die Se enelken (Spirographis) (Fig. 51) vor uns, Würmer, welche felbftgebaute Chitinröhren bewohnen und mit diefen im Meeresgrunde feftgewachfen find. Der fchöne blumenartige Körperteil, welcher aus der Wohnröhre herausragt, ift ihr Kiemenapparat. Eigentlich follte das Tier nach dem Typus der Anneliden (s. S. 10) auf allen Körperfegmenten die den freilebenden Würmern zukommenden federförmigen Kiemen befiten. Diefe find jedoch verloren gegangen offenbar im Zufammenhang mit der Annahme der feftfitzenden Lebensweife in einer Röhre. In einer folchen ift aber, da fie dem Körper knapp anliegt, der Wafferwechfel zum Atmen fehr erfchwert, wenn nicht überhaupt minimal und die Hautatmung könnte deshalb in nicht ausreichendem Maße die fehlenden Kiemen erfetzen. Deshalb find für diefe Tiere gerade erft recht fpezielle Atmungsapparate nötig. Ein folcher ift tatfächlich am Kopfe in einer in Spiralform angeordneten Federkrone durch Umbildung aus einem Fühlerpaare des Kopfes entfanden. Alfo ein Organ hat feine urfprüngliche Beftimmung als Sinnesorgan bei gleichzeitiger Umbildung feiner Form verloren und fich in einen Atmungsapparat umgewandelt. Dies wäre eines jener Beifpiele, mit welchen man fehr fhön das Prinzip des Funktionswechfels demonftrieren kann. Neue Organe entftehen nicht als vom Grund aus vollftändig frifhe Bildungen, fondern gehen aus bereits vorhandenen durch Umwandlung derfelben hervor. Darin liegt eine große Ókonomie. Bei Betrachtung der Kieme von Spirographis beachte man auch die vorzügliche Raumausnützung, welche in ihrer Geftalt durchgeführt ift, indem die Anordnung der Kiemenfäden in einer Spirale eine möglichft große Oberflächenentfaltung auf kleinftem Raume ermöglicht. Diefe Form der Kieme hat ferner den Vorteil, daß fie fich beim Zurüdkziehen des Wurmes in die Röhre regenfchirmartig zufammenlegt und kein Hindernis für die Bewegung abgibt.

Anläßlich des Suchens nach den Seenelken entdedkt man häufig die im Grunde mit einem Zopfe feiner Hornfafern verankerten Stedk- oder Schinkenmufcheln (Pinna) (Fig. 111), deren Schalen bis $70 \mathrm{~cm}$ lang werden können und die in der 

Figur

\section{Tafel X}

76. Muschelwächter (Pinnotheres) (S. 51). Länge $1-2 \mathrm{~cm}$, weichfchalig, Farbe hellbraun bis gelb.

77. Strandkrabbe (Carcinus maenas) (S. 19, 33). Länge bis $4 \mathrm{~cm}$, Färbung braun bis grün, lokal variierend.

78. Meerspinne (Maja squinado) (S. 89). Körper bis $20 \mathrm{~cm}$ lang, Färbung braunrot. Man beachte die Männchen (ital. Granzevolo) mit großen Scherenfüßen und fchmalem Hinterleib und die Weibchen (ital. Granzevola) mit kleinen Scherenfüßen und breitem Hinterleibsabfchnitt zur Bildung eines Brutraumes.

79. Pisa (S. 89). Länge bis $3,5 \mathrm{~cm}$; Färbung braunrot. Der Körper ift behaart und häufig mit Schwämmen bewachfen (Maskierung).

80. Stenorhynchus (S. 45). Körper bis $2 \mathrm{~cm}$ lang, graugelb. Maskiert fich hauptfächlich mit Algen.

81. Inachus (S. 45). Körper bis $2 \mathrm{~cm}$, Füße $8 \mathrm{~cm}$ lang, Färbung gelbbraun. Diefe Krabbe bevorzugt zur Maskierung Schwammftüdxchen.

82. Dorippe lanata. Länge des Körpers $4 \mathrm{~cm}$; dicht behaart und graubraun; trägt zur Maskierung Mufchelfchalen, auch andere lebende Tiere mit Hilfe des letzten Fußpaares herum.

83. Wollkrabbe (Dromia vulgaris). Länge des famtartig behaarten dunkelbraunen Körpers bis $8 \mathrm{~cm}$. Die auf den Rücken hinaufgerüdkten Fußpaare tragen Schwammftücke, zufammengefetste Seefcheiden und dergleichen zur Maskierung herum. 
Tafel X
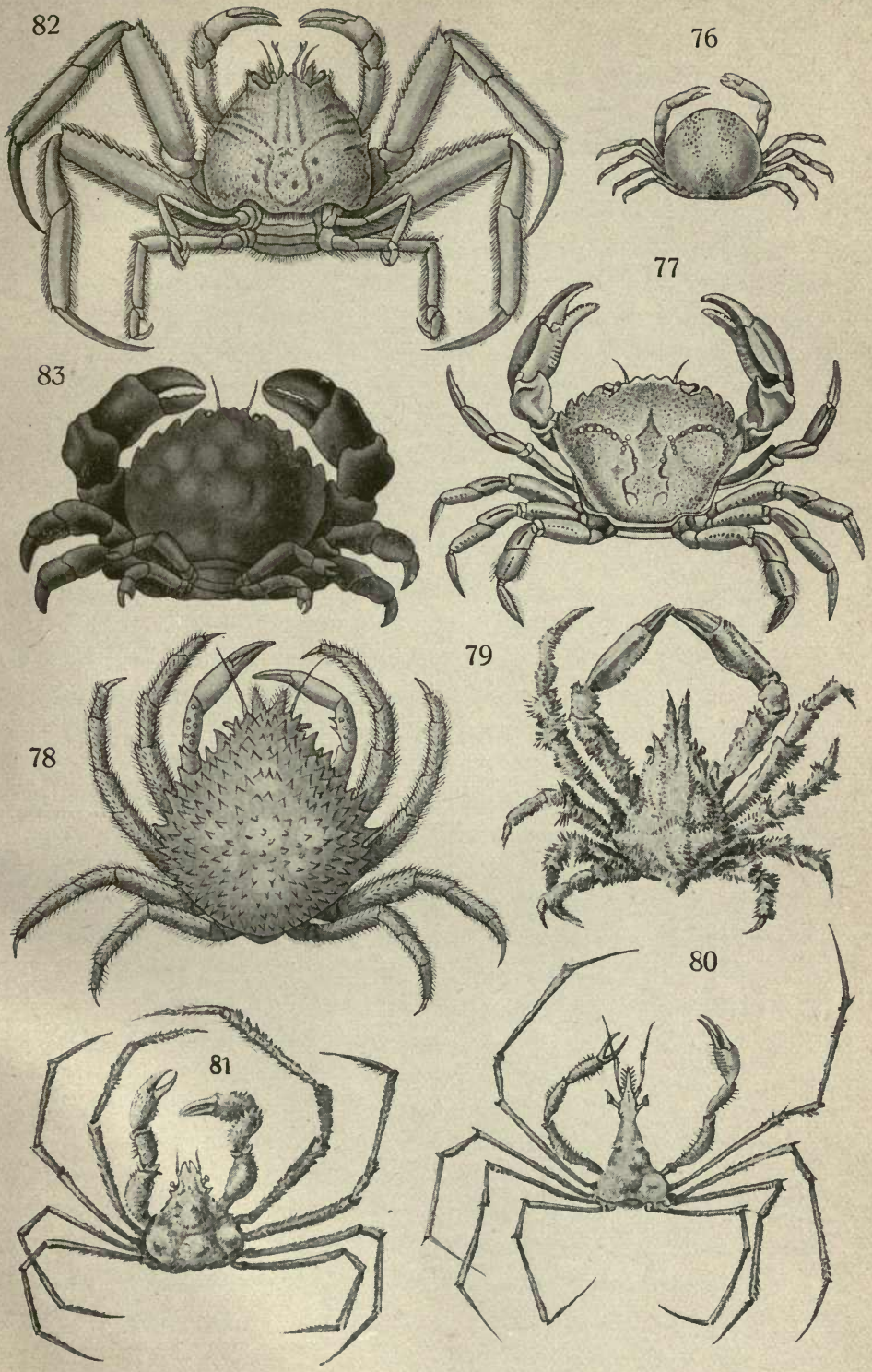

Mittelmeer- und adriatifhen Fauna zu den größten Mufcheln gehören. Das Vorderende derfelben ift zugefpitzt und fteckt im Boden, während das breite Hinterende in das Waffer hineinragt. Bei dem ungeftörten Tiere klaffen hier die Schalen und die Mantelränder der Mufchel treten dann wulftartig hervor, indem fie eine Pforte für den Eintritt und Austritt des Waffers formieren. In der Ausftrömungsöffnung wird ferner ein fingerförmiger vorftredkbarer Fortfaty fichtbar, deffen Funktion nicht ganz klar ift. Die Befeftigung im Meeresgrunde gefhieht, wie erwähnt, durch hornige Byffusfäden, die einerfeits an kleinen Steinchen angeklebt find und andererfeits im Tiere in einer Höhlung bezw. einer Drüfe des fogenannten Fußes entfpringen. Wie das Spinnen diefer Hornfäden erfolgt!, werden wir an einem anderen Beifpiele fpäter zeigen. Obwohl nun die Pinna mit dem Mundende nach abwärts gekehrt im Grunde eingegraben ift, nimmt fie nicht etwa die Nahrung von hier aus auf, fondern diefe wird ihr von der Einfuhrsöffnung am Hinterende des Tieres aus dem freien Waffer zugeführt und zwar in der Weife, daß die mit der Strömung an der Mufchel vorbei treibenden Diatomeen und organifcher Detritus durch einen Strom des Wimperepithels der Kiemen und des Mantels afpiriert werden. Wer Glüdk hat, findet in den Mantelrändern der Pinna mitunter ganz hüblh entwidkelte Perlen.

Ostrea. Bei Durchmufterung des Inhaltes des Schleppnetzes findet man in diefem Gebiete fehr häufig Auftern (Ostrea) (Fig. 114) einzeln auf Steinen und anderen Mufchelfchalen angeheftet oder zu Gruppen miteinander vereinigt. Eigentlich gehört diefes Tier fauniftifh in die Region der Felfenküfte. $\mathrm{Da}$ aber in der Adria derartig reiche natürliche Beftände von Auftern, fogenannte Aufternbänke, fehlen und da die künftliche Zucht diefes gefchätsten Schaltieres gerade in der Flachküfte mit reichem Pflanzen- und Algenwuchs bevorzugt wird, fo wollen wir an diefer Stelle einiges über die adriatifche Aufter mitteilen. Faft erfheint dies überflüffig, da gerade über diefe weit verbreitete Mufchel fchon viel gefchrieben worden ift. Für das gute Gedeihen und das rafche Wachstum derfelben müffen gewiffe Bedingungen erfüllt werden. Zunächlt erweift fich eine Cori, Der Naturfreund. 
geringe Ausfüßung des Meerwaffers als günftig, wie dies in ftillen gefchütten Buchten durch kleine hier einmündende Wafferläufe oft der Fall ift. Das Waffer muß ferner mindeftens 1-2 $\mathrm{m}$ tief und entfprechend temperiert fein. Dem Sturm und Seegang ausgefeţte Stellen find für den vorliegenden $\mathrm{Z}_{w e d k}$ ungünftige Ortlichkeiten. Ferner muß noch vom hygienifchen Standpunkt aus die Forderung geftellt werden, daß fich in der Nähe von Aufternparks keine menfchlichen Anfiedlungen oder Fabrikanlagen befinden, daß dort keine Kloaken ausmünden und daß der Verkehr von Dampffchiffen ferngehalten werde. Denn durch alle diefe Momente befteht die Gefahr, daß menfchliche Fäkalien in das Waffer gelangen und dadurch die Auftern mit gefährlichen krankheitserregenden Mikroben infiziert werden, die beim Genuffe der lebenden Aufter im menfchlichen Darme fdhwerfte Krankheitszuftände hervorrufen können. Die reich gegliederte und nicht ftark befiedelte Küfte Iftriens und Dalmatiens hat folche für künfliche Aufternzuchten günftige Ortlickkeiten in reichem Maße und die Adriaaufter if daher ebenfo tadellofer Provenienz wie die ausländifchen fehr teuren, und fie fteht diefen außerdem an Wohlgefhmadk und Fettigkeit nicht nach. Ferner darf der Vorteil nicht überfehen werden, daß beifpielsweife aus der Aufternzüchterei in Cherfo (Iftrien) die Ware rafcher und daher frifcher $\mathrm{zu}$ erhalten ift, als vom Auslande und außerdem fällt ins Gewicht, daß der Preis ein ganz ungewöhnlich billiger ift. (Ein Fünfkilo-Poftpaket mit ca. 50 Auftern koftet inklufive Porto [Expreßzuftellung] 5 Kronen.)

Es wird vielleicht gut angebracht fein, hier noch auf zwei Punkte hinzuweifen. Es ift eine vielfach verbreitete Anficht, daß die Aufter im Frühjahr mit Eintritt ihrer Gefchlechtsreife giftig fei. Diefe Annahme hat fich in der Praxis, insbefondere in Frankreich mit feiner enormen Aufternkultur und feinem bedeutenden Konfum diefer Tiere als vollftändig unrichtig herausgeftellt. Der zweite Punkt betrifft das ambulante Verkaufen von Auftern in Reftaurants in Hafenorten. Vor dem Genuß folcher Auftern kann nicht genug nachdrüdklich gewarnt werden. Denn gerade auf diefem Wege find nachweislich viele jener alarmierenden Erkrankungen an Typhus und fchweren Darm- 
zuftänden erfolgt, welche begreiflicherweife das Publikum mißtrauifch und ängftlich machen. Die Gefährlichkeit folcher ambulant in der Stadt verkauften Auftern hängt damit zufammen, daß die von Speifehaus zu Speifehaus ziehenden Aufternverkäufer ihre Ware, die von Haus aus vollftändig tadellos fein kann, meift im fhmutigen Hafenwaffer deponieren und hier ift dann der Ort, wo die Tiere nur zu leicht fhädliche und gefährliche Keime in fich aufnehmen und fefthalten. Diefen Zuftänden, die bedauerlicherweife ein aufblühendes Gewerbe, wie es die Aufternzucht in der Adria ift, vollftändig in Mißkredit bringen können, wäre nur durch eiferne Strenge zu begegnen. Würde bei nachweislicher Erkrankung durch den Genuß von Auftern der betreffende Verkäufer derfelben ftreng geftraft und ihm die Verkaufslizenz entzogen werden, fo würden folche Fälle ausgefchloffen fein. Vor allem müßte natürlich das Deponieren von Auftern in Häfen ausdrüdklich verboten werden.

Es foll hier endlich noch darauf aufmerkfam gemacht werden, daß fich auch in der Aufter Perlen entwidkeln und man achte daher beim Genuß diefer Tiere auf diefe Möglichkeit, und weiter, daß in diefer Mufchel, wie auch in der Pinna nicht felten eine kleine weichfchalige Krabbe (Pinnotheres) (Fig. 76) als Mietswohner angetroffen wird.

Nebft der Aufter erbeutet das Schleppnety in dem in Rede ftehenden Gebiete von Mufcheltieren nicht felten die Pilger$\mathrm{mufhel}$, und zwar in zwei Arten, die Jakobspilgermufchel (Pecten jacobäus) (Fig. 113) und (Pecten glaber). Beim Vergleiche beider Arten fällt zunäch̊t auf, daß die erftere eine gewölbte und eine dedkelartig flache Schale und die zweite Spezies zwei fymmetrifch gebaute Schalen befitzt. Während fich die gleichklappigen Pilgermufcheln mit Hilfe von Byffusfäden an Gegenftänden verankern können, fehlt diefe Fähigkeit der großen ungleichklappigen Jakobspilgermufchel im erwachfenen Zuftande. Sie lebt am Meeresgrunde liegend, und daraus und aus ihrer relativen Größe erklärt fich wohl die ungleiche Ausbildung der Schalen, eine Eigentümlichkeit, die auch der Aufter und einigen anderen Mufcheln mit einer an der Unterlage feftgewachfenen Schalenklappe zukommt. 
Den Mufcheln fehlen Sinnesorgane, wie fie fonft den Weichtieren in Form von Fühlern und Augen am Kopfe eigen find. Der Mangel folcher Kopforgane bedingt, daß diefe Tiere keinen befonders abgefetzten Kopfabfchnitt äußerlich erkennen laffen und die Urfache für diefen Mangel fteht im Zufammenhang mit der vorwiegend grabenden Lebensweife im Meeresgrunde. Eine Anzahl von Formen befiten aber doch Augen und zwar in Vielzahl und merkwürdigerweife am Mantelrande; fo auch Pecten. Diefe Mantelrandaugen zeigen in einzelnen Fällen eine fo hohe Entwidklung, daß man von ihnen auch eine entfprechende phyfiologifhe Leiftung vorausfetzen kann. Durch rafches Zufammenklappen der Schalenhälften können diefe Tiere fprungartig durch das Waffer fhießen und auf diefe Weife rafch den Ort wechfeln.

In den nächiften Abfätzen follen einige Formen behandelt werden, welche in das Gebiet der Zofterawiefen zur Zeit der Gefchlechtsreife zur Ablage ihrer Eier in großen Mengen einwandern. In der übrigen Zeit des Jahres leben diefe Tiere $\mathrm{da}$ und dort verftreut, befonders im Winter in benachbarten tieferen Gebieten des Meeres.

Im Meeresgrunde eingegraben und diefen durchwühlend findet man die Kugelfchnedke (Acera bullata). Bemerkenswert ift an dem Tiere die floffenartige Verbreiterung des Fußes, welcher nach oben gefchlagen die dünnwandige Schale einhüllt. Mit Hilfe diefes Flügelfußes vermag das Tier durch das Waffer zu fchwimmen und der Anblidk einer folchen fawimmenden Schnedke erinnert dann an die Bewegungen einer Serpentintänzerin.

Verwandt mit der eben erwähnten Schnedxe ift die Tethys (Fig. 102), aber in der Form ganz abweichend und höchft auffallend geftaltet. Für gewöhnlich bewohnt fie die Flachküfte, am Meeresgrunde hinkriechend, aber zu gewiffen Zeiten erfheint fie pelagifch und ift dann mit ihren fchwerfälligen Schwimmbewegungen eine höhift merkwürdige Erfheinung im blauen klaren Meerwaffer. Eine einzige Schnedke im Netze verrät ihre Anwefenheit, ehe fie noch entdedkt ift, durch den eigenen mofchusartigen Geruch. Ihr Körper ift gallertig durch- 
Figur

\section{Tafel XI}

84. Käferschnecke (Chiton). Länge $3-5 \mathrm{~cm}$, Färbung grüngrau. Diefes intereffante Weichtier lebt in der Region der Felfenküfte und des Mufchelfandgrundes.

85. Schlitzschnecke (Fissurella) (S. 73). Länge bis $5 \mathrm{~cm}$.

86. Schlitzschnecke (Fissurella italica) (S. 73). Schale von oben gefehen mit dem zentralen Loche.

87. Seeohr (Haliotis tuberculata) (S. 73). Länge 5 bis $8 \mathrm{~cm}$.

88. Napfschnecke (Patella tarentina) (S. 79), am Felfen haftend.

89. Uferschnecke (Litorina) (S. 81). Höhe 10-25 mm.

90. Cerithium vulgatum (S. 21). Länge $7 \mathrm{~cm}$.

91. Turmschnecke (Turitella) (S. 99, 100). Länge $8 \mathrm{~cm}$.

92. Pelikanfuß (S. 100), mit dem Tiere von der Mündungsfeite der Schale aus gefehen.

93. Pelikanfuß (Aporrhais pes pelecani) (S. 100). Leere Schale von der Rüdkfeite aus gefehen.

94. Tonnenschnecke (Dolium galea) (S. 89) ift die größte Schnecke des Mittelmeergebietes. Höhe $20-25 \mathrm{~cm}$; Gehäufe braungelb.

95. Helmschnecke (Cassidaria echinophora) (S. 89). Höhe 7-11 cm.

96. Brandhorn (Murex trunculus) (S. 55). Höhe 7-8 cm, hell und braun gebändert.

97. Stachelschnecke (Murex brandaris). Höhe $8-10 \mathrm{~cm}$, die Länge der Stacheln variiert je nach dem Meeresgrund, auf welchem fie leben. 
Tafel XI
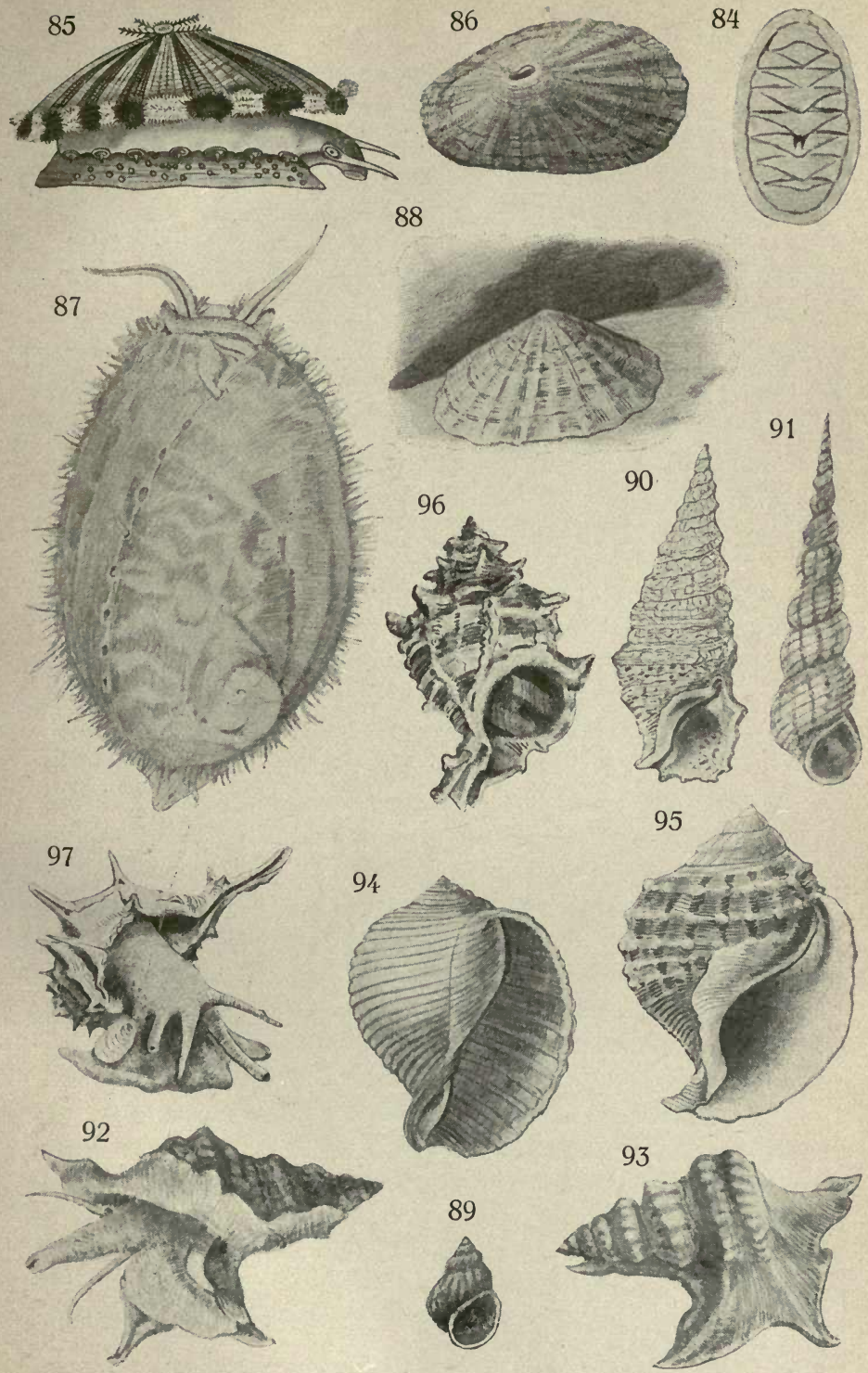


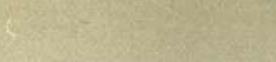


fheinend und auf diefem opaken Untergrunde bringt die fchwarze und rote Pigmentierung der lappenartigen Rüdkenanhänge eine ftarke Kontraftwirkung hervor. Der Kopf erfcheint durch riefige gefrante Lippen lappenartig verbreitert und der Fuß zeigt eine breite Kriechfohle. Nicht minder auffallend ift ferner die Erfcheinung, daß die erwähnten Rüdkenanhänge, die wahrfcheinlich der Hautatmung dienen und die fehlenden Kiemen zu erfetzen haben, fchon auf geringe Reize hin abgeworfen werden. Diefe riefige Nadktfchnedke, die eine Länge bis $30 \mathrm{~cm}$ erreichen kann, zeigt auch fonft noch andere Abweichungen von ihrem Typus. Es foll diesbezüglich nur hervorgehoben werden, daß ihr der Kauapparat, die fogenannte Schnedkenzunge, fehlt, und doch fheint das Tier ein arger Räuber zu fein, denn wir fanden wiederholt ihren geräumigen Magen mit Jungfirchen vollgepfropft.

Im Sediment des Grundes verftedkt liegt die Sand garneele (Crangon vulgaris) (Fig. 63) auf Beute lauernd, und fie ift ein lehrreiches Beifpiel für die Anpaffung an die Umgebung durch die Form des Kolorits.

Aus der Gruppe der wandernden Grundtiere kann uns weiter die S e pia (Sepia officinalis) (Fig. 117) intereffieren. Wenn man im Frühjahr den Fifchmarkt von Trieft oder Venedig befucht, fo findet man auf demfelben oft faft nichts anderes als große Mengen von weißlichen Körpern, in einer fhwarzen Sauce liegend auf den Verkaufsftänden ausgebreitet, es find Sepien, die mit großen Schleppnełzen im Zofteragebiet erbeutet wurden. In guten Fangjahren beträgt die Menge der auf dem Triefter Fifchmarkt ausgebotenen Sepien weit über hunderttaufend Kilogramm! Dem Binnenländer erfcheinen diefe Meeresprodukte höchft unappetitlich und doch finden fie reißenden Abfaty als billiges Volksnahrungsmittel. Wer fich dann mit einigem Ekel davon abwendet, weiß nicht, daß er einen Vertreter einer Tiergruppe von hohem Alter und einer reichen Gefchichte vor fich hat. Die Tintenfifche find uns bereits in den älteften foffilienführenden Schichten, dem Silur und Devon bekannt, und die riefigen Ammoniten repräfentieren vielleicht die Glanzperiode ihrer Entwidklung. Man kennt bis 
jetst über 4500 ausgeftorbene Arten, und diefen ftehen kaum 200 lebende Spezies gegenüber. Alfo eine große Vergangenheit und ein unverkennbarer Niedergang! Doch das ift ja der Lauf der Dinge. Wird das Menfchengefchlecht einftmals eine folche Lebensdauer aufweifen können?

Während des größten Teiles des Jahres lebt die Sepia verftreut auf den tieferen Schlammflächen, und erft im Frühjahr erfcheint fie dann im Gebiete der Flachküfte, um hier ihre Eitrauben an Algen und anderen paffenden Gegenfänden abzulegen (Fig. 120). Jedes $\mathrm{Ei}$ hat die Form einer in eine ftumpfe Spitze auslaufenden Beere, und feine fchwarze Farbe fheint von einem Uberguß bezw. von einer Beimifchung des Tintenextraktes, mit welchem das in Rede Atehende Tier in reichem Maße verfehen ift, herzurühren. In einer dicken gallertigen Hülle gefhïtt liegt dann das eigentliche $\mathrm{Ei}$, aus welchem fich im Verlaufe einiger Wochen ein kleiner Tintenfirch entwidkelt. Es ift dann ein fehr anziehendes Bild, diefes etwa ein Centimeter lange Junge, das fich bereits ganz wie die Alten gebärdet, durch Zerzupfen der Eihüllen zu ifolieren und in einer Glasfchale zu beobachten. Eine Lupe leiftet hierbei fehr gute Dienfte. Den Tintenfirchen verleiht in Zufammenhang mit ihrer befonderen Körpergeftalt und den beweglichen Fangarmen die Eigenfchaft, das Kolorit rafch und lebhaft wechfeln zu können, ein ganz eigenartiges und dämonifches Ausfehen. Das Wechfeln der Farbe wird durch eigene Farborgane in der Haut hervorgerufen, die das Tier durch Ausdehnung dunkler, durch $\mathrm{Zu}$ fammenziehen aber heller erfcheinen laffen. Die Zeichnung und das Kolorit wechfelt mit der jeweiligen Stimmung und dem Erregungszuftande der Nerven, und fo fpiegelt fich fozufagen die Seele der Sepia auf ihrer Haut ab.

Das Vermögen des Farbenwechfels hat hier eine doppelte Bedeutung im Leben diefer Tiere. Sie können fich dadurch fehr vollkommen dem allgemeinen Helligkeitswerte und der Farbe der Umgebung anpaffen und werden dann von ihren Feinden, den Haififchen und Delphinen fchwerer gefunden, wie fie andererfeits dadurch ihren Beutetieren gegenüber gut gedeckt erfcheinen. Ein wirkfamer Schuts und ausreichende Nah- 
rung find ja die wertvollften Faktoren für die Erhaltung einer Art in der Konkurrenz mit anderen Tieren.

So wie bei anderen Tieren fteht die Erfheinung des Farbenwechfels auch bei den Tintenfifchen in enger Beziehung zum Auge und diefes Phänomen verfchwindet fofort, wenn der $\mathrm{Zu}$ fammenhang diefes Organes mit dem übrigen Körper aufgehoben ift. Die Mundmaffe der Schnedken, die fogenannte Radula, der Kauapparat diefer Tiere, hat bei der in Rede ftehenden Gruppe noch eine Vervollkommnung durch die Ausbildung zweier Hornkiefer erfahren, die einem Papageifchnabel ähneln. Dadurch find die Tiere imftande, felbft den harten Panzer der Krebfe, ihrer Hauptnahrung, zu eröffnen, um dann die Muskelfubftanz und inneren Organe derfelben vollkommen auszunagen. Eine gefangene Sepia wehrt fich auch mit ihren Kiefern und beißt in die Hand blutende Wunden, wenn man fie nicht gefahidkt faßt. Die am Nehrungsftrande häufig ausgeworfenen Sepienfchulpen liegen im Tiere ganz in der Haut verftedkt und fie find die kümmerlichen Refte der einft fo anfehnlichen Ammonitenfchale.

Die Sepia ins kleinfte überfett ftellt uns die Sepiola (Sepiola Rondeletii) (Fig. 118), einer der kleinften Tintenfifche, dar, den man nicht felten im Gebiete des Flachftrandes mit dem Schleppnetze fängt. Man bringe diefes zierliche Tierchen in ein Aquarium, um fein Gebaren zu beobachten.

Am Nehrungsftrande begegneten uns fchwammartige Ballen, die eigentlich aus lauter zufammengeklebten Hornkapfeln beftanden. Es handelte fich um die Klumpen von Eikokkons der Stachelfchnedke oder des Brandhornes (Murex brandaris und trunculus), ital. Garufa (Fig. 96, 97), welche im Frühjahr die Küftengebiete zur Ablage der Eier auffucht. Die oft anfehnlich großen Maffen diefer Kokkons werden nicht von einer einzigen Schnedke abgelegt, fondern diefe Tiere fharen fich zum Laichen zufammen, und fo kommt es dann zu einer derartigen maffenhaften Vereinigung ihrer Eikapfeln. Jede folche Kapfel enthält die kleinen Eier in größerer Anzahl, die fich zu fpäter freifchwimmenden Larven entwickeln. Die eine Art, Murex brandaris, befittt ein ftacheliges Gehäufe, das, je nachdem die Tiere 
im weichen Schlamm leben, mehr ftumpftachelig ift oder bei der Lebensweife im härteren Mufchelfande mehr dünnfpitzige und längere Stacheln zeigt. Diefer Stachelbefats wird als eine Schutgeinrichtung betrachtet. Murex trunculus hat an Stelle folcher Stachelfortfätse nur Wülfte und Budkeln, dafür aber ein bedeutend didkwandigeres Gehäufe. Sobald die Tiere irgendwie gereizt werden, ziehen fie fich augenblicklich in das Innere der Behaufung zurüdk und verfchließen die Offnung mit einem hornigen Dedkel, der auf der Rüdkenfeite des Fußes feftgewachfen ift und der bei den meiften marinen Gehäufefchnedken angetroffen wird. Diefe Tiere haben den klaffifchen Völkern, den Griechen und Römern, den Purpurfarbftoff geliefert, deffen Entdedkung nach der Sage bekanntlich durch einen Hund erfolgt fein foll, indem diefer von einer am Strande liegenden Purpurfahnedke feine Schnauze rot gefärbt erhielt. Alles fpricht eigentlich gegen die Richtigkeit diefer Uberlieferung. Eher hat die Zubereitung und der Genuß der Tiere zur erwähnten Entdedkung die Veranlaffung gegeben. Den Purpur liefert nämlich eine in der Kiemenhöhle liegende Drüfe in Form eines gelblichen Sekrets, das erft unter der Einwirkung des Sonnenlichtes einen roten bis blauvioletten Farbton annimmt. Die Methoden, wie in klaffifchen Zeiten der Purpurfarbftoff aus den genannten Tieren gewonnen wurde, find verloren gegangen, aber jedenfalls war auch damals die Gewinnung desfelben eine mühevolle und zeitraubende Arbeit, da felbft eine große Anzahl von Schnedken nur fehr wenig Farbfubftanz liefert. Die Murex if ein fo häufiges und leicht erlangbares Tier, daß es bei einem Aufenthalt am Meeresftrande gewiß nicht fowwer ift, felbft den intereffanten Vorgang der Bildung einer Farbe unter dem Einfluffe des Lichtes einmal zu verfolgen. Hierzu ift nichts anderes nötig, als die Schnedkenfhale vorfichtig zu zertrümmern und dann die feine durchfheinende Haut der Kiemenhöhle oberhalb des Kopfes mit einem einfachen Tafchenmeffer zu fchliţen. Dann fällt fofort der gelbliche Drüfenftreifen neben der federförmigen braunen Kieme auf, deffen fchleimiges Sekret nur abgeftreift und auf ein Stüdkchen Stoff oder Papier ausgebreitet und dem Sonnenlichte ausgefetyt zu werden braucht. 

Figur

\section{Tafel XII}

98. Wurmschnecke (Vermetus arcuarius) (S. 73), auf einem Steine feftgewachfen. Das Tier gelb bis rotbraun gefärbt. Länge der Schale bis $10 \mathrm{~cm}$.

99. Flankenschnecke (Pleurobranchus aurantiacus) (S. 89). Länge $4 \mathrm{~cm}$, Farbe hell- bis dunkelrot.

100. Seehase (Aplysia punctata) (S. 57). Länge $10 \mathrm{~cm}$. Färbung olivgrün mit helleren Fledken.

101. Sternschnecke (Doris Johnstonii) (S. 73, 89). Länge $4 \mathrm{~cm}$, auf hellerem Grunde braun gefledkt. Die ihr verwandte Schnedke Doriopfis ift von weicherer Befchaffenheit des Körpers und dunkelbraun bis fchwarz gefärbt.

102. Tethys leporina (S. 52). Länge bis $30 \mathrm{~cm}$.

103. Phyllirrhoe bucephalum (S. 120). Länge $2-3 \mathrm{~cm}$.

104. Kielschnecke (Carinaria mediterranea) (S. 119). Länge bis $20 \mathrm{~cm}$.

105. Herzmuschel (Cardium edule) (S. 34). Länge $2-4 \mathrm{~cm}$. Schale hellgelb mit roftbraunen, paralell zum Rande verlaufenden Streifen. 
Tafel XII
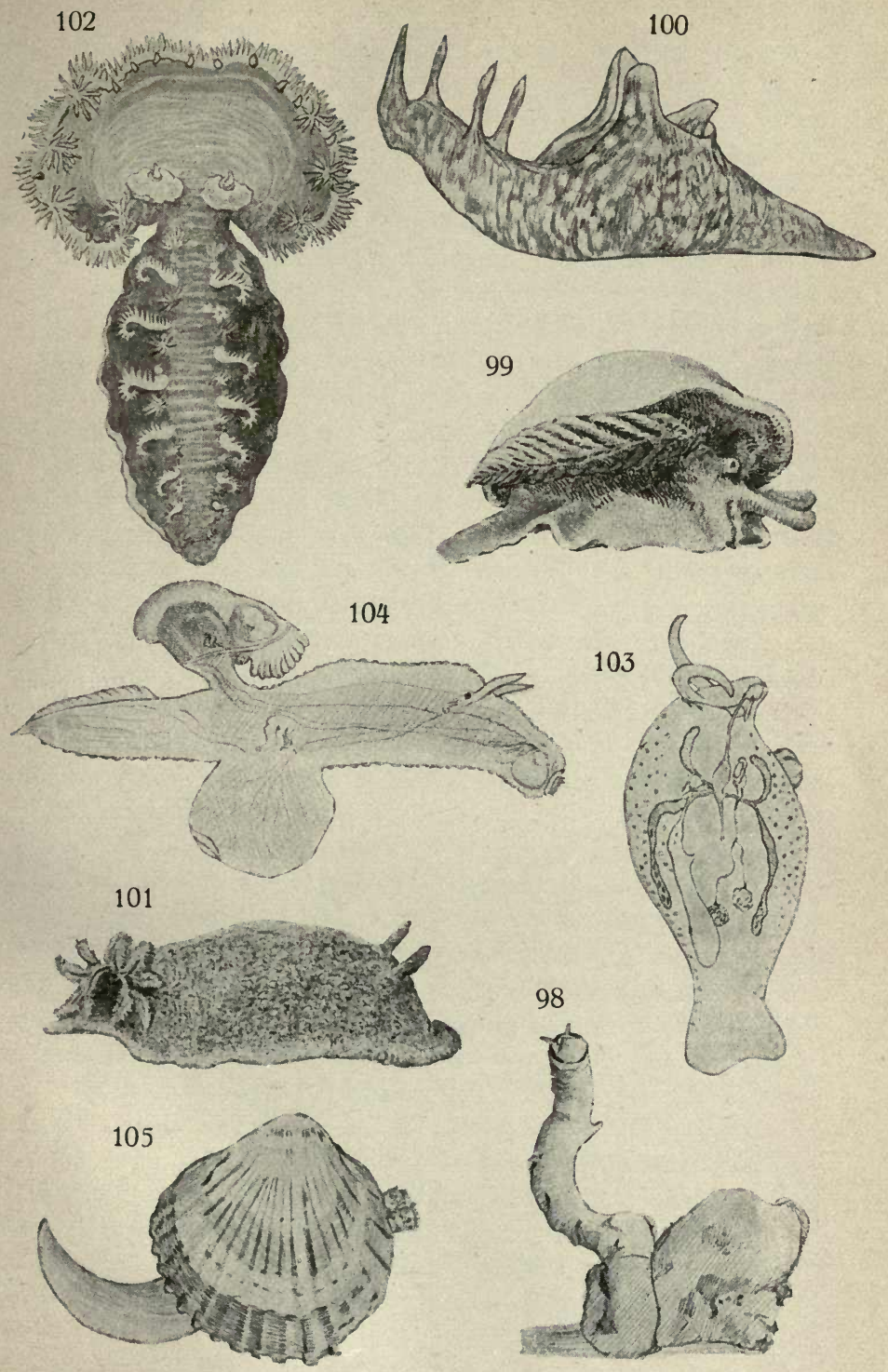

Von der Bevölkerung der Mittelmeerküften wird die befagte Schnedke gekocht genoffen, doch find fchwere Vergiftungserfcheinungen nach dem Genuffe derfelben wiederholt vorgekommen und deshalb find fie an manchen Hafenplätzen vom Marktverkehr ausgefchloffen.

Der Seehafe (Aplysia) (Fig. 100), eine Schnedke mit einem rudimentären in der Haut verftedkten Gehäufe, kommt ebenfalls zum Ablegen feiner durchfcheinenden bräunlichen Eifchnüre in die Flachküfte. Nach Abfolvierung diefes Gefchäftes fterben merkwürdigerweife diefe Tiere. Es fei ferner noch darauf hingewiefen, daß die Aplyfia gereizt einen weinroten Saft fezerniert, der aber nichts mit dem Purpur zu tun hat.

Aus den bisherigen Ausführungen diefes Kapitels ergibt fich, daß die Fauna der niederen wirbellofen Tiere das Gebiet der Zofterarafen in fehr weitgehender Weife ausnütst, indem fie nicht bloß die Waffermaffe bis zum Grunde, fondern auch diefen felbft bewohnen. Ahnliches zeigen, auch nicht wenige Vertreter aus der arten - und geftaltungsreichen Klaffe der Fifche. Ein Teil derfelben bewohnt die oberflächlichen Wafferfchichten, ein anderer fucht Schuts im Pflanzenwuchs, wieder andere führen ein temporär feffiles Leben, dann gibt es am Grunde lebende Formen und endlich folche, die fich in denfelben eingraben.

Die die oberflächlichen Wafferfchichten belebenden Fifche find zum Teil folche, welche eigentlich Hochfeeformen find und nur zeitweife in Küftennähe kommen, wie die verfhiedenen häringsartigen Fifche (Sardellen), die Makrelen und andere. Wir wollen ihrer vor der Hand nur dem Namen nach Erwähnung tun und kommen fpäter noch einmal auf fie zurüdk. Dagegen find für diefes Gebiet eine Anzahl Fifche, die wir als Strandfirche bezeichnen, charakteriftifch. Einige von diefen haben wir fhon im Lagunengebiet kennen gelernt, wie den Wolfsbarfch (Fig. 150), die Goldbraffe (Fig. 152) und die Meerärchen (Fig. 154, f. S. 29). Letztere bilden gewöhnlich Gefellfchaften, die entlang der Küfte des Zofteragebietes hin- und herftreichen, während die beiden anderen Gattungen mehr folidär leben. $\mathrm{Zu}$ den eigentlichften Strandfifchen gehören: 
die artenreiche Familie der Braffen (Fig. 151), ferner die Lippfirche (Labridae) (Fig. 182), welch lettere fich befonders durch ihre bunte lebhafte Färbung auszeichnen, dann die Bartumber (Umbrina cirrhosa) (Fig. 166) und der Seerabe (Corvina nigra) (Fig. 167). Die in Schwärmen auftretenden Ahrenfifche (Atherina) (Fig. 160) gehören auch in diefe Kategorie. Bei einem längeren Aufenthalte am Meere wäre dem fich für die Fifchfauna intereffierenden Naturfreund fehr zu empfehlen, im Zofteragebiete der Flachküfte mit Fifchreufen (lokal Naffe genannt), zu filchen. Es ift dies eine einfache faft mühelofe Fifchereimethode während der warmen Jahreszeit, die den Vorzug hat, lebendes und ganz unverlettes Material, wie man es für Sammlungen wünfht, zu erhalten. Der Gruppe der Strandfifche werden wir nochmals begegnen im Gebiete der Felfenküfte.

Eine andere Gruppe von Fifchen führen eine zeitweife feftfitzende Lebensweife, indem fie fich mit ihrem floffenlofen Widkelfchwanz an Seegrashalmen, Algenftengeln ufw. verankern. Wir denken dabei an die Se epferd ch en (Hippocampus) (Fig. 181), und in jener Gepflogenheit diefer Tiere läßt fich eine Parallelerfcheinung mit der Spadella (f. S. 43) erkennen, die fich durch zeitweifes Feftkleben an der Unterlage zum feffilen Tier madht. Zur felben Ordnung der fogenannten Büfchelkiemer gehört noch ein zweiter im felben Gebiet lebender Firch, nämlich die Seenadel (Syngnathus, Nerophis). Wenn folche Tiere im Waffer zwifhen den Zofterazweigen bewegungslos ruhen, ift es wirklich nicht leicht, fie vermöge ihrer Körperform von den Zofterablättern und Algenbüfcheln zu unterfcheiden. Beide genannten Fifche focwimmen wenig und verhalten fich vorwiegend ruhig im Schute der marinen Vegetation. Nur, wenn fie irgend ein kleines Krebschen erhafchen wollen, werden fie etwas lebhafter. Bemerkenswert ift die Brutpflege bei diefen Tieren. Hier find es die Männchen, welche diefes Gefhäft übernommen haben. Sie befitzen nämlich auf der Bauchfeite eine fadkartige Tafhe (beim Seepferdchen) bezw. eine Rinne (bei der Seenadel), in welcher fich dann die vom Weibchen dahin abgelegten Eier entwidkeln, fo 
daß fchließlich die kleinen winzigen Seepferdchen und Seenadeln bereits vollkommen entwidkelt vom Männchen geboren werden. Die Brutpflege ift hier eine Erfcheinung, welche mit der halbfeffilen Lebensweife der genannten Fifche in $\mathrm{Zu}-$ fammenhang fteht.

Als Grundfifche diefes Gebietes wären zu nennen der Drachenk opf (Scorpaena) (Fig. 157), ferner verfchiedene Arten der Meergrundel (Gobius), die Schleimfifche (Blennius) (Fig. 159) und die Meerquappe (Motella). Diefe Tiere liegen faft ftändig am Meeresgrunde und fpähen nach Beute aus. Im Zufammenhang mit diefer Lebensweife ift ihr Körper durchweg mehr weniger breit und abgeplattet, die Augen find nach oben gerichtet und die Mundfpalte breit. Mit ihrem Kolorit erfcheinen fie fehr gut der Umgebung angepaßt. Die Scorpaena hat außerdem den Körper mit vielen kleinen Hautläppchen, die Algenftödxchen ähneln, befetyt. Das träge Liegen am Meeresgrunde hat alle diefe Fifche zu wenig ausdauernden Schwimmern gemacht. Manchen fehlt fogar die Schwimmblafe. Beim Durchfuchen des Netzinhaltes aus diefem Gebiete heißt es jedoch acht geben, daß man nicht unverfehens in zu innige Berührung mit dem Drachenkopf kommt, der etwa unter den erbeuteten Algen und Zofterablättern verftedkt liegen könnte. Berührt man ihn, fo fchlägt er um fich, bläht fich auf und fpreizt feine Stacheln nach allen Seiten. Bohren fich letztere in die Haut ein, fo impfen fie dann ein giftiges Sekret mit ein, fo daß die Wunde heftig fhmerzt und der betroffene Körperteil anfchwillt. Beim Baden befteht daher die Gefahr, am Fuße von diefem oder von einem anderen giftigen Fifch, dem ebenfalls im Grunde vergraben liegenden Petermännchen (Trachinus) (Fig. 158) verwundet zu werden. Der Befits von Giftdrüfen in Verbindung mit Stacheln und die Wehrftellung durch Aufblähen muß als eine Schutgeinrichtung gegen Feinde angefprochen werden. Intereffant ift, daß das Spreizen der Stacheln und die Annahme der Schredkftellung durch Reize am Schwanze ausgelöft wird, während der Kopf in diefer Beziehung faft unempfindlich erfcheint oder erft auf viel ftärkere Reize reagiert. Bei den Gobiiden entftand durch 
Verwachfung der Bauchfloffen ein Haftorgan zum Verankern an Steinen und dergleichen. Die leţtgenannten Fifche und die Blenniiden kleben ihre Eier an Gegenfänden am Meeresgrunde an, fo daß die ausfchwärmende Brut gleich wieder diefe günftigen Gebiete bevölkern kann.

Ahnlich jenen Formen, wie die Sandgarnelle u. a. gräbt fich das eben genannte Petermännchen in den Sand ein und lugt nur mit feinen Augen hervor. Von den Fifchern wird diefes Tier wegen feiner giftigen Stacheln am Kiemendedkel und im Gebiete der erften Rückenfloffe noch mehr gefürchtet als die Skorpäna. Ganz unfchuldig dagegen ift das Bartmännchen (Ophidium) (Fig. 173), ein etwa $30 \mathrm{~cm}$ langer, bandförmig fchmaler und rot gefärbter Fifch, der fich bei Tage im Meeresgrunde verftedxt hält und fonft eine nächtliche Lebensweife führt. Das Eingraben bewirkt er fo, daß er fich mit feinem Schwanze zuerft in den weichen Grund einbohrt, und fo verfchwindet das Ophidium ziemlich fchnell, und nur der Kopf, deffen große Augen und deffen fonftiger Habitus an Tieffeefifche erinnert, fchaut aus dem Grunde heraus. Während beim Petermännchen das Eingraben in den Meeresgrund die Bedeutung hat, feine Beutetiere aus dem Hinterhalte leicht überfallen zu können, denn bei dem gering entwidkelten Schwimmvermögen wäre eine andere Art des Nahrungserwerbes erfhwert, gewährt dem wehrlofen Bartmännchen das Einwühlen Schuts. 


\section{V. \\ DIE FELSENKUSTE.}

W enn wir bisher vom Nehrungsftrande, von Zofterawiefen, von der Felsküfte im Sinne von Lebensbezirken fprachen, fo möchte betont werden, daß fich diefe Gebiete nicht immer fcharf voneinander abgrenzen laffen, fondern oft Ubergänge zeigen oder nebeneinander vorkommen. Dies hängt damit zufammen, daß hierbei nicht allein das geologifhe Subftrat, fondern auch die geographifche Befchaffenheit maßgebend ift. Bei der Schilderung fchweben uns natürlich immer beftimmte Ortlichkeiten vor, die wir aus eigener Anfchauung kennen und welche einen jeweiligen Typus möglicht fcharf zeigen. Wenn wir nun daran gehen, die Felsküfte und ihre Lebewelt zu fchildern, fo denken wir uns in das Gebiet der Weftküfte Iftriens mit den vielen Infeln, Felsriffen und Untiefen verfetyt, wo einmal vor geologifchen Zeiten am Ende der Kreidezeit ein reiches Strandleben florierte. Wir brauchen nur dem Felsblodke, von welchem aus wir voll Bewunderung die bunte Fülle der vielen Tier- und Pflanzenformen in dem herrlich blauen, kriftallklaren Waffer betrachten, ein wenig Aufmerkfamkeit zu fchenken, und da gewahren wir eine Menge Folfilien, oft förmlich eine neben die andere gefchichtet. Sie fagen uns, daß damals hier Flachfee war, die einer individuenreichen Mufchelart, den Rudiften, günftigen Boden zu reicher Entfaltung gewährte. Dann folgte für diefes Gebiet eine lange Periode der Feftlandszuftandes, und nun branden Wogen eines neuen jungen Meeres am alten Strande. So find gerade die Randpartien der Meere folchem fortwährenden geologifchen Wechfel unterworfen.

Die Nehrungsküfte, die Zofterawiefen und die Felskülte find alfo eigentlich nur fpezialifierte Gebiete der Flachfee, die Johann Walter mit dem Ausdrudk Schorre bezeichnet, aber vielleicht 
in keinem Teil der lełteren find die äußeren Lebensbedingungen fo mannigfaltig als an dem Felsftrande. Während der Nehrungsftrand mit feiner fanften Böfchung und feinem gefchmeidigen Sandgrund förmlich befänftigend auf die heranrollenden Wogen einwirken muß, fordert die fefte Umrahmung des Meeres durch ftarren Felfen diefes zu ftändigem, heftigem Angriff heraus und tatfächlich wogen, ftürmen und tofen nirgends fo die Wellen, wie gerade am felfigen Strande. Das Profil des letzteren ift gewöhnlich ein fteiles, da hier das Meer mit feinem immer wieder erneuerten Anfturm wie mit Meißel und Hammer fenkrecht das fefte Material bearbeitet und eine fteil abfallende Mauer mit Hohlkehlen und Nifhen herftellt. Dazu kommen noch die fich täglich zweimal durch die Wirkung von Ebbe und Flut einftellenden Verfchiebungen der Wafferlinie. Alfo wir können es gleich fagen, die faft fortwährende Bewegung ift das Hauptmerkmal des Gebietes. Ausmündende Flußläufe find entlang der Weftküfte Iftriens und an der dalmatinifhen und griechifchen Küfte eine Seltenheit. Dem Waffer werden alfo hier wenig Sinkftoffe beigemengt, und daher ift das Waffer von einer kriftallklaren Durchfichtigkeit. Es laffen fich beifpielsweife Ortlichkeiten finden, wo man noch in 40 Meter tiefem Waffer weiße Felsblödke als helle Fledke unterfcheiden kann. Aus diefem Grunde kann das Licht viel bedeutendere Tiefenwirkung entfalten als z. B. im dem Gebiete des Triefter Golfes mit feinem an Sinkftoffen reicheren Waffer. Im Gegenfats zum Flachftrande wird an der Felsküfte das Meerwaffer nicht fo intenfiv erwärmt, da die Wafferfäule eine mächtigere ift und durch die fortwährende Bewegung eine ftändige Mirchung der oberflächlichen und tieferen Wafferfhichten erfolgt.

Wir haben bereits am Nehrungsftrande die Wirkung der Anziehungskraft von Mond und Sonne auf die Waffermaffe des Erdmeeres als Ebbe und Flut kennen gelernt und durch die zeitweife Entblößung der flachen Sandküfte müffen fich die meiften Tiere mit dem Sinken des Waffers zurüdkziehen, während andere in den Sand ftändig eingegraben den Tiefftand des Waffers zur Ebbezeit fchadlos überdauern. An der Felsküfte find die Verhältniffe auch in diefer Beziehung wefentlich andere. 
Wir wollen nun die Lebewelt der Felsküfte kennen lernen und unternehmen deshalb fleißige Wanderungen entlang diefes Gebietes. Wir fehen dann, daß fich in bezug auf das gegenfeitige Verhalten von Meer und Feftland drei Zonen in vertikaler Richtung unterfcheiden laffen und zwar eine ftändig unter Waffer ftehende, die untergetauchte Region; fie reicht bis zur Linie der tiefften Ebbe, dann folgt die auftauchende oder Emerfionsregion, durch den tiefften Ebbe- und höchften Flutftand begrenzt, und endlich die Brandungsregion, die von der Linie der Hochflut fo weit in die Höhe reicht, als bei ftarkem Winde und Sturm das Waffer als Brandungswelle getragen wird.

Wenn wir bisher einfach immer nur von der Felsküfte fprachen, fo erfcheint es doch notwendig, in bezug a uf die Fauna und $\mathrm{Fl}^{\mathrm{l}}$ ora hervorzuheben, daß es fich dabei nicht um einen Lebensbezirk einheitlicher Befchaffenheit handelt, im Gegenteil, hier find die Verhältniffe oft auf kleinem Raume fo wechfelvolle, wie wir es bisher noch nicht kennen gelernt haben. Wie Licht und Schatten fharf aneinander grenzen, fo gegenfałvoll ift häufig das Bild in Abhängigkeit von den jeweiligen Umftänden.

Wenn im Sommer das warme klare Waffer des Mittelmeeres und der Adria zu einem Bade einladet, fo muß ein folches ein um fo größeres Vergnügen bereiten, fobald man hierbei Gelegenheit hat, das wenig bekannte Leben des Meeres aus nächfter Nähe kennen zu lernen und manch intereffante Beobachtung felbft zu machen. Es ift nur nötig, daß wir unfere Füße mit feften Badefchuhen verfehen, um beim Wandern über die untergetauchten Klippen Verwundungen am fcharfkantigen Felfen, an Murchelfchalen und an den ftacheligen Seeigeln zu vermeiden. Weiter rüften wir uns mit einem fog enannten Gudkfenfter aus, d. i. ein Holzkaften von zirka $30 \mathrm{~cm}$ Seitenlänge und Höhe, deffen Boden aus einer ftarken Spiegelfcheibe befteht. Der Blick ins Meer wird fchon durch jede leichte Bewegung des Waffers getrübt und undeutlich. Um nun folche Störungen $\mathrm{zu}$ vermeiden, verwendet man das genannte einfache Inftrument. Indem man diefes auf die Wafferfläche legt, fezt man dem Meere fozufagen ein Fenfter ein, durch 
welches man mit voller Deutlichkeit alles unter Waffer beobachten kann. Oft hört man von fubmarinen Landfchaften fprechen und ihre fchönen Farben und den Reichtum an Formen fchildern. Mit Hilfe diefes Fenfters hat man aufs Leichtefte und Bequemfte Gelegenheit, dies alles felbft $z u$ fehen. Wir können nicht warm genug diefe Methode der direkten Beobachtung empfehlen, denn auf keine gleich bequeme und einfache Weife ift man imftande, fich fo gut eine Vorftellung von der Bedeutung der Form der Meerespflanzen und -tiere in der Wechfelbeziehung zur Außenwelt zu verfhaffen. Ferner gewinnt man erft ein Bild von der zahlenmäßigen Verbreitung der marinen Tiere und Pflanzen eines Gebietes. Um wieviel fchöner muß

- es allerdings fein, wenn man ausgerüftet mit einem Taucherapparat diefe neue Welt felbft betreten kann. Es möge auch noch hinzugefügt werden, daß die Fifcher zum Glätten des Waffers 01 verwenden, welches auf diefes aufgetropt wird. Steht kein Gudkfenfter zur Verfügung, fo kann man fich diefes Notbehelfes bedienen.

Man beginne folche Studien direkter Beobachtung mittels des Gudkfenfters in der untergetaudten Region, und benütye hierzu die Zeit tiefer Ebbe. Zunächft fällt uns dann auf, (vorausgefetyt ift ein Punkt mit nicht zu heftiger Brandung), daß im Gebiete der Felfenküfte das Pflanzenleben fehr üppig entwidkelt ift und gegenüber den Tieren vorzuherrfchen fheint. Wenn wir uns die Algenbeftände genauer betrachten, läßt fich ferner beobachten, daß diefe nicht gleichmäßig angeordnet find. Dies wird dadurch verftändlich, daß die einzelnen Algenfamilien ähnlich wie die Feftlandspflanzen auf eine gewiffe Lichtintenfität abgeftimmt find und fich daher die Pläłze ihrem Lichtgenuffe entfprechend ausfuchen. Weiter ift zu berüdkfichtigen, daß die einzelnen Strahlen des weißen Lichtes nicht alle gleich tief in das Waffer eindringen, indem die roten Lichtftrahlen bereits in den oberflächlichen Wafferfchichten abforbiert werden, während das gelbe Licht etwas tiefer hinabreicht und das weitefte Gebiet die grünen Strahlen beherrfchen. Der blaue Teil des Spektrums verfohwindet auch fchon in geringeren Tiefen. So kommt es, daß die Rotalgen tiefer hinabfteigen 

Figur

\section{Tafel XIII}

106. Striegelmuschel (Solecurtus strigilatus) (S. 99). Schalenlänge $4-6 \mathrm{~cm}$.

107. Messerscheide (Solen vagina) (S. 12). Länge bis $12 \mathrm{~cm}$, Schalenfärbung gelb bis braun.

108. Archenmuschel (Arca noae) (S. 86). Länge bis $10 \mathrm{~cm}$, Färbung braunrot.

109. Bohrmuschel (Pholas dactylus) (S. 76). Länge $8-12 \mathrm{~cm}$, Färbung der Schale grau. Von einem zweiten Exemplare fieht man aus dem Felfen nur die Siphonen hervorragen. Eine andere felsbohrende Mufchel ift die Meerdattel (Lithodomus lithophagus), welche eine braune Schale mit glatter Oberfläche befitzt.

110. Archenkammuschel (Pectunculus glycimeris) (S. 13). Länge bis $10 \mathrm{~cm}$, Schale braun.

111. Steck- oder Schinkenmuschel (Pinna squamosa) (S. 48). Schale rotbraun und wird bis $80 \mathrm{~cm}$ lang.

112. Pilgermuschel (Pecten varius) (S. 98). Höhe $4 \mathrm{~cm}$. Charakteriftifch für diefe Art ift die feine Riffung der braungefärbten Schale.

113. Jacobspilgermuschel (Pecten jacobaeus) (S. 51), die linke rotbraune Schale ift flach und bildet einen Dedkel für die konkave weiße Schalenhälfte. Die Rippen find breit. Höhe 8-15 cm.

114. Auster (Ostrea cristata) (S. 49). 
Tafel XIII

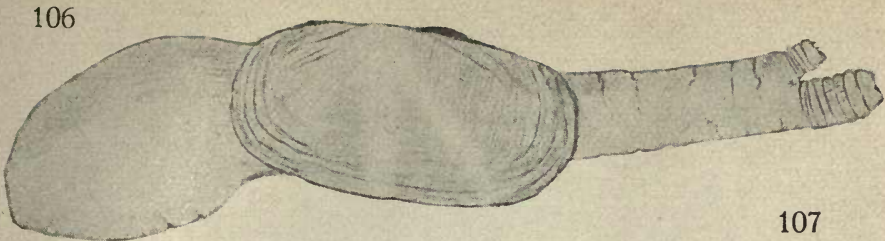

\section{1}

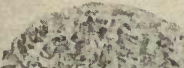
Exy 2 tw

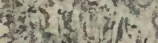
zut a is

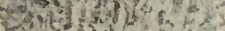
क्षे

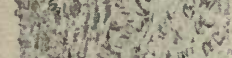
-2t $\mathrm{b}^{3}$ ?

\section{4}

(e) सान की की

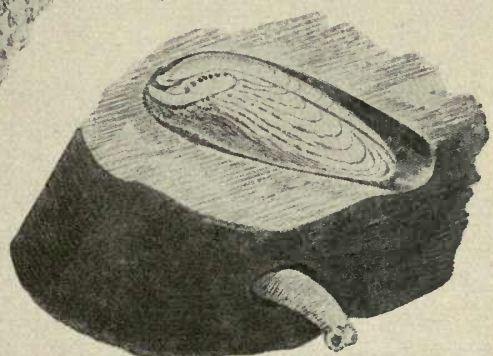

108
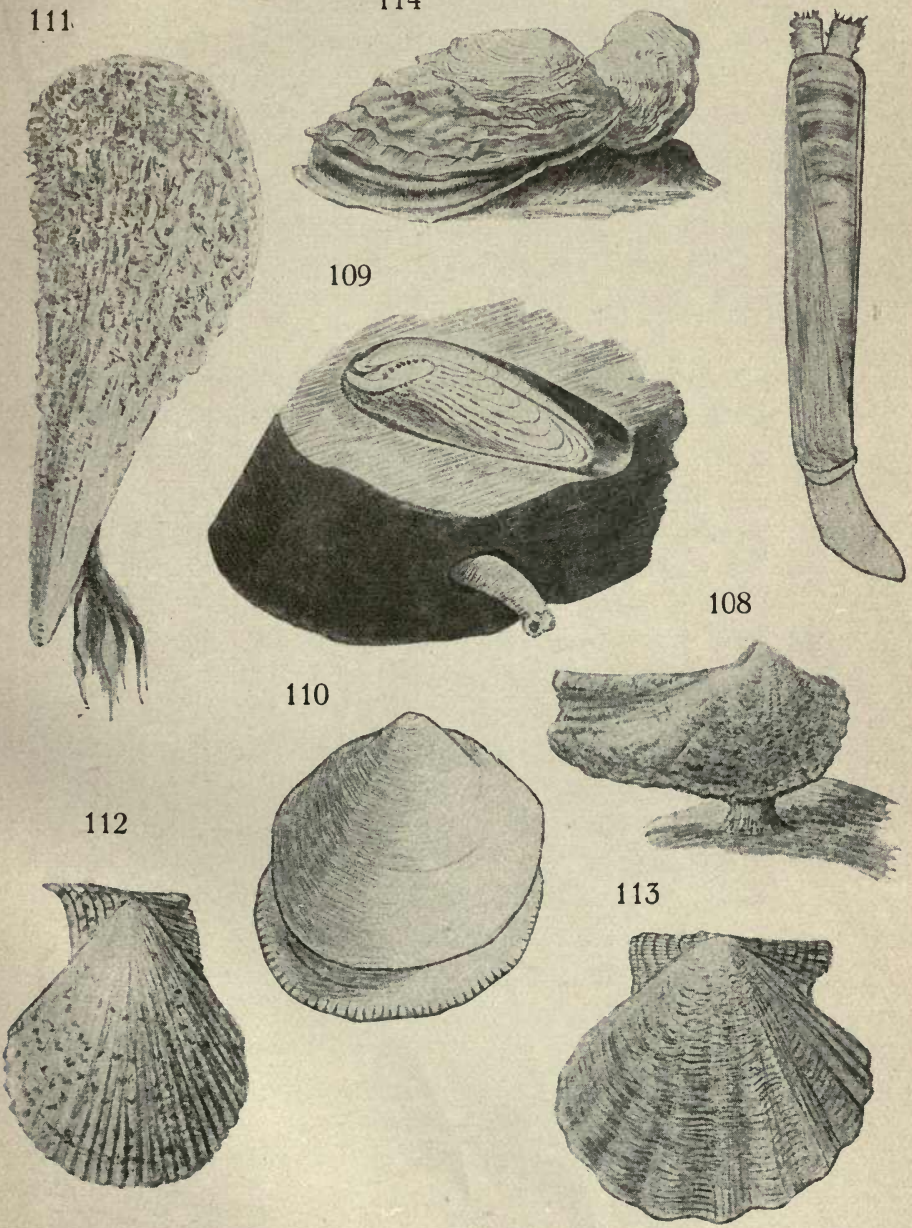
$30,04 x^{2}+3$

39 
können, weil fie auch dann noch die für ihren Stoffwechfel verwertbaren grünen Strahlen finden. Die Grünalgen und Braunalgen dagegen find mehr an die oberflächlichen Wafferfhichten gebunden, weil fie, je tiefer die Waffermaffe wird, defto weniger das für fie in Frage kommende rote Licht vorfinden. Was fich in bezug auf die Verteilung der Algen im Küftengebiet als eine Allgemeinerfcheinung erkennen läßt, wiederholt fich im kleinen an einer einzigen Algenpllanze, an welcher epiphytifh andere Algen wachfen. An den äußeren dem Lichte zugekehrten Zweigen herrfchen wieder Grünalgen, im Innern der Verzweigungen jedoch Rotalgen, als Schattenformen vor. Mit dem Gudkfenfter unterfuche man fpeziell auch Spalten und Klüfte, und man wird dann manchesmal über die Farbenfülle der hier geradezu wuchernden Rotalgen aufs höchfte überrafht fein.

Diejenige Alge, welche in den oberflächlichen Partien der untergetauchten Zone beherrfchend auftritt, welche über meterlang werden kann und in Form dichter waldartiger Beftände überall die Küfte begleitet, ift die Cyftofeira. Im Schutse folcher Cyftofeirawälder herrfcht ein reges und intereffantes Leben. Man wähle deshalb als Beobachtungsort ein Riff zum Niederlaffen am Rande einer fchluchtartigen Spalte, und nun beobachte man die fubmarine Landfhaft mit dem Fenfter. In nächfter Nähe bemerkt man zunächft verfhiedene kleine Fifchchen hin- und herhufchen, die, wenn fie fich niederlaffen, plötlich dem Auge entfchwinden, fo gut ift ihre Zeichnung und Färbung zur Umgebung abgeftimmt. Sie gehören der Familie der Meergrundeln an. Man entdedkt aber auch auffallend rot gefärbte kleine Fifche. Deren Kopf ähnelt dem einer Eidechfe, und fie heften fich mit einer Saugfheibe, die durch Umbildung der Bruft- und Bauchfloffen entitanden ift, an der Unterlage feft; der wiffenfchaftliche Name diefer Fifchchen if Lepadogafter, lokal heißen fie Tacco sasso (Fig. 169). Dann erfcheinen durchfichtige Garneelen und zupfen an ihrer Beute, indem fie die Biffen mit ihren zierlichen Scheerenfüßen zum Munde führen. Je länger man fchaut, defto $\mathrm{mehr}$ an intereffanten Formen erfpäht man. Auch entdedkt man am Felfen zwifchen Cori, Der Naturfreund. 
den Algen blumenartige Gebilde, die roten Kiemenkronen von Röhrenwürmern (Serpula) (Fig. 49, 50), welche fich in eine felbftgebaute Kalkröhre zurüdkziehen können. Ferner fallen eine Menge kleiner zarter Bäumchen auf. An jedem ihrer Zweige fityen kelchartige Gebilde mit einer aus beweglichen Fäden beftehenden Blumenkrone. Aber diefe Dinge haben nichts mit Pflanzen zu tun, es find echte Tiere, es find Tierkolonien, die an der Unterlage feftgewafchen find und die wir Polypen (Fig. 17, 19) nennen. Man übertrage vorfichtig folche Zweighen in ein Glas und betrachte fie mit der Lupe. Ferner entdedken wir Seefcheiden als knollenartige Gebilde mit zwei röhrenartigen Ausziehungen. Um fie vom Felfen loszulöfen, muß man einige Gewalt anwenden. Beobachtet man fie ebenfalls in einem Gefäß mit Seewaffer, fo fieht man bei der einen Offnung das Waffer eintreten und bei der andern wieder ausftrömen. Aus dem Felfen felbft ragen kurze glashelle Röhren hervor, die fich bei Berührung fchließen; fie gehören einem im Felfen bohrenden Schwamm der Vioa (Fig. 11) an.

Bringt man einen Cyftofeiraftodk in ein Gefäß zur genaueren Betrachtung, fo ift man aufs neue überrafht, was für eine Fülle pllanzlicher und tierifcher Formen auf ihm angefiedelt ift, Shwämme, Polypen, Moostierchen, Seefcheiden u. a. Mit der Befchreibung diefer Welt würde man allein einen guten Teil des vorliegenden Büchelchens füllen können. Man beobachte ferner, daß immer die dichtefte Anfiedlung von folchen Formen am Stengel und in der Nähe desfelben, alfo an möglichft gefchützter Stelle ftattfindet. In der Raumausnützung wetteifern alfo Pflanzen und Tiere.

Aber das ift noch lange nicht die ganze Summe aller auf Cyftofeira lebenden Tiere. Um noch andere und zum Teil intereffante Formen kennen zu lernen, beutle man einen folchen vorfichtig aus dem Meere genommenen Algenzweig in einem Gefäß aus, dann wimmelt das Waffer nur fo von einer Menge kleiner W ürmer, von $\mathrm{Krebschen}$ und kleinen blau und gelb geftreiften $\mathrm{Nadkt-}$ fch ne dken, während die vielen Gehäufefchnedken und Foraminiferen zu Boden finken. Alle diefe vielen Formen leben und kriechen auf der genannten Braunalge und finden hier 
Schuts und reiche Nahrung. Aber damit ift immer noch nicht die Kleinfauna der Cyftofeirawälder erfchöptt. Zieht man ein Planktonnets durch diefelben, fo befteht dann der Fang vorwiegend aus kleinen Krebfen und Strudelwürmern, ähnlich wie wir dies in der Zofteraregion fanden.

Laffen wir nun unfere Blidke weiter in die talartigen fubmarinen Felsrinnen fchweifen, fo bemerken wir verfhiedene Fifche, die zum Teil auffallend gefärbt und gezeichnet find. Unter diefen erkennen wir zunächlt eine Gruppe von Wolfsbarfchen (Fig. 150), uns fhon vom Lagunengebiet und den Zofterawiefen her bekannt. Auch große Fifche, in der Geftalt der Goldbraffe ähnlich, deren Mund jedoch mit kräftigen Zähnen bewaffnet ift, tauchen auf; es handelt fich um die Zahnbraffe (Dentex vulgaris) (Fig. 153). In der Tiefe eines Spaltes unter einem überhängenden Felfen entdedken wir einen Fifch, deffen Körper braune Querbinden trägt und der an der Bauchfeite fchön blau gefärbt ift. Man follte glauben, daß diefes Tier in feiner Umgebung eine fehr auffallende Erfcheinung fein müßte, dies ift aber nicht der Fall, und man muß das Auge fchon einigermaßen geübt haben, um den Schriftbarfch (Serranus scriba) (Fig. 149) fofort aus dem Gewirr von Algenftengeln und -äften herauszufinden, befonders wenn er ruhig fteht, und dies ift feine Gewohnheit. Nur fein Auge wird in ftändiger Bewegung gehalten. Letzteres erfcheint aber durch einen braunen Streifen, der oberhalb desfelben über den ganzen Körper verläuft, gededkt und weniger auffallend gemaht, das Auge ift alfo fozufagen maskiert, und ähnlichen Einrichtungen begegnet man noch bei verfchiedenen anderen Tieren. Geißbraffen (Fig. 151) gibt es hier auch in Menge, und diefe wie überhaupt alle Fifche find lebhafter gefärbt als im Gebiete des trüberen Waffers am Nehrungsftrande. Recht intereffant ift es weiter, das Gehaben der verfchiedenen oft fehr bunt gefärbten Lippfirche $\mathrm{zu}$ beobachten, wie einzelne fich ftändig zwifhen den Algenpflanzen aufhalten und hier äfen, während andere mit dem Kopfe nach abwärts gekehrt im Didkicht der Zweige ftehen und Ruhe halten. Diefe meift fehr bunt gefärbten Fifche erinnern an die farbenprächtigen Fifche der Korallenbänke. 
Wieviel intereffantes Tierleben bleibt uns aber noch in jenen Spalten verborgen, die bei Tage Tieren mit einer nächtlichen Lebensweife eine Zufluchtsftätte bieten. Man kann jedoch auch diefen beikommen. Wenn man etwa Pulver von ungelöfchtem Kalk ins Waffer wirft, dann verlaffen fie ihre durch die eindringende ätzende Kalkfubftanz unficher gemachten Schlupfwinkel. Auf diefe Weife laffen fich fpeziell die Meerpolypen (Octopus) (Fig. 116) aus ihren Verftedken herausjagen und erbeuten. Auch mit einem an einem Faden herabgelaffenen Spiegel kann man übrigens letztere hervorlodken. Diefe Tiere gehören zu derfelben Klaffe wie die Sepia, find alfo Tintenfirche. Während fich aber der gemeine Tintenfifch im Schwimmen perfektioniert hat, kriecht der Octopus vorwiegend auf feinen acht Armen. Solch ein erfchredxtes Tier aufgeregt dahin ftelzen zu fehen, wie es ftändig fein Kolorit ändert, "erblaffend" und wieder "erbräunend", wie es feine Augen bewegt und tief atmet, ift ein hoch ïberrafchender Anblick, bis fich faließlich das Bild in eine Wolke ausgeftoßener Tintenflüffigkeit auflöft.

Für die Felfenküfte ift ferner der $\mathrm{H}$ u m m e r (Homarus vulgaris), lokal Aftice genannt (Fig. 72), eine charakteriftifhe Form. Er bewohnt Felsfpalten und Felslöcher, die er erft am Abend verläßt, um nach Nahrung auszugehen. Beim Genuffe diefer Tiere werden vielleicht fchon manchem die verfchieden gebauten Scheren aufgefallen fein. Diefe Erfheinung wird gewöhnlich für eine Zufälligkeit gehalten, fie ift aber eine regelmäßige und hängt damit zufammen, daß die beiden Scherenfüße eine verfchiedene Funktion befitzen. Von leţterer kann man ja immer die Geftalt in ftrenger Abhängigkeit finden. Dies läßt fich in bezug auf den Hummer fehr leicht erkennen, wenn man ein folches Tier in einem Aquarium bei der Nahrungsaufnahme beobachtet. Liegt das Nahrungsobjekt am Boden, fo wird es zuerft von den Schreitfüßen entdedkt und der fchwächeren Schere, der Greiffchere, zugeführt. Sonft greift der Krebs immer mit diefer Schere zuerft $\mathrm{zu}$, wenn es fich darum handelt, eine Beute direkt zu erhafchen. Das Beuteftück, etwa eine Mufchel, wandert nacher in die Umklammerung der breiten knorrigen Knadkfchere. Leţtere ift deshalb fo mächtig entwidkelt, weil fie einen 
ftarken, viel Raum beanfpruchenden Muskel in fich birgt. Die vielfach geltende Annahme, daß der Hummer fich von Aas nähre, läßt fich mit diefen Tatfachen nicht in Einklang bringen, und feine natürliche Nahrung befteht vielmehr aus lebenden Mufcheltieren, Schnedken, Stachelhäutern ufw. Und nun läßt fich auch verftehen, wozu eine fo kräftige Knadkfchere vorliegt. Aber die Hummer verfamähen deshalb keineswegs auch Nahrung von weicher Befchaffenheit, wie etwa Fifche.

Eine ähnliche Lebensweife wie der Hummer führt im Gebiete der Felsküfte die Langufte (Palinurus vulgaris), lokal Aragofta genannt (Fig. 71).

Für die Hummerbefände der Adria find die Kradken (Octopus) (Fig. 116) fehr gefährliche Feinde. Wenn man felbft einmal die Kraft der mit Saugnäpfen befetzten Arme derfelben kennen gelernt hat und weiß, wie fhwer man fich aus deren Umftrickung befreien kann, dann verfteht man, daß felbft diefe großen Krufter mit ihren wehrhaften Scheren den Meerpolypen gegenüber nicht aufkommen können. Die Krebfe befitzen, wie fchon früher erwähnt, die Fähigkeit, ihre Extremitäten felbfttätig abwerfen zu können - man nennt diefen Vorgang Autotomie - und nachher wieder zu regenerieren. Diefe Eigenfhaft fpielt gerade beim Hummer, der ein langfam wachfendes Tier ift, eine Rolle in der Wechfelbeziehung zu feinem obengenannten Feinde, dem Octopus. Läßt er diefem als Löfegeld eine Schere in feinen Armen zurüdk, fo rettet er damit fein eigenes Leben und kann noch neuen Generationen Leben fchenken. Der Verluft einer Schere mag ja für ihn nicht ganz gleichgültig fein und ihm eine gewiffe Störung nicht erfparen, aber er bringt fich fchließlich doch über diefe Zeit hinweg bis bei der nächlten Häutung das Regenerat der verlorenen Extremität an Größe entfprechend zugenommen und wieder aktionsfähig geworden ift.

Die Frage der Häutung bringt uns auf die Frage des Alters diefer Tiere. Bei größeren Exemplaren von etwa $20 \mathrm{~cm}$ Körperlänge - die Scheren find dabei nicht mitgerechnet, - erfolgt der Wechfel der Haut des adriatifhen Hummers in Intervallen von etwa zwei Jahren, aber es liegen uns auch Beob- 
achtungen an im Aquarium gehaltenen Tieren vor mit einem Häutungsintervall von nur einem Jahr. Die Längenzunahme nach Abfolvierung diefes Prozeffes, wieder nur auf den Körper bezogen, beträgt zirka $1 \mathrm{~cm}$. Alfo diefer Krebs wächft im mittleren Alter alle zwei Jahre um $1 \mathrm{~cm}$. In den erften Jahren folgen die Häutungen wohl rafcher aufeinander, in höherem Alter dürften fie feltener eintreten.

Der Häutungsprozeß bedeutet alfo gleichzeitig auch Wachstum, indem die noch weiche neue Haut nach dem Abftreifen des alten Panzers durch Aufnahme von Waffer quillt und fo ihre Dimenfionen vergrößert. Bezüglich des Vorganges der Häutung ift zu erwähnen, daß das eng gewordene Panzerkleid in der Gänze abgeworfen und ausgezogen wird. Bei der Kompliziertheit der Form desfelben if dies durchaus keine einfache Aufgabe und keine fo unbedenkliche Sache für die Tiere. In der Gefangenfchaft wenigftens gehen fie nicht felten daran zugrunde, wenn fie nicht rafh genug aus dem Panzer herauskommen, weil inzwifhen die neue Haut derart aufquillt, fo daß fie, offenbar infolge des gefteigerten inneren Drudkes, zugrunde gehen.

Diefe Krebfe haben alfo ein langfames Wachstum, aber dies ungünftige Moment wird durch die große Fruchtbarkeit wieder ausgeglichen. Aus den Beobachtungen über den Zeittermin zwifhen dem aufeinander folgenden Panzerwechfel und der dabei beftehenden Längenzunahme läßt fich das Alter der Tiere annähernd abfhätjen und jene Prachtftüdke von großen Hummern, die befondere Zierde von Feftafeln, find gewiß fhon fehr betagte Gefellen, deren Lebensfpanne mit der manches alten Menfthen konkurrieren kann.

Die Felsküfte ift ferner die eigentliche Heimat und das Gebiet reichen Vorkommens der $S \mathrm{hwämme}$. Dies hängt damit zufammen, daß die Spongien einen harten Untergrund zum Feftfetzen benötigen und daß fie fehr Sauerftoff bedürftige Tiere find. Entlang der Küfte mit der ausgiebigen Durchlüftung des Waffers durch die Brandung, der reichen Sauerftoff produzierenden Vegetation, der ftändigen Küftenftrömung und der reichlichen Nahrung ift das Gebiet des öftlichen Mittelmeeres 
und der Adria wohl befonders günftig für das Gedeihen der genannten Tiergruppe, da fie außerdem eine mittlere Höhe des Temperaturjahresmittels beanfpruchen. Wir können uns hier natürlich nur mit einigen wenigen bemerkenswerten Vertretern diefer Gruppe befchäftigen und insbefondere mit folchen, die wir leicht direkt beobachten und felbft erbeuten können. Hierbei bedienen wir uns wieder unferes Gudkfenfters.

Das meifte Intereffe dürfte wohl dem Badefchwamm (Euspongia officinalis) (Fig. 16) entgegengebracht werden. Er findet fich überall entlang der Felsküfte des Adriatifhen Meeres, der griechifchen und kleinafiatifchen Küfte in der Strandregion bis hinab zu Tiefen von über 100 Metern. Die berufsmäßige Schwammfifcherei wird fpeziell in der Adria von den Bewohnern des Ortes Grappano betrieben, die mittels mehrzinkiger Gabeln den Badefhwamm von Grunde ablöfen. Es gewährt einen ganz eigenartigen Anblick und es mutet einen faft wie längft vergangene Zeiten an, wenn man den kleinen Flotillen primitiver und plumper Boote der Grappanefen begegnet. Diefe Art der Fifcherei wird bei verläßlichftem Sommerwetter ausgeführt, da nur bei ruhigem Waffer die am Grunde als fchwarze verfchieden große Ballen und Klumpen erfcheinenden Schwämme ausgenommen und gefircht werden können. Die gefifchten Badefchwämme müffen nun zur Gewinnung des Horngerüftes, deffenhalben fie fo eifrig gefucht werden, ihres Weichkörpers durch abwechfelndes Trodknen, Kneten und Einweichen beraubt werden. Derartig vorpräparierte und getrodknete Exemplare werden als Rohware von den großen Schwammhändlern aufgekauft und durch Behandeln mit Säuren, durch Bleichen und Wafchen für den Handel verarbeitet. Obzwar es eine große Anzahl Arten von Hornfchwämmen gibt, eignet fich doch nur der Badefchwamm und der ordinäre Pferdefchwamm vermöge ihrer elaftifchen und fandlofen Hornfafern für die Zwedke des Haushaltes und der Technik.

Ein anderer häufiger und durch feine fchwefelgelbe Farbe fich auszeichnender Schwamm ift die Aplyfina (Fig. 14), die ebenfalls zu den Hornfchwämmen gehört. Sie bildet Gruppen röhrenartiger nebeneinander aufragender $\mathrm{Zweige,} \mathrm{die} \mathrm{an} \mathrm{ihrem}$ 
Ende immer eine Offnung tragen. Sobald eine folche Kolonie aus dem Waffer herausgenommen und der Luft ausgefetyt wird, verändert fie die hellgelbe Farbe in dunkles Blau.

Andere Gruppen von Schwämmen enthalten Gerültwerke aus Kiefelfubftanz in Form von Nadeln und Stäben. Diefe Kiefelfchwämme find fehr artenreich, und wir wollen hier als Beifpiele nur zwei Formen anführen, nämlich Geodia gigas und Tethya lyncurium (Fig. 8). Erftere bildet an überhängenden Felfen mächtige blaßgelbe Uberzüge. Wenn aber deren Larve in das Meer hinaus vertragen fich am Grunde desfelben feftfetst, fo entftehen dann große runde Schwammftüdke mit einem Durchmeffer bis zu $60 \mathrm{~cm}$. Die Oberfläche von Geodia erfcheint haarig und rauh. Ihre Schwammmaffe ift von gewundenen ziemlich weiten kanalartigen Hohlräumen durchfeţt, welche fchließlich nach außen münden. Im Schutge diefer Kavernen und Gänge fiedelt fich eine ganz beftimmte Fauna an, welche hier als harmlofe Mitwohner (Kommenfalen) leben. Zerbricht man fo ein Schwammonftrum, fo gibt es dann eine intereffante Ausbeute vor allem an Würmern. Unter diefen findet fich regelmäßig der bis meterlang werdende Wurm Marphysa sanguinea. Es erfordert aber eine ziemliche $\mathrm{Ge}-$ duld, ein folches Tier unzerftüdkelt aus dem Schwamme herauszufchälen. Dann wäre als Mitinwohner ein kleiner Krebs (Alpheus) (Fig. 65) erwähnenswert, der mit der Schere einen knallenden Ton hervorbringen kann.

In Form von orangegroßen gelben Kugeln wächft die Te thya (Fig. 8) im gleichen Gebiete. Sie findet fich jedoch auch auf den harten Mufchelfandgründen. Dann gibt es Schwämme von kautfchukartiger Konfiftenz (Fig. 13) und kruftenbildende Arten von verfchiedener, meift gelber, roter oder blaufchwarzer Färbung. Diefe Gebilde können eventuell mit zufammengefetzten Seefcheiden verwechfelt werden. Letztere find aber meift von lederartiger oder gallertiger Befchaffenheit und zeigen die Anordnung der Einzeltiere in Form von Rofetten (Fig. 138).

Es foll noch einer einfachen Methode Erwähnung getan werden, die es uns ermöglicht, intereffante Tierformen und das Nebeneinander der Formen kennen zu lernen. Diefe be- 
Figur

\section{Tafel XIV}

115. Miesmuschel (Mytilus galloprovincialis) (S. 22). Schale violett bis fchwarz, Höhe $6-8 \mathrm{~cm}$.

116. Meerpolyp (Octopus vulgaris) (S. 68, 104), mit einer Saugnapfreihe auf den Armen. Sehr ähnlich dem Octopus ift der Moschuspolyp (Eledone moschata), welcher aber nur eine Reihe von Saugnäpfen befitt.

117. Sepia (Sepia officinalis) (S. 53, 103). Länge des Körpers bis $30 \mathrm{~cm}$. Befitzt ebenfo wie die folgenden zwei Arten zehn Arme, wovon zwei befonders lang find und zum Erhafchen der Beute dienen.

118. Sepiola Rondeletii (S. 55). Körper 4-6 cm lang.

119. Kalmar (Loligo vulgaris), wird bis $60 \mathrm{~cm}$ lang, mit wohl entwidkelter Schwimmfloffe.

120. Eier von Sepia.

121. Eitrauben vom Kalmar.

122. Rückenschulpe von Sepia. 

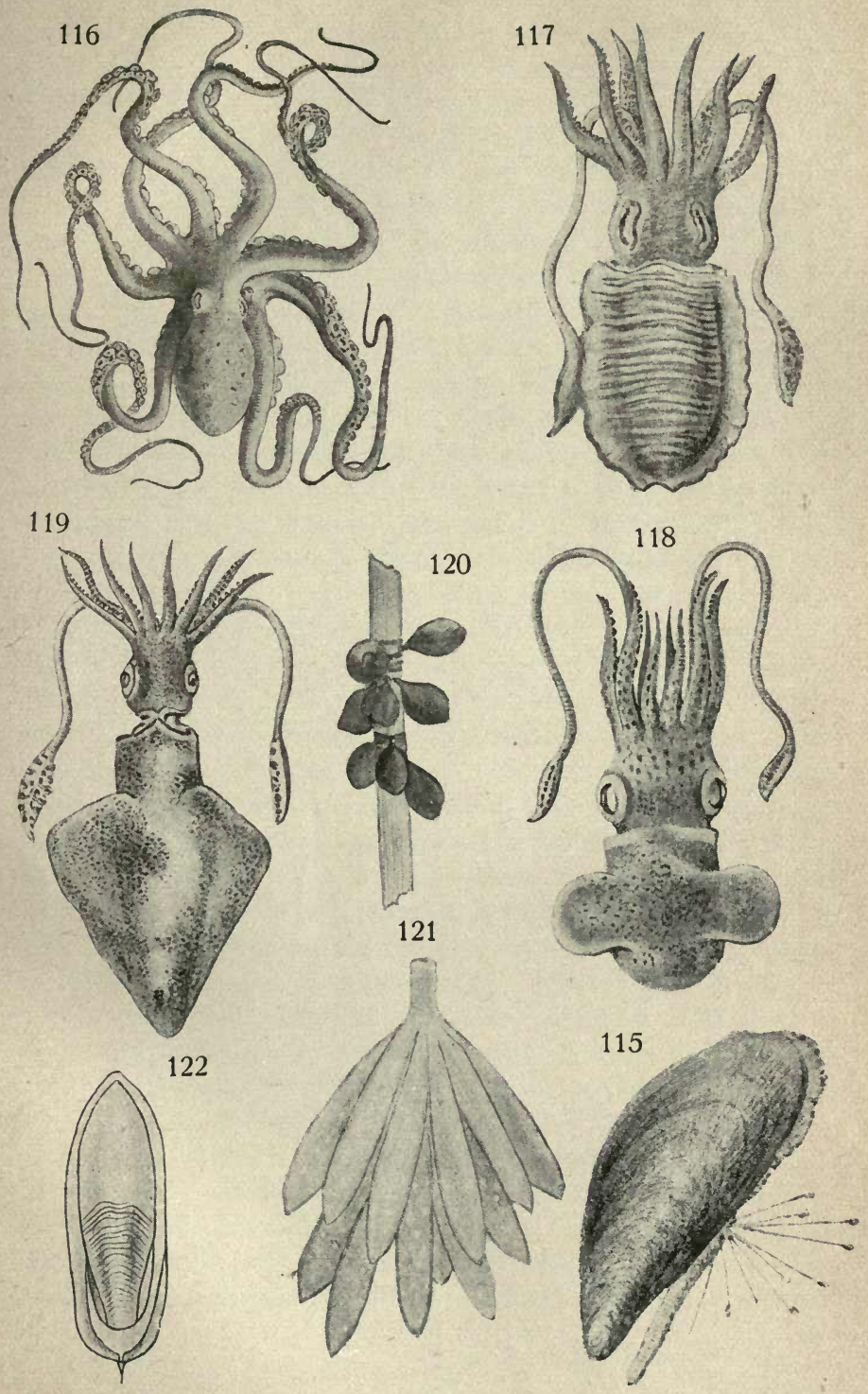

fteht darin, daß man mit einer fogenannten Steinzange lofe Steine und kleine Steinblödke vom Meeresgrund hebt. Diefes Inftrument ift bei den Fifchern vielfach in Verwendung, wenn es fich darum handelt, lofe Felsftüdke, die von Meerdatteln bewohnt find, oder Pfähle mit Auftern zu heben. Diefes Inftrument ift eine Zange, deren eine Branche an einer zirka vier Meter langen Stange befeftigt ift, während die andere Zangenhälfte mittels einer Schnur bewegt bezw. gefchloffen werden kann. Mit diefem nütlichen Werkzeug laffen fich natürlich auch allerlei andere Gegenftände, die uns intereffieren, heraufholen. Die meiften fo gewonnenen Steine find an der dem Lichte zugekehrten Oberfeite mit Algen bewachfen und an der Unterfeite, befonders wenn fie hohl lagen, ift eine ganze Welt von Polypen, Moostierchen, Schwämmen, zufammengefełten Seefcheiden, Röhrenwürmern und anderen Tieren angefiedelt. An den Seiten des Steines fitzen allerlei Schnecken, wie das Seeohr (Haliotis) (Fig. 87), deffen Schale mit einer Reihe von Löchern für den Austritt des Atemwaffers und der Refte des Stoffwechfels verfehen ift. Die diefer verwandte Schlitfchnecke (Fiffurella) (Fig. 85 u. 86) befitst nur ein einziges, dem gleichen Zwedk dienendes Loch auf der Spite ihrer kegelförmigen Schale. Ferner gewinnt man auf diefem Wege auch gehäufelofe Schnedken, wie Doris (Fig. 101) und Doriopfis, je nach der Art oft fehr fchön gefärbt. Die Rofette am hintern Teil des Rüdkens diefer letztgenannten Tiere ift eine Kieme. Eine andere Schnedke, die Wurmfchnedke (Vermetus arcuarius) (Fig.98), welche intereffanterweife die feftitzende Lebensweife angenommen hat, ift mit ihrer unregelmäßig gekrümmten Röhre an der Unterlage feftgewachfen. Zertrümmert man endlich einen folchen Stein, fo ift die Ausbeute an Würmern oft eine fehr reiche, insbefondere dann, wenn fich in demfelben Spalten oder Höhlungen befinden. Einer diefer Würmer ift nicht bloß wegen feiner Geftalt, fondern auch in anderer Hinficht bemerkenswert. Abweichend von der typifchen langeftredkten Körperform der Anneliden hat diefer grün geförbte Wurm, die Bonellia viridis (Fig. 48) einen kugeligen oder eiförmigen Körper, der fich in einen fehr lang ausdehnbaren und am Ende gegabelten 
Rüffel fortfetzt. Die Unterfeite desfelben ift rinnenförmig ausgehöhlt und mit einem Flimmerepithel verfehen, mit deffen Hilfe die Nahrung zum Munde herbeigeftrudelt wird; dabei bleibt das Tier felbft in der Steinhöhle verftedkt und fendet nur feinen Rüfrel wie einen langen Arm aus. Diefe Tiere find durchweg weiblichen Gefchlechtes, und die Männchen entzogen fich lange Zeit der Beobachtung, bis man darauf kam, daß fie als mikro1kopifch kleine, infuforienähnliche Wefen im Darme der Weibchen fchmarotzen, - gewiß eines der merkwürdigften Beifpiele aus dem intereffanten Kapitel über Parafitismus.

Wer fich für Foraminiferen intereffiert, für jene einzelligen Wefen mit Kalkgehäufen von fo mannigfaltigen und ftilvollen Formen, der wafche die auf folchen Steinen wachfenden Algen und die von Sand bededkte Oberfeite derfelben in ein Gefäß hinein ab und fawemme dann das fo gewonnene Material durch oftmaligen Wafferwechfel vollfändig rein aus. Die kleinen Kammerlinge kriechen alsbald mit Hilfe ihrer protoplasmatifchen Scheinfüßchen (Pfeudopodien) an der Glaswand der Gefäße empor und bilden durch Zufammenfließen jener feine Pfeudopodiennetze. Im Bodenfaty dagegen finden fich die Gehäufe der abgeftorbenen Tiere.

Felsbohrende Tiere. Unferer Sammlung von Objekten des Meeres möchten wir gerne auch einige fchön bewachene Felsftüdke einverleiben und trachten daher bei recht tiefer Ebbe einzelne Stüdke vom Felfen und von Steinen, die wir uns aus der untergetauchten Region mit Hilfe eines Hammers losfchlagen, zu erlangen. Merkwürdigerweife hallen die Hammerfchläge dumpf auf den fcheinbar fo foliden Felsmaffen, und diefe gehen leichter in Trümmer, als wir dies erwarteten. $\mathrm{Zu}$ unferer Uberrafchung ift alles unterminiert und durchlöchert und zwar von Tieren, welche der fteinbohrenden Fauna angehören. Daß der nahrungshaltige Schlamm und Sand des Meeresgrundes bewohnt gefunden wird, läßt fich begreifen, daß aber der harte Felfen den Angriffen der Tierwelt nicht widerftehen kann, das erfcheint uns nicht leicht faßbar. Wir wollen uns diefe kleinen Bohrmeifter etwas genauer anfchauen.

Die Arbeitsmethode diefer Tiergruppe ift eine dreifache: 
Entweder wird der Felfen auf chemifchem Wege, durch Produktion von Säure, oder er wird durch mechanifche Bearbeitung angegriffen oder endlich es treten beide Arten miteinander in Kombination. Die Produktion von Säuren und fauer reagierenden Sekreten, abgefehen von jenen der Verdauung dienenden, fheint eine viel häufigere Erfheinung bei der marinen Fauna zu fein, als wir es im allgemeinen vermuten.

In den abgefchlagenen Gefteinsftüdken finden fich eine Menge Hohlräume, die durch dünne Scheidewände voneinander getrennt und mit dem weichen, gelb oder rot gefärbten Bohrfhwamme (Vioa) (Fig. 11) erfüllt find. Nach außen find diefe wabenartigen Hohlraumfyfteme nur durch eine fohwache Steinfchicht gededkt, und lettere erfcheint von kleinen Offnungen durchbrochen. Durch diefe läßt der Schwamm jene dünnwandigen zarten Röhren hervortreten, welche uns bereits auffielen, als wir unfere Beobachtungen an der Felsküfte anftellten. Solche lehrreiche Proben von der Ärbeitsleiftung diefer Tiere findet man übrigens faft überall am Strande im Gefchiebe. Die Vioa bohrt aber auch die Schalen von Mufcheln an. Kein anderer Vertreter aus der Gruppe der felsbohrenden Seetiere nagt in fo intenfiver Weife am Felsftrande wie gerade der Bohrfchwamm, und zwar gefchieht dies ausfchließlich auf chemifchem Wege durch Säureproduktion. Man kann daher von einer allgemeinen Karies der Kalkfteinküfte fprechen, welche eine fortfhreitende Zerftörung derfelben bewirkt und den Wogen ihre zerftörende Arbeit leichter macht. Ja, man kann fich leicht überzeugen, daß die Vioa einen hervorragenden Einfluß auf die Bildung der Küftenlinien nimmt. Dabei ift andererfeits nicht zu verkennen, daß fich die Menge aller der am Felfen wachfenden Algen und feftitgenden Tiere wie ein fhützendes Kleid um den Felfen fchlingt und der Zerftörung der Küfte ein etwas verlangfamtes Tempo vorfchreibt.

Es gibt auch bohrende Würmer. Hiervon kann man fich beim Zertrümmern von jenen Steinen überzeugen, die wir mit der Zange vom Meeresgrund gehoben haben. Die Steinmaffe erfcheint dann häufig von engen fharf gebohrten Gängen 
durchzogen, welche durch fauer reagierende Sekrete diefer Tiere erzeugt worden find.

Neben dem Bohrfhwamm beteiligen fich ferner noch zwei Mufcheln, die Bohrmufchel (Pholas dactylus) (Fig. 109) und die Meerdattel (Lithodomus lithophagus) in hervorragender Weife an dem Zerftörungswerk der Felsküfte. Beide Mufcheln bohren fich vollkommen in den Kalkfelfen ein und ftellen Höhlungen her, die ihre Körperform wiedergeben. Mit diefer Tätigkeit beginnen fie bereits als ganz junge Tiere, und wenn fie fobließlich groß geworden find, ift der Zugang $z u$ ihrer fteinernen Wohnung $z \mathfrak{u}$ eng, um ihnen etwa einmal einen Umzug zu geftatten. Erftgenannte Mufchel bevorzugt mehr weiche Steine, lebt auch im lehmigen und fandigen Meeresgrund, die zweitgenannte dagegen kann auch die ganz dichten und harten marmorartigen Kalkfteine anbohren. Bei beiden Tieren dürfte die Bohrarbeit auf chemifhem Wege erfolgen, denn einmal zeigen deren Schalen keinerlei Abnütgung, was hierbei nicht zu vermeiden wäre, ferner könnte nur dann durch mechanifche Arbeit ein nennenswerter Effekt erzielt werden, wenn ein Härteunterfchied zwifhen der Maffe des angebohrten Felfens und der Schale vorläge. Bemerkenswert ift endlich, daß das Sekret von Pholas im Dunkeln leuchtet.

Eine unge mein häufige Erfcheinung der Küfte ift der fchwarze Seeigel (Paracentrotus lividus) aus der Gruppe der Stachelhäuter. An gefchüttten Stellen fitzen die Tiere oft in ungezählten Mengen, und befonders die großen Exemplare findet man dann in grubenartigen Vertiefungen des Felfens wie in einem Nefte gebettet. Diefe Gruben follen die Tiere auf rein mechanifche Weife herftellen. Alfo auch diefe Tiere gehören zu den Felszerftörern. Es wird vielleicht auch auffallen, daß diefe Seeigel befonders dort, wo man fie an exponierten Stellen findet, auf ihrer Oberfeite kleine flache Steinchen, Mufchelfhalen und dergleichen vermutlich als eine Schuteinrichtung gegen ihre Feinde herumtragen. Man könnte dies auch wieder als eine Art Maskerade bezeichnen, wie wir dies bei der Seefpinne (Maja verrucosa) und bei Inachus und Stenorh yndh u fehen (S. 45, 46). Solch ein Seeigel mit feinem Stachel- 
kranz fieht eigentlich recht unbeholfen aus, um dies alles fertig zu bringen, aber wir müffen wiffen, daß fich zwifchen dem Stachelbefaty eine große Menge kleiner Saugfüßchen und Zängelden befinden - mit einer Lupe kann man fich hiervon fehr leicht überzeugen - und mit diefen macht er fo gefchidkte Arbeit. Lehrreich ift es auch, durch Aufbrechen der Schale den kompliziert gebauten Kieferapparat, deffen Zähne man fchon von der Mundöffnung aus fehen kann, kennen zu lernen.

Als zweite deutlich abgegrenzte Region der Felsküfte haben wir die Emerfionszone genannt. Diefe liegt zwifhen der Ebbe- uud Flutlinie und follte normalerweife immer nach zwölf Stunden bei Eintritt jeder neuen Ebbe vom Waffer entblößt werden. Aber das Flut- und Ebbephänomen verhält fich nicht jeden Tag in gleicher Weife, fondern fpielt fich in Zufammenhang mit den Mondphafen periodenweife ab, fo daß zur Zeit des Voll- und Neumondes die tiefften Ebben und höchften Fluten (Springzeit) zu beobachten find, während das Meer in den Zwifhenzeiten (Nippzeit) ein mittleres Niveau einnimmt und diefes wenig verändert. Auch die Monate verhalten fich diesbezüglich verfhieden, und in der Adria wird im Monat Januar das Maximum diefer Erfheinungen erreicht. Der Ablauf diefer Wafferbewegungen wird ferner noch durch das Wetter beinflußt, indem z. B. auflandige Winde die Flut fteigern und die Ausbildung der Ebbe hindern, bezw. abfchwächen können. Ablandige Luftbewegungen verhalten fich gerade umgekehrt. Die Höhendifferenz zwifchen Flut- und Ebbeftand ift nicht an allen Orten des Mittelmeeres und der Adria gleich und beträgt $30-75 \mathrm{~cm}$.

Wenn wir fehen, daß einerfeits zur Ebbezeit ein Teil der Felfenküfte vom Waffer entblößt ift, daß zuzeiten dann der Felfen intenfiver Befonnung ausgefeţt if, daß zuzeiten der Wind austrocknend und im Winter oft eifigkalt über ihn hinwegftreicht, und wenn wir andererfeits aus Erfahrung wiffen, wie leicht Seetiere abfterben, fobald fie aus dem Waffer an die Luft gebracht werden, fo find wir überrafcht, in der auftauchenden Region der Felsküfte noch marines Leben, und gar nicht in fo ärmlicher Entfaltung, anzutreffen. Tatfächlich können 
diefe Lebensformen folche extreme Veränderungen der Exiftenzbedingungen ertragen, wie fie fich zwifchen Flut- und Ebbezeit im Ablauf weniger Stunden in fehr gegenfatgreicher Weife vollziehen. Die Erklärung hierfür liegt in dem Umftande, daß es eine Anzahl von Tieren und Pflanzen verftand, diefen befonderen Lebensbedingungen fich anzupaffen. Die Lebewelt fucht ja, wie wir immer wieder fehen, jeden Platy für fich auszunützen, und dies Beftreben führt zur Ausbildung befonderer Einrichtungen, deren Erfcheinungskomplex wir kurzweg Anpaffung nennen. Von diefem Standpunkt aus betrachtet bietet daher gerade die Emerfionszone des befprochenen Gebietes reiche Gelegenheit zu anregenden Beobachtungen. In der Nordfee ift infolge der weit größeren Niveauunterfchiede zwifchen Hochund Niedrigwaffer diefe Zone viel breiter und reicher entwidkelt, aber auch im Mittelmeer und in der Adria find die angedeuteten Erfcheinungen mit aller Deutlichkeit zu finden, und man verabfäume daher nicht, dem Felsftrand bei Ebbezeit feine Aufmerkfamkeit zu widmen.

Wenig unter der Flutlinie entfaltet fich hier zunächft in Form eines Vegetationsbandes der Blafentang (Fucus virsoides), eine Alge, die hier gegenüber ihren Verwandten in den Nordmeeren nur eine befchränkte Entfaltung nach Arten, Ausbreitung und Größe zeigt. Es hat den Anfchein, daß der Blafentang zu feinem Gedeihen das öftere Auftauchen aus dem Waffer direkt notwendig hat. Es gibt merkwürdigerweife nur wenige epiphytifche Algen, die fich auf dem Fucus niederlaffen, wie der Meerfalat (Ulva lactuca) und die Enteromorpha, ebenfo vermiffen wir feftfitgende Tiere auf diefer Alge. Die ftarke Schleimbildung derfelben ift wahrfheinlich eine Schutgeinrichtung gegen das Austrocknen während der Ebbezeit.

Faft im gleichen Niveau mit dem erwähnten Tang lenken am Felfen beim Niedrigwaffer leuchtend rot gefärbte runde Patyen unfere befondere Aufmerkfamkeit auf fich, - fie könnten aus rotem Siegelladk hergeftellt fein, fo fehen fie aus. Ihre Natur erkennt man aber erft, wenn das Waffer wieder fteigt, denn dann entfalten fich diefe Dinge zu prächtigen roten Rofen. Es find Seeanemonen und zwar die Pferdeaktinie (Actinia 
equina) (Fig. 24). Eine höchft auffallende Erfcheinung ift hier die knallrote Farbe diefer Tiere. Die Bedeutung der Farben im Tier- und Pflanzenreich ift von Fall zu Fall eine fehr verfchiedene und oft fchwer deutbare. Bald dienen fie als Lodkfarben, bald als Warnfarben, bald auch zum Schutye gegen Feinde. Im vorliegenden Falle dürfte es fich um eine Schutseinrichtung gegen die Sonnen- und Wärmeftrahlen handeln, die durch das rote Pigment inaktiviert werden.

Eine zweite charakteriftifche Form für die in Rede ftehende Zone ift die Napffchnedke (Patella) (Fig. 88), welche nicht wie die meiften anderen Schnedken eine gedrehte, fondern eine niedrige kegelförmige Schale befitzt. Wie ein Sturz bededxt diefe das Tier. Zur Ebbezeit wird fie dann feft auf die Unterlage durch die Muskelwirkung ihres Spindelmuskels aufgedrüdkt. So ift das Tier gegen Vertrodknen gefchütt, und bei Sturm können die Wogen über dasfelbe hinwegrollen, es hat ihm nichts an. Dort, wo eine folche Schnedke fitt, findet fich am Felfen häufig eine grubenartige Vertiefung, welche das Tier felbft durch Säurewirkung erzeugt hat. Aus den konzentrifchen Linien am Grunde diefer Vertiefungen läßt fich erkennen, $\mathrm{da}$ es vielleicht fchon von feiner frühen Jugend an an derfelben Stelle fitt, fo daß fich allo ein freibewegliches Tier felbft die feftfitende Lebensweife auferlegt hat. Auch eine kleine Miesmufchel (Mytilus minimus) findet man in diefer Zone oft in dicht gedrängten Mengen in Steinfpalten angefiedelt.

Nebft der fchon erwähnten durch ihre rote Farbe auffallenden Pferdeaktinie finden fich in der Emerfionszone noch andere Aktinienformen. Während aber jene die oberfte Flutzone bevorzugt, befiedeln diefe die mit der Ebbegrenze beginnende Zone, fo daß fie nur bei tiefftehendem Niedrigwaffer aus dem Wafferniveau auftauchen. Man fuche die nachgenannten Anemonen an Stellen von Brandungsbuchten und Spalten, die mit Sand und Gefchiebe erfüllt find; auch unter Steinen fitzen fie nicht felten. Häufig z. B. ift die grün gefärbte und quer gebänderte Actinia cari (Fig. 25) und die Anemonia sulcata (Fig. 26) zu finden. Letstere ift fehr variabel im Kolorit und zeigt oft fehr fchöne und lebhafte Farben. Nicht leicht auffindbar ift 
zur Ebbezeit die Sonnen ro fe (Heliactis bellis) (Fig. 31), folange der Blick hiefür nicht gefchult ift, weil es fich im zurüdkgezogenen Zuftande durch die am Körper mit Hilfe von Wärzchen angeklebten Steinchen und Mufhelfragmente von dem umgebenden Sand nicht abhebt. Das Fefthalten von Fremdkörpern gewährt dem Tier wahrfheinlich einen gewiffen Schuts gegen die Wirkung der Sonne und gegen das zu ftarke Austrodknen während der Entblößung vom Waffer. Eine fünfte Aktinie folcher Ortlickkeiten ift die fchöne in ihrer Farbe fehr variable Aiptasia mutabilis (Fig. 30), welche fich mit ihrem ziemlich langgeftredkten Körper gewöhnlich eingegraben hat. Die leţtgenannte Anemone findet fich übrigens auch im Gebiete der Zofterarafen, z. B. auf den Aufternpfählen. Die Sonnenrofe und die Anemonia sulcata fircht man auch mit dem Schleppnets aus der Schlamm- und Mufchelfandregion. Man kann alle diefe Seeanemonen unbefchadet in die Hand nehmen, da fie nicht neffeln. (Vgl. S. 110.)

Die Brandungszone bildet eigentlich fhon den Ubergang zum Feftlande, denn nur bei hodgehender See werden hier die Felfen vom Meere befpült, und es können Wochen vergehen, ehe dies wieder einmal der Fall ift. Andererfeits üben die gleichen Faktoren ihre volle Wirkung aus wie dort, nämlich Sonne, Wind, Regen, Wärme und Kälte. Bot fhon die Emerfionszone ein relativ faunenarmes Bild dar, fo ift dies in noch erhöhtem Maße hier der Fall, indem es nur zwei Formen find, die wir hier finden. Die Exiftenzbedingungen für eine marine Fauna find eben hier auf das Minimum des Möglichen gefunken.

In einer nach Umftänden wechfelnden Breite erfheint die Felswand oberhalb der Flutlinie mit einer Menge kleiner Hödker befetzt, hinter denen fich kaum Lebewefen vermuten ließen; deffen wird man aber fofort gewahr, wenn ein heruntergebrochenes Felsftück ins Meerwaffer gebracht wird. Dann bekommen die tot ausfehenden Dinge Leben, hurtig langen beftändig kleine handartige Extremitäten aus dem Zentrum diefer Hödker heraus. Man fieht dann auch, daß fie aus einzelnen Kalkplatten zufammengefetyt find. Außen formieren diefe 


\section{Tafel XV}

Figur

123. Seewalze (Holothuria) (S. 90). Länge bis $35 \mathrm{~cm}$. Färbung an der Oberfeite dunkelbraun, an der Unterfeite heller.

124. Seeigel (Sphaerechinus granularis) (S. 90) mit kurzen dicken Stacheln, Färbung hell bis dunkelviolett, wobei die Stachelfpitzen meift weiß find. Durchmeffer bis $15 \mathrm{~cm}$.

125. Schlangenstern (Ophiothrix fragilis) (S. 90). Die Schlangenfterne unterfcheiden fich von den Seefternen, abgefehen von anatomifchen Unterfchieden, durch die fehr lebhaften Bewegungen ihrer fehr gelenkigen Arme.

126. Asterias glacialis (S. 90) gehört mit zu den größten Seefternen, erreicht einen Durchmeffer von $40 \mathrm{~cm}$. Färbung gelbgrün-rötlich. Die Arme zeigen relativ große Gelenkigkeit.

127. Echinaster sepositus (S. 90). Größe bis $25 \mathrm{~cm}$, Färbung lebhaft zinnoberrot. Haut ohne Stacheln.

128. Palmipes membranaceus. Durch Verwachfung und Verkürzung der Arme hat diefer Seeftern die Geftalt einer fünffeitigen dünnen Platte erlangt. Färbung hellzinnoberrot an der Oberfeite, gelblich an der Unterfeite. Durchmeffer $15 \mathrm{~cm}$.

129. Astropecten aurantiacus (S. 100), eine fehr häufige und anfehnlich große Seefternform mit kräftigen Stacheln an den Armrändern und rofettenartigen Warzen auf der Oberfläche. Färbung dunkelzinnoberrot. Durchmeffer bis $45 \mathrm{~cm}$.

130. Haarstern (Antedon rosacea) (S. 90). Größe bis $15 \mathrm{~cm}$. Die beweglichen Arme brechen leicht ab. Färbung gelb, braun oder rot. Auf der Mundfcheibe und den Armen findet fich nicht felten ein kleiner fcheibenförmig geftalteter Wurm (Myzostoma) Raumparafit. 
Tafel XV

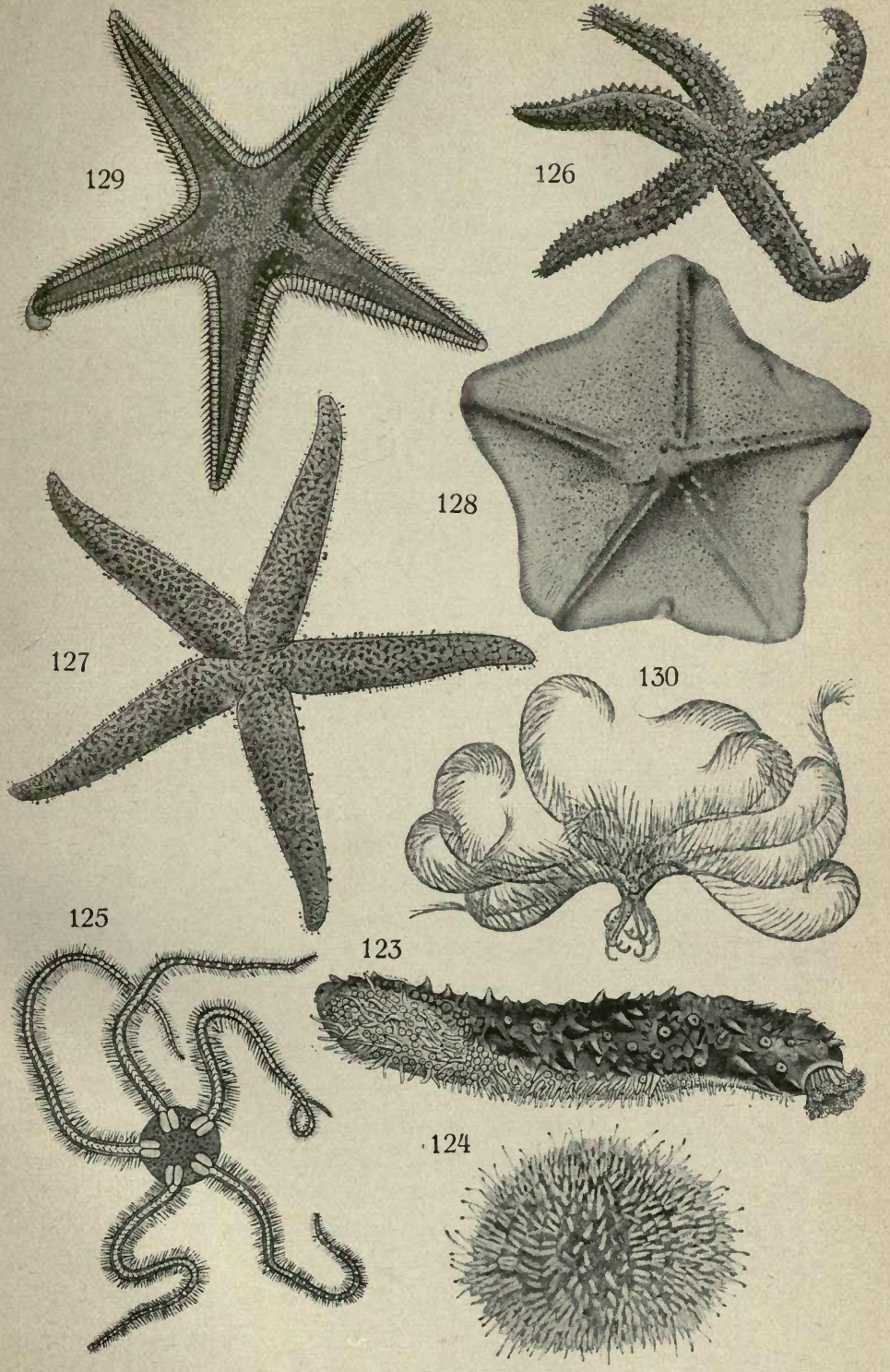


45 
einen am Steine feftgewachfenen Kranz in kegelförmiger Anordnung, in deren Mitte andere Kalkftüdke beweglich find und fich fpaltförmig. jedesmal zum Durchtritt der oben erwähnten Greiffüße öffnen. Es handelt fich hier um feftgewachfene Krebfe, die Meereicheln, auch Se ebodken genannt (Balanus) (Fig. 53). Sie gehören zur Familie der Rankenfüßler (Cirripedien), welche mit dem Kopfe feftgewachfen, ihre rankenartigen Bruffüßße beftändig blindlings in ihre Welt hinausgreifen laffen, um Nahrung zu erhafchen, die ihnen das bewegte Meer zuführt. Das find wohl fehr genügfame Exiftenzen. $\mathrm{Zu}-$ nächt durchlaufen fie in der Jugend ein freifhwimmendes Larvenftadium (Fig. 54) und fetzen fich, nachdem fie noch ein Zwifchenftadium durchgemacht haben, kopffeits feft. Diefe Tiergruppe zeigt eine weite Verbreitung über die Erde. Hierher gehören auch die Entenmufcheln (Lepas) (Fig. 56), deren Vorderkörper zu einem Stil ausgewachfen erfcheint. Man trifft diefe Tiere auf treibendem $\mathrm{Holz}$ angewachfen, und mit Vorliebe befiedeln fie die Böden von Segelfchiffen. Die Meereicheln kommen aber auch in der untergetauchten Region des Meeres vor, ferner find fie als Raumparafiten von Walfifchen und Seefchildkröten bekannt.

Das zweite Tier der Brandungszone ift die kleine in vieler Hinficht intereffante Strand fch ne dke (Litorina) (Fig. 89), welche, nach ihrer Organifation zu fchließen, fich vom Leben im Meere zu entwöhnen anfhidkt. So lange der Felfen trodken daliegt, kleben diefe Tiere in Menge in gefchüttten Ritzen und Löchern, und erft wenn fie überflutet find, erwadht in ihnen aktives Leben.

Endlich bewohnt diefes Gebiet eine Affel, die Ligia (Fig. 68), die in Scharen am Felfen herumlaufend, unfere Aufmerkfamkeit auf fich lenkt.

So fieht es denn in der befprochenen Region troty der beiden lettgenannten Grenzpoften des Meeres recht öde und ausgeftorben aus. Oberhalb diefer Zone fetzt fich der Fels vegetationslos noch in wechfelnder Höhe fort, je nachdem hier die Sturmflut heraufreicht. Dann beginnt erft in refpektvoller Entfernung vom Meere mit einer ziemlich fcharfen Grenze die Feftlandsvegetation, und von diefer wagen nur einige wenige befcheiden Cori, Der Naturfreund. 
ausfehende Vertreter (Halophytgewächfe) in diefes noch zeitweife von der See beherrfhte Gebiet vorzudringen. Es find graue Pflänzchen von bizarrer Form, die man in Spalten angefiedelt findet.

Unfere Exkurfion am Felsftrande hat uns wieder viele neue Erfahrungen und Tatfachen gebracht. Wenn wir diefe der Hauptfache nach zufammenfaffen, können wir fagen, daß fich hier zwar auch ein reiches Leben entfaltet, aber diefe Fülle tritt nicht fo augenfällig zutage. Belebend wirkt vor allem die reiche formen- und farbenmannigfaltige Algenvegetation. Eines lernen wir aber hier vielleicht in einer noch klareren Weife als bisher erkennen, daß die Organismen die fich ihnen darbietenden Lebensbedingungen förmlich bis zur Erfchöpfung derfelben ausbeuten. Sind diefe fchwierig und nicht allen oder vielen Lebewefen leicht zugänglich, fo wird der Mangel an der Mannigfaltigkeit der Formenentfaltung durch einen größeren Individuenreichtum einzelner Formen, die fich in die Verhältnifle hineingelebt haben, kompenfiert. 


\section{VI. \\ AUF SCHLEPPNETZFAHRTEN.}

W ir haben bisher die leicht zugänglichen küftennahen Gebiete und deren Leben kennen gelernt, und nun intereffiert es uns auch zu erfahren, was am Meeresgrund zu finden ift. Die Mittel, um dies zu erreichen, find, entweder als Taucher ausgerüftet hinabzufteigen, oder fich der Netze und anderer Fanggeräte $z u$ bedienen. Den vollftändigften Eindrudk von der Grundfauna und -flora könnte man wohl nur durch direkte Beobachtung empfangen, und es müßte ein Herrliches fein, dies alles mit den Augen des Naturforfhers fehen zu können. Aber erftens find dem Vordringen in die Tiefe bald Grenzen gefetst, $-40 \mathrm{~m}$ ift ja überhaupt die größte mittels Taucherausrüftung erreichbare Tiefe - und weiter ift das Tauchen an und für fich für einen nicht berufsmäßig Gefchulten keine fo unbedenkliche Sache. Die zweite und hauptfächlich geübte Methode zur Gewinnung eines Uberblidkes über das Leben am Meeresgrunde beruht auf dem Fifchen mit Netzen und anderen Fangvorrichtungen. Aber es ergibt fich zunächft das erfchwerende Moment, daß man mit verfhiedenen Fangapparaten arbeiten muß, um annähernd ein Gefamtbild zu erhalten, und das wird troţdem nie vollifändig erreicht. Ferner find die erbeuteten Tiere, fobald fie in unfere Hände kommen, bereits aus ihrem Milieu geriffen, und uns wird dadurch das Verftändnis für ihre Organifation erfchwert. Troty der Unvollkommenheit diefer Methode bietet doch die Teilnahme an Fifchereifahrten, bei denen Berufsfifcher mit Grundfchleppnetzen filchen, reiche Gelegenheit, aus dem Inhalte folcher Netze recht lehrreiche Eindrüdke über die Grundfauna und -flora zu gewinnen. Es kann daher nur empfohlen werden, fich Fifchern auf ihren Fifchereifahrten anzurdhließen.

Es wurde bisher wiederholt auf die Abhängigkeit der Fauna und Flora von allgemeinen und von phyfikalifchen Eigen- 
fchaften der Umgebung, d. i. von ihrem Milieu, hingewiefen oder wie man dies auch ausdrüdken kann, auf die Beziehungen zwifchen Form und Funktion aufmerkfam gemacht. So müffen wir erwarten, daß auch die Zufammenfetyung der Fauna und Flora des Meeresgrundes je nach deffen Befchaffenheit eine verfchiedene fein wird. Es kommen diesbezüglich die fogenannten Mufchelfand- und Schlammgründe in Betracht.

Zunächft follen uns die Gebiete des $\mathrm{Mufchelfandgrundes}$ intereffieren. Die Benennung Mufchelfand rührt davon her, daß man in den fo bezeichneten Sedimenten in wechfelnder Menge von Mufchel- und Schnedkengehäufen herrührende Fragmente findet, die zum großen Teil von Fifchen und Krebfen durch das Freffen folcher Schaltiere erzeugt werden.

Die Mufchelfandgründe ftehen in inniger Beziehung zum Feftlande und zu den Infeln, und fie ftellen eigentlich den von der felsbohrenden Fauna, den Wogen und den Atmofphaerilien durch gemeinfame Arbeit zertrümmerten Felsftrand dar. Infolgedeffen begleiten Streifen von folchen Gründen die Felsküfte, und das Sediment befteht der Hauptfache nach aus Bruch. ftüdken verfchiedener Größe des am Strande anftehenden Felfens, aus Konchilienfragmenten und anderen Reften von animalifhen Hartteilen. Dem Mufchelfand kann je nach äußeren Umfänden mehr weniger Schlamm beigemengt fein, und fo vollzieht fich dann ohne fcharfe Grenze der Ubergang zu den Schlammgründen, die das Terrain des offenen Meeres einnehmen. Im allgemeinen enthält aber der genannte Sand um fo weniger Schlammteile, je näher das Gebiet der Küfte liegt, und dies ift dadurch bedingt, daß durch den Küftenftrom und die Wirkung der Brandung in unmittelbarer Küftennähe die Schlammteile fortwährend ausgewafchen und entfernt werden.

Die Mufchelfandgebiete werden von den italienifchen Fifchern als "fondi duri", als harte Gründe bezeichnet. Auf diefe Eigenfchaft müffen wir bei Betrachtung der Fauna diefer Zonen achten, denn durch fie wird den größeren Formen das Eingraben in das Sediment erfchwert. Die Oberfläche diefer Gebiete wird fich daher ähnlich verhalten wie der Felfen, indem hier der feftfitgenden wie der kriechenden Fauna eine relativ 
harte Unterlage geboten wird. Eine zweite Gruppe bilden kleine Tiere, deren Körperquerfchnitt ein günftiges Verhältnis zu den Lüdkenräumen der Sandkörner befitt, und fie kriechen und zwängen fich einfach durch diefe hindurch. Endlich handelt es fich um Wefen mit genügender Muskelkraft und ftarkem Turgor, d. h. Prallheit der Leibeswand, um in den feften Grund eindringen zu können. Die Beimengung von Schlamm trägt zur Verfeftigung des Mufchelfandes bei, während reiner folcher Sand relativ lodker ift.

Jene Mufchelfandgründe an der Weftküfte Iftriens, deren fauniftifche und floriftifche Eigenfchaften wir fchildern wollen, liegen durchfanittlich 1-3 Seemeilen, alfo etwa $2-5 \mathrm{~km}$ weit vom Lande entfernt, und die Waffermaffe fteht in einer Mächtigkeit von $25-50 \mathrm{~m}$ über ihnen. $\mathrm{Da}$ in diefen Küftengebieten nur wenige Wafferläufe einmünden, fo fällt die Beimengung von trübenden Schlammteilen weg, und infolgedeffen ift das Waffer klar. Während beifpielsweife im Golfe von Trieft die Sichttiefe, - d. i. die Tiefe, in welcher eine herabgelaffene weiße Scheibe den Blidken eben entfchwindet, $-15-18 \mathrm{~m}$ beträgt, kann fie fich dort bis $40 \mathrm{~m}$ fteigern. Alfo am Meeresgrunde diefer $\mathrm{Ge}-$ biete werden noch ziemlich ausnutbbare Lichtverhältniffe herrfchen. Das Bodenwaffer befindet fich hier in ftändiger Bewegung durch Strömungen entlang der Küfte und gegen diefelbe, und hiedurch wird ein reger Transport von Nährfubftanzen unterhalten. Die Temperaturverhältniffe find hier recht günftige, indem das Temperaturjahresmittel in Wechfelwirkung mit den klimatifchen Verhältniffen des angrenzenden Landgebietes am Grunde einen höheren Wert aufweift als im Golfe von Trieft. Auch der Salzgehalt des Waffers zeigt keine großen und plötlichen Schwankungen. Im ganzen genommen liegen alfo in diefen Teilen günftige Verhältniffe für die Entwidklung und das Gedeihen eines reichen marinen Lebens vor.

Wir wollen uns einem Mufchelfifcher anfchließen und mit ihm zum Fang hinausziehen. Für diefen $Z$ wedk fteht der fogenannte "Mufcholiere" in Verwendung, das ift ein Netfadk aus Rebfchnüren mit einer Mafchenweite von ca. $8 \mathrm{~cm}$, der am Meeresgrund hingefchleift wird. Da die Unterkante der 
oblongen Netzöffnung mit großen Bleiftüdken befchwert ift, während die obere Seite durch Korke fchwebend erhalten wird, fo finkt ein folches Nety rafh auf den Grund, und beim langfamen Fahren mit Segel oder Ruder wird dann der Neţbeutel über dem Meeresgrund hingezogen. Dabei rafiert das bleibefhwerte Unterfimm alles am Grunde befindliche $a b$, und das Material wird rom Netyfack aufgenommen. Diefes Netz ift fehr verbreitet, und es wird faft in allen Küftenorten mit ihm gefifcht. Wir ftellen uns vor, daß wir etwa von dem altertümlichen Städtchen Parenzo in Iftrien, berühmt durch feinen Dom als eines architektonifchen Kleinodes aus frühchriftlicher Zeit und wertvoll durch fein noch zu wenig gekanntes und gewürdigtes gutes Winterklima, ausgezogen find, wo einige Seemeilen vom Lande der Mufcholiere ausgeworfen wird. Vorforglich haben wir uns wieder mit einer Lupe und einigen Glasgefäßen ausgerüftet. Wenn dann der Netinhalt auf dem Verdedk des Fahrzeuges ausgebreitet liegt, fo entfaltet fich uns wieder ein neues buntes Bild der Fauna und Flora des Meeres. Nicht allein, daß wir Formen fehen, denen wir bisher nicht begegneten, fo ift vor allem der überwiegend rote und braune Farbenton diefer Mufterkarte auffallend und bemerkenswert. Auch find die Farben vieler Tiere hier viel lebhafter und leuchtender als in Gebieten mit trüberem Waffer.

Was die Zufammenfetzung der Mufchelfandfauna anlangt, fo wäre zu bemerken, daß diefe ebenfowenig wie mit einem Zaune von benachbarten Gebieten abgegrenzt erfcheint, wie jene der Zofterawiefen und andere fauniftifche Bezirke. Je nach der Ortlichkeit und Jahreszeit findet daher auch hier ein gewiffer Wechfel in der am Boden kriechenden Tierwelt ftatt, fo daß die Konftanz der Erfcheinungen hauptfächlich durch die feftfitzende Lebewelt gegeben erfcheint. Wir wollen daher diefe zuerft befprechen.

Die Archenmufchel (Arca noae) (Fig. 108), im adriatifchen Gebiete "Mussolo" genannt, - daher heißt das Netz zum Fangen diefer Tiere "Muffoliere", - ift vielleicht diejenige Form, welche dem Gebiete mit Rüdkficht auf ihr maffenhaftes Vorkommen den Charakter aufdrüdkt. Ihrethalber verlohnt fich deshalb auch das Fifhen in diefem Gebiete zur Gewinnung 
eines billigen und beliebten Volksnahrungsmittels. Diefe Tiere kommen hier zu Klumpen vereinigt vor, indem fie fich entweder mit ihrem bandförmigen fehr kräftigen Byffus an allerlei Gegenftänden oder eine auf der anderen feftheften. Die ftarke Entwidklung diefer genannten Hafteinrichtung deutet eigentlich darauf hin, daß die Arca eine der Felsküfte angehörende Form ift, wo gerade eine folide Befeftigung mit Rüdkficht auf die Wafferbewegung Bedeutung hat, während das Tier am Meeresgrund in diefer Form verankert eigentlich mehr leiftet als nötig wäre, da ja die Kraft der Strömungen in der Tiefe bereits fehr abgefchwächt und verfchwindend klein erfcheint gegenüber dem Brandungsgebiete der Küfte. Tatfächlich findet man diefes Tier vielfach im Gebiete der Felsküfte, aber meift ohne befondere Entfaltung einer großen Individuenzahl. Das Auftreten und Propagieren von Formen in einem diefen fremden Gebiete ift eine für den Biologen intereffante Erfcheinung, die der Beachtung wert ift.

Für den Mufchelfandgrund find ferner die Kalkalgen, Lithothamnien und Lithophyllen, fehr typifche Erfcheinungen, die als Kruften und dünnwandige kraufenartige Stödke von brauner und violettroter Farbe wachfen. Ihre Bruchftücke bilden eine ftarke Beimifchung des Mufchelfandes, ja man kann Ortlichkeiten finden, wo der Sand nur aus Bruchteilen folcher Algen befteht.

Neben der Archenmufchel nehmen vielleicht den meiften Raum die Ascidien ein, welche zu den Manteltieren gehören. Dies find recht intereffante Formen, zunächft einmal dadurch, daß fie während ihres Larvenlebens eine fogenannte Chorda dorsalis befitzen, eine Rüdkenfaite, welche das primitive Skelett aller Wirbeltiere darftellt (vergl. S. 123). Durch diefen Befits und durch gemeinfame Züge in Hinficht auf den Schichtenbau ftehen fie in Beziehung zu diefem Tiertypus und werden als Vorläufer der Wirbeltiere angefehen. Es fei ferner erwähnt, daß andere Manteltiere - fo genannt wegen des Befityes einer konfiftenten Hülle ihres Körpers - zeitlebens die Chorda befitzen, wie die Copelaten, und diefe zeigen das Lagerungsverhältnis der Organe viel deutlicher in dem oben ausgefprochenen Sinne. Die Ascidien 
demonftrieren weiter, wie mächtig der verändernde Einfluß der Annahme der feftfitgenden Lebensweife auf freifchwimmende Tiere ift. Befonders lehrreich ift deshalb der Vergleich der Organifation der freibeweglichen Ascidienlarven und der feftgewachfenen Ascidie.

Wir haben bereits früher erwähnt, daß vielfach bei der feffilen Lebensweife die ungefchlechtliche Fortpflanzung in Form der Knospung auftritt. Diefer Modus führt dann zur Bildung von Tierkolonien. Auch bei den Ascidien ift dies eine häufige Erfheinung, und auf diefem Wege entftehen die zufammengefeţten Ascidien (Synascidien). Die Einzeltiere derfelben fitzen eingebettet in der gallertigen oder knorpeligen Mantelfubftanz, wobei fie fich rofettenartig um eine gemeinfame Kloakenöffnung anordnen (Fig. 138). In diefen Kloakenraum münden der Kiemendarm, der Enddarm und die Gefchlechtsorgane ein. Die Synascidien formieren Uberzüge auf anderen Tieren oder Steinen oder fie bilden Knollen mitunter von ganz anfehnlicher Größe. In der Färbung wiegen die gelben und roten Töne vor; weniger häufig if Blau und Grau.

Die Synascidien kommen im Mufchelfandgebiet in artenund individuenreicher Entfaltung vor, und man kann fie ebenfalls als Leitformen diefer Fazies bezeichnen. Insbefondere wird das große konifch geformte gelbrote $A \mathrm{~m}$ arou cium auffallen. Von den folitären Ascidien find häufige Gattungen die Cynthia dura (Fig. 134, 135), die in der Jugend fchön rot gefärbt ift; im Alter dagegen erfheint ihre derbe runzelige Haut ganz überzogen von allerlei epiphytifchen Algen und Tieren, fo daß man folche Exemplare eher für einen bewachfenen Stein halten würde, wenn man nicht an dem Tiere die beiden roten Siphonenöffnungen entdedken möchte. Eine zweite ähnliche Form ift Microcosmus (Fig. 137) mit einem lederartigen, in Falten gelegten Mantel von dunkelbrauner Farbe. Beide Formen wachfen auch häufig auf Felfen. Die Cynthia papillosa (Fig. 136) ift eine knallrot gefärbte Ascidie, deren Siphonen fehr deutlich abgefetst find.

Auf den Schalen von Arca findet man fehr häufig in diefem Gebiete Hydroidpolypenkolonien in Form von kleinen zierlichen 

Figur

\section{Tafel XVI}

131. Ascidia mammillata (S. 87), Mantelhülle didk knorpelartig durchfcheinend, gelblich- oder bläulich-weiß. Länge bis $15 \mathrm{~cm}$.

132. Styela plicata, Mantel lederartig. An den beiden Körperöffnungen (Mund- und Kloakenöffnung) vier braune Längsftreifen. Länge $3-6 \mathrm{~cm}$.

133. Ciona intestinalis von fchlangenförmiger Geftalt; die beiden Körperöffnungen an deutlich entwidkelten Röhren. Mantel dünn und läßt die Längsmufhelzüge deutlich durchfcheinen.

134. Cynthia dura (S. 88), rote Jugendform.

135. Cynthia dura, erwachfenes Exemplar mit runzeligem derben Mantel; Färbung dunkelbraun, Größe bis $8 \mathrm{~cm}$. Die Tiere find häufig mit Algen dicht bewachfen.

136. Cynthia papillosa (S. 88), leicht erkenntlich an der dunkelroten Farbe, an den deutlich abgefetzten Siphonen mit den Körperöffnungen. Größe 7-9 cm.

137. Microcosmus vulgaris (S. 88), Mantel rotbraun, lederartig, und in quere Falten gelegt. Siphonenröhren glatt und konifch. Größe bis $10 \mathrm{~cm}$.

138. Botryllus, eine zufammengefeţte Ascidie (Synascidien) (S. 88). 
Tafel XVI
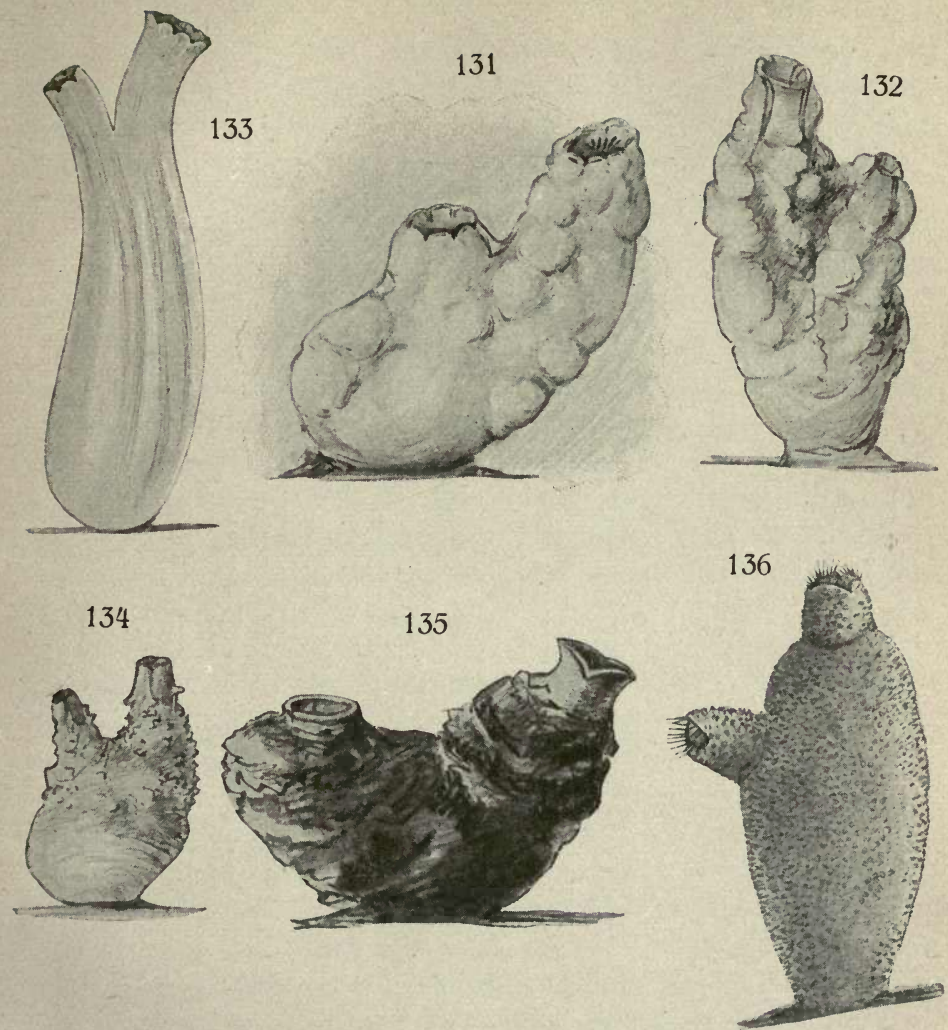

138
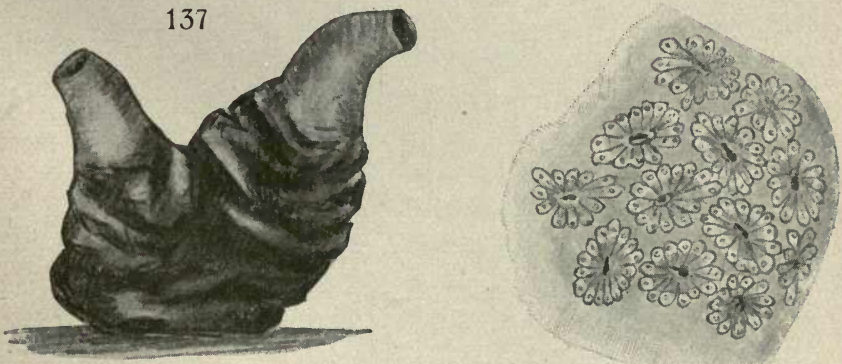

Bäumchen und Federn angefiedelt (Fig. 18). Diefe Tiere find fehr empfindlich gegen das Austrodknen, und man muß fie daher fofort in ein Glas mit Waffer übertragen, wo man dann mit der Lupe ihre Köpfchen mit den Tentakelkränzen betrachten kann. Ferner findet man bis zwei Spannen lange Rutenzweige von grauer Farbe, auf welchen fich kleine Gruben erkennen laffen. Im Waffer entfalten fich erft diefe Zweige, und fie erfheinen nun ganz mit Rofetten befetyt. Wir haben hier eine Hornkoralle (Eunicella) (Fig. 36) vor uns, deren Einzeltiere fich ausgeftredkt haben. Auch zwei Aktinien kommen fpeziell in folchen Gebieten vor und zwar die Ragactis (Fig. 29) und Cereactis. Bei erfterer ift der Körper rot gefledkt, während ihre Tentakel und Mundrcheibe grau und braun quer getigert erfcheinen. Die zweite fehr fchöne Anemone ift häufiger in Küftennähe im Sande eingegraben zu finden.

Die Tiere, die wir im folgenden befprechen, find durchweg am Meeresgrunde frei beweglich und infolgedeffen nicht regelmäßig im Gebiete anzutreffen.

Wir beginnen mit den Krebfen, welche ja mit wenigen Ausnahmen kriechende und fhwimmende Formen find. Volkswirtfchaftlich fpielt vor allem die Seefpinne (Maja squinado) (Fig. 78) eine Rolle, indem diefe große Krabbe entlang der Küfte auf dem Felfen- und Mufchelfandgrund jährlich zu vielen Taufenden von Exemplaren gefangen und zu Markt gebracht wird. Eine andere jedoch kleine Krabbe ift die Pifa (Fig. 82), die fich mit Spongien und Hydroidpolypenftödkchen maskiert.

Sehr reich ift das Mufchelfandgebiet an Nadktfchnedken, wie Doris (Fig. 101), und Doriopfis, die wir fchon an der Felfenküfte kennen gelernt haben. Dann fällt die leuchtend rot gefärbte Flankenfchnedke (Pleurobranchus aurantiacus) (Fig. 99) auf. Während die Dorisarten am Rücken eine rofettenförmige Kieme tragen, hat letterer an der rechten Seite eine Kammkieme. Intereffant find auch die Gehäufefchnedken, Helmfchnedke (Caffidaria) und Tonnenfannedke (Dolium) (Fig. 95, 94) deshalb, weil fie in ihren Speicheldrüfen Schwefelfäure produzieren, die dazu dient, den kohlenfauren Kalk der ihnen 
zur Nahrung dienenden Tiere in pulverförmigen fchwefelfauren (Gips) umzuwandeln. Beide Tiere leben im Sande wühlend.

Die Stachelhäuter find durch verfchiedene Arten von Seefternen vertreten, welche jedoch zum Teil auch im Gebiete der Schlammgründe vorkommen. Der fchön zinnoberrot gefärbte Echinaster sepositus (Fig. 127) und der große mit beweglichen Ârmen verfehene Ásterias glacialis (Fig. 126) lebt jedoch nur am Mufchelfand oder an der Felfenküfte. Außen am Netze hängen oft in großer Anzahl Haarfterne (Antedon) (Fig. 130), manchmal vorwiegend von gelber Farbe, während an anderen Lokalitäten nur rote oder braune Exemplare zu finden find. Die Seeigel zeichnen fich hier durch eine recht anfehnliche Größe aus. Man findet nicht felten den Sphaerechinus granularis (Fig. 124) und ferner den mehr kugeligen oft kindskopfgroßen Echinus melo. Letterer bewegt fich weiter, indem er fich auf feine Stacheln ftütt. In großen Mengen erbeutet man endlich S hlang enfterne (Fig. 125) und die braunen Seewalzen (Holothuria) (Fig. 123). Diefe befitzen ein weites Verbreitungsgebiet in verfchiedenen fauniftifchen Bezirken. Charakteriftifch für das Mufchelfandgebiet ift jedoch die hellbraun und rotgefärbte Holothurie Stichopus regalis. Befonders merkwürdig if an diefem Tier, daß ein kleiner Fifh, Fierasfer (Fig. 170, 171) feinen Enddarm bewohnt; auch ein ungewöhnlicher Fall von Raumparafitismus!

Der Mufchelfand felbft ift von keiner fehr reichen Fauna meift kleinerer Wurmformen bewohnt, und dies erklärt fich vielleicht damit, daß diefes Sediment zu wenig verwertbare organifche Subftanzen enthält. Dagegen eignet es fich gut zur Anlage von Wohnröhren.

An folchen Stellen, wo das genannte Sediment ziemlich rein von Schlammteilen auftritt, wie dies vor allem in Küftennähe der Fall if, da bewohnt ihn ein für die Forfhung hochintereffantes Tier, nämlich das Lanzettfifchen, der Amphioxus lanceolatus (Fig. 139). Wenn wir den Ausdrudk Lanzettfifchchen gebrauchen, fo foll damit nicht gefagt fein, daß dies wirklich eine zu den Fifchen gehörige Form fei. Obzwar diefen verwandtfchaftlich nahe ftehend, repräfentiert fie vielmehr einen felb- 
ftändigen und einfacheren Typus. Die Art und Weife der Entwidklung diefes Tieres, fowie auch manche feiner anatomifchen Verhältniffe haben den Schlüffel für viele, die Wirbeltieranatomie betreffende Fragen geliefert, denn es ftellt förmlich ein vereinfachtes Schema mancher Organifationsverhältniffe der letzteren dar. Darin liegt eben die Bedeutung diefes kleinen etwa 4-5 cm langen Tierchens ohne deutlich abgefetten Kopf, mit farblofem Blute und ohne paarige Floffen. Es befitt auch das primitive Skelett, die fogenannte Chorda dorsalis, wie alle Wirbeltiere eine folche zeitlebens oder nur im Embryonalftadium aufweifen (vergl. S. 87 u. 123); ebenfo befitt es Kiemen, und im übrigen zeigt es dasfelbe Lagerungsverhältnis feiner Organe wie jene. Wenn man den Amphioxus aus dem mittels eines Schleppnetzes gefifchten Sande herausfucht und ihn dann in ein mit etwas Sand befchidktes Glas überträgt, kann man fich überzeugen, wie außerordentlich flüchtig diefes Tier ift und wie es fich augenblidklich mit großer Behendigkeit in den Sand eingräbt und verfteckt. Das Licht mag vor allem auf diefes ftändig in Dunkelheit lebende Gefchöpf einen ftarken Reiz ausüben und es zum rafhen Eingraben veranlaffen.

Wenn man das Tierfyftem als Ganzes betrachtet, fieht man, daß die einzelnen Tierklaffen eine verfaiedene Organifationshöhe erreicht haben, wobei fich nicht verkennen läßt, daß ein Entwidklungsprinzip das gefamte Tierreich beherrfat. Während es alfo manche Formen in ihrem Werdegange auf eine höhere Stufe gebracht haben, find die anderen zurïdk- bezw. ftehen geblieben. Dies genau betrachtet ift gewiß eine fehr merkwürdige Erfheinung. Nun gibt es eine kleine Anzahl von Tieren, welche uns primitive und daher befonders intereffante Typen veranfchaulichen, wie z. B. der Polygordius, dann der Balanogloffus, der Amphioxus u. a. Alle diefe Repräfentanten führen eingegraben im Grunde eine zurüdkgezogene und verftedkte Lebensweife, und gerade darin mag die Urfache für die Erhaltung der primitiven Organifationszuftände gelegen fein.

Der vom Amphioxus bewohnte Sand birgt auch fonft noch eine intereffante Wurmfauna, und unter diefer nennen wir 
fpeziell den oben erwähnten Polygordius, ein kleines fadendünnes Würmchen, das für die Erkenntnis des Wurmtypus etwa eine ähnliche Bedeutung hat, wie der Amphioxus für den Wirbeltierkreis.

Es erübrigt nun noch der Fifchfauna des Mufchelfandgebietes Erwähnung zu tun. Im allgemeinen herrfcht hier kein großer Reichtum an diefen Tieren, und es handelt fich hauptfächlich um Grundfifche. Die Meeresgrundeln haben wir bereits in den Zofterawiefen kennen gelernt, fie kommen auch hier häufig vor; ferner wäre der Seefchwalbe, Knurrhahn (Trigla) (Fig. 164) zu erwähnen, ein fhön rot gefärbter Fifh mit eigentümlichen Taftorganen, die aus einzelnen losgelöften Skelettftrahlen der Bruftfloffe entftanden find. Diefes Tier hat ferner die Eigentümlichkeit, wenn es erfchredkt wird, feine große Bruftfloffe mit ihrer Unterfeite nach oben $z \mathfrak{u}$ kehren und fächerartig auszubreiten, wodurch dann auf blau irifierendem Grunde plöţlich ein großer Augenfledk hervorgezaubert wird. Man deutet dies im Sinne eines Abfchredkmittels.

Relativ häufig find die Haififche und Rochen in diefen Gebieten zu finden. Man ftellt diefen mit langen Standnetzen oder mit der Langleine (Parangal) nach. Leţteres Fanggerät ift eine unter Umftänden mehrere taufend Meter lange Schnur, an welcher mittels Seitenfchnüren Hunderte von Angelhaken befeftigt find. Mit Köder befhidkt wird das Ganze am Meeresgrund ausgelegt. Die Haififche, die man hier fängt, find harmlofe Tiere, wie der Katyen hai (Scyllium) (Fig. 142), der Dornhai (Acanthias) (Fig. 145) und der Glatthai (Mustelus) (Fig. 140). Die beiden leţtgenannten Formen find lebendig gebärend, indem die ganze Entwidklung der Eier im mütterlichen Leib erfolgt. Der Katenhai dagegen legt fehr große in Hornkapfeln (Fig. 143) wohlgefchütte Eier $a b$, die am Meeresgrunde an Korallen und anderen Gegenftänden mittels langer Hornfäden feftgewidkelt werden. So verankert, verweilt dann das Ei durch viele Monate, während welcher Zeit fich aus ihm ein kleines Fifchchen entwidkelt. Auf diefe Weife wird die geringe Fruchtbarkeit diefer Fifche, deren Weibchen nur alle 14 Tage ein Paar Eier während der etwa 4-5 Monate währenden Laichzeit ablegen und daher 
nur eine kleine Anzahl von Keimen der Natur übergeben, ausgeglichen. Die auskriechenden Jungen find dann fhon derart vollkommen entwidkelt, daß fie den Kampf ums Dafein mit gutem Erfolge führen können. Daraus erfehen wir, daß auf fcheinbar ganz verfhiedenem Wege dasfelbe für die gefamte Lebewelt höchfte Ziel, d. i. die Erhaltung der Art, bei den wenig fruchtbaren Haien und bei manchen eine enorme Zahl von Eiern produzierenden Fifchen erreicht wird. Im letteren Falle werden fehr kleine, aber zahlreiche Eier abgelegt, von welchen nur ein verfchwindender Teil zu gefchlechtsreifen Tieren heranzuwachfen braucht, um die Arterhaltung zu fichern; im Gegenfats dazu fteht der Fall bei den Haififchen und Rochen, die wohl große dotterreiche, aber nur wenige Eier produzieren, deren Entwidklung jedoch unter forgfältigem Schuł erfolgt. Das aufgewandte Material hält fich daher in beiden Fällen die Wage, und dies hebt den fcheinbaren Gegenfaty und Widerfpruch bei den angeführten Beifpielen, betreffend die Fruchtbarkeit, auf.

Bei jenen Haififhen und Rochen, welche lebendige Junge zur Welt bringen, bezweckt diefe Art der Fortpflanzung, die im Grunde genommen als eine Form der Brutpflege zu bezeichnen ift, ähnliche Vorteile für die Arterhaltung wie bei den eierlegenden Formen.

Im Mufchelfandgebiet nimmt auch die marine Pflanzenwelt eine anfehnliche Pofition ein. Wie wir in der Region der Flachküfte von den Gefäßpflanzen das Seegras in reicher Entfaltung antrafen, fo if hier eine diefem verwandte und fehr ähnliche, jedoch viel robuftere Form, nämlich die Pofitonia, anzutreffen. An manchen Punkten fteigt diefe Pflanze bis in relativ feichtes Waffer in die Höhe und bildet dann fehr üppige Beftände. Die Grünalgen find nur durch wenige Formen vertreten und zwar durch die Gattung Codium, Halimeda und Valonia. Intereffant ift die erft genannte Alge infofern, als wir innerhalb ihrer Gattung ganz verfhiedenen Geftaltungsformen begegnen. Im Mufhelfand ift die Codium bursa fehr häufig, welches die Geftalt von runden, flachgedrüdxten, grünen Körpern mit einem Durchmeffer bis $20 \mathrm{~cm}$ hat. In der Region der Felsküfte dagegen kommt die Art Codium tomentosum vor, 
deren Thallus infolge einer reichen Verzweigung ein baumkronenformiges Wachstum befitzt, und im felben Gebiet trifft man eine dritte Art, nämlich Codium adhaerens in einer ganz niedrigen unregelmäßig kruften - und knollenförmigen Geftaltung. Beim Codium bursa könnte man geneigt fein, die runde Wachstumsgeftalt als eine Refultante oftmaliger Umlagerung durch Strömungen zu erklären, die Art adhärens dagegen würde einen Mitteltypus zwifhen beiden Extremen darftellen. Ein ähnliches Verhältnis befteht bei Suberites, einem Kiefelfchwamm der Schlammregion; Suberites massa zeigt fingerförmige Verzweigungen, während Suberites domuncula runde Knollen bildet (Fig. 9 u. 10). Leţtere Spezies lebt regelmäßig auf einem Schnedkengehäufe, das von einem Einfiedlerkrebs bewohnt ift und herumgetragen wird. Hier fcheint es ganz eklatant zu fein, daß die ftändige Bewegung des Schwammes durch das Kriechen des Einfiedlers feine Verzweigung unterdrüdkt hat.

Während alfo die Grünalgen nur durch wenige Arten am Grunde des Mufchelfandgebietes vertreten find und Braunalgen ganz fehlen können, zeigen die Rotalgen eine recht reiche Entwidklung felbft noch in größerer Meerestiefe. Von diefen kann man als Leitformen die Vidalia volubilis, erkenntlich an ihren fahraubenförmig gedrehten Blättern und ferner die Rytiphlöa tinctoria bezeichnen. Beide Algen kommen oft in bedeutenden Mengen vor. Damit ift aber die Rotalgenflora diefes Gebietes noch lange nicht erfchöpft. Sie ift vielmehr durch eine ganze Anzahl von zarten und feinftengeligen Arten vertreten, deren Habitus darauf hindeutet, daß dort, wo fie gedeihen, keine heftigen Wafferbewegungen ftattfinden können. Wer dafür Sammlerintereffe hat, bringe diefe Algen in eine halb mit Meerwaffer, halb Süßwaffer gefüllte Schüffel und fange die fo flottierenden Algen auf ein untergefchobenes weißes Papier auf. Solche Blätter läßt man zunächft an der Luft halbwegs trodknen und preßt fie dann zwifchen Fließpapier.

Würden wir uns auf den Grund der Murchelfandgebiete hinabbegeben und fie bei Tageslicht betrachten können, fo 
würden wir den Eindrudk einer vorwiegend in roten und braunen Tönen gehaltenen Landfchaft empfangen. Wir haben ja gefehen, daß die Mehrzahl der dort vorkommenden Lebensformen gelb bis rot gefärbt erfheint, und dies ift gewiß eine auffallende Erfheinung. Bei den Pflanzen ift die Reaktion ihres Protoplasmas gegenüber dem Lichte bekannt; bei den Tieren weiß man, daß fich deren Körperbededkung mit ihren verfchiedenen Pigmenten nicht indifferent gegenüber den Lichtftrahlen verhält. Sollte fich daher bei diefen nicht audh eine Rüdzwirkung gegen beftimmte Strahlengattungen herausgebildet haben? Im vorliegenden Falle würde es fich dann vorwiegend um eine Lichteinftellung für die grünen Strahlen handeln.

Das Mufchelfandgebiet erweift fich alfo als ein in vieler Beziehung intereffanter Lebensbezirk. Wenn wir das ftarke Hervortreten der feftritzenden Fauna in Betracht ziehen und hier Tiere wie die Arca, die Ascidien u. $a$. in reicher Propagation fehen und wenn wir auch noch folche Formen, wie Afterias und Echinafter, ferner den Seeigel Sphärechinus, weiter die Nadktfchnedken nicht außer acht laffen, fo erinnert uns das Bild nicht wenig an das der Felsküfte. Sollte damit vielleicht noch eine Reminifzenz aus jener Zeit zum Ausdrudk kommen, als dort, wo heute der Mufhelfand fich ausbreitet, einftmals das Meer an fchroffen Felfen brandete?

Den größten Teil der Adria nehmen ausgedehnte Gebiete mit S chla mm als Sediment ein. Leţtere wird zum größten Teil von den Flüffen dem Meere zugeführt und befteht vorwiegend aus feinft gemahlenem Felsmehl. Sobald das die Schlammteilchen führende Flußwaffer mit dem Meerwaffer in Berührung tritt, beginnt das Ausfällen derfelben als eine Folge der Kontaktwirkung der beiden Flüffigkeiten, denn bei dem relativ hohen fpezififchen Gewicht des Meerwaffers könnten eigentlich diefe Teilchen viel länger fhwebend erhalten werden. Die Flußläufe führen dem Meere auch noch organifche Subftanzen $\mathrm{zu}$, - folche werden übrigens in anfehnlichen Mengen auch vom Plankton in Form von Schleim produziert, und diefe Materialien fchlagen fich gleichfalls zu Boden. So entfteht der graue Schlamm oder Schlidk. Ferner erhält das Meer ftändig fedi- 
mentbildendes Material durch Abwehen von Staub und durch Abfchwemmen von Erde bei Regengüffen vom Lande aus zugeführt. Die Provenienz des Schlammes läßt fich häufig fchon aus feiner Farbe erkennen, wie im Golfe von Trieft, wo unter dem Einfluffe der Flyfchlandfchaft in Küftennähe der Schlamm gelb oder in Iftrien, dem Lande der Terra rossa, wo er rot gefärbt erfcheint.

Im Gegenfats zum Mufchelfand ftellt der graue Schlidk, wie er in der Adria auf großen weiten Flächen ausgebreitet liegt, ein weiches Subftrat dar, das fchweren Körpern wenig Widerftand entgegenfetzt und diefe daher leicht einfinken läßt. Das Material der Schlammgründe befteht jedoch nicht nur aus diefen erwähnten feinft zerriebenen mineralifchen Teilchen, fondern es mengen fich ihm auch noch allerlei Bruchftüdke von Hartteilen von Tieren bei, wie Foraminiferengehäufe, Wurmröhrenftücke, Krebspanzer, Konchilienfragmente u. a., ferner ift immer ein Betrag von feinem Sand nachzuweifen. Alle diefe Dinge bilden einen fchwankenden und nicht bedeutenden Anteil des Schlammes bis zu jener Tiefe, wo durch Setzung eine entfprechende Dichte des Schlammgrundes eingetreten ift, und diefe Beftandteile nicht tiefer finken können. Darüber breitet fich dann immer eine dünne Schicht homogenen feinen Schlammes aus. Diefe Schichtung ift $j a$ fehr charakteriftifch für die durch Sedimentierung entftandenen Gefteine.

Infolge der ftärkeren Trübung durch Sinkftoffe bezw. der geringeren Lichtdurchläffigkeit des Waffers empfängt die Unterfeelandfchaft der Schlammgründe weniger Licht, als die eben befprochenen Mufchelfandgebiete. Strömungen entfalten fich auch nur in geringer Mächtigkeit, die Verhältniffe der Temperatur und des Salzgehaltes endlich zeigen die jahreszeitlichen Veränderungen ohne plötzliche Kontrafte.

Um das Leben in diefen Gebieten kennen zu lernen, fchließt man fich am beften einem Boote an, welches mit den großen üblichen Grundfchleppnetzen, hier Tartana und Cocchia genannt, fifht. Die hierzu verwendeten Fahrzeuge Bragozzi werden im adriatifchen Gebiete von Fifchern aus Chioggia bei Venedig geführt, braven, tüchtigen und unerfchrodkenen Seeleuten und 

Figur

\section{Tafel XVII}

139. Lanzettfischchen (Amphioxus lanceolatus) (S. 90). Länge 5-7 cm, weiß, durchfcheinend.

140. Glatthai des Aristoteles (Mustelus laevis) (S. 92). Schiefergrau, Länge bis $1 \mathrm{~m}$, Zähne ftumpf und plattenartig angeordnet.

141. Heringshai (Lamna cornubica) (S. 126). Spritglöcher fehr klein, Färbung graufchwarz. Länge bis $3,5 \mathrm{~m}$.

142. Katzenhai (Scyllium stellare) (S. 92). Färbung rötlichbraun mit großen und kleineren dunkelbraunen Flecken. Länge bis $1 \mathrm{~m}$.

143. Ei vom Katzenhai (S. 92), welches mit Hilfe der Hornfäden an Serpularöhren feftgewickelt ift.

144. Fuchshai (Alopias vulpes) (S. 126). Länge bis $4 \mathrm{~m}$. Färbung blaugrau.

145. Dornhai (Acanthias vulgaris) (S. 92). Färbung fchiefergrau, Haut wenig rauh, die beiden Rückenfloffen befityen an der Vorderkante je einen Hornftachel. Länge bis $1 \mathrm{~m}$.

146. Sternroche (Raja asterias) (S. 92, 101). Männchen, Länge bis $50 \mathrm{~cm}$. Rüdken braun mit einzelnen dunkel umrandeten hellen Fledxen.

147 und 148. Stechroche (Trygon pastinaca) von der Ober- und Unterfeite. Färbung dunkelbraun. Länge $1-2 \mathrm{~m}$. Der Gifttachel am Schwanze ift aus einer umgebildeten und reduzierten Rückenfloffe hervorgegangen. S. auch Fig. 155. 
Tafel XVII
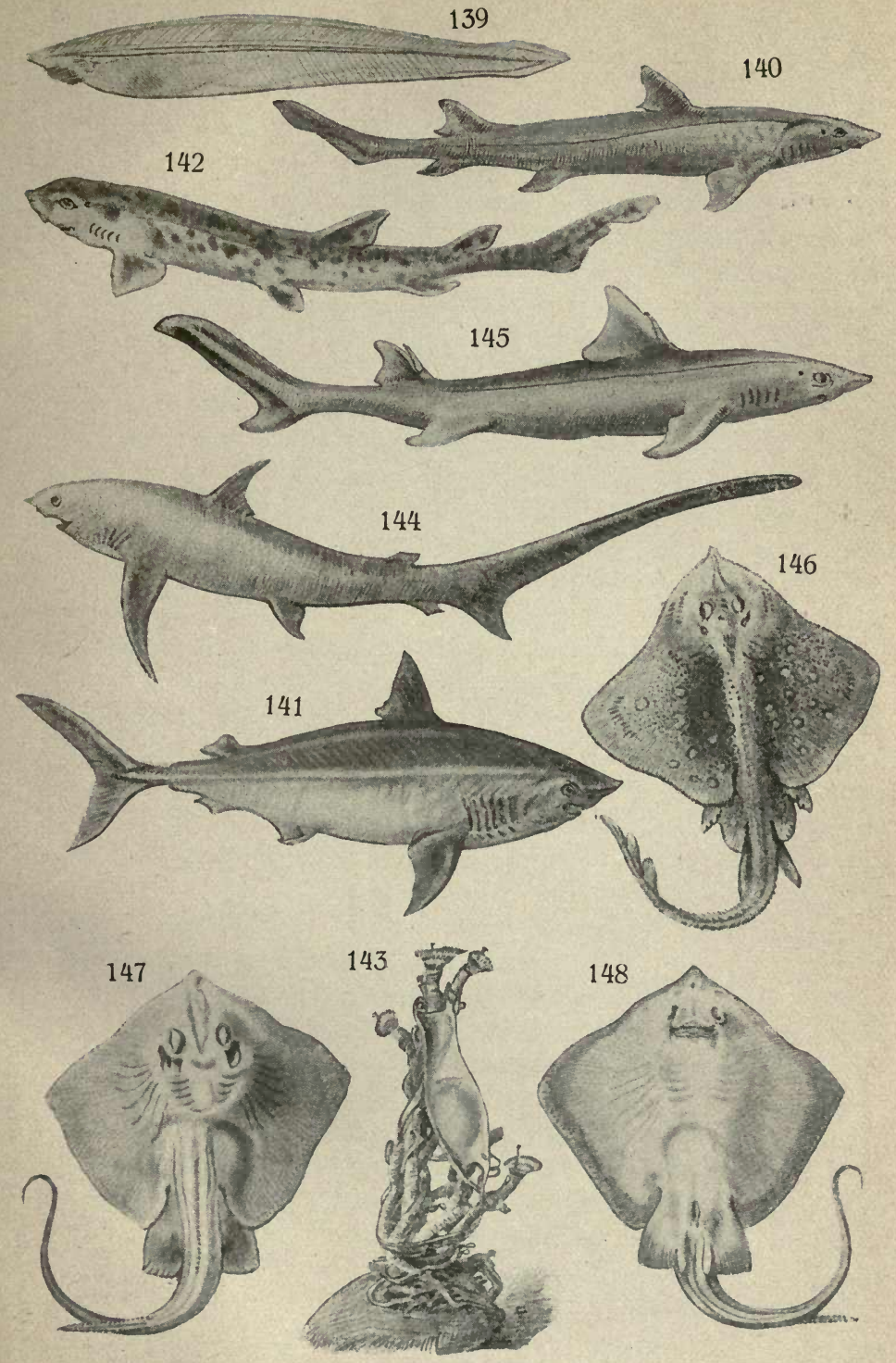


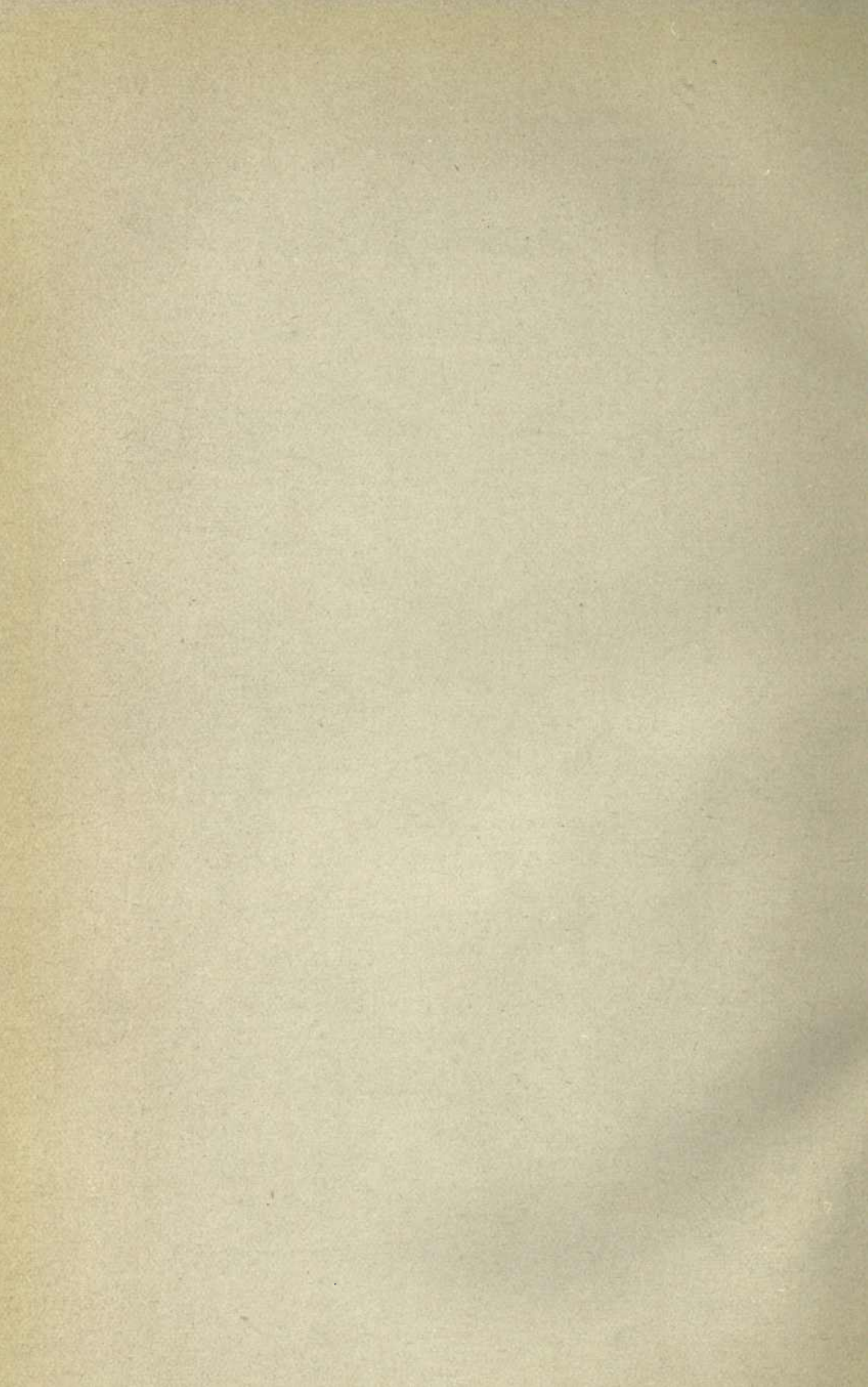


Fifchern, denen man fich ruhig anvertrauen kann. Die genannten Netye beftehen im wefentlichen aus langen fpity zulaufenden Netyfädken, die an der Offnung in fenkrecht frehende Flügel auslaufen. Die untere Kante des Gerätes ift wieder mit Blei befchwert, während das Oberfimm mit Korkftücken armiert ift. Beim Fifchen wird das Nety am Grunde fchleifend von einem oder zwei Booten unter Segel langfam gezogen. Wenn dann die Fifcher fich anfchidken, die langen didken Taue einzuholen, da beginnt die Erwartung des Zufhauers fich zu fteigern. Nun erfcheint endlich der Netffack. Viel trübes Waffer entquillt ihm und fhwebt als graue Wolke in dem herrlich blauen Wafferfpiegel. Bitter enttäufht fehen wir nun zu, wie fich auf dem Verdeck faft nichts als ein Haufen grauen Schlammes ausbreitet. Es werden nun Kübel Waffers über das Ganze gegoffen, und alsbald beginnt es fich zu regen und zu zappeln in der fchmutigen Lache. Schließlich ift man doch überrafcht über die Menge Leben, die der Schlamm gebar.

Die Fauna gruppiert fich auch hier wieder fo, daß ein Teil der Formen auf den Schlammflächen lebt, während andere in der Schlammaffe eingegraben find. Die auf dem Schlammgrund lebenden Tiere find zum größeren Teil feftfitzende Formen, zum geringeren Teil freibewegliche. Die freifchwimmende Fauna ift faft ausfchließlich durch Fifche repräfentiert. Die feftfitsenden und eingegraben lebenden Komponenten ftellen das ftabile Kontingent des Gebietes dar; die kriechenden Formen find dagegen wandernde und je nach Jahreszeit und Umfänden auch in anderen Gebieten $\mathrm{zu}$ finden.

Die eintönige fubmarine Schlammlandfchaft erhält etwas Abwechflung durch die reiche Entwidklung an Schwämmen, die auf der Schlammfläche aufliegen und vorwiegend gelb und rot bis rotbraun gefärbt find. Konchylienfchalen und dergleichen Gegenftände bieten den frei umher fchwimmenden Schwammlarven Gelegenheit zum Fefteten, was fonft in dem weichen Schlamm nicht möglich wäre. Die roten weichen, fich fchlüpfrig anfühlenden Arten gehören zur Gattung Myxilla und die braunen elaftifchen zur Gruppe der Hornfchwämme, die harten konfiftenten orangefarbenen zur Gattung Suberites

Cori, Der Naturfreund. 
(vgl. S. 94), die ein Gerüft aus einachfigen Kiefennadeln befitzen. Dann findet fich noch eine korallenartig verzweigte, knallrote und ziemlich refiftente Form, ebenfalls zu den Kiefelfchwämmen gehörig, die Clathria. Damit ift aber die Lifte der hier vorkommenden Spongien noch nicht erfchöpft.

Diefe Schwammkolonien ftellen fozufagen Infeln und Riffe dar, die das Schlammeer überragen, und von vielen anderen Tieren als Aufenthaltsort benutst werden. Daher ift auf ihnen immer ein reiches Leben $z u$ beobachten. Vorwiegend find es Krabben, wie der behaarte rote Pilumnus und die Miniaturkrabbe Porcellana, ferner laffen fich Pecten varius, eine gleichklappige Pilgermufchel (Pecten varius) (Fig. 112), Hydroid polypenftödkchen anführen, die in diefe Lebensgemeinfhaften gehören. Im Schlamme ftedken ferner mit einem ftielartigen $\mathrm{Abfchnitt}$ die roten Korkkorallen (Alcyonium) (Fig. 35), auf deren aftartigen Verzweigungen die Einzeltiere in Form von Tentakelkronenblumen angeordnet find. Verwandt mit diefen Tieren find ferner die Seefedern (Pteroides und Pennatula) (Fig. 34), die Aktinienkolonien darftellen und ebenfalls Bewohner der Schlammgründe find. Aber auch folitäre Aktinien findet man im Schlammgebiete, wie die Sonnenrofe (Heliactis bellis) (Fig. 31) und die fcönen großen Anemonia sulcata (Fig. 26). Diefe Anemonen gehören eigentlich der Fauna der Felsküfte an. In Ermangelung eines feften Subftrates, wie es der Felfen bietet, begnügen fie fich mit einer Auftern- oder Miesmufhelfchale zum Feftetzen.

Der Schlammgrund felbft enthält noch genügend ausnutzbare organifche Subftanzen, und deshalb finden wir ihn recht reich bevölkert und zwar haupfächlich von fchlammfreffenden Tieren. $\mathrm{Zu}$ diefen gehören viele Würmer, von den Se e walzen die Gattung Holothuria (Fig. 123) und Synapta. Diefe genannten Tiere laffen große Mengen des Sedimentes ihren Darm paffieren und bearbeiten dasfelbe auf diefe Weife, wie es ähnlich am Land mit der Adkererde durch die Regenwürmer der Fall ift. Diefer Punkt wurde bereits bei Befprechung der Lagunenfauna berührt.

Im Schlammgrunde leben ferner eine große Anzahl von Mufhelgattungen und Arten, und es foll von diefen nur die 
merkwürdig geftaltete Striegelmufchel (S ole curtus) (Fig. 106) erwähnt werden. Bei diefer find der Fuß und die zu einer Röhre verwachfenen Siphonen von unverhältnismäßiger Größe, während die Schale zu klein ift, als daß beide Organe zwifchen ihr Schuts und Raum fänden. Eine merkwürdige Molluskenform ift weiter das Dentalium, deffen Schale einem Miniaturelefantenzahn vergleichbar ift. Auch die Schnecken ftellen Formen bei, welche im Schlamme wühlen. Vor allem betrifft dies die Gruppe der fogenannten Hinterkiemenfchnedken (Opisthobranchier). Zu diefen gehört z. B. die Philine, eine fleifchfarbige kleine Schnedke mit rudimentärer Schale. Von den Gehäufefchnedken kann man mitunter von einzelnen Arten fehr große Mengen auf kleinem Raum finden, während es dann wieder benachbarte Gebiete gibt, in denen man ihr Vorkommen nur fporadifch nachweifen kann. Hier denken wir an die Turmfchnedke (Turitella) (Fig. 91). Diefes nefterweife Auftreten von manchen Tieren innerhalb eines fich gleichmäßig verhaltenden Gebietes, wie in den ausgedehnten Schlammflächen, ift eine oft beobachtete und beachtenswerte Erfcheinung. Sie dürfte damit eine Erklärung finden, daß in folchen Gebieten am Meersgrunde nur geringe Meeresftrömungen vorhanden find oder faft Ruhe herrfchen kann. Die Larven, deren Eigenbewegung für einen Weitertransport nicht ausreicht, verbleiben daher an ihrer Geburtsftätte, wo fie fich neben den Eltern einen Platy fichern. Es fei hier eingefchaltet, daß es gerade die Strömungen find, welche Larven weitertragen und über weite Gebiete ausfäen. So fiedeln fich in obigem Falle Generationen nach Generationen im felben Territorium an, und die Zahl der leeren gefifchten Gehäufe überwiegt mitunter jene, welche noch Tiere enthalten. Zerbricht man folche leere Turitellafchalen, fo find diefe gar nicht felten von einem braun gefärbten Wurm mit lederartiger Haut, dem Aspid ofiph on, bewohnt. Diefe Tiere bringen uns auf eine andere der Bonellia ähnliche und diefer verwandten Wurmgattung, die Thalassema gigas, welche im Schlamme eingegraben lebt. In Körpergeftalt und Farbe jener fehr ähnlich unterfcheidet fie fich dadurch, daß ihr Rüffel am Ende nicht gegabelt ift. 
In den Zofterawiefen findet man in den Frühjahrsmonaten in großen Mengen die Stachelfchnedke (Murex) (Fig. 97), welche um diefe Periode zum Laichen dahin wandert. In der übrigen Jahreszeit lebt fie zerftreut vorwiegend im Gebiete der Schlammgründe. Diefe Tiere, wie andere verwandte Schnecken, find ausgefprochene Aasfreffer, und bemerkenswert ift ihre feine Witterung, die ihr das Auffinden der Nahrung erleichtert. Auf den Murexgehäufen fieht man übrigens häufig ein oder mehrere Schmarotzeraktinien (Adamsia Rondeletii)(Fig.38) angefiedelt. Ift die Schnedke abgeftorben, fo bezieht das leere Schnedkengehäufe ein Einfiedlerkrebs (Paguristes maculatus), und die Aktinie lebt dann in Raumgemeinfchaft mit letterem. Die kleine unanfehnliche Mantelaktinie (Adamsia palliata) vergefellfchaftet fich dagegen mit dem Einfiedlerkrebs Eupagurus Prideauxii. Der obenerwähnte Pagurus maculatus geht übrigens häufig auch eine Symbiofe mit dem roten Schwamm Suberites domuncula (Fig. 10) ein, der ebenfalls häufig in der Schlammund Mufchelfandregion gefifht wird. Aus dem Zufammenleben von zwei oder mehreren Tieren, ähnlich wie es uns diefe Beifpiele lehren, gewinnen die Komponenten diefer Tiergemeinfchaft (Symbiofe) Vorteile. Die Zahl folcher Fälle ift eine fehr große, und fie bieten viel Intereffantes vom biologifchen Standpunkte. In der Ausbeute des Netzes if ferner ein Seeftern (Astropecten) (Fig. 129) häufig zu finden. Diefe Form zeigt eine ftarke Entwidklung ihrer Skeletteile, und infolge ihres relativ hohen Gewichtes muß fie in die oberflächlichen weichen Schichten des Schlammgrundes einfinken, die fie dann durchwandert, um als Nahrung allerlei Schnedken, Mufcheln und Aas in den geräumigen Magen aufzunehmen. Manchmal findet man diefen vollgepfropft mit den Gehäufen der Turmfchnedke und des Pelikanfuß (Fig. 91, 92, 93). Wenn man die Langleine zum Fange von Haififchen ausgelegt hat, macht es einem viel Verdruß, den feinen Spürfinn der Stachelfchnedke und Seefterne praktifch kennen zu lernen, indem diefe den Köder der Angelhaken abfreffen und fo die Fifcherei ftören.

Die Schlammgründe haben ihre fpezielle Fifchfauna. Die Repräfentanten diefer rekrutieren fich aus verfhiedenen Fa- 
milien. Faft alle diefe Fifchformen haben den Charakter von Grundfifchen. Die Meergrundeln (Gobius) und die Schleimfifche (Blennius) (Fig. 161) haben wir fchon anderwärts kennen gelernt. Andere zeigen eine noch weiter gediehene Anpaffung an das Grundleben durch eine ftarke Abplattung des Körpers. Diefe verhindert das zu tiefe Einfinken des Fifches in den Schlamm, wenn er auf Beute lauernd oder ausruhend in demfelben eingegraben liegt. In diefem Sinne wäre auch die ftarre Befchaffenheit des obengenannten Seefternes aufzufaffen, deffen Arme gegenüber anderen in der Felfenregion lebenden Seefternarten fehr wenig beweglich find.

Von diefem Gefichtspunkte aus ift auch die Gruppe der Rochen (Fig. 146) aufzufaffen, welche durch Breitenwachstum aus den fchlanken Haififchen hervorgegangen find, und ein verfchiedener Grad in der Ausbildung diefer Wachstumtendenz demonftriert uns noch den Werdegang diefer Umwandlung. Unter den Rochenarten erfcheint der elektrifche Roche, der Zitterroche (Torpedo) (Fig. 155) befonders intereffant durch den Befity eines elektrifchen Organes. Ein folches kommt auch noch einigen anderen Fifchen aus verfohiedenen Familien zu, und in jedem Falle ift es durch Umwandlung aus Muskelpartien entftanden. Hier liegt wieder ein Beifpiel für den Funktionswechfel eines Organes vor. Beim Torpedo lieferte die Kiemenmuskulatur das genannte Organ, und diefes liegt daher zu beiden Seiten des Kopfes. Wenngleich diefe Tiere ziemlich heftige Schläge erteilen können, fo ift es doch zweifelhaft, ob diefe Organe die Bedeutung haben können, etwa Beutetiere immobil zu machen, denn in dem die Elektrizität fo gut leitenden Seewaffer wird die Wirkung eines folchen Schlages ftark abgefchwächt. Deshalb werden auch die Schläge außer Waffer ftärker empfunden als im Waffer. Vielleicht dienen diefe nur zum Auffcheuchen von Beutetieren, die ebenfalls im Schlamme verftedkt liegen. Die Bedeutung einer Schutgeinrichtung kommt wohl hier nicht in Frage.

Ein anderer durch feine Körperform auffallender Firch des Schlammgrundes ift derS e e te u fel (Lophius piscatorius)(Fig. 175). Der Rumpf und Schwanz, die für die übrigen Fifche beim Schwimmen eine fo große Rolle fpielen, find hier ftark reduziert, 
und diefer Fifh ift faft nur Kopf. Wenn der Lophius fein Maul zu einem riefigen mit fpitzen Zähnen bewachten Eingangstor der geräumigen Mundhöhle aufreißt, kann das phantafievolle Gemüt des Künftlers das fchönfte Vorbild für ein Meerungeheuer empfangen. Der Speziesname "Piscatorius" deutet an, daß diefer Fifch felbft Fifcher ift. Auf der Oberlippe befitt er nämlich einen von der Rüdkenfloffe losgelöften Strahl mit einer fächerartigen Verbreiterung, und diefes Organ wird von dem im Meeresgrunde verftedkt liegenden Seeteufel fo bewegt, daß andere Fifhe und Seetiere angelodkt werden - denn die meiften Seetiere fehen ihre Beute nur im bewegten Zuftande -, ein Auf- und Zuklappen des gewaltigen Mundes, und um den Ahnungslofen ift es gefchehen. Nach der Menge feines oft reichlichen Mageninhaltes $z u$ fchließen, find dem Lophius im allgemeinen Nahrungsforgen erfpart.

Eine dritte Gruppe von Fifchen, die im Schlamm eingegraben leben, find die Plattfifche (Pleuronectiden), zu welchen als bekanntefte Formen die Scholle (Platessa platessa, ital. Passera) (Fig. 179) und die Seezunge (Solea vulgaris, ital. Sfoglia) (Fig. 177, 178) gehören; fie erfcheinen uns auch als recht merkwürdige Tiere. In der Jugend find es fymmetrifch gebaute freifhwimmende Fifchchen, die fich aber in einem gewiffen Lebensftadium auf den Meeresgrund niederlaffen. Dabei legen fie fich je nach der Art immer auf eine beftimmte Körperfeite, und der Körper felbft wächlt in die Breite. So wird wieder die Platte hergeftellt, die nicht tief in den Schlamm einfinkt, fondern mehr obenauf liegen bleibt. Mit diefer Umbildung der Körperform fteht ferner in Beziehung die Wanderung des Auges der dem Grunde aufliegenden Seite noch oben, fo daß fich dann beide Augen auf der dem Lichte zugekehrten Stirnfeite befinden. An der Oberfeite ift der Fifch pigmentiert, und die Pigmentzellen zeigen infofern eine deutliche Reaktion gegenüber dem Lichte, als fich die Zeichnung und Färbung diefer Fifche je nach der Umgebung ändert und diefer anpaffen kann. Bemerkenswerterweife gefchieht dies durch Vermittlung des Auges. Die Unterfeite ift pigmentlos und weiß. Die kleineren Plattfifchformen ernähren fich von Tieren, die im 
Schlamme leben, und ihr Mageninhalt befteht oft nur aus einer einzigen Art von Beutetieren. Die großen Steinbutten (Rhombus) (Fig. 176) find Raubfirche, die hauptfächlich kleine Fifche und Krebfe freffen. Zur Zeit der Gefchlechtsreife fcharen fich die Plattfirche zufammen, und da ift es wieder der Menfch, der ihnen gerade während ihres Liebestaumels nachftellt und fie in großen Mengen mit Standnetzen fängt. Viele Grundfirche legen Eier ab, die am Meeresgrunde befindlichen Gegenftänden angeklebt werden. Die Ple uro nectiden dagegen produzieren fehr viele und kleine Eier, die im Meere flottieren. Dies deutet noch darauf hin, daß diefe Gruppe von freifhwimmenden Fifchen ihren Ausgangspunkt genommen hat.

$\mathrm{Zu}$ den Grundfifchen gehört noch eine bizarre Form, die fich wohl auch im Mufchelfand findet, nämlich der Sterngudker (Uranoscopus) (Fig. 168). Bei diefem Fifh zeigt hauptfächlich wieder der Kopf die Formveränderung, bedingt durch das Leben im Sediment. Die Kopffpitze ift auf die Stirnfläche verfhoben, indem der Mund dahin gerüdkt ift. Innen an der Unterlippe befitzt diefes Tier einen Hautlappen, den er als Lodkmittel für Beutetiere auswerfen kann.

Den Schlammgrund felbft bewohnt der Heufchredkenkrebs (Squilla mantis) (Fig. 62), welcher fich Wohnröhren in letteren gräbt, fonft aber fchwimmend feiner Beute nachgeht. Die Panzerteile diefes Krebfes find in fcharfe Spitzen ausgezogen, und leţtere haben offenbar die Bedeutung von Wehrftacheln gegenüber feinen Feinden, den Fifchen. Bei den Krebfen ift die Brutpflege eine faft allgemeine Erfheinung. Während aber meift der Schwanz diefem Zwedke dient und in anderen Fällen die Bruftbeine diefe Aufgabe erfüllen wie bei der Myfis, trägt der Heufchredkenkrebs feine Eier in Form eines Ballens zwifchen den beiden großen Raubbeinen herum, die ihrer eigentlichen Bedeutung nach im Dienfte des Mundes und des Nahrungserwerbes ftehen.

Die dritte Gruppe von Tieren find durch frei am Meeresgrunde herumkriechende Formen repräfentiert. So lebt die Sepia, die uns fchon im Zofteragebiet begegnete, außerhalb ihrer Laichzeit auf den Schlammgründen zerftreut. Ein ftän- 
diger Bewohner diefes Gebietes ift ferner der Mofchuspolyp (Eledone), der dem Octopus in Geftalt ähnelt, jedoch von leţterem leicht unterfcheidbar ift, wenn man beachtet, daß feine Arme nur mit einer Reihe von Saugnäpfen befeţt find, während fich bei der Krake zwei Reihen von diefen finden.

Es erübrigt, fchließlich noch jene Fifche zu erwähnen, welche die Region über den Schlammflächen bewohnen. Diefe Gruppe füllt keine große Lifte. Eigentlich find es nur wenige Schellfifcharten (Gadiden), wie der Mittelmeerdorfch (Gadus euxinus), der $\mathrm{Z}$ wergd orfh (Gadus minutus), der $\mathrm{Hecht-}$ dorfh (Merlucius esculentus). Während diefe Fifchfamilie in den Nordmeeren beherrfchend auftritt, zeigt fie in der Adria keine fo reiche Entwidklung, weder in bezug auf die Arten noch auch hinfichtlich der Individuenzahl und Größe.

$\mathrm{Zu}$ gewiffen Jahreszeiten zieht fich die Meerbarbe (Mullus) (Fig. 159) von der Küftenzone in das tiefere Waffer der Schlammgründe und wird dann hier ziemlich viel gefangen.

Die Algenvegetation tritt in der Schlammregion unverkennbar zurüdk gegenüber den bisher befprochenen Gebieten; eigentlich ift fie nur durch eine häufigere Gattung und Art vertreten, nämlich durch die Rotalge Rodimenia. Diefe Region erfüllt eben wenig die Lebensanfprüche der Algen. Vor allem fehlt das Subftrat zum Feftetzen; nur die Schwämme böten diesbezüglich einigen Erfaţ, und auch die Lichtverhältniffe find keine günftigen.

Aus der Uberficht über das Schlammgebiet ergibt fich alfo, daß diefes reich belebt ift, insbefondere aber durch jene Formen, welche den Schlammgrund felbft bewohnen. In Zufammenhang mit der an niederen Tieren reichen Schlammfauna fteht auch der relative Reichtum an Grundfifchen. So gewinnt das Gebiet auch durch folche Tiere, welche dem Menfchen als Nahrung dienen, eine nicht geringe Bedeutung. Was uns vor allem vom allgemein biologifchen Standpunkt auch hier wieder auffallen muß, ift die fpezififche Anpaffung vieler Vertreter der Schlammfauna an die befonderen Lebensverhältniffe. Je höher diefe Tiere im Syftem ftehen, defto deutlicher treten die adaptiven Eigenfchaften hervor, wie dies fo deutlich die Fifche zeigen. 

Figur

\section{Tafel XVIII}

149. Schriftbarsch (Serranus scriba) (S. 67). Länge $20-25 \mathrm{~cm}$.

150. Wolfsbarsch (Labrax lupus) (S. 29, 57, 67). Länge 80-90 cm. Färbung des Rüdkens silbergrau.

151. Geißbrasse (Sargus Rondeletii) (S. 67). Länge bis $30 \mathrm{~cm}$. Färbung des Rüdkens filbergrau mit 4-6 dunkleren Querbinden. An der Schwanzwurzel ein fchwarzer Fledk.

152. Goldbrasse (Chrysophrys aurata) (S. 29, 57). Länge 50 bis $60 \mathrm{~cm}$. Färbung des Rüdkens graugrün mit 20 goldigen Längsftreifen. An der Wurzel der Bruftfloffe ein karminroter, an der Stirn ein goldgelber Fledk.

153. Zahnbrasse (Dentex vulgaris) (S. 67). Länge bis $1 \mathrm{~m}$. Färbung des Rüdkens blaugrau, an der Seite ins Kupferige übergehend mit unregelmäßigen kleinen fchwarzen Flecken.

154. Meeräsche (Mugil) (S. 29, 57). Fifche mit didkem, etwas abgeplattetem Kopf und fleifchigen Lippen. Färbung des Rückens fchiefer- bis dunkelgrau. Länge $30-50 \mathrm{~cm}$. 


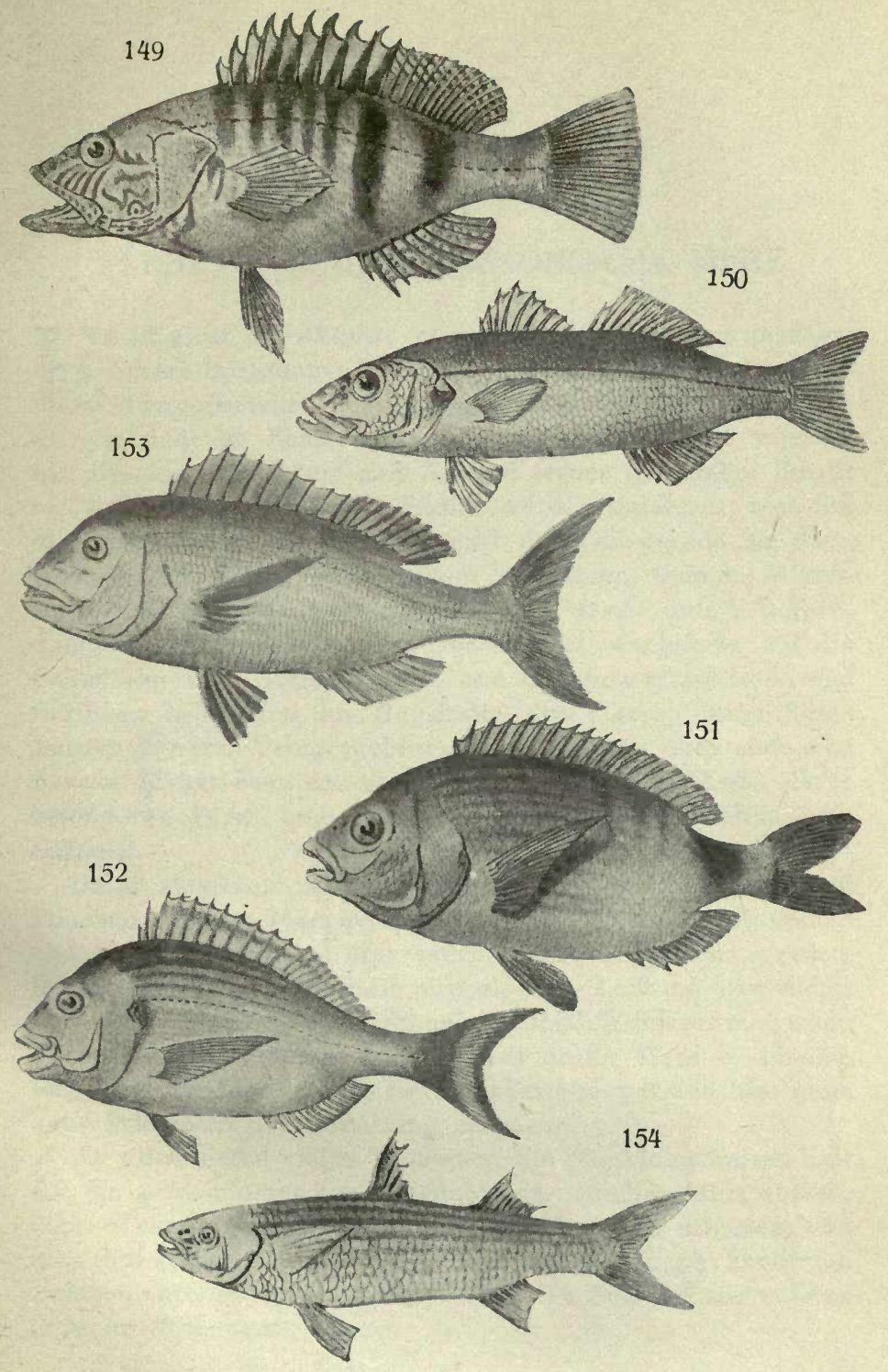





\section{VII. \\ PLANKTON UND PLANKTONISCHE TIERE.}

Ws ift nicht die Abficht, in diefem Abfchnitt eine ausführlichere Darftellung deffen zu geben, was das Plankton des Meeres betrifft, denn diefes Thema ift an anderen Orten in verfhiedener Form und eingehender behandelt worden, als dies hier der Raum zuließe, und ferner foll unfere Schrift im wefentlichen fich hauptfächlich an das anlehnen, was fich unmittelbar beobachten läßt. Und dies ift gerade bei dem, was man fhlechtweg als Plankton bezeichnet, ohne ein Mikrofkop nicht möglich. Aber andererfeits würde unfere Befprechung eine Lüdke aufweifen, wenn nicht wenigftens auf die Bedeutung der vielen kleinen und kleinften pflanzlichen und tierifchen Lebewefen im Haushalte des Meeres hingewiefen werden möchte. Ferner gehören zum Plankton doch auch eine Anzahl folcher Formen, die fich vermöge ihrer Größe, ihrer befonderen Form und Farbe dem Beobachter förmlich aufdrängen.

Unter Plankton verfteht man die Summe von Tieren und Pflanzen, die im Meere fhwebend und treibend vorkommen und die paffiv von den Meeresftrömungen mitgeführt werden. Der Formenreichtum und die phyfiologifhe Leiftung aller diefer Gebilde, - feien fie kaum erkennbar mit Hilfe unferer modernen Mikrofkope oder feien es anfehnlich große Tiere - ift eine fehr bedeutende, und dem Feftlandsbewohner treten hier ganz neue Prinzipien der Geftaltung entgegen.

An allen diefen vielen Taufenden von Planktongeftalten läßt fich ein gemeinfamer Zug erkennen, der nämlich dahin abzielt, diefe Wefen möglichft im Waffer fchwebend zu erhalten, und man hat gefunden, daß diefes Streben ebenfo phyfikalifchen Gefetzen unterworfen ift, wie der Lauf der Geftirne und unferer Erde im Weltraum. 
Werfen wir ein Stükkchen Blei ins Waffer, fo finkt dies fchlankweg unter, ein Stüdk Holz dagegen fchwimmt, weil erftere Subftanz, wie man fich kurzweg ausdrüdkt, fchwerer, letstere jedoch leichter als Waffer ift. Ein Stückchen Bimsftein bleibt ähnlich einem Holzteil fchwimmend, trotzdem Bimsftein fpezififch fchwerer als Waffer ift. Diefer Widerfpruch klärt fich damit auf, daß die genannte Subftanz in ihren zahlreichen Hohlräumen viel Luft enthält, die fie fpezififch leichter macht. Ahnlich wie der Bimsftein verhalten fich die Planktonten, womit man die einzelnen Planktonwefen bezeichnet. Sie find zwar ihrer Materie nach meift fpezififch fhwerer als das fie umgebende Medium, bleiben aber doch fchwebend. Das Schweben wird nun in folgender Weife erreicht. Zunächft erfcheint das fpezififche Gewicht der Planktonformen durch ihren Gas- und Fettgehalt meift faft ausgeglichen gegenüber dem des Meerwaffers. Dazu kommen aber noch andere Faktoren, die dem Abfinken entgegenarbeiten. So ift immer eine Form angeftrebt, die einen möglichlt großen Widerfand der Schwerkraft entgegenfetst, und weiter fpielt hierbei das Verhalten der Oberflächenbefchaffenheit diefer Formen zum Medium, die in der Reibung zum Ausdrudk kommt, eine Rolle. Endlich ift noch das Verhältnis zwifchen der Körperoberfläche und Körpermaffe von Bedeutung. In letterem Punkte verhalten fich diefe beiden Faktoren bei ihrer $\mathrm{Zu}$ - und Abnahme verfchieden, denn das Wachfen der Maffe findet rafcher ftatt als das Wachfen der Fläche. Nun fehen wir gerade bei der Lebewelt im allgemeinen die Tendenz vorliegen, diefes Mißverhältnis aus verfchiedenen Gründen dadurch günftiger zu geftalten, daß die Oberfläche durch Falten und Hohlraumbildungen vergrößert wird, wodurch gleichzeitig die Maffe relativ eine Verminderung erfährt; fo auch bei den Planktonformen. Das wären die allgemeinen Prinzipien, um die es fich in bezug auf das phyfikalifche Moment und die Geftaltung der Planktonten handelt.

Dazu kommt weiter der Umftand, daß die meiften Planktonwefen entweder durch rhythmifch fchlagende feinfte protoplasmatifhe Wimpern oder durch Muskelaktion eine Eigenbewegung befityen, die wohl nicht hinreicht, um ihnen etwa ein 
Schwimmen gegen Meeresftrömungen zu geftatten, welche aber genügend ftark ift, um den beftehenden Unterfchied zwifchen dem fpezififchen Gewicht des Meerwaffers und des eigenen Körpers zu gunften des letzteren auszugleichen. Dies läßt fich durch direkte Beobachtung folcher lebender Formen erkennen, indem diefe abfinken fobald die Eigenbewegung aufhört, wie dies unter verfchiedenen Bedingungen und beim Tode eintritt. Andere Formen gleichen wieder das Pofitivum ihres fpezififchen Gewichtes durch Bildung von Gasblafen und Fettropfen aus. Hier fei übrigens noch die Bemerkung eingefügt, daß fich ein idealer vollkommener Ausgleich zwifhen dem fpezififchen Gewicht eines Tieres und dem des Meerwaffers in der Praxis als ganz irrelevant erweifen würde, da ja jenes des Waffers gar keine konftante Größe darftellt, fondern felbft fortwährenden kleineren und größeren Schwankungen unterworfen ift.

Nun möge mit einigen Worten auf die Bedeutung des Planktons für die marine Fauna und insbefondere für die größeren Tiere hingewiefen werden. Wie bereits erwähnt, fetzt fich diefes aus pflanzlichen und tierifhen Wefen zufammen, die fich aber in bezug auf den Chemismus des Stoffwechfels verfchieden verhalten. Die Pflanze kann nämlich ihren Körper direkt aus den Elementen aufbauen, - man kann ja bekanntlich Pflanzen in Löfungen beftimmter Salze kultivieren, - und auf diefem Wege wird durch die Pflanzenwelt auf unferer Erde ftändig fogenannte lebendige Subftanz (Protoplasma) neu gebildet. Der tierifche Körper befteht ebenfalls aus Protoplasma, aber zum Aufbau desfelben genügen nicht die anorganifchen Verbindungen als folche, fondern das Wachstum, wie man auch die Produktion von neuer Maffe nennt, ift nur möglich auf Grund bereits vorhandener lebendiger Subftanz, und diefe müffen die Pflanzen liefern. Mit anderen Worten, das Tier muß fich in lezter Linie der Pflanze als Nahrung bedienen, um fich zu erhalten. Infolgedeffen fteht das Tierreich in ftrengfter Abhängigkeit vom Pflanzenreich. Ins praktifche Leben überfetyt kommt dies fo zum Ausdrudk, daß die Pflanze immer wieder herhalten muß, damit Tiere gedeihen können, indem ein Teil derfelben jene als Nahrung aufnimmt, während 
fich ein anderer Teil das pflanzliche Protoplasma auf dem Umwege durch den Genuß von Pflanzenfreffern zunutye macht.

Welche Bedeutung fpielt nun im Haushalte des Meeres fpeziell das Plankton, foweit es vorwiegend aus kleinen Lebewefen befteht? Am Feftlande ift das Abhängigkeitsverhältnis der einzelnen Glieder der Lebewelt voneinander recht augenfällig; es läßt fich einem Syftem von ineinander greifenden Zahnrädern vergleichen. Nicht anders ift dies auch im Meere der Fall. Zunächlt find es die arten- und formenreichen Planktonalgen, welche für das gefamte tierifche Leben im Meere die Grundnahrung abgeben, denn fie find die ftändig tätigen Neuerzeuger von lebendiger Subftanz. Wir dürfen eben nicht vergeffen, daß das Meer für diefe Gebilde eine Nährlöfung darftellt, aus deren Elementen fie Protoplasma aufbauen können. Dies gilt auch für die feftitzenden Meeresalgen von oft anfehnlicher Größe. Alle die Algen nehmen zum Unterfchiede von den Landpflanzen die Nahrung mit der gefamten Oberfläche ihres Körpers auf, während jene der Wurzeln bedürfen, um dem Boden die nötigen Nährfubftanzen zu entnehmen, da ja letzterer der Träger des Waffers bezw. der zum Gedeihen und zum Wachstum nötigen wäfferigen Salzlöfung ift.

Jene kleinen und kleinften im Meere fchwebenden Planktonalgen werden von kleinen Tieren als Nahrung aufgenommen. Letstere werden von größeren Tieren gefreffen, und fo geht es weiter bis $z \mathfrak{u}$ den großen Meerestieren, von denen jedes mehr oder weniger an eine beftimmte organifche Nahrung in feiner Organifation angepaßt ift. Auffallend erfcheint es jedoch, daß die reiche Flora der fefflitzenden Meeresalgen von der marinen Tierwelt wenig als Nahrung ausgenütt wird. So läßt fich alfo zeigen, daß die Exiftenz aller Meerestiere, fo auch die jener großen Seeungeheuer, wie der Waltiere und Haififche in letzter Linie von den mikrofkopifch kleinen Planktonalgen abhängig ift. Würden leţtere aus dem Meere verfohwinden, fo wäre damit auch das Shidkfal des gefamten tierifchen Lebens des Meeres befiegelt.

Es möge ferner darauf hingewiefen werden, daß das tierifche Plankton zu einem anfehnlichen Teil aus Entwidklungs- und 
Jugendftadien, fogenannten Larvenformen verfchiedener Tiere befteht. Lehrreich ift dann der Vergleich der Lebensweife der Elterntiere und ihrer Larven, die oft vollftändig verfchieden ift, und dies kommt auch in augenfälligfter Weife in der Körperorganifation zum Ausdrudk. Es ließe fich hierüber viel Intereffantes fagen.

Das Studium des Planktons und die Ergründung der das Leben desfelben beherrfchenden Gefetze ift ein ebenfo intereffantes wie fchwieriges. Zunächft ift fchon die Methode des Einfammelns eine nicht einfache und deren exakte Anwendung im Meere keineswegs leicht. Eigene Expeditionen wurden fpeziell zur Erforfchung diefer Verhältniffe ausgefandt, und zahlreiche Forfcher widmen fich diefen Aufgaben als Spezialgebiet. Wenn uns dank diefer vielfachen und oft aufopfernden Bemühungen ein gewiffer Einblick in das Leben diefer Welt fchon jett möglich ift, fo find wir doch erft am Anfange diefer Erkenntnis. Nicht bloß der Biologe, fondern auch der Chemiker, Phyfiker und Phyfiologe haben da noch ein weites Gebiet zu bearbeiten.

Die Technik der Planktongewinnung aus dem Meere zum Zwedke des Studiums ift eine fehr mannigfaltige. Im wefentlichen kommen aber nur zwei Methoden in Anwendung, nämlich das Abzentrifugieren der im Waffer befindlichen Organismen oder das Abfiltrieren derfelben. Auf letterem Prinzipe beruhen fpeziell alle Planktonnetze. Diefe find nämlich aus einem wafferdurchläffigen Sadke hergeftellt, der durch das Waffer gezogen wird, und indem diefes durch die Gewebslüdken entweicht, werden je nach der Größe der leţteren Planktonwefen im Neţfacke zurüdkgehalten. Wenn es fich jedoch um die kleinften Lebensformen des Meeres handelt, verfagt die Filtriermethode, und man muß zur Zentrifuge Zuflucht nehmen.

Wenngleich alfo, wie oben fchon angedeutet wurde, zum Studium der Planktonformen ein Mikrofkop unerläßlich ift, fo kann man trotgdem fchon durch Betrachtung von Proben lebenden Planktons mittels einer Lupe eine gewiffe Vorftellung von der Fülle des marinen Kleinlebens gewinnen.

Eingangs wurde erwähnt, daß man zum Plankton auch eine Anzahl von Formen rechnet, die anfehnlich groß werden. In 
diefe Gruppe gehören vor allem die Medufen. Infolge ihrer einfachen Organifation nehmen fie im Tierreich eine niedrige Stellung ein, denn dem Prinzip nach ftellt ihr Körper einen aus zwei Zellfchichten beftehenden Sadk dar, deffen einziges Hohlraumfyftem nur eine Öffnung nach außen, nämlich den Mund befitst. Sie gehören zum Kreife der Neffeltiere, welcher Name davon herrührt, daß diefe Tiere bei Berührung mit der menfchlichen Haut durch die Wirkung ihrer Neffelzellen ein Brennen ähnlich jenem der bekannten Brenneffel hervorrufen. Die fcheibenförmige Geftalt der Quallen fteht im Zufammenhang mit dem freifchwimmenden Leben im Meere. Am Rande ihrer hauptfächlich aus einer Gallerte beftehenden Scheibe befinden fich je nach der Gattung und Art eine verfchiedene Anzahl von Fäden, fogenannten Tentakel, welche nichts anderes find, als fchlauchförmige Ausftülpungen der Körperwand. Sie dienen dem Erwerb der Nahrung, die in allerlei kleinen Krebschen, auch Fifchchen und dergleichen befteht. In manchen Fällen fehlen übrigens diefe Bildungen oder der Schirmrand kann auch feftonartig geformte Lappen tragen. Bemerkenswert ift, daß diefe Tiere troty ihrer einfachen Organifation Sinnesorgane und zwar Augen und Gleichgewichtsorgane (fiehe S. 118) (Statolithenbläschen), am Rande des Schirmes befitzen. In der Mitte der unteren konvexen Fläche der Scheibe hängt der bald längere, bald kürzere Mund- und Magenfchlauch herab. Die Fortbewegung diefer Tiere erfolgt durch Muskelkontraktionen, indem hierdurch die Scheibe ftärker gewölbt und bei jeder Kontraktion das Waffer aus der Scheibenkonkavität ausgepreßt wird. Man nennt diefe Form der Bewegung Schwimmen durch Rüdxłtoß.

Von befonderem Intereffe ift die Lebensgefchichte diefer gallertigen Tiere, deren Körper kaum mehr als aus $1 \%$ fefter Subftanz befteht, während der Reft Waffer ift. Die Quallen find der Regel nach getrenntgefchlechtliche Tiere und produzieren Eier, aus welchen fich aber nicht wieder Medufen entwickeln, fondern eine ganz andere Geftaltungsform, nämlich feftfitzende Polypen. Und an diefen entitehen dann erft entweder auf dem Wege der Knofpung oder durch Querteilung die Me- 
dufen, die fich vom Mutterpolypen loslöfen können und dann freifchwimmend werden. Es wechfeln alfo gefchlechtliche und ungefchlechtliche Generationen $a b$, und man bezeichnet dies als Generationswechfel (Fig. 20, 43, a, b). Lehrreich ift dabei der Vergleich der Körperform und der Organifation der freifchwimmenden Qualle und des feftitzenden Polypen einerfeits und der verfchiedenen Lebensweife beider Geftaltungsformen andererfeits, da hierbei die Abhängigkeit der Geftalt und Arbeitsleiftung von der Art der Lebensführung recht klar zum Ausdrudk kommt. Die Medufe befitt als freifhwimmendes Tier eine Scheiben- oder Glodkenform, alfo jene günftige Geftalt, welche dem Abfinken im Waffer einen großen Widerftand entgegenfetyt und das Schweben und Schwimmen erleichtert. Gleich allen freibeweglichen Tieren kommen, wie fhon oben bemerkt, auch der Medufe Sinnesorgane zu, die dem Polypen als feftitzendem Wefen fehlen. Während wir bei jener die Hauptachfe verkürzt und die quere Achfe vergrößert finden, liegt bei diefem gerade das Gegenteil vor, denn er zeigt eine Wachstumstendenz vorwiegend in der Längenachfe des Körpers. Leţteres ift eine häufige Erfcheinung bei feftritzenden Tieren, denn in diefem Falle handelt es fich um die Ausnützung der zum Anheften dienenden Fläche für eine möglichft große Individuenzahl und um die Konkurrenz diefer um den Raum. Wenn wir an ein Getreidefeld denken, finden wir diefes Prinzip im Pflanzenreich in einer fehr weitgehenden Weife' zum Ausdrudk gebracht.

Es bedarf vielleicht nicht des fpeziellen Hinweifes, daß man den Körper der Medufe und des Polypen in ihren einzelnen Abfchnitten direkt aufeinander beziehen kann und daß es fich in beiden Fällen um gleiche Bildungen handelt. So entfprechen die Medufenfcheiben dem Polypenkelch, die Medufententakel den Polypententakeln und der Medufenmund dem Polypenmund. Man faßt die Medufe direkt als einen freifhimmend gewordenen Polypen auf.

Hier möge auch noch die Bemerkung eingefügt werden, daß der Generationswechfel, wie wir ihn oben als reines Schema fhilderten, infofern in vielen Fällen eine verfchieden ftarke Abänderung erfährt, als die Medufen zwar angelegt 
werden, aber nicht zur Ablöfung kommen, und dann finken fie felbft zu feftitzend gewordenen Gefchlechtstieren herab. Gerade diefer Fall des Generationswechfels in feinen verfchiedenen Graden der Aus- und Rüdkbildung zeigt, wie in der Natur immer das Beftreben vorliegt, eine vorhandene Tendenz in der verfchiedenften Richtung zu variieren und auszuprobieren.

Medufen fieht man zu gewiffen Zeiten oft in großen Schwärmen auftreten und dann wieder verfchwinden. Wenngleich diefe Tiere felbft Schwimmbewegungen ausführen, fo handelt es fich dabei doch nicht um ein aktives Wandern, vielmehr find es die Meeresftrömungen, von welchen fie paffiv mitgenommen werden. Innerhalb diefer machen fie noch ihre eigenen Wege in Form von aneinander gereihten Schleifen.

Die Strömungen find eine charakteriftifche Eigenfchaft des Meeres, welches, wenngleich es doch bei fchönem Wetter einen oft vollkommen ruhigen Eindrudk macht, fich in Wirklichkeit in ftändiger Bewegung befindet. Im wefentlichen werden die Meeresftrömungen durch zwei Momente hervorgerufen, einmal durch den Temperaturausgleich zwifhen wärmeren und kälteren Waffermaffen und weiter durch Windwirkung. In dem ringsum abgefchloffenen Mittelmeerbecken und in der Adria fpielt die lettgenannte Urfache die Hauptrolle. Wenn fich vor unferen Augen plötlich der Wind erhebt, fo wird der vorher ganz glatte Wafferfpiegel unruhig, und bald fehen wir Wellen auftreten, die fich mit weißen Kämmen überfchlagen. Die Bewegung der Luft hat fich auf das Waffer übertragen und treibt diefes vorwärts. In dem langgeftredkten fchmalen Adriatifchen Meere, wo fich die Wirkung der Luftbewegung als Urfache der Meeresftrömungen fehr fchön erkennen läßt, find es die aus füdlicher Richtung ftreichenden Winde, wie vor allem der Südoft (Scirocco), welcher im Ablauf des Jahres die Oberhand hat und feine eigene Bewegungsrichtung dem Waffer aufzwingt. Daraus erklärt fich, daß entlang der Weftküfte der Adria der Küftenftrom nach Nordweft verläuft, dann den Golf von Trieft umkreift und fich entlang der Oftküfte Italiens wieder nach dem Süden fortfetyt. Einzelne quer über die Adria verlaufende Seitenzweige des in diefem Meere 
6 
Figur

\section{Tafe1 XIX}

155. Zitterroche (Torpedo marmorata) (S. 101). Länge $40-50 \mathrm{~cm}$. Oberfeite braun, auch auf hellerem Grunde marmoriert.

156. Stör (Acipenser sturio). Länge bis $6 \mathrm{~m}$. Ein durch feine fpitze Schnauze und feine Knochenfchilder auffallender Fifch der fehr alten Fifchgruppe der Schmelzfchupper.

157. Drachenkopf (Scorpaena) (S. 59). Bei diefem Fifch ift befonders der Kopfteil ftark entwidkelt und mit Knochfpitzen bewehrt. Färbung braun bis mennigerot. Länge 30 bis $50 \mathrm{~cm}$.

158. Petermännchen (Trachinus) (S. 59). Länge $30-40 \mathrm{~cm}$. Färbung rotbraun mit dunkleren, fchräg verlaufenden Querftreifen. Die erfte Rückenfloffe ift mit einem fchwarzen Fledk verfehen.

159. Meerbarbe (Mullus barbatus) (S. 104). Länge $25-30 \mathrm{~cm}$. Im Leben braun, nach dem Tode hellrot gefärbter Fifch mit 2 Bärteln am Kinn.

160. Ährenfisch (Atherina) (S. 58). 8-10 cm lange fchlanke Fifchchen, die der Sardelle und Sardine entfernt ähneln, mit filbergrauem Rüdken und 2 Rüdkenfloffen.

161. Schleimfisch (Blennius tentacularis) (S. 59, 101) mit 2 Hautläppchen über den Augen, einer langen Rücken- und Afterfloffe. Färbung auf braunem Grunde mit helleren und dunkleren Punkten. Länge bis $10 \mathrm{~cm}$.

162. Aal (Anguilla vulgaris) (S. 30). Bis $1 \mathrm{~m}$ lang. Die lange Rückenfloffe beginnt hinter dem Kopfe, während diefe beim Meeral (Conger vulgaris) am Kopf einfetzt.

163. 2 Aallarven (Lepthocephalen) und zu unterft ein Jungaal (Montee) (S. 31). 
Tafel XIX
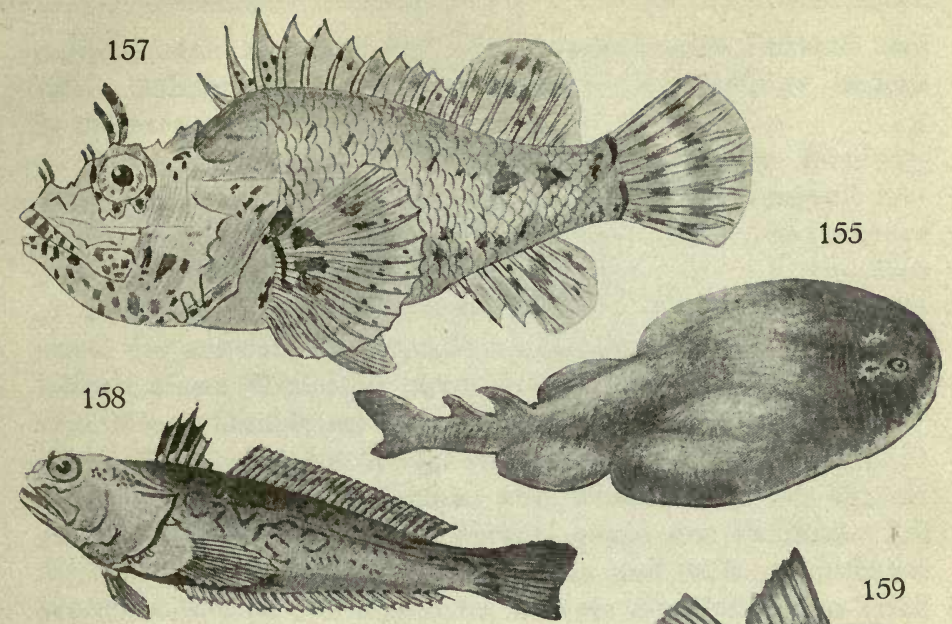

$x+5$
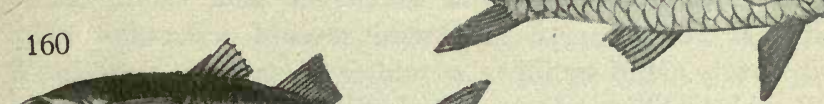

159

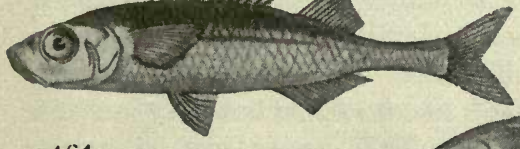

162

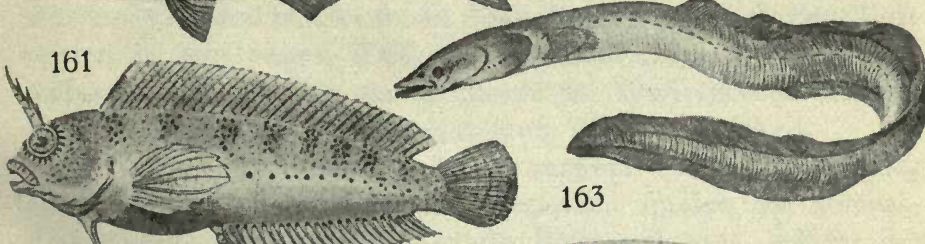

156
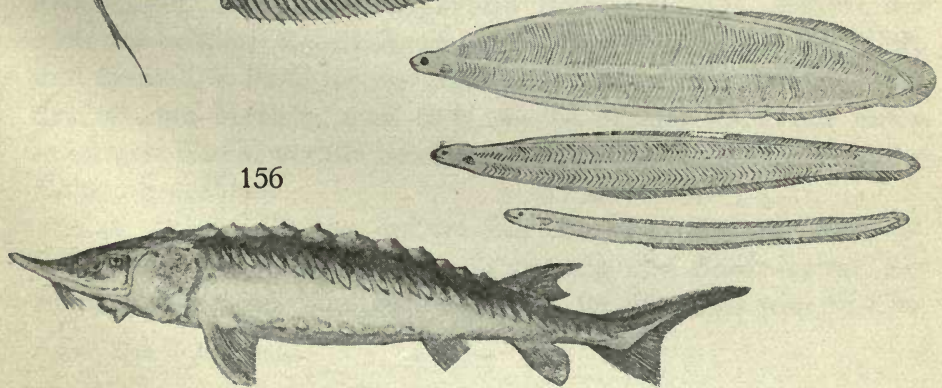
auffeigenden Stromes find durch vorftehendes Feftland und Infeln bedingt, wie man dies z. B: an der Südfpitze Iftriens beobachten kann.

Noch eine andere Strömungserfcheinung durch Windwirkung hat eine nicht geringe Bedeutung für die Lebewelt fpeziell in der Adria. An deren Weftküfte fpielt neben dem Scirocco noch der Nordoft, die gefürchtete und berüchtigte Bora, über große Stredken eine hervorragende Rolle. Die Bora ift ein Fallwind, der aus dem Hinterlande kommend, oft mit orkanartiger Gewalt einem Wafferfall gleich von der Höhe über die Geftade zum Meere hinabftürzt und dabei eifig kalt fein kann. Durch diefen Wind wird das Waffer von der Küfte abgeftaut, und die Folge davon ift ein Zuftrömen von Waffermaffen am Grunde aus der Region des offenen Meeres gegen das Feftland. Auf diefe Weife findet ein fehr ausgiebiger und rafch verlaufender Wafferwechfel an Boratagen im Gebiete des Golfes von Trieft und Fiume und überhaupt in Buchten und im Küftengebiete ftatt.

Der Flut- und Ebbeftrom hat im allgemeinen in den in Rede ftehenden Meeresabfhnitten keine große Mächtigkeit. Wohl können aber in Gebieten zwifchen Infeln durch die Gezeiten (Flut und Ebbe) Niveaudifferenzen zwifchen dem Wafferfpiegel außerhalb und innerhalb der Infeln hervorgerufen werden, und dadurch kommen dann die bekannten ftarken Korrenten in den engen Wafferftraßen infelreicher Küftengebiete zuftande. Solche Höhenunterfchiede im Wafferniveau können in Infelgebieten aber ebenfogut auch Winde bewirken.

Für die Verteilung und den Transport der Lebewefen des Meeres und für das Gedeihen derfelben fpielen die Meeresftrömungen eine bedeutungsvolle Rolle. Daraus erklärt fich auch der größere Reichtum an Grundfauna im Gebiete der Küfte und fpeziell in Paffagen zwifchen Infeln gegenüber den Gebieten des offenen Meeres, weil dort die Strömung nicht nur einen kräftigen Wafferwechfel bewirkt, fondern auch ftändig reichliche Nahrung zuführt.

Am augenfälligften äußert fich die Wirkung der Meeresftrömungen in bezug auf die Verteilung und Beförderung der Planktontiere an den Medufen, da fie förmlich wie fawimCori, Der Naturfreund. 
mende Bojen die Strömungsrichtung anzeigen. In Buchten und Golfen werden dann diefe Tiere oft in ungeheuren Mengen zufammengetrieben. Durch fchätzungsweife Zählung berechneten wir einmal, daß im Golfe von Trieft 40000 Rhizoftomamedufen (Fig. 4) auf den Quadratkilometer kamen, foweit man diefe Tiere in den oberflächlichen Wafferfchichten fehen konnte.

Wenn wir etwa im Triefter Golfe diefen Medufenfchwärmen begegnen, fo ift die Frage, woher kommen eigentlich diefe Tiere, eine zu felbftverfändliche. Wir können darauf antworten, fie kommen mit dem Küftenftrom aus dem Süden und vermuten, daß ihre eigentliche Heimat in dem füdlichen Tiefteile der Adria $z u$ fuchen fei. Es ift eine vieljährige Beobachtung, daß diefe Tiere im genannten Golfe nicht das ganze Jahr auftreten, fondern faifon- und ftoßweife erfcheinen und dann wieder verfchwinden, indem fie mit dem nach Süden entlang der Oftküfte Italiens zurüdkkehrenden Strom wieder mit fortgenommen werden. Diefe Tiere machen fomit eine förmliche Reife rund um die Adria. Die erwachfenen Exemplare legen dabei ihre Eier $a b$, aus welchen fich in großen Mengen die feftitzenden Polypenftadien entwidkeln, und fheinbar werden dann die von letteren gebildeten jungen Meduschen auch wieder in die füdlichen Gebiete des Adriatifchen Meeres verfchleppt, um vielleicht als gefchlechtsreife Tiere fpäter die eben erwähnte Rundreife anzutreten. Die Vermutung, daß diefe Medufen aus der füdlichen Adria kommen, läßt fich als richtig durch die Beobachtung erkennen, daß man diefe Tiere und andere derartige große Planktonformen im Sommer und überhaupt zu jenen Zeiten auf hoher See im füdlichen Teil der Adria antreffen kann, wenn fie in dem nördlichen Abfchnitt diefes Meeres fehlen. In gewiffen Gebieten kann man dann direkt ihre Wanderung nach Norden beobachten. Intereffant und lehrreich ift auch der Umftand, daß im Frühjahr als Begleiter der großen Schwärme von Lungenquallen (Rhizostoma) (Fig. 4) im Triefter Golfe faft regelmäßig der Mondfifch (Fig. 180), deffen Heimat ficher der Süden ift, auftritt.

Im allgemeinen fcheinen diefe Medufen im tiefen Waffer zu treiben, denn im Inhalte der am Grunde fifchenden Schlepp- 
netze finden fich oft folche Tiere, während fie in den oberflächlichen Wafferfchichten zur·gleichen Zeit vollftändig fehlen und erft durch auffteigende Strömungen im Anfchluß an Boratage werden fie dann an die Oberfläche gebracht.

Im Syftem nehmen diefe Tiere wegen ihrer einfachen und zugleich urfprünglichen Organifation eine niedrige Stellung ein, und fie gewinnen noch dadurch allgemeines Intereffe, daß alle höheren Tiere in ihrer Entwidklung ein Stadium, die fogenannte Becherlarve (Gaftrula) durchlaufen, welche dem Prinzipe nach denfelben Bauplan zeigt. Hier fei die Bemerkung angefchloffen, daß vom fyftematifchen Standpunkt aus betrachtet fich nicht alle Medufen und Polypen gleichwertig verhalten, aber wir wollen dies hier außer acht laffen und hervorheben, daß wir in den bisherigen Ausführungen Medufen und Polypen immer im mehr biologifchen Sinne aufgefaßt wiffen wollten.

Die Wurzelmundqualle (Rhizostoma Cuvieri) (Fig. 4) ift die größte und häufigfte Medufe der Adria. Der Durchmeffer ihres Schirmes mißt bis $80 \mathrm{~cm}$, und diefe fonft opake Qualle ift leicht kenntlich durch den blauen Schirmrand mit feftonartigen Lappen, zwifchen welchen fich in Nifhen immer eine Gruppe von Sinnesorganen und zwar ein Gleichgewichtsorgan, ein als Riechgrube gedeutetes Organ und endlich ein Augenfledk finden. Auch die aus der Schirmhöhle hervorragenden Mundarme find blau gefärbt. Befonders bemerkenswert ift der Umftand, daß die Ränder des Mundes bis auf kleine Saugmünddhen miteinander verwachfen find. Diefe Tiere rufen auf unferer Haut kein fühlbares Neffeln hervor, doch muß darauf aufmerkfam gemacht werden, daß ihr Sekret durch die Hände etwa auf die Schleimhäute der Nafe und der Augen übertragen eine ftarke Sekretion, einen "Quallenfchnupfen" hervorruft, der aber nach einigen Stunden wieder vergeht. Nicht felten läßt fich beobachten, daß im Schutge der Schirmhöhle diefer Riefen unter den Medufen Jungfifchchen verfchiedener Fifcharten fhwimmen.

Die Cotylorhiza tuberculata ift eine der eben genannten Wurzelmundqualle verwandte Medufe, die ebenfalls durch teilweife Verwachfung ihres Mundes charakterifiert ift. Die Unterfcheidung beider Formen ift dadurch leicht, daß die 
Cotylorhiza eine flache Scheibe von gelbbrauner Farbe befitzt und daß an den Mundarmen zahlreiche geknöpfte, blau gefärbte Saugkolben herunterhängen.

Die Chrysaora mediterranea (Fig. 5) kann vielleicht als die fchönfte Medufe der Adria gelten. Sie erreicht gleichfalls eine anfehnliche Größe und ift durch ihre braungelbe Farbe auffallend. Auf der Oberfeite des Schirmes bilden dunkelbraune radiär angeordnete Streifen eine fternartige Zeichnung. Die Mundarme diefer Form find fehr lang und kraufenartig geftaltet. Am Schirmrande befinden fich anfehnlich lange Tentakel.

Durch ihr Leuchtvermögen zeichnet fich die Pelagia noctiluca (Fig. 6) aus und außerdem minder angenehm durch die befondere Wirkfamkeit ihrer Neffelorgane, die bei Berührung mit der menfchlichen Haut nicht bloß ein heftiges Judken, fondern auch ein Schwellen derfelben verurfacht.

Die Ohrenqualle (Aurelia aurita) (Fig. 7) wird fo manchem fchon von Befuchen der Oft- und Nordfee her bekannt fein, wo fie gleichfalls häufig auftritt. In diefem Falle haben wir es mit einer zart rofa gefärbten Medufe zu tun, deren Sheibe tellerförmig flach ift und am Rande zwifchen Randlappen zahlreiche Tentakel trägt. Auf ihrer Oberfeite fallen uns in der durchfheinenden Körperwand als dunkler gefärbte ringförmige Gebilde die Gefchlechtsorgane auf, welche im Magenraum gelegen find.

Eine zweite Gruppe von Medufen, welche fich in mancher Beziehung von den bisher befprochenen unterfcheiden, ift dadurch gekennzeichnet, daß fie an einem Polypen als Knofpen ihren Urfprung nehmen und fich dann von diefem loslöfen und freifchwimmende $\mathrm{Hy}$ dromedufen werden, während die früher genannten Scyphomedufen durch Querteilung eines Polypen entftehen (Fig. $143 a$ u. b).

Die Aequorea forscalea (Fig. 3) dürfte die größte der Hydromedufen fein. Ihre flache Scheibe, die einen Durchmeffer bis zu $10 \mathrm{~cm}$ erreichen kann, trägt an der Unterfeite den fehr erweiterbaren Mund auf einem kaum ausgebildeten Magenftiel. Die zahlreichen dunkelblauen Wülfte zwifhen dem Schirmrande und dem Magen find die fogenannten Radiär- 
kanäle, welche einen Teil des Hohlraumfyftemes diefer Tiere darftellen und die erft dadurch deutlicher fichtbar werden, daß fich entlang diefer Kanäle die Gefchlechtsorgane entwickeln. Die Äquorea und die folgenden hier aufgezählten Quallen find Erfcheinungen des Winters und des Frühjahrs.

Die Tima flavilabris (Fig. 1) zeichnet fich von den bisher genannten Medufen durch die glashelle Befchaffenheit ihres Körpers aus, fo daß diefe Tiere im blauen durchfichtigen Meerwaffer fchwer erkennbar find; leichter wird dies erft bei Sonnenfchein. Die Durchfichtigkeit ift eine vielen planktonifchen Seetieren zukommende Eigentümlichkeit.

Die Tiara pileata (Fig. 2) befitgt eine konifhe hohe Scheibe, in deren Mitte der karminrot gefärbe Magen hervorleuchtet. Die Tima und Tiara werden nur wenige Zentimeter groß.

Höchft eigentümliche und fehr auffällige Planktontiere find die fogenannten Röhrenquallen (Siphonophoren), es find dies Medufenkolonien, deren Einzeltiere aber eine fehr verfchiedene Geftaltung, entfprechend ihren verfhiedenartigen Aufgaben befitzen und die fich ihrer Organifation nach den fogenannten Hydromedufen anfchließen. Das Prinzip der Arbeitsteilung ift hier in weitgehender Weife durchgeführt. An mehrfachen Beifpielen wurde fchon darauf hingewiefen, daß die Geftalt durch die Funktion bedingt ift. So fehen wir in diefem Falle einzelne der Individuen diefer Tierkolonie zu Schwimmblafen umgewandelt, andere führen Schwimmbewegungen aus, und folche Schwimmglodxen haben meift noch am beften die Medufencharaktere bewahrt, wieder andere Einzeltiere dienen dem Nahrungserwerb und der Fortpflanzung.

Die größte Röhrenqualle ift wohl die Se eblafe (Phyfalia) (Fig.22), die mittels einer großen Schwimmblafe an der Meeresoberfläche treibend in ganzen Schwärmen auftritt und die Aufmerkfamkeit der Seefahrer auf fich lenken muß. Ihre Fangfäden kann fie auf viele Meter Länge ausdehnen, und folch eine Schar von hunderten und taufenden Exemplaren ift lebendigen Treibnetzen zu vergleichen, die das Meer abfifchen. Die Matrofen follen das Pulver getrodkneter Seeblafen in das Geficht ihrer Nebenbuhler werfen, um hierdurch heftige 
Augenentzündungen zu erzeugen. Dies hängt damit zufammen, daß diefe Tiere fehr wirkfame Neffelorgane in ihren Geweben befitzen.

Einer roten ins Waffer geworfenen Blume ift dagegen die Phyfophora (Fig. 23) nicht unähnlich, indem fich die zinnoberrot gefärbten Dedkftüdke um die zahlreichen Nährmedufen mit ihren Senkfäden und um die Gefchlechtstiere wie Blumenblätter gruppieren. Nach oben davon find um einen Stamm, der mit einer kleinen gaserfüllten Schwimmblafe abfchließt, die Schwimmglodken angeordnet.

Höchft überrafchend ift der Eindrudk, wenn man die Oberfläche des Meeres von ungezählten Mengen fchön blau gefärbter fheibenartiger Tiere mit vielen franfenartig angeordneten Fäden bedeckt fieht. Es handelt fich in diefem Fall um die blaue Segelqualle (Vele1la) (Fig. 39), die von Meeresftrömungen in folchen Maffen in ftillen Hafenwinkeln und Buchten zufammengetrieben werden kann, daß die Oberfläche des Meeres von ihr vollkommen bededkt ift. Ein querer Kamm auf der Oberfläche der Scheibe dient dem Wafler und dem Winde als Angriffsfläche ähnlich einem Segel.

Neben diefen wenigen hier aufgezählten und anderen oft fehr prächtig gefärbten und großen Siphonophoren gibt es aber andererfeits viele ganz durchfichtige und kleine, faft mikrofkopifche Formen.

Befonders intereffante Erfcheinungen find auch die Rippenquallen; diefe Tiere werden mit den Schwämmen und den Neffeltieren zur Gruppe der Hohltiere vereinigt. Ihre Ăhnlichkeit mit den Medufen ift aber nur eine allgemeine, denn fie repräfentieren einen ganz anderen Typus. Eine befondere Eigentümlichkeit ihrer Organifation ift der Befits von acht Wimperftreifen, welche vom Mundpol zum Sinnespol verlaufen und aus rhythmifh fchlagenden, im Lichte irifierenden Platten beftehen. Diefe Wimperplatten arbeiten wie zahlreiche Ruder im Takte zufammen und bewirken das Schwimmen der Tiere. Bemerkenswert ift ferner ein Gleichgewichtsorgan an dem dem Munde gegenüber liegenden Pole. Letzteres befteht wie alle derartigen Organe aus einer Gruppe von mikrofkopifch kleinen 
Kriftällchen, den fogenanten Statolithen, die im vorliegenden Falle ähnlich wie ein Brillant in feiner Faffung von vier kurzen protoplasmatifchen Sinneshaaren getragen werden. Durch Verklebung folcher Haare miteinander ift über das Ganze ein durchfichtiger Sturz geftülpt. Je nach der Stellung des Körpers werden jene Träger der Statolithen verfchieden belaftet bezw. gereizt, und auf diefe Weife wird das Tier über feine Körperlage , unterrichtet. An der Seite des Körpers befitzen die meiften Rippenquallen zwei Tentakel, welche in Tafchen zurüdkgezogen werden können.

Eine ungemein zarte und hinfällige Rippenqualle if die Eucharis multicornis, die bis $20 \mathrm{~cm}$ lang wird und fchwach braun gefärbt ift. Um diefe Tiere betrachten zu können, erbeutet man fie im Meere am beften durch Schöpfen mit einem Glafe.

Die merkwürdigfte Erfcheinung unter den Rippenquallen ift zweifellos das Venusband (Cestus veneris) (Fig. 41). Im adriatifhen Gebiete if diefe Form felten, und nur $a b$ und zu findet man einzelne kleine Exemplare, die zwerghaft klein find im Vergleich zu den bei Meffina und Neapel und anderen Orten des Mittelmeeres vorkommenden von Meterlänge. Der. Körper diefer Rippenqualle ift durch ftarkes Wachstum in der Richtung der einen Querachfe bandartig fchmal geworden, und wenn man die eleganten fchlangenartigen Bewegungen diefer Tiere im Waffer beobachtet, fo gewährt dies einen befonderen und intereffanten Anblick.

Sozufagen zu einer Kugel konzentriert erfcheint dagegen der Körper der farblofen und glashellen Cydippe plumosa (Fig. 40), während die Beroe ovata (Fig. 42) wieder plattgedrüdkt und zungenförmig geftaltet ift. Letzterer Form fehlen die Tentakel.

Aus der Klaffe der Schnedken haben fich eine nicht geringe Anzahl dem pelagifchen Leben angepaßt, und von diefen follen einige Beifpiele angeführt werden. In den das Entzüdken jedes Zoologen hervorrufenden Korrenten, wie man folchen in Meffina und Neapel begegnet, tritt auch eine merkwürdig geftaltete Schnedke, die Kielfhnedke (Carin a ria) (Fig. 104), auf. Der durch- 
fcheinende Körper diefes Tieres wird mittels des allen Schnedken eigentümlichen, hier aber floffenförmigen Fußes durchs Waffer bewegt. Eine andere ganz durchfichtige und in der Nacht leuchtende Schnedkenform, die Phyllirrhoe (Fig. 103) hat einen in Anpaffung an die fhwimmende Lebensweife feitlich vollftändig plattgedrückten Körper. Die Blaufchnedke (Janthina) pflegt fich aus fchaumigem Sekret ein Floß zum Treiben an der Meeresoberfläche herzuftellen. Bei den fogenannten Floffenfhne dken (Pteropoden), welche ebenfalls Planktonformen find, ift der Fuß in zwei zum Schwimmen eingerichtete Flügel ausgezogen.

Die Salpen find ebenfalls auffallende Erfheinungen des Planktons und follen daher hier Erwähnung finden. Sie gehören gleich den uns fhon bekannt gewordenen Seefheiden zu den Manteltieren. Die intereffanten Beziehungen diefer Gruppe zu den Wirbeltieren wurden auch fchon früher berührt. Die in Rede ftehenden Tiere treten zum Teil als folitäre, zum Teil als fogenannte Kettenformen auf. Dies erklärt fich damit, daß letztere auf dem Wege einer ungefchlechtlichen Fortpflanzung durch einen Knofpungsprozeß entftehen, während die einzelnen Kettenindividuen mittels Eiern Einzelfalpen erzeugen, die dann wieder Kettenfalpen bilden. Es handelt fich alfo hier wieder um einen Generationswechfel. Der glashelle Körper diefer Tiere befteht zum größten Teile aus dem Kiemendarme. Der ockergelb gefärbte Kern an dem einen Körperende ift der Darmtraktus. Mit dem weiten fpaltförmigen Munde machen fie ftändig Schludkbewegungen und nehmen auf diefe Weife Planktonalgen und ähnliche fehr kleine Formen als Nahrung auf, deren Skelettrefte man dann im Magen findet. Ihr Magenund Darminhalt ftellt daher für den Diatomeenfammler eine Mufterkarte oft der fchönften und feltenften Diatomeenformen dar.

Wir wollen zunächft die größte der Salpenformen die Salpa africana maxima nennen, deren folitäre Individuen bis $51 \mathrm{~cm}$ lang werden und deren Ketten einen Meter und mehr meffen können. Eine zweite ungleich häufigere und kleinere Art ift die violett gefärbte Salpa mucronata democratica. Wenn diefe lettgenannte Salpe in den Wintermonaten 



\section{Tafel XX}

Figur

164. Seeschwalbe (Trigla) (S. 92). Fifche mit großem, gepanzertem Kopf von roter Farbe.

165. Flughahn (Dactylopterus volitans) (S. 131), ist im Habitus der Seefchwalbe ähnlich, befitt aber noch wefentlich längere, faft bis zur Schwanzfpitze reichende Bruftloffen.

166. Bartumber (Umbrina cirrhosa) (S. 58). Länge $50-70 \mathrm{~cm}$. Färbung grau bis gelb mit dunkleren, fchräg verlaufenden Wellenftreifen. Trägt am Kinn ein ganz kleines Bärtel.

167. Seerabe (Corvina nigra) (S. 58). Färbung fchwarz mit metallifchem Glanze. (Die zweite Rüdkenfloffe etwas zu niedrig dargeftellt.) Länge $40-60 \mathrm{~cm}$.

168. Sterngucker (Uranoscopus scaber) (S. 103), ift ein Verwandter vom Petermännchen von $15-25 \mathrm{~cm}$ Länge und hellbrauner Färbung.

169. Lepadogaster (S. 65), bis $10 \mathrm{~cm}$ lang und je nach der Ârt verfchieden gefärbt, unfcheinbar grau oder fehr lebhaft grün, rot, blau.

170. Fierasfer (S. 90). Länge $10-20 \mathrm{~cm}$. Färbung braun, bisweilen mit dunkleren Fledken.

171. Nexilifer, der pelagifche lebende Jungfifch vom Fierasfer (S. 90).

172. Fregattfisch (Trachypterus taenia) (S. 135). Länge bis $120 \mathrm{~cm}$.

173. Bartmännchen (Ophidium barbatum) (S. 60). Länge 20 bis $30 \mathrm{~cm}$. 
Tafel XX

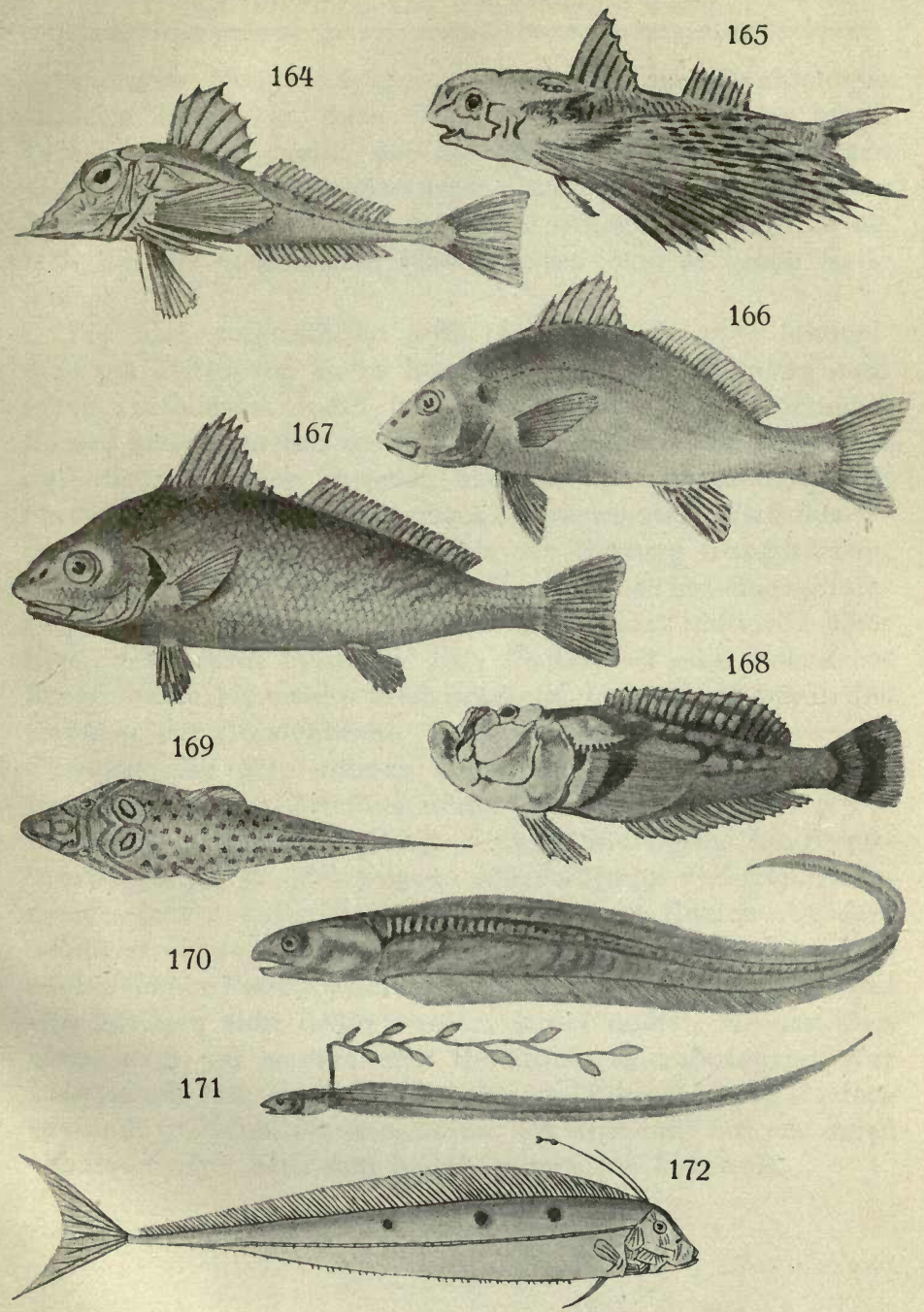

173 Fond 

in enormen Mengen erfheint, fetzen für den Planktologen fhlechte Zeiten ein, denn dann verarmt das Plankton rapid. Dies erklärt fich damit, daß das Meer von diefen gefräßigen Tieren einfach leer gegeffen wird, indem gerade jene kleinften Algenformen durch fie aus demfelben entfernt werden, die als Nahrung für viele kleine Planktontiere eine fo große Rolle fpielen.

Die hier aufgezählten größeren Planktonformen fammelt man am beften von einem Ruderbote aus, und da fallen nicht felten, befonders, wenn fich auch Salpen in den Korrenten finden, kleine herrlich metallifh blau fchimmernde Scheibchen auf, die im Waffer fhweben und bei ihren Wendungen den blauen Farbenton in ein kupferiges Rot verwandeln. Diefe Scheibchen find kleine Schmarotyerkrebfe der Gattung Sapphirina, und zwar die Männchen, während die Weibchen in Salpen fchmarotjen. Die fchöne Färbung diefer Tiere rührt nicht von einer Eigenfarbe durch Pigmente her, fondern if eine fogenannte Interferenzfarbe, welche durch Brechung der Lichtftrahlen in den Geweben der Tiere entfteht. Von einer anderen Krebsform, der Phronima (Fig. 57), wohnen ebenfalls die Weibchen in dem tönnchenförmigen Zellulofemantel von Feuerwalzen (Pyrosoma) und treiben fo gefchütt in den Strömungen. Die Pyrofom en ftellen $20-30 \mathrm{~cm}$ lange röhrenförmige und freifchwimmende Aszidienkolonien dar, die ihren Namen von dem Leuchtvermögen erhalten haben. Man könnte mit dem Aufzählen folcher Planktontiere von augenfälligerer Größe, Geftalt und Färbung nicht fertig werden, leider müffen wir uns hier, wenn auch nur ungern eine Befchränkung auferlegen. Wer Gelegenheit hat, verabfäume nicht die Fifcherei in den Korrenten nach größeren Planktontieren. Es erfchließt fich uns dabei wiederum eine neue und höchft intereffante Lebewelt. 


\section{VIII.}

\section{TIERE DER HOCHSEE.}

Tn den folgenden Abfchnitten follen einige größere Tiere befprochen werden, welche als Vertreter der Hochfeefauna dem Reifenden begegnen können. Die Lebensbedingungen in diefen Gebieten haben wir der Hauptfache nach fchon in dem Abfchnitte über die planktonifhen Formen gekennzeichnet. Dort brachten wir auch in Erfahrung, daß die Planktonlebewefen entweder fhwebende oder fhwimmende Formen find, bei welchen aber das Schwimmvermögen für die Fortbewegung keine große Rolle fpielt. Die Tiere, welche wir nun kennen lernen werden, find durchweg Schwimmer und meift nicht nur gute, fondern zum Teil ausgezeichnete.

Wir wollen diefe Betrachtung mit den Haififchen einleiten. Diefe Tiere find ausfchließlich auf das Meer befăränkt und daher dem Binnenländer unbekannte neue $\mathrm{Ge}-$ ftaltungsformen. Im Syftem der Wirbeltiere nehmen fie eine niedere Stellung, ja faft die niedrigfte Stufe ein, denn diefe Fifche zeigen in ihrer Organifation vielfach einfache und zugleich urfprüngliche Zuftände, wie folche merkwürdigerweife von den höher Itehenden Wirbeltieren während ihrer Entwidklungsperiode durchlaufen werden. Die Haifirchorganifation repräfentiert dem Naturforfcher ein ehrwürdiges Denk$\mathrm{mal}$ in dem Werdegang des formenreichen Kreifes der Wirbeltiere. Nicht fo leicht vermag eine andere Tiergruppe in bezug auf die Mannigfaltigkeit der verfchiedenen Organifationstypen mit dem Wirbeltierftamme in Vergleich zu treten. Dabei find wir in der Lage, die einzelnen Typen desfelben in Form eines Stammbaumes voneinander abzuleiten. An der Wurzel diefer genealogifchen Reihe ftehen nun die Haififche. Diefe Tiere haben wir als altehrwürdige Denkmäler in der Gefchichte der Vertebraten bezeichnet, und in der Tat läßt fich ihr Vorkommen 
bereits in den älteften foffilführenden Schichten unferer Erdrinde auf Grund ihrer als Foffilien erhaltenen Zähne nachweifen. Wie viele Phafen und Schidkfale des Erdballes haben daher diefe Tiere miterlebt und überdauert. Das bedeutet eine bewundernswerte Lebenszähigkeit und Schmiegfamkeit an den Wechfel der Lebensbedingungen, wie er durch die verfchiedenen Epochen der Erdgefchichte bedingt war. Daher fragen wir uns unwillkürlich, warum haben es diefe Tiere in ihrer progreffiven Entwidklung nicht weiter gebracht und, warum find diefe im Beginne des Wettlaufes ftehen geblieben, während ihnen andere weit voran geeilt find?

Wir wollen nun im folgenden verfuchen zu zeigen, inwiefern die Haififche intereffante und wichtige Formen für die Forfchung darftellen und damit zugleich auch einiges aus ihrer einfachen und urfprünglichen Organifation erklären. $\mathrm{Zu}$ diefem Zwedke foll zunächft das für den Wirbeltierkreis fo charakteriftifche Organ, nämlich das Skelettfyftem in feiner ftammesgefchichtlichen Entwicklung betrachtet werden. Urfprünglich befaßen die Vertebraten nur einen elaftifchen Stab unterhalb des Rüdkenmarkes, "die Rüdkenfaite" oder "Chorda dorsalis" als einzige ftütgende Achfe ihres Körpers, wie es bei den Manteltieren und dem Amphioxus der Fall ift. Die Chorda ftellt daher die erfte Etappe des inneren Skelettes der Wirbeltiere dar. Sie alle befityen eine folche und zwar die im Syftem tiefer ftehenden zeitlebens und die höher organifierten nur in jugendlichen Entwidklungsftadien bezw. im erwachfenen Zuftande nur in Form von Reften. Bemerkenswerterweife deutet die Entftehungsgefchichte der Rüdkenfaite auf einen urfprünglichen $\mathrm{Zu}$ fammenhang mit dem Darme hin. Die zweite Etappe der Skelettentwidklung ift durch das Auftreten von Knorpelbogen gekennzeichnet, welche fich an jene Rüdkenfaite zum Schuţe des Rüdkenmarkes und Gehirnes und der in der Bauchhöhle befindlichen Organe anlegten. In der Kopfpartie lieferten dann diefe Knorpelbogen durch Verfchmelzung miteinander eine knorpelige Schädelkapfel zur Umhüllung des Gehirnes. Befondere Knorpelbogen traten ferner im Bereiche des Kiemendarmes auf, und unfer Ober- und Unterkiefer ift aus einer diefer vorderften Kiemen- 
knorpelbogen hervorgegangen. An der Skelettbildung beteiligt fich in dritter Etappe weiter auch noch die Haut durch die Bildung von Knochenfhuppen. Und das vierte und letyte Stadium ftellen Verknöcherungen im Bereiche des Knorpels dar.

Bei den Haififchen kann man nun diefen Werdegang fehr fchön bis zur dritten Stufe erkennen, während dies an den höher ftehenden Säugetieren mit folcher Klarheit nachzuweifen weitaus fchwieriger gewefen wäre, vorausgefeţt, daß uns die Haififche als Bindeglied nicht erhalten geblieben wären. Letztere befitzen nämlich zeitlebens die Chorda, und ihr in den Fleifhmaffen gelegenes Skelett befteht lediglich aus Knorpel, während das Syftem der Hautknochen bei ihnen nur erft durch kleine in der Haut eingebettete Knochenfchuppen, die der Haifirchhảut die charakteriftifche Rauhigkeit verleihen, repräfentiert ift. Die Zähne find nichts anderes als folche ungebildete Knochenfchuppen der Kieferhaut. Durch Vergrößerung und Verfchmelzung folcher knöcherner Hautfchuppen können dann wie bei den fogenannten Panzerfirchen, den Knochenfilchen, den Lurchtieren, Reptilien, den Vögeln und Säugetieren ausgedehnte Knochenplatten befonders im Bereiche des Schädels entftehen. So find alle die Knochen unferes Schädeldaches auf derartige Knochenfchuppen im Bereiche der Kopfhaut zurüdkzuführen. Verknöcherungen im Knorpel fehlen dagegen den Haifirchen vollftändig.

Die Haififche find auch noch in bezug auf andere Fragen höchlt lehrreich. Wer würde es bei Betrachtung unferes Gehörsorgans für möglich halten, daß diefes in einem wichtigen Abfchnitte, dem Gehörgang, ein altes Erbftück aus der Fifhepoche der Wirbeltiergefchichte darftellt. Leţterer if nämlich nichts anderes als eine erhalten gebliebene Kiemenfpalte, die beim Ubergang vom Waffer- zum Landleben ihre Funktion als Atmungsorgan aufgegeben hat und in den Dienft des Gehörsorganes als fchalleitender Kanal getreten ift. Wenn wir einen Haifirch genauer befehen, finden wir bei diefem meift knapp hinter dem Auge eine Offnung, das fogenannte Spritloch. Es ift dies der Zugang zur erften Kiemenfpalte, die infofern bei diefen Tieren fchon Beziehungen zum Gehör- 
apparat zeigt, als fie unmittelbar jenem Abfhnitte des Knorpelfcädels angelagert ift, der den Bogengangapparat, d. i. den fogenannten Gehörapparat der Haie enthält. Diefes Beifpiel erfcheint daher lehrreich einerfeits für die Erfcheinung des Funktionswechfels eines Organes und andererfeits zugleich für die Entftehungsgefchichte eines fo kompliziert gebauten Organes, wie es gerade das Gehörorgan der landbewohnenden Wirbeltiere und fpeziell der Säugetiere ift.

Wenn wir die gefamte Gruppe der Knorpelfifche, zu welchen eben die Haififche gehören, betrachten, fo fehen wir auch bei diefen wieder das gleiche Streben, wie es im Tierreich allgemein $z u$ beobachten ift, möglichft alle fich darbietenden Lebensbedingungen auszunützen, und daher zeigen fie auch recht verfchiedenartige Geftaltungen und Organifationen. Es gibt die freien Gebiete und die oberflächlichen Wafferfchichten bewohnende Haie, es gibt folche, welche den Grund bewohnen, und aus letteren hat fich fpeziell die plattenartige Körpergeftalt der Rochen als echte Grundfifche entwidkelt. Jeder einzelne Fall demonftriert uns in feiner Ausbildung vom Standpunkt der Mechanik das notwendige Maß, deffen er bedarf, um als Spezialmafchine gut funktonieren zu können, und darin findet das Zwedkmäßige feine natürliche Erklärung.

In diefem Kapitel intereffieren uns aber fpeziell jene Haifirche, welche pelagirch leben, $d$. h. die fich auch in den oberen Wafferfchichten aufhalten und auftauchen, fo daß fie direkt gefichtet werden können. $\mathrm{Zu}$ Beginn jeder Badefaifon geht faft als Tradition durch die Zeitungen der Hafenorte des Mittelmeergebietes die Nachricht vom Auftreten von Menfchenhaien. Das Publikum betrachtet folche Mitteilungen vielfach als Zeitungsenten einer ereignisarmen Sommerszeit oder als tendenziöle Warnungen einer übertriebenen Angflichkeit. Die Sache ift aber durchaus nicht fo leicht zu nehmen. Wohl kann man fagen, daß das Mittelmeerbedken an diefen gefräßigen, menfdhengefährlichen Tieren ungleich ärmer als die tropifchen Meere ift, immerhin find fie in manchen Gebieten doch nicht zu feltene Erfcheinungen und der böfe Zufall kann es wollen, daß auch an anderen fonft diesbezüglich als ficher geltenden Küften- 
orten gelegentlich ein großer Haififh auftaucht und ein Opfer an Menfchenleben fordert. Im allgemeinen läßt fich fagen, daß diefe großen Tiere das feichte Waffer und die FlachItrandgebiete ebenfo meiden, wie es Schiffe mit größerem Tiefgang tun müfen, weil in beiden Fällen die Gefahr zu ftranden befteht. Im tiefen Waffer dagegen, wie auf offenen Reeden oder im Küftengebiete fteilabfallender Infeln follten Badende immer in direkter Küftennähe bleiben. Welche Macht der Kiefer und welche Geräumigkeit des Magens die großen Haififchformen befitzen, ergibt fich daraus, daß man als Mageninhalt ganze Delphine gefunden hat.

An diefer Stelle müffen wir uns darauf befchränken, jene Haififche, denen man bei Seefahrten begegnen kann und die zum Teil menfchengefährlich find, dem Namen nach aufzuzählen und verweifen wir gleichzeitig auf die nebenftehenden $\mathrm{Ab}$ bildungen.

Der größte und zugleich aggreffivfte Hai des Mittelmeergebietes, der aber auch im Indifchen und Atlantifchen Ozean auftritt, if der Carcharodon Rondeletii, der bis $13 \mathrm{~m}$ lang wird. Seine Mundränder find mit großen dreiedkigen fcharfen Zähnen in mehreren hintereinander liegenden Reihen befetzt und vermöge der umfangreichen Kaumuskulatur ift die Kraft der Kiefer eine gewaltige. Verwandt mit diefem Hai ift der Herings hai (Lamna cornubica) (Fig. 141), der etwa nur ein Drittel fo lang wird, aber auch menfchengefährlich ift. Der Fuchshai (Alopias vulpes) (Fig. 144), ausgezeichnet durch einen ungewöhnlich langen Schwanz, ift, trotgdem er die anfehnliche Länge bis zu fieben Meter erreicht, dem Menfchen nicht gefährlich. Die bisher erwähnten Haififche find durchwegs auf der Rüdkenfeite mehr weniger grau gefärbt, dagegen ift durch eine fchöne veilchenblaue Farbe der Rückenhaut der Blauhai (Carcharias glaucus) auffallend. Merkwürdigerweife fehlen leţterem die Spritzlöcher. Auch er greift Menfchen an.

Jene pelagifch auftretenden Fifche, welche wir nun befprechen wollen, gehören zu den Knochenfifchen, $\mathrm{zu}$ welchen der größte Teil unferer Genußfifche des Meeres und des Süßwaffers zählt. Gegenüber den Haifirchen nehmen fie im Syftem eine 
höhere Stufe ein, und dies zeigt fich vor allem an der Befchaffenheit ihres Knochenfyftemes; denn die Chorda dorsalis ift im erwachfenen Zuftande bei ihnen nur mehr in Reften vorhanden, die Hautverknöcherungen haben fich hier zu anfehnlichen Knochenplatten weiter entwidkelt, und der Knorpel erfcheint oft in ausgedehntem Maße durch Verknöcherungen erfetzt.

Die meiften der in der Hochfee lebenden Knochenfifche gehören der Familie der Makrelen (Scombridae), einer artenreichen, intereffanten Fifchgruppe an. Viele von ihnen kommen auf ihren Wanderungen auch in Küftennähe, wo man fie leichter beobachten kann und wo man eifrig ihrem Fange nachgeht, denn es find lauter gefchätste Fifcharten.

Ein auch im Binnenlande als Konferve bekannter Vertreter diefer Familie ift die Makrele (Scomber scombrus, italienifch: Scombro, Maccarello) (Fig. 183), welcher über das ganze Mittelmeergebiet bis in den Atlantifhen Ozean verbreitet ift und in großen Schwärmen auftritt. Auf hoher See wird man folcher gewöhnlich erft dadurch gewahr, daß Delphine diefe Fifche jagen. In den Sommermonaten kommen die Makrelen an die Küfte, und dann fifcht man fie entweder mit Netzen oder mit der Angel. Wer Freude am Angelfport hat, kann gerade beim Angeln diefer Fifche reichlich auf feine Koften kommen, denn mitunter ift der Fang fo ergiebig, daß man kaum genug Zeit findet, die Beute heraufzuholen und den Angelhaken aufs neue zu beködern. Abgefehen von dem Reize des Sportes als folchen hat man hierbei auch noch das Vergnügen, den Tag am Meere in ftaub- und keimfreier Luft bei reichlicher Befonnung zu verbringen. Für manchen Rekonvaleszenten und Erholungsbedürftigen wäre diefes Fifchen zweifelsohne ein recht zwedkmäßiger Zeitvertreib. Die Makrele befitgt als gute Schwimmerin, gleich der ganzen Familie, eine reichlich entwickelte Rumpfmuskulatur, die ein fehr zartes, fchmadkhaftes und grätenarmes Fleifh liefert.

Volkswirtfchaftlich fpielt unter den Makrelenfirchen wohl der Thunfifch (Thunnus thynnus, italienifh: Tonno) (Fig. 185) die hervorragendfte Rolle, denn er ift ein anfehnlich großer Fifh, der bis zwei Meter lang und 500 Kilo fchwer werden kann, und der in Schwärmen manchmal von Taufenden von 
Exemplaren in der Küftennähe auftritt. Hier find dann eigene Fangvorrichtungen angebracht, welche alle darauf beruhen, daß ein Schwarm diefer Fifche in eine durch ftarke Netze gebildete Sadkgaffe geleitet wird, aus der es dann kein Entrinnen mehr gibt. Die Tonnaras, - fo nennt man diefe Thunfirchfangvorrichtungen im italienifchen Küftengebiet und die vielfach in Anwendung in der Nähe der öfterreichifchen Rivieraorte Abbazia, Lovrana, Volosca, ftehen - erlauben, daß man vom Strande aus den ganzen Vorgang des Fifchens mit anfehen kann, und dabei hat man Gelegenheit, zu beobachten, welche Kraft dem Körper eines folchen Tieres innewohnt. Es darf dies auch nicht wundern, denn der anfehnlich große Körper diefes Fifhes befteht faft nur aus Muskulatur im Vergleich $z u$ den übrigen Organen. Es gibt auch nicht viele Fifche, ausgenommen die Haififche, welche ein fo kompaktes Fleirch in fo anfehnlichen Stüdken liefern. Die reich entwidkelte Rumpfmuskulatur, die Körperform, die glatte Befchaffenheit der Haut läßt es erklärlich erfoheinen, daß der Thunfirch ein ausgezeichneter Schwimmer ift. Am Fifchmarkt werden diefe Tiere in Form von Koteletts ausgehadkt, und der Querfohnitt läßt dann erkennen, daß die Muskulatur teils in dunkle teils in helle Partien gruppiert ift. Beide Muskelarten unterfcheiden fich auch dadurch, daß die erftere aus Fafern befteht, die fich langfam kontrahieren, dafür aber den Kontrationszuftand lange fefthalten können, während bei den anderen ein gerade umgekehrtes Verhältnis befteht. Ein Gleiches findet fich übrigens auch bei Landtieren, und man fpricht dort von weißem und dunklem Fleifche. Die Kombination diefer fich verfhieden verhaltenden Muskelarten ift im Sinne einer Arbeitsteilung innerhalb der Muskulatur aufzufaffen. Ahnliches zeigt z. B. auch der Schließmuskel der Mufcheln.

Uber die Lebensgefchichte des Thunfifches außerhalb der Zugund Laichzeit wiffen wir leider recht wenig. Aber es läßt fich vermuten, daß er eigentlich ein Hochfeetier ift. Bemerkenswert ift auch, daß man diefe Fifche während ihrer Laichzeit meif mit ganz leerem und kontrahiertem Magen findet, wenigftens beobachteten wir dies im adriatifchen Gebiete. 



\section{Tafel XXI}

Figur

174. Petersfisch (Zeus faber), ein auffallend geformter Fifh der Region Schlammgründe, der bis $1 \mathrm{~m}$ lang wird. Seine Färbung if hellgelb bis hellbraun. An der Seite befitzt er je einen großen fchwarzen Fledk. In der Haut find Knochplatten mit Dornen eingepflanzt.

175. Seeteufel (Lophius piscatorius) (S. 101). Länge bis nahezu $2 \mathrm{~m}$. Färbung des Rüdkens braun.

176. Steinbutt (Rhombus maximus) (S. 103) ift der größte der Plattfifche. Länge bis $2 \mathrm{~m}$. Färbung der linken Seite braun mit dunkleren Punkten und Fledken.

177. Seezunge (Solea vulgaris) (S. 102). Länge $30-60 \mathrm{~cm}$. Färbung gelbbraun.

178. Kopf der Seezunge von der augenlofen (blinden) d. i. linken Körperfeite gefehen (S. 102).

179. Scholle (Platessa platessa) (S. 102). $30-80 \mathrm{~cm}$ lang. Färbung im allgemeinen braun, jedoch fehr variabel.

180. Mondfisch (Orthagoriscus mola) (S. 114, 133).

181. Seepferdchen (Hippocampus) (S. 58). Länge bis $18 \mathrm{~cm}$. Zur felben Gruppe gehören die langgeftredkten Seenadeln. 
Tafel XXI

176 muit)

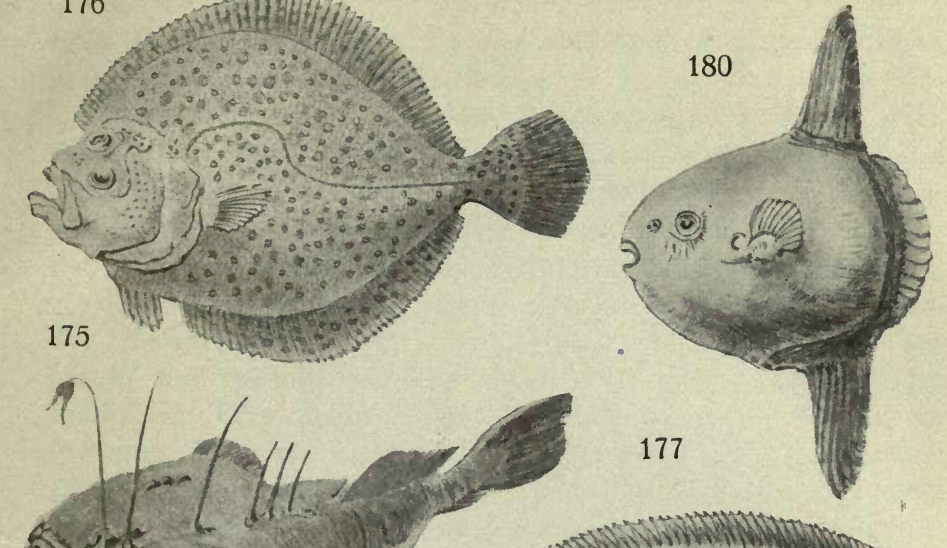

S) 15 (4) $-x^{6}-$
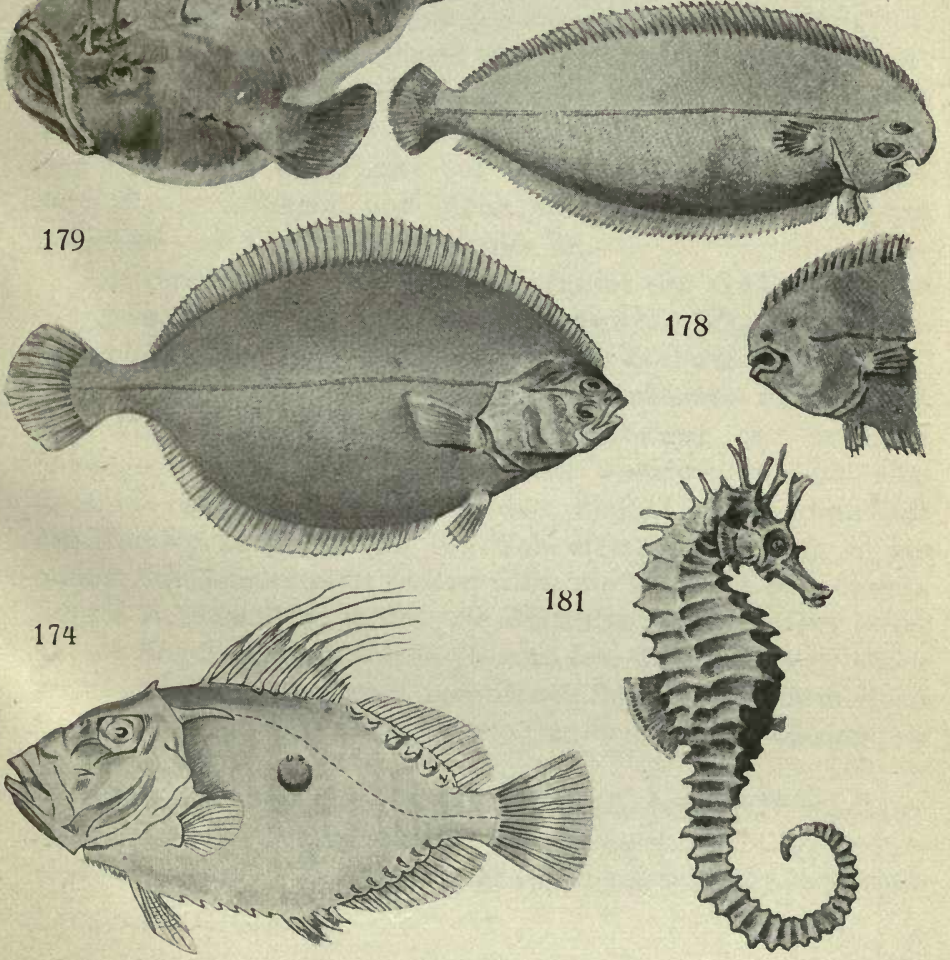

Dies ift eine Erfcheinung, die man auch fonft an anderen Fifchen während der Brunftperiode feftftellen kann. Der ganze Bewegungsdrang, der fonft dem Nahrungserwerb dient, wird dann vollkommen in den Dienft des Liebeslebens geftellt, und der Entgang an Nahrung wird wahrfcheinlich durch Referveftoffe gededkt, die fich als Fett an beftimmten Orten wie in der Leber, den Muskeln ufw. während der Freßperiode anhäufen.

Dem Thunfirch ift in bezug auf Form ungemein ähnlich der Bonitfifch (Sarda sarda, italienifch: Palamita), der jedoch nur etwa $80 \mathrm{~cm}$ lang wird. Bei diefem Fifche ift die Fähigkeit, beim Jagen nach der Beute aus dem Waffer zu fpringen, die mehr oder weniger allen makrelenartigen Fifchen eigen ift, befonders entwidkelt. Die Schwärme der Palamita find manchesmal fo groß und bewegen fich in fo dicht gedrängten Maffen, daß fich bei ihrem Zuge auf glatter See eine fortlaufende und fich überfchlagende Welle bildet. Treffen fie auf Sardinen oder Anchovi, fo fieht man zunächlt leţtere in kurzem Bogen auf der Flucht vor dem gefährlichen Feinde aus dem Waffer fpringen, und gleich hinter ihnen hebt dann ein Springen und Tummeln des Bonits an.

Auf offener See begegnet man ferner der Goldmakrele (Coryphaena hippurus, italienifch: Lampuga) (Fig. 184), einem makrelenartigen Fifch von fchöner blauer Farbe und abenteuerlicher Geftalt. Der blaue bis braune Farbenton der Haut ift eine Eigentümlichkeit, die vielen Vertretern der in Rede ftehenden Firchfamilie zukommt und wahrfcheinlich als eine Reaktion der Hautdecke unter dem Einfluß der Lichtqualität der Hochfee zu betrachten ift. Von diefem Firch, dem es als gutem Schwimmer nicht fchwer fällt, die in Fahrt befindlichen Schiffe zu begleiten, wiffen die Matrofen, daß er fehr leicht an die Angel geht, und deshalb wird fein Erfheinen von diefen fofort ausgenütt, um dem monotonen Schiffsmenü durch einen fchmadkhaften Lampugabraten eine erwünfchte Abwechslung zu geben.

Durch eine Saugfheibe am Kopfe ift der Schiffshalter (Echeneis naucrates, italienifh: Suffapega) (Fig. 187) ausgezeichnet, und diefe Einrichtung ift wieder ein lehrreiches Beifpiel Cori, Der Naturfreund. 
für die Erfcheinung des Funktionswechfels, durch welches Prinzip die meiften Spezialorgane entfanden find. Jene Saugfheibe ift nämlich nichts anderes als ein Teil der umgebildeten Rückenfloffe, und fie dient zum Feftheften an größeren Fifchen, wie befonders an Haififchen und gelegentlich auch an Shiffsböden.

Ein anderer intereffanter Hochfeefirch ift der S chwertfifch (Xiphias gladius, italienifch: Pesce spada) (Fig. 186), deffen Oberkiefer zu einem langen fchwertartigen Fortfaty ausgezogen erfcheint, mit welchem er wie mit einer Lanze auf feine Beute losfchießt und dabei auch einen weiten Sprung aus dem Waffer machen kann. Diefe Kieferbildung ift gleichzeitig auch eine wirkfame Waffe zur Verteidigung. Wie die anderen Makrelenfilche ift auch er ein gewandter Schwimmer, der vier bis fünf Meter lang und mehrere Zentner fohwer wird. Die Tiere können auch aggreffiv werden, fo daß deren Fang, wie er befonders in Sizilien mittels Harpune betrieben wird, gar nicht fo gefahrlos ift. Während die Kopfknochen der Knochenfirche meift nur dünne und wenig fefte Platten darftellen, befteht der Oberkieferfortfats des Xiphias aus fehr harter Knochenfubftanz, und ein Beleg für feine Feftigkeit und die dem Tiere innewohnende Kraft liefert ein Stüdk einer mit Kupferblech befchlagenen Schiffswand im Hamburger naturwiffenfchaftlichen Mufeum, welche von einem Schwertfortfatye eines foldhen Tieres durchftoßen wurde, wobei diefer in dem Ledke ftedken blieb. Während die anderen makrelenartigen Fifche eine gute Bezahnung in den Kiefern befityen, mangelt dem Schwertfifch eine folche; diefe wird eben funktionell durch den Kieferfortfaty erfetyt, der das Beutetier immobil macht, fo daß es leicht verfaludkt werden kann. Bei den Raubfirchen haben die Zähne der Kiefer und des Mundes auch nur die Bedeutung, die lebende Beute feftzuhalten, und eine Bezahnung zur Zerkleinerung der Nahrung ift eine erft zu der Aufnahme pflanzlicher Koft in Beziehung ftehende Erwerbung.

Den Makrelenfirchen ähnlich ift der Flugfifch (Exonautes Rondeletii, italienifch: Rondine1la) (Fig. 188), der Familie der Makrelenhedhte (Scomberesocidae) angehörig, dem man im Mittelmeergebiet nicht felten begegnet; man kann dann beobachten, wie fich plötlich aus dem Waffer eine Schar von Flug- 
tieren erhebt, eine Stredke über das Waffer fchwirrt und dann wieder in demfelben verfchwindet. Man hat bei dem rafchen Ablauf der Erfheinung faft den Eindrudk, als ob es fich um eine Art großer Libellen handelte. Die Brufttloffen diefer Tiere find exzeffiv lang, reichen faft bis zur Schwanzfpite, und fie find es, welche ähnlich den Fledermausflügeln rafh flatternde Bewegungen ausführen. Als Steuer dient dabei die Bauchfloffe und der vergrößerte untere Lappen der Schwanzfloffe. Die allmähliche Ausbildung des Flugvermögens fand wahrfcheinlich den Ausgangspunkt und wurde gefördert durch die Fähigkeit, mittels forcierter Sdhwimmbewegungen aus dem Waffer zu fpringen, wie dies viele Fifche tun können.

Der Flughahn (Dactylopterus volitans, italienifch: Civet ta Falco) (Fig. 165), der zu einer ganz anderen als der früher erwähnten Firchfamilie, nämlich zu den Panzerwangen gehört, befitzt ebenfalls das Vermögen, fich über die Oberfläche des Waffers mittels eines Sprunges zu erheben und unter gleichzeitiger Zuhilfenahme feiner großen Bruftloffen eine Stredke wie mit Hilfe eines Fallfhirmes über dem Meere hin zu fhweben. Einen Verwandten diefes Fifches haben wir fchon bei Befprechung der Grundfauna des Mufchelfandgebietes im Knurrhahn (S. 92), einem Grundfilch, kennen gelernt, deffen Bruftfloffen anfehlich groß waren, und diefe zeichneten fich dort fpeziell durch eine auffallende Färbung an der Oberfeite aus, die aber der Fifch, nur wenn er erfchredkt wurde, entfaltete. So ift es recht intereffant, wie beim Flughahn und Knurrhahn die Bruftloffe eine ganz verfchiedene Bedeutung durch ftarkes Wachstum angenommen hat. Vermutlich gab zu diefer anderen Entwidklungsrichtung der Umftand den AnftoB, daß Vertreter aus diefer Fifchfamilie die fchwimmende Lebensweife in den oberflächlichen Wafferfchichten angenommen haben.

Ahnlich wie der Hering in den Nordmeeren, fo treten die zur felben Familie gehörenden Sardellen und Sardinen als Maffenfifche im Mittelmeergebiet auf. Sie bewegen fich in großen Schwärmen und kommen in der warmen Jahreszeit auch in Küftennähe, wo fie dann in Mengen gefangen werden. Diefe Tiere werden von anderen Fifchen, wie von 
den Thunfifchen, und ferner von den Delphinen eifrig verfolgt, und bilden für diefe die vorwiegende Nahrung. Sie felbft find Planktonfreffer und fpielen daher eine vermittelnde Rolle in der Abhängigkeitskette der Lebensformen, zwifhen den kleinen Lebewefen des Meeres und den großen und größten Tieren desfelben. In bezug auf die Nahrung der genannten beiden heringartigen Fifche ift es recht intereffant, daß ihr Mageninhalt oft nur eine einzige beftimmte Planktonform - faft ausfchließlich find es kleine Krebschen - enthält, und fo zeigt fich auch hier wieder die an manchen anderen Fifchen gemachte Beobachtung, daß bei der Nahrungsaufnahme aus dem bunten Gemifch des Planktons eine Auswahl, wir möchten vielleicht verfucht fein, zu fagen, eine Auswahl nach Gefchmadk getroffen wird. Aber es dürfte fich hier vielmehr um einen Anreiz handeln, der durch die Form und Bewegungsart des Beutetieres ausgelöft vom Auge des Beutefreffers aufgenommen wird. Wie bei allen Hochfeefifchen if der Farbenton der beiden genannten Fifche an ihrer Oberfeite ein mehr oder weniger blauer bis grauer, während die Bauchfeite weiß if. Diefer Gegenfats in der Färbung der Rückenund der Bauchfeite bei den freifchwimmenden Fifchen ift als eine direkte Wirkung des Lichtes auf die Fifchhaut unter Vermittlung und Regulation des Auges zu betrachten. Bemerkt möge hier auch werden, daß jene bunten Färbungen und mannigfaltigen Zeichnungen, wie fie bei Fifchen der Strandregion häufig zu beobachten find, im Gebiete der Hochfee fehlen.

Der Fang der Sardine und Sardelle wird in mannigfaltiger Weife betrieben. Dem Wefen nach laffen fich zwei Methoden unterfcheiden, nämlich der Gebrauch von Standnetzen auf See und der von Zugnetzen in Küftennähe. Intereffant ift ferner die Anwendung des künftlichen Lichtes für Fangzwedke. In dunklen mondlofen Nächten fahren dann die mit Azetylenapparaten ausgerüfteten Boote ins Meer hinaus, und auf die während der Dunkelheit der Nacht ausgeruhten und daher gegen Lichtreize fehr empfindlich gewordenen Augen diefer Fifche wirkt dann das grelle Azetylenlicht fo ftark im Sinne des pofitiven Heliotropismus ein, daß fie fich in Schwärmen 
um das Boot fammeln und von diefem alimählich in eine paffende Bucht geführt werden, wo dann die ganze Menge von Netyen umfchloffen wird. Es ift fehr intereffant und lehrreich, einer folchen Nachtfifcherei anzuwohnen. Der ganze Vorgang, wie zunächft die Fifcher die Sardellenfchwärme mittels eines ins Waffer gelaffenen Fadens auffuchen, - aus dem mehr oder weniger häufigen Anftoßen der Firche an den Faden fahließen fie auf die Menge derfelben, - wie dann allerlei anderes Meergetier, Tintenfifche, Krebfe, Würmer auftauchen und umherfchießen, wie zunächft einzelne Fifche erfcheinen, dann immer mehr und mehr, und wie fchließlich diefe ganze verblendete Schar willenlos in die Netzmafchen folgt, das ift ein anziehendes und auch aufregendes Bild.

Die Sardine, Pilchard (Clupea pilchardus, italienifch: Sardina) (Fig. 189) wird bis $25 \mathrm{~cm}$ lang und if gegenüber der Anchovi, Sardelle (Engraulis encrasicholus, italienifch: Sardon) (Fig. 190) die größere Form. Beide find leicht nach der Geftalt und Färbung voneinander zu unterfcheiden. Die Sardelle if fohlanker, und ihre Schnauzenfpize ift abgerundet, der Unterkiefer gegen diefe zurüdktretend, die Augen find relativ groß, und die Färbung des Rückens ift eine mehr graue. Der Pilchard if dagegen deutlich blau, beim toten Tier ins Grünliche fchillernd gefärbt. Der Kopf läuft fpiłz zu, und der Unterkiefer ift faft gleich lang wie der Oberkiefer. Hier fei noch erwähnt, daß im adriatifchen Gebiete befonders in den Wintermonaten noch eine dritte Clupaeide als Maffenfirch in Geftalt der höchftens $10 \mathrm{~cm}$ langen Papalinenfardelle (Clupea papalina, italienifch: $\mathrm{P}$ a palina) auftritt und ein billiges Volksnahrungsmittel abgibt. Endlich ift der Maififch (Alosa vulgaris, italienifch: Cерpa), ebenfalls zu den Heringsfifchen gehörend, infofern von Intereffe, als er in die Flüffe eindringt, um dort zu laichen. Im Mittelmeergebiet ift diefer Fifch, der bis $40 \mathrm{~cm}$ lang wird, die größte Clupaeide, jedoch hat er nicht die Bedeutung eines Maffenfifches.

$\mathrm{Zu}$ den Fifchen, welche zeitweife an der Oberfläche des Meeres erfcheinen, deren Heimat aber eigentlich die Tieffee ift, gehört der merkwürdig gefärbte geftaltete und anfehnlich 
große Mondfifch (Orthagoriscus mola, italienifch: Pesce 1una) (Fig. 180). Bei Seefahrten begegnet man diefen Tieren mitunter, und fie machen fich dann dadurch bemerkbar, daß ihre große fichelförmige Rückenfloffe hin- und herfallagend zeitweife aus dem Meere auftaucht. Gelegentlich findet man einen folchen Fifch auch auf dem Fifchmarkt, wohin er der Kuriofität halber gebracht wird; fein Fleifh gilt als nicht genießbar. So ein Mondfifch fcheint eigentlich nur aus einem kleinen Kopfabfchnitt und aus einem gedrungenen Leib zu beftehen, während der fonft bei den Fifchen gut entwidkelte Schwanzteil im vorliegenden Falle ftark rüdkgebildet ift. Die kleine Mundfpalte wird im Ober- und Unterkiefer von je einer ftarren Zahnplatte begrenzt. Auch das äußere Kiemenloch, das fich nicht wie bei anderen Fifchen unter dem Schutze eines knöchernen Kiemendedkels nach außen öffnet, - im vorliegenden Falle erfetst letzteren eine Hautfalte, - hat die Form einer engen Spalte. Einen befonderen Eindrudk macht das im Leben lebhaft bewegliche Auge, deffen Augapfel fauftgroß ift. In der fhiefergrau gefärbten Haut finden fich an Stelle der für die Knochenfifche fo charakteriftifchen hornigen Schuppen kleine kornförmige Hautverknöcherungen, die fie rauh erfcheinen läßt, fobald die fie bedeckende didke Schleimfchicht entfernt wurde. Auffallend ift auch der Mangel an Kalkfalzen im ganzen Skelett, deffen Teile mehr eine knorpelartige Befchaffenheit zeigen.

Nach den Abbildungen und der Art und Weife, wie Mondfirche in Mufeen aufgeftellt werden, wird wohl die Meinung fuggeriert, daß fie im Waffer aufrecht fowwimmen. Das ift aber nicht der Fall, vielmehr liegt diefer Fifch hierbei mehr weniger auf der Seite. Dies wird auch verftändlich, wenn man bedenkt, wie fohwer der feitlich und ftark abgeplattete Körper eines folchen großen und fchweren Tieres in Verbindung mit der ungewöhnlichen großen Rüdken- und Afterfloffe aufrecht ftehend im Waffer zu balancieren wäre. Während bei den meiften anderen Fifchen der Schwanzteil des Körpers beim Schwimmen die Hauptrolle übernimmt und die anderen Floffen nur zur Steuerung und Balancierung dienen, haben im vorliegenden Falle die genannte Rüdken- und Afterfloffe die Hauptaufgabe 
bei der Fortbewegung im Waffer zu leiften. Damit fteht auch im Zufammenhang die große freie Beweglichkeit diefer Floffen nach rechts und links, wie fie fonft bei Knochenfifchen nicht zu finden ift.

Uber die Lebensgefchichte diefes in Rede ftehenden Fifches find wir nur unvollkommen unterrichtet. Man trifft ihn im Mittelmeer und im Atlantifchen Ozean bis an die Küfte Norwegens. Die faft kreisrunden jungen Mondfirche leben in der Tieffee. In der nördlichen Adria erfheint merkwürdigerweife diefer Fifch im Mai dann, wenn die großen Schwärme der Lungenquallen (Rhizofto $\mathrm{m} \alpha$ ) (Fig. 4, f. S. 114) mit dem Küftenftrom nach Norden und in den Golf von Trieft treiben. Im Magen des Orthagoriscus haben wir wiederholt Stïdke von diefer Medufe gefunden, manchesmal war er leer oder er enthielt etwas Seegras und kleine Krebschen (Idothea) oder auch Schlamm. Die in der Tieffee erbeuteten Mondfifche dagegen wiefen als Mageninhalt Aallarven (Leptocephalus) (Fig. 163) auf. Das Erfcheinen und Auftauchen des Orthagoriscus ift wohl fo zu erklären, daß diefe Tiere aktiv dem Nahrungsftrom der Korrenten folgend, dabei als nicht befonders gute Schwimmer felbft von den Meeresftrömungen mit an die Oberfläche geleitet werden. Die bedeutenden Veränderungen der äußeren Bedingungen, denen fie hierbei unterworfen find, mögen diefe Fifche, fobald fie an die Oberfläche kommen, matt und müde machen. Man hat fhon anfehnlich große Exemplare von $2^{1} / 2 \mathrm{~m}$ Länge und mehreren Zentnern Gewicht gefangen, und eines der größten befindet fich im Mufeo civico in Trieft.

Einen ganz fremdartigen und zugleich fhönen Anblidk gewährt in bezug auf Geftalt und Färbung der Fregattfifch (Trachypterus taenia, italienifh: Pesce bandiera) (Fig. 172), wenn er im klaren blauen Waffer befchienen von der Sonne als ein breites filberglänzendes Band, das an der Seite große fchwarze Fledken trägt und oben von einer zinnoberrot gefärbten Rüdkenfloffe begrenzt wird, dahintreibt. Erhöht wird noch diefer Eindrudk durch die zwei großen Augen am feitlich plattgedrüdkten Kopfe und durch das röhrenartig vorftredkbare Maul. In den an intereffanten Tierformen fo reichen Korrenten 
der Meerenge von Meffina, deren Fülle an pelagifchem Leben man am bequemften im Hafen diefer Stadt beobachten kann, erbeutet man nicht felten ganz junge Fregattfirche von etwa Fingerlänge. Sonft treten an der Oberfläche des Meeres an anderen Orten des Mittelmeergebietes nur ganz große einen Meter und mehr meffende Exemplare auf, denen man an ihren müden Bewegungen anfieht, daß fie fich nicht in normaler Kondition befinden. Wir fanden diefe Fifche, die nach der Form ihres Mundes zu fchließen, Planktonfreffer find, auch immer mit leerem Magen und ohne Eingeweideparafiten, ein Zeichen dafür, daß fie fchon lange gehungert hatten. Wer weiß denn eine wie lange Reife fie fchon hinter fich hatten, ohne daß fie Nahrung aufnahmen. Sie find eigentlich Bewohner der Tieffee, aus welcher fie wahrfcheinlich durch Meeresftrömungen gelegentlich an die Oberfläche gebracht werden, ähnlich wie wir dies beim Mondfifch annahmen.

Auf der weiten Wafferfläche zieht ja jeder am Meere fchwimmende Gegenftand die Aufmerkfamkeit des Reifenden auf fich. Nebft dem Treiben der auf hoher See lebenden Vogelwelt find folche Begegnungen bei langer Fahrt oft die einzigen Abwechslungen. Da fieht man mitunter einen dunklen runden Körper nahe der Wafferoberfläche ruhig verweilen oder von Zeit zu Zeit auftauchen. Schließlich entpuppt fich diefer als eine Seefchildkröte (Thalassochelys corticata). Diefe Tiere können eine recht anfehnliche Größe erreichen, fo daß deren Schild faft meterlang wird. Ihr Körper ftellt eine Scheibe dar, die von floffenartigen Extremitäten gefchickt weiter gerudert wird. Zum Zwedke der Eiablage fuchen diefe Tiere den Flachftrand auf, fonft findet man fie oft weit draußen auf See. Weder ihr Fleifch noch ihr Schildpatt findet eine Verwertung.

Die Haififche, die ausgeftorbene Repitilienform Ichthyofaurus und die Delphine find ein fehr lehrreiches Beifpiel dafür, wie das Leben und Schwimmen im Waffer bei drei voneinander fo fehr verfchiedenen Wirbeltierklaffen dasfelbe Prinzip der Körperform bewirkt haben. Es kommt hier wieder die Atrenge Abhängigkeit der Form von der Funktion zur Anfhauung. Die Haififche find dem Meere angeftammte Tiere, 


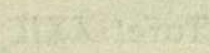

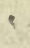

$x^{4}+x^{2}+x^{2}=$ 


\section{Tafel XXII}

Figur

182. Pfauenlippfisch (Crenilabrus pavo) (S.58). Befonders lebhaft ift die Färbung der Männchen zur Paarungszeit, grün, gelb. blau. Länge $20-35 \mathrm{~cm}$.

183. Makrele (Scomber scombrus) (S. 57, 127). Länge 50-60 cm. Färbung blau mit dunkleren Querbinden.

184. Goldmakrele(Coryphaena hippurus)(S. 129). Länge 80-120 cm.

185. Thunfisch (Thunnus thynnus) (S. 127). Färbung dunkelblau. Diefem fehr ähnlich nur kleiner ift der Bonitfifch. (S. 129).

186. Schwertfisch (Xiphias gladius) (S. 130).

187. Schiffshalter (Echineis naucrates) (S. 129). Länge bis $90 \mathrm{~cm}$. Färbung braun bis blau.

188. Flugfisch (Exonautes Rondeletii) (S. 130). Länge 30-50 cm. Färbung graubraun.

189. Sardine, Pilchard (Clupea pilchardus) (S. 133).

190. Sardelle (Engraulis encrasicholus) (S. 133). Länge 10-15 cm.

191. Delphin (Delphinus tırsio) (S. 136). Länge $3,5-4,5 \mathrm{~m}$. Hinter dem Auge ift die fehr kleine Öfnung des äußeren Gehörganges fichtbar (S. 139). 
Tafel XXII

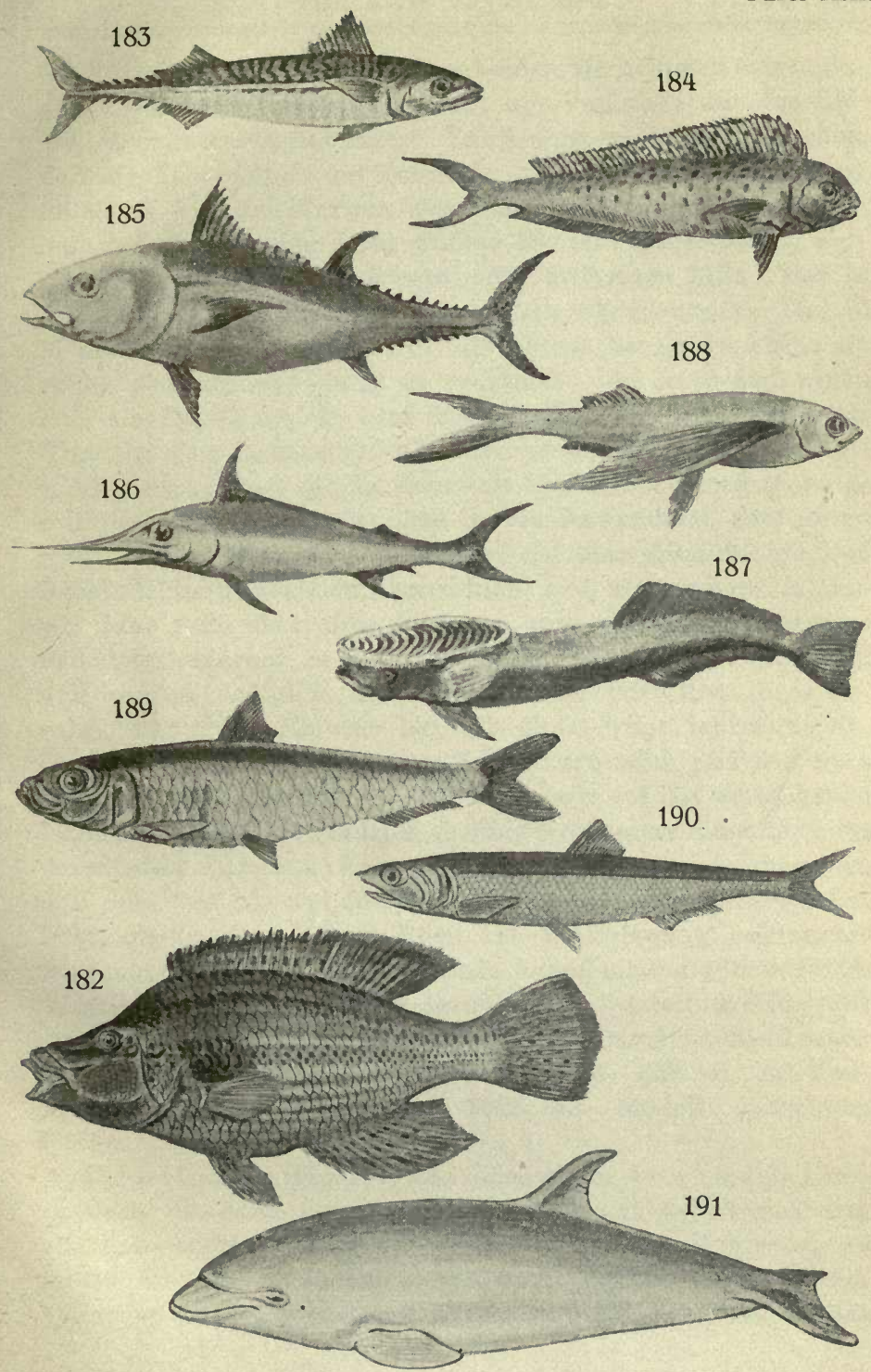



die Vorfahren der leţtgenannten beiden Tiergruppen waren dagegen echte vierfüßige Landtiere, ein Umftand, der das Beifpiel noch intereffanter macht. Es ift ohne weiteres einzufehen, daß die Lebensweife am Feftlande und im Waffer ganz verfchiedene Arbeitsleiftungen von Seite diefer Tiere vorausfetzt und daß die Anpaffung ans flüffige Element ganz andere Formen und Kraftentfaltung notwendig erfcheinen läßt. Der in diefer Hinficht günftigfte Typus für ein fchwimmendes Tier ift in der Stammesgefchichte der Wirbeltiere bereits im Fifche erreicht worden, und fo ift es erklärlich, wie fo in dem einen Fall ein Reptil und in dem anderen Fall ein Säugetier beim Ubertritt vom Feftlande ins Waffer wieder zur Fifchgeftalt zurüdkkehrte. Wenn wir die Lebewelt in ihrer enormen Mannigfaltigkeit hinfichtlich der bei ihr in Anwendung gebrachten mechanifchen Prinzipien, die immer auf eine möglichft günftige Arbeitsleiftung abzielen, betrachten und unterfuchen, fo find wir dann recht überrafcht, zu fehen, daß eigentlich nur wenige Prinzipien hierbei in Frage kommen und daß der Reichtum der Formen lediglich auf einer reichen Variation jener beruht. Um einen Hinweis auf für diefe Frage lehrreiche Erfcheinungen, die uns befonders leicht zugänglich find und auch auffallen müfen, zu machen, verweifen wir auf die weitgehende Formengleichheit der Blätter verfhiedener unter einander nicht verwandter Pflanzen. Aus allen diefen Beifpielen erfehen wir, daß das, was wir zwedkmäßig nennen, in nichts anderem befteht, als in dem Notwendigen zur Vollbringung beftimmter Leiftungen, und daß die fogenannte Anpaffung lediglich auf dem Wechfel diefes Notwendigen beruht. Daß fpeziell im Fifchtypus das Notwendige zur Erzielung beftmöglichfter Arbeitsleiftungen im Waffer erreicht ift, ergibt fich daraus, daß wir bei Konftruktion der Torpedos den Firch als Modell genommen haben.

Die Delphine (Fig. 191) find Säugetiere, die lebendige Junge gebären, die durch Lungen atmen, und denen dem Typus nach vier Extremitäten zukämen. Welche notwendigen Abänderungen haben fich nun an diefen Tieren durch das Leben im Waffer vollzogen? Die allgemeine Körperform ift die eines Fifches 
zum Unterfchied des mehr walzenförmigen Körpers der Landfäugetiere. Der Körper erfcheint daher verjüngt nach vorne und hinten, einerfeits um den Wafferwiderftand beim Schwimmen gut zu überwinden und andererfeits, um zum motorifchen Teil, dem Schwanze, einen reichlichen Wafferzufluß zu leiten. Durch den Verluft des Haarkleides ift die Körperoberfläche glatt geworden, und hierdurch erfcheint wieder der Reibungswiderftand fehr herabgefetst. Haare finden fich beim Delphin, wie $K$ üdkenthal neuerdings zeigte, nur mehr als Haarbälge in der Haut, die äußerlich gar nicht fichtbar find. Wahrfcheinlich haben diefe Haaranlagen jetzt die Bedeutung von Hautfinnesorganen erlangt. Durch eine reichlich entwickelte Speckfchicht ift das fpezififche Gewicht des Körpers entfprechend herabgefetzt. Die Vorderfüße find verkürzt und $z u$ floffenartigen Bildungen umgewandelt, die, wie bei den Fifchen, der Steuerung $z u$ dienen haben. Ein weiterer Parallelismus mit dem Fifhtypus befteht darin, daß der Delphin auch eine Rüdzenfloffe befitgt, aber diefe ift lediglich als ein Hautlappen aufzufaffen und enthält keinerlei Skeletteile wie die Fifchrïdkenfloffe. Es handelt fich alfo hier nur um funktionell gleiche Bildungen, und nicht um folche, die auf verwandtchaftlicher Grundlage beruhen. Die hinteren Extremitäten, die den Bauchfloffen eines Fifches entfprächen, find hier in Wegfall gekommen, wie wir dies ja auch in vielen Fällen bei Fifchen bezüglich der Bauchfloffen finden. Während die Fifche aber durch fchlangenartige Bewegungen ihres Körpers und Schwanzes, die in Form von Wellen ablaufen, fchwimmen, arbeitet beim Delphin der horizontal geftellte, doppellappige Schwanz ähnlich einer Schiffsfhraube, und der Rumpf ftellt dabei mehr weniger einen ftarren Körper dar. Es liegt alfo hier ein anderer Bewegungstypus vor als beim Fifh. Die Frage nach der Urfache diefer Verfchiedenheit ift gewiß fehr intereffant. Sie dürfte wohl in dem Organifationstypus des Säugetieres ihre Begründung finden. Der eigentïmliche Bewegungsmodus eines Delphinfchwanzes bleibt intereffanterweife nicht ohne Wirkung auf den übrigen Körper, denn er erzeugt im Schädelfkelett, worauf ebenfalls Kü dkenthal, unfer ausgezeichneter Kenner 
der Waltiere, aufmerkfam machte, eine Affymetrie durch den ungleichmäßigen Wafferdrudk auf die beiden Gefichtshälften.

Vom Standpunkt des Schiffsbauers ftellt ein zwei Meter langer Delphin ein kleines Fahrzeug mit einem fehr kräftigen Motor dar, der reichliche Betriebsmittel aufbraucht, um diefem eine fo anfehnliche Schnelligkeit, wie dies hier der Fall ift, zu verleihen. Der Mengenverbrauch an letyteren kommt bei diefem Tiere durch eine große Gefräßigkeit zum Ausdrudk. Die Delphine find höchft räuberifche Tiere, die Fifchen und Tintenfifchen eifrigit nachftellen und daher nicht zu den Freunden der Fifcher zählen. Die weite Mundplatte des fchnabelartig verlängerten Gefichtsteiles mit den zahlreichen Zähnen in den Kiefern erleichtert den Nahrungserwerb. Für einen Fleifchfreffer haben diefe Tiere einen auffallend langen Darm, und dies hängt wahrfcheinlich mit den Mengen der aufgenommenen und zu verarbeitenden Nahrung zufammen. Für ein im Waffer fchwimmendes Säugetier ift die Luftbefchaffung zur Atmung wefentlich anders als am Feftlande. Auch diesbezüglich fehen wir die notwendigen und fpeziellen Einrichtungen getroffen. Die beiden Nafenöffnungen find nämlich zu einem einzigen äußeren, mit einer Klappe verfchließbaren Nafenloch verfchmolzen und von der Schnauzenfpitze gegen die Stirn hinauf gerüdxt. Durch die fchnabelartige Abfetzung der Kieferpartie gegenüber dem Stirnteil erfcheint fowohl in bezug auf die Lage und die Funktion der Augen, als auch für das Atemholen ein günftiger Zuftand gefchaffen. Am Kopfe eines Delphins vermiffen wir ferner die Ohrmufcheln, die für die Säugetiere fo charakteriftifchen Bildungen, welche als für das Leben im Waffer nicht mehr notwendig in Wegfall kamen. Auch der äußere Gehörgang, der dem Typus nach allen vierfüßigen Tieren zukommt, ift hier fo weit verengt, daß er felbft mit einer dünnen Sonde gar nicht loder nur fchwer paffierbar ift. Die Schalleitung unter Waffer erfolgt hier direkt durch die Kopfknochen, in welchen das Gehörorgan eingefchloffen ift. Im Zufammenhang damit fteht, daß fich gerade diefe Partie des knöchernen Schädels, das fogenannte Felfenbein, gegenüber den übrigen Schädelknochen durch ihre Härte bezw. durch 
ihren Kalkreichtum auszeichnet, und eben durch diefe Eigenfchaft if es für die Ubernahme des Schalles aus dem Waffer erft befähigt worden. Solche, einem Schnedkengehäufe nicht unähnliche Felfenbeine von Delphinen und Waltieren find charakteriftifche Fundfüdke im Sediment der Tieffee, wo fie im Schlamme eingebettet der Zerftörung widerftehen können. Das ift ein intereffantes Beifpiel für das Verfändnis, wie Foffilien entftehen, aber auch dafür, wie dann derartig vereinzelnde Skelettfïudke dem Paläontologen bezüglich der Feftftellung ihrer Natur unter Umftänden viel Kopfzerbrechen bereiten können.

Als Säugetiere haben die Delphine ihr gewöhnlich einziges Junges zu fäugen. Nun ift aber der Saugakt der Säuger ein Mechanismus, der im engen Zufammenhang mit der Luftatmung fteht. Im Waffer ftößt daher diefes Prinzip auf Schwierigkeiten, diefe fehen wir aber dadurch umgangen, daß die Delphinmutter ihrem Sprößling das Saugen erfpart, indem fie ihm die rahmartig dicke Mildh in den Mund fpritt. Die Milddrüfen find äußerlich als Euter gar nicht fichtbar und münden mit Zityen in Tafchen aus, die als Spalten zu beiden Seiten des Afters gelegen find. In diefe Eutertafchen ftedken offenbar die jungen Delphine ihre fpitye Schnauze hinein, um die mütterliche Nahrung zu empfangen.

Vom biologifchen Standpunkt intereffiert es immer zu erfahren, welche Nahrung ein Tier aufnimmt und in welcher Art und Weife, denn gerade diefe Momente nehmen in bezug auf die Entwidklung und Formgeftaltung des Tierreiches den mächtigften Einfluß, ja fie find zweifelsohne vielfach mächtige Triebfedern für den Ausbau und die Weiterentwidklung des Tierftammes gewefen, andererfeits ift im gleichen Sinne von eminenter Bedeutung, mit welchen Feinden die einzelnen Formen zu rechnen haben. Den erften Punkt haben wir fchon oben berührt. Die Delphine als anfehnlich große Tiere und gewandte Schwimmer könnten uns als unumfhränkte Herrfcher des Meeres erfcheinen, und doch ift dies nicht der Fall. Es find die großen Haififchformen, die ihnen nachftellen und die fie fich als fette Biffen ausfuchen. Als Schuts gegen 
diefe Feindfchaft mag ihnen wohl die befondere Schwimmgewandtheit von Bedeutung geworden fein. Daß übrigens auch Krankheiten der Vermehrung der Delphine Grenzen ziehen mögen, ergibt fich daraus, daß man manchesmal vollftändig abgemagerte Tiere erbeutet. Eine Gefahr bedeutet für fie weiter der Flachftrand, wo fie von Strömungen und Seegang erfaßt ins feichte Waffer geraten und ftranden können.

Gerne würden die Fifcher den Delphinen eifrig nachftellen, denn fie machen ihnen nicht bloß viel Schaden an den Firchbeftänden der Küftengebiete, fondern fie zerreißen ihnen auch die Netze. Mitunter verftricken fich Delphine in folchen Netzen und erfticken dann, da fie ja zum Atmen auftauchen müßten. Auch mit Pulver und Blei und mit der Harpune jagt man ihnen nach. Trots ihrer Größe find diefe Tiere gegen Verletzungen recht empfindlich, und es genügt daher fchon Hafenfchrot zu ihrer Jagd. Ein Schuß im Momente des Auftauchens richtig angebracht, hat feine volle Wirkung. Den Schwärmen der Sardinen und Makrelen folgen oft ganze Herden von fünfzig und mehr Stüdke diefer Meerfäugetiere, und es ift ein höchlt intereffanter Anblick, die Haft und Gier im Nahrungserwerb derfelben zu beobachten. Für den Nimrod des Binnenlandes wäre es gewiß eine neue und anregende Seite des Jagdiportes, fich der Delphinjagd hinzugeben und fich zum Spezialiften auf diefem Gebiete auszubilden. Gleichzeitig würde damit auch der Nutffifcherei ein Dienft erwiefen werden. 


\section{Einige empfehlenswerte Bücher über das Meer und fein Leben.}

Brehms Tierleben, Band Fifche und niedere Tiere. Bibliogr. Inftitut, Leipzig und Wien.

Faber, G. L., The fisheries of the Adriatic and the fish thereof. London, B. Quaritch, 1883.

Giberne, $\mathbb{A}$., Das Meer und was wir darüber wiffen. Deutfh von E. Kirchner. S. Cronbach, Berlin, 1903.

Griffini, A., Ittiologia italiana. Hoepli, Milano, 1903. Ein recht brauchbares Manuale über die mediterrane Fifchfauna.

Janfon, O., Meeresforfhung und Meeresleben. B. G. Teubner, Leipzig. 2. Auflage. Diefes kleine Werkchen bietet auf engem Raume fehr viel.

Johnstone, J., Conditions of life in the sea. Cambridge, at the University Press. 1908.

Ke1le r, C., Das Leben des Meeres. Leipzig, Ch. H. Tauchnit, 1895. Wenn auch diefes ausgezeichnete Werk einige Jahrzehnte alt ift, fo ift deffen Studium trotzdem fehr empfehlenswert.

Krifch, A., Die Fifcherei im Äriatifchen Meere. Pola, 1900. Komm.-Verlag

C. Gerold's Sohn, Wien. Eine vorzügliche Darfellung der adriatifchen Fifcherei.

Krümme1, O., Der Ozean. Leipzig, G. Freitag. Der Name des Autors bürgt für einen trefflichen Inhalt des Buches.

Maas, O., Lebensbedingungen und Verbreitung der Tiere. B. G. Teubner, Leipzig, 1906.

May, W., Korallen und andere gefteinbildende Tiere. B. G. Teubner, Leipzig, 1909.

Schle iden, M. J., Das Meer. O. Salle, Braunfchweig, 1888. Die Lektüre diefes Werkes ift fehr zu empfehlen.

Shoenichen, W., Die Natur. 1. Bd. Aus der Wiege des Lebens. A. W. Zidkfeldt. Ofterwiedk, Harz. In diefem Büchelchen werden in anregender Form eine Anzahl intereffanter Fragen des marinen Lebens behandelt.

Sudker, L., Die Fifche nebft den ebbaren wirbellofen Tieren der Adria und

ihre Zubereitung. F. H. Shimpff, Trieft, 1895. Diefes Buch gibt eine gute Zufammenftellung der Vorkommniffe des Triefter Fifchmarktes, und mancher Leferin dürften auch die Geheimniffe der "marinen Kochkunft" erwünfcht fein.

Walther, Johannes, Allgemeine Meereskunde. J. J. Weber, Leipzig. Wa1ther, Johannes, Die Gefhichte der Erde und des Lebens. Veit u. Co., Leipzig, 1908. Die glänzende Darftellungskunft des Verfaffers kommt in den beiden letstgenannten Werken zur vollen Geltung und kann die Lektüre derfelben nur angelegentlich empfohlen werden. 


\section{REGISTER}

Aal S. 30, Fig. 162

Acanthias S. 92, Fig. 145.

Acera bullata S. 52 .

Acipenser Fig. 156.

Actinia cari S. 79, Fig. 25.

equina S. 78, Fig. 24.

Adamsia palliata S. 100.

" Rondeletii S. 100, Fig. 38.

Aglaophenia Fig. 17.

Ährenfirche S. 58, Fig. 160.

Aequorea forsealea S. 116, Fig. 3.

Aiptasia mutabilis S. 80, Fig. 30.

Aktinien S. 47.

Alcyonium S. 98, Fig. 35.

Alopias vulgaris S. 126, Fig. 144.

Alosa vulgaris S. 133.

Alpheus S. 72, Fig. 65.

Amaroucium S. 88.

Amphioxus lanceolatus S. 90, Fig. 139.

Anchovis S. 133, Fig. 190.

Anemonia sulcata S. 79, 98, Fig. 26.

Anguilla vulgaris S. 30, Fig. 162.

Anneliden S. 10, 32.

Antedon S. 90, Fig. 130.

Antennularia antennina Fig. 18.

Aphrodite aculeata Fig. 45.

Aplysia S. 57, Fig. 100.

Aplysina S. 71.

Aporrhais Fig. 92, 93.

Arca noae S. 86, Fig. 108.

Archen-Kammurchel S. 13, Fig. 110.

Archenmurchel S. 86, Fig. 108.

Arenicola piscatorum S. 9, Fig. 47.

Ascidia Fig. 131.

Ascidien S. 87.

Aspidosiphon S. 99.

Asterias glacialis S. 90, Fig. 126.

Astropecten S. 100, Fig. 129.

Atherina S. 58, Fig. 160.

Aurelia aurita S. 116, Fig. 7.

Austern S. 22, 49, Fig. 114.
Badefchwamm S. 71, Fig. 16.

Balanoglossus S. 16, 91, Fig. 52.

Balanus S. 80, Fig. 53.

Bärenkrebs S. 20, Fig. 67.

Bartmännchen S. 60, Fig. 173.

Bartumben S. 58, Fig, 166.

Becherlarve S. 115.

Beroe ovata S. 119, Fig. 42.

Bisatto S. 30, Fig. 162

Blauhai S. 126.

Blaufdhnecke S. 120 .

Blennius S. 59, 101, Fig. 161.

Bohrmufcheln S. 76, Fig. 109.

Bohrfchwamm S. 75, Fig. 11.

Bonellia viridis S. 73, Fig. 48.

Bonitfirch S. 129.

Botryllus S. 88, Fig. 138.

Bragozzi S. 96.

Brandhorn S. 55, Fig. 96.

Branzino S. 29, Fig. 150.

Braffen S. 57.

Bunodes Fig. 27.

Callianassa Fig. 66.

Carcharias glaucus S. 126.

Carcharodon Rondeletti S. 126.

Carcinus maenas S. 19, 33, Fig. 77.

Cardium edule S. 34, Fig. 105.

Carinaria S. 119, Fig. 104.

Cassidaria S. 89, Fig. 95.

Centenara S. 37.

Ceppa S. 133.

Cereactis S. 89.

Cerianthus S. 47, Fig. 33.

Cerithium vulgatum S. 21, Fig. 90.

Cestus veneris S. 119, Fig. 41.

Chaetognathen S. 44.

Cbiton Fig. 84.

Chondrosia reniformis Fig. 13.

Chorda dorsalis S. 87.

Chrysaora mediterranea S. 116. 
Chrysophrys aurata S. 29, Fig. 152.

Cievolo S. 29.

Cimotocea S. 41.

Ciona intestinalis Fig. 133.

Cirripedien S. 81.

Civetta falco S. 131.

Cladonema radiatum S. 45, Fig. 21.

Clathria S. 98.

Clupea papalina S. 133.

pilchardus S. 133, Fig. 189.

Cochia S. 96.

Codium adhaerens S. 94.

" bursa S. 93.

" tomentosum S. 93.

Conger S. 31.

Copelaten S. 87.

Corbola S. 33.

Corvina nigra S. 58, Fig. 167.

Coryphaena hippurus S. 129, Fig. 184.

Cotylorhiza tuberculata S. 115.

Crangon vulgaris S. 53, Fig. 63.

Crevet S. 28, Fig. 70.

Cyclonassa neritea S. 21.

Cydippe plumosa S. 119, Fig. 40.

Cylinderrofe S. 47, Fig. 33.

Cynthia dura S. 88, Fig. 134, 135. papillosa S. 88, Fig. 136.

Cypristadium Fig. 55.

Cystoseira S. 65.

Dactylopterus volitans S. 131, Fig. 165.

Delphin S. 136, Fig. 191.

Dentalium S. 99.

Dentex vulgaris S. 67, Fig. 153.

Diogenes varians S. 20, Fig. 74.

Dolium S. 89, Fig. 94.

Doriopsis S. $73,89$.

Dorippe Fig. 82.

Doris 73, 89, Fig. 101.

Dornhai S. 92, Fig. 145.

Drachenkopf S. 59, Fig. 157.

Dromia Fig. 83.

Edheneis naucrates S. 129, Fig. 187.

Edhinaster sepositus S. 90, Fig. 127.

Edinocarditum mediterraneum S. 14.
Echinus melo S. 90.

Edelfteinrofe Fig. 27.

Eichelwurm S. 16, Fig. 52.

Einfiedlerkrebs S. 20, 100, Fig. 74.

Eledone S. 104.

Engraulis encrasicholus S. 133, Fig. 190

Entenmufheln S. 81, Fig. 56.

Enteromorpha S. 78.

Eucharis multicornis S. 119.

Eunicella S. 89, Fig. 36.

Eupagurus Prideauxii S. 100.

Euspongia officinalis S. 71, Fig. 16.

Exonautes Rondeletii S. 130, Fig. 188

Fadenrofe S. 47, Fig. 33.

Feuerwalzen S. 121.

Fierasfer S. 90, Fig. 170.

Fifchreufen S. 58.

Fifchreufenfchnedke Fig. 20.

Fissurella S. 73, Fig. 85, 86.

Flankenfchnedke S. 89, Fig. 99.

Flohkrebfe S. 22.

Floffenfchnedke S. 120.

Flughahn S. 131, Fig. 165.

Flugfirch S. 130, Fig. 188.

Foraminiferen S. 66, 74.

Fregattfirch S. 135, Fig. 172

Fuchshai S. 126, Fig. 144.

Fucus virsoides S. 78.

Gadiden S. 104.

Gadus euxinus S. 104.

., minutus S. 104.

Galathaea S. 20, Fig. 73.

Gammarus Fig. 58.

Garneelen S. 65.

Gastrula S. 115.

Gebia litoralis S. 33, Fig. 64 .

Geißbraffen S. 67, Fig. 151.

Geodia gigas S. 72 .

Glatthai S. 92, Fig. 140.

Gobius S. 59, 101.

Goldbraffe S. 29, 57, Fig. 152.

Goldmakrele S. 129, Fig. 184.

Gonoplax Fig. 75.

Gorgonia S. 89, Fig. 36.

Granatkrebs S. 28, Fig. 70. 
Grippo S. 43.

Gudkfenfter S. 63.

Haarfterne S. 90.

Haififche S. 92, 122 ff.

Haifirchei S. 92, Fig. 143.

Hakenkieferwürmer S. 43.

Halimeda S. 93.

Haliotis S. 73, Fig. 88.

Halophytenflora S. 36.

Hechtdorfh S. 104.

Heliactis bellis S. 79, 98, Fig. 31 .

Heringshai S. 126, Fig. 141.

Herzmufchel S. 34, Fig. 105.

Herzfeeigel S. 14.

Heufdhredkenkrebs S. 103, Fig. 62.

Hinterkiemenfdnedken S. 99.

Hippocampus S. 58, Fig. 181.

Holothuria S. 90, 98, Fig. 123.

Homarus vulgaris S. 20, 68, Fig. 72.

Hornkoralle S. 89.

Hornfhwämme S. 97.

Hummer S. 20, 68 ff., Fig. 72.

Hydroidpolypenftödkchen S. 98.

Hydromedufen S. 116.

Ihthyosaurus S. 136.

Idothea S. 135.

Ilyanthus S. 47, Fig. 32

Inachus S. 45, Fig. 81.

Jakobspilgermufchel S. 51, Fig. 113.

Janthina S. 120.

Kððferfchnedke Fig. 84.

Katzenhai S. 92, Fig. 142.

Kautfhukfhwamm Fig. 13.

Kehlfüßer Fig. 59.

Kielfchnedke S. 119, Fig. 104.

Knurrhahn S. 92, 131, Fig. 164.

Kommensalen S. 72 .

Korkkoralle S. 98, Fig. 35.

Kraken S. 69.

Kugelfdhnedke S. 52.

Labrax lupus S. 29, 57, 67, Fig. 150.

Labridae S. 58.
Lamna cornubica S. 126, Fig. 141.

Lampuga S. 129, Fig. 184.

Langleine S. 92.

Languste S. 69, Fig. 71.

Lanzettfirchchen S. 90, Fig. 139.

Lepadogaster S. 65, Fig. 169.

Lepas S. 81, Fig. 56.

Leptocephalen S. 31, Fig. 163.

Leptocephalus S. 135, Fig. 163.

Lidi S. 6.

Ligia S. 81, Fig. 68.

Lippfirche S. 58, 67.

Lithodomus lithophagus S. 76.

Lithophyllen S. 87.

Lithothamnien S. 87.

Litorina S. 81, Fig. 89.

Loligo Fig. 119.

Lophius piscatorius S. 101, Fig. 175.

Lungenquallen S. 114, Fig. 4.

Macearello S. 127, Fig. 183.

Maifirch S. 133.

Maja verrucosa S. 76.

- squinado S. 89, Fig. 78.

Makrelen S. 57, 127, Fig. 183.

Makrelenhechte S. 130.

Mantelaktinie S. 100.

Marphysa sanguinea S. 72

Medufen S. 110.

Meeraal S. 31.

Meerärchen S. 29, 57, Fig. 154.

Meerbarbe S. 104, Fig. 159.

Meerdatteln S. 73, 76.

Meereicheln S. 80, Fig. 53.

Meergrundeln S. 59, 65, 101.

Meerpolypen S. 68, 69, Fig. 116.

Meerquappen S. 59.

Meerfalat S. 41, 78.

Melonenqualle S. 119, Fig. 42.

Merlucius esculentus S. 104.

Mefferfcheide S. 12.

Microcosmus S. 88,.Fig. 137.

Miesmufhel S. 22, Fig. 115.

Mittelmeerdorfh S. 104.

Mondfifh S. 114, 133, Fig. 180.

Montata S. 31. 
Montée S. 31.

Moostierchen S. 66.

Morchuspolyp S. 104.

Motella S. 59.

Mugil S. 29, 57, Fig. 154.

Mullus S. 104, Fig. 159.

Muräne S. 31.

Murex S. 100.

- brandaris S. 22, 55, Fig. 97.

- trunculus S. 55, 56, Fig. 96.

Mufchelfandgrund S. 84 .

Mussoliere S. 86.

Mussolo S. 86.

Mustelus S. 92, Fig. 140.

Myrideen S. 21, 28, Fig. 69.

Myrin S. 43, 103, Fig. 69.

Mytilus galloprovincialis S.22, Fig.115.

Myxilla S. 97.

Nadktfhnedken S. 66.

Napfrchnecke S. 79, Fig. 88.

Nassa reticulata Fig. 20.

Nasse S. 58.

Nauplius Fig. 54.

Nehrungen S. 6.

Nerophis S. 58.

Octopus S. 68, 104, Fig. 116.

Ohrenqualle S. 116, Fig. 7.

Ophidium S. 60, Fig. 173.

Ophiothrix fragilis S. 90, Fig. 125.

Opisthobranchier S. 99.

Orada S. 29, Fig. 152.

Orthagoriseus mola S. 134, Fig. 180.

Oscarella S. 47.

Ostrea S. 49, Fig. 114.

Paguristes maculatus S. 100.

Palamita S. 129.

Palaemon S. 28, Fig. 70.

Palaemonetes varians S. 29.

Palinurus S. 69, Fig. 71.

Palmipes Fig. 128.

Papalinenfardelle S. 133.

Paracentrotus lividus S. 76.

Parangal S. 92.

Passera S. 102, Fig. 179.
Patella S. 79, Fig. 88.

Pecten glaber S. 51.

- jacobaeus S. 51, 52, Fig. 113.

- varius S. 98, Fig. 112

Pectunculus S. 13, Fig. 110.

Pelagia noetiluea S. 116, Fig. 6.

Pelikanfuß S. 100, Fig. 92, 93.

Pennatula S. 98.

Pesce bandiera S. 135, Fig. 172.

- Iuna S. 134, Fig. 180.

n spada S. 130, Fig. 186.

Petermännchen S. 59, Fig. 158.

Petersfifh Fig. 175.

Pferdeaktinie S. 78, Fig. 24.

Pflanzenwelt der Lagune S. 35.

Philine S. 99.

Pholas dactylus S. 76, Fig. 109.

Phronima S. 121, Fig. 57.

Phyllirrhoe S. 120, Fig. 103.

Physalia S. 117.

Physophora S. 118, Fig. 23.

Pilchard S. 133, Fig. 189.

Pilgermufchel S. 51, Fig. 112, 113.

Pilumnus S. 98.

Pinie S. 37.

Pinna S. 48, Fig. 111.

Pinotheres S. 51, Fig. 76.

Pisa S. 89, Fig. 79.

Plankton S. 105.

Planktonten S. 106.

Platessa platessa S. 102, Fig. 179.

Plattfifche S. 102.

Pleurobranchus aurantiacus S. 89 ,

Fig. 99.

Pleuronectiden S. 102.

Podocoryne carnea Fig. 20.

Polygordius S. 91, 92.

Polypen S. 66.

Ponthydrachniden S. 43, Fig. 61.

Porcellana S. 98.

Positonia S. 41, 93.

Proto Fig. 59.

Pseudopodien S. 74.

Pteroides S. 98, Fig. 34.

Pteropoden S. 120.

Pyrosoma S. 121. 
Quallenfánupfen S. 115.

Ragaetis S. 89, Fig. 29.

Raja asterias Fig. 146.

Rankenfüßler S. 81 .

Raspaillia viminalis Fig. 12.

Rhizostoma S. 114, 135, Fig. 4. Cuvieri S. 115, Fig. 4.

Rhombus S. 103, Fig. 176.

Rippenquallen S. 118.

Rochen S. 92, 101.

Röhrenquallen S. 117.

Röhrenwürmer 22, 66.

Rodimenia S. 104.

Rondinella S. 130, Fig. 188.

Rudisten S. 61.

Rytiphloea tinctoria S. 36, 94.

Salpa africana maxima S. 120.

" mucronata democratica S. 120.

Salpen S. 120.

Salzflora S. 36.

Sandgarneele S. 53, Fig. 63.

Sandwurm S. 9, Fig. 47.

Sapphirina S. 121.

Sarda sarda S. 129.

Sardellen S. 57, 131, 133, Fig. 190.

Sardine S. 133, Fig. 189.

Sardon S. 133, Fig. 190.

Sargus Rondeletii S. 67, Fig. 151.

Scardobola S. 33.

Schellfifche S. 104.

Schiffshalter S. 129, Fig. 187.

Schinkenmufhel S. 48, Fig. 111.

Schlangenfterne S. 90, Fig. 125.

Schleimfirche S. 59, 101.

Schlityfahnedke S. 73, Fig. 85, 86.

Schmarotzeraktinien S. 100, Fig. 38.

Schnittbarfh S. 67, Fig. 149.

Scholle S. 102, Fig. 179.

Schwämme S. $22,47,70$.

Schwertfirch S. 130, Fig. 186.

Scomber scombrus S. 127, Fig. 183.

Seombere socidae S. 130.

Scombriden S. 127.

Scombro S. 127, Fig. 183.
Scorpaena S. 59, Fig. 157.

Seyllarus S. 20.

Scyllium S. 92.

Scyphomedufen S. 116.

Seyphopolyp Fig. 43 b.

Seeanemonen S. 47.

Seeblafe S. 117.

Seebodken S. 80, Fig. 53.

Seefedern S. 98, Fig. 34.

Seegras S. 36, 39.

Seehafe S. 57, Fig. 100.

Seeknödel S. 36.

Seenadel S. 58.

Seenelken S. 48, Fig. 51.

Seeohr S. 73, Fig. 87.

Seepferdchen S. 58, Fig. 181.

Seerabe S. 58, Fig. 167.

Seeraupe Fig. 45.

Seefheiden S. 66.

Seefchildkröten S. 136.

Seefchwalbe S. 92, Fig. 164.

Seefpinne S. 89.

Seeftern S. 100.

Seeteufel S. 101, Fig. 175.

Seewalzen S. 90, Fig. 123.

Seezunge S. 102.

Segelqualle S. 118, Fig. 39.

Sepia officinalis S. 53, 103, Fig. 117.

Sepien S. 22, 53, Fig. 117.

Sepiola S. 55, Fig. 118.

n Rondeletii S. 55.

Serpula S. 66, Fig. 49.

Serranus scriba S. 67, Fig. 149.

Sfoglia S. 102, Fig. 177.

Siphonophoren S. 117.

Sipumutus nudus S. 11.

Solea vulgaris S. 102, Fig. 177.

Solecurtus S. 99, Fig. 106.

Solen vagina S. 12, Fig. 107.

Sonnenrofe S. 79, 98, Fig. 24.

Spadella S. 43, Fig. 44.

Spaltfüße S. 21.

Spaltfüßige Krebfe S. 28.

Spariden S. 57.

Sphaerechinus granularis S. 90.

Spirographis S. 48, Fig. 51. 
Spongellia S. 47, Fig. 15.

Spongien S. 47.

Squilla mantis S. 103, Fig. 62.

Stachelfchnedke S. 55, 100, Fig. 96, 97.

Statice limoneum S. 36.

Stechroche Fig. 147, 148.

Stedkmufcheln S. 48, Fig. 111.

Steinbutt S. 103, Fig. 176.

Stenorhynchus S. 45, Fig. 80.

Sterngudker S. 103, Fig. 169.

Sternroche Fig. 146.

Sternfhnedke S. 73, 79, Fig. 101.

Stichopus regalis $\mathrm{S}, 90$.

Stör Fig. 156.

Strandkrabbe S. 19, 33, Fig. 77.

Strandfchnedke S. 81, Fig. 89.

Striegelmufchel S. 99, Fig. 106.

Strudelwürmer S. 44.

Styela plicata Fig. 132.

Suberites S. 97.

- domuncula S. 94, Fig. 10.

" massa S. 94, Fig. 9.

Sussapega S. 129, Fig. 187.

Symbiofe S. 100.

Synapta S. 98.

digitata S. 15.

Synascidien S. 88, Fig. 138.

Syngnathus S. 58 .

Taceo sasso S. 65, Fig. 169.

Tartana S. 96.

Thalassema gigas S. 99 , Fig. 8 .

Thalassochelys corticata S. 136.

Thetya 1yncurium S. 72.

Thetys S. 52, Fig. 102.

Thunfirch S. 127, Fig. 185.

Thunnus thynnus S. 127, Fig. 185.

Tiara pileata S. 117, Fig. 2.

Tima flavilabris S. 117, Fig. 1.

Tonnaras S. 128.

Tonnenfchnedke S. 89, Fig. 94.

Tonno S. 127, Fig. 185.
Torpedo S. 101, Fig. 155.

Trachinus S. 59, Fig. 158.

Tradypterus taenia S. 135, Fig. 172

Trigla S. 92, Fig. 164.

Trygon Fig. 147, 148.

Turbellarien S. 44 .

Turitella S. 99, Fig. 91.

Turmf́hnedke S. 99, Fig. 91.

Uiva lactuca S. 41.

Umbrina eirrhosa S. 58, Fig. 166.

Uranoscopus S. 103, Fig. 168.

Valonia S. 36, 93.

Velella S. 118, Fig. 39.

Venusmufhel S. 13.

Venus verrucosa S. 13.

Venusband S. 119, Fig. 41.

Vermetus arcuarius S. 73, Fig. 98.

Vexilifer Fig. 171.

Vidalia volubilis S. 94.

Vioa S. 66, 75, Fig. 11.

Virbius S. 43, Fig. 60.

Vogelwelt der Lagune S. 35.

Volpino S. 27.

Wachsrofe S. 79, 98, Fig. 26.

Warzenkoralle S. 89 , Fig. 36.

Waffermilben, marine S. 43, Fig. 61 .

Wolfbarfh S. 29, 57, 67, Fig. 150.

Wollkrabbe Fig. 83.

Würmer S. 8, 10, 32, 98.

Wurmfannedse S. 73, Fig. 98.

Wurzelmundqualle S. 115.

Xiphias gladius S. 130, Fig. 186.

Zahnbraffe S. 67, Fig. 153.

Zeus faber Fig. 174.

Zitterroche S. 101, Fig. 155.

Zostera S. 36, 39-40.

Zwergdorfh S. 104. 


